\title{
RESTRUCTURING MATHEMATICS TEACHING | LEARNING: CO-TEACHING AS A DESIGNED APPROACH TO TEACHERS' COLLABORATIVE INQUIRY
}

BY

\section{RAEWYN MAY EDEN}

\author{
A thesis \\ submitted to the Victoria University of Wellington \\ in fulfilment of the requirements for the degree of \\ Doctor of Philosophy
}

Victoria University of Wellington

2019 



\begin{abstract}
This study explores how participation in collaborative inquiry opens space for an expanded set of understandings and practices for mathematics teaching | learning. It examines the affordances of collaborative inquiry to promote, or constrain, teacher learning in the context of teachers' day to day work.

Sociocultural perspectives underpin the study whereby professional learning is presumed to be situated in the social and cultural contexts of teachers' work. A survey of the literature supports the assumption that persistent underachievement in mathematics for some groups of learners requires shifts in what teachers know and can do and reveals the importance of collaboration and inquiry for teacher learning.

The study involved a participatory, design-based approach underpinned by an authentic and appreciative inquiry stance. Design-based research was chosen for its proximity to practice and its focus on connections between the enactment of learning designs and outcomes of interest. The research was iterative and cyclical whereby the researcher worked with a group of four teachers in one New Zealand primary school to design, implement and refine an approach to teachers' collaborative inquiry. A range of data were gathered during a 6-month collaboration, including from teacher interviews, classroom observations and three-weekly group meetings. The analysis took a pragmatic and multi-theoretical approach to examine what it meant to design and enact teachers' collaborative inquiry. Cultural-historical activity theory (CHAT) was employed to capture the complexity of the teachers' collaborative inquiry activity and to analyse and interpret the contradictions that arose.
\end{abstract}

A key finding was that a co-teaching inquiry approach fostered conditions that afforded teachers' expanded access to and depth of engagement with new, and often dissonant, practice ideas. Through co-teaching, mathematics teaching | learning was restructured within three interconnected fields of practice: the teachers' enacted practice, their talk about practice, and their noticing of student thinking within practice. The co-teaching inquiry activity was increasingly directed at a collective purpose; involved an interplay of risk and trust; supported shifts in teachers' roles and responsibilities; and allowed teachers to constantly renegotiate the goals of their 
shared activity. The co-teaching arrangement disrupted practice whereby teachers' actions served as minor interruptions to each other's practice and thus became a resource for teacher learning. Opportunities to engage deeply with one another's practice opened space for an expanded set of actions for each of the teachers in their own practice.

This thesis adds nuanced understandings of the interrelated roles of collaboration and inquiry in improving teaching. It contributes to the growing body of literature exploring co-teaching arrangements for teacher learning, in this case in the previously under-examined context of teachers' collaborative inquiry for their ongoing professional learning. It offers insights into how co-teaching might support teachers to enact new and challenging pedagogies aimed at addressing the persistent and considerable challenges posed by an ethical imperative to promote mathematics learning for diverse (all) students. Participating in the co-construction of a design for their collaborative inquiry enabled teachers to restructure their work and expand the possibilities for their individual and collective practice. It allowed teachers to reconstruct their identities from the lone operator whose professional reputation needs protection from exposure of any weaknesses in their mathematics knowledge or practice, to a learner whose naïve questions and gaps in practice served as a resource for all in their learning. 
To Ngamarama, you are the reason that I do what I do - I wrote this for you.

You are, and always will be, my superhero. 


\section{Acknowledgements}

Firstly, I acknowledge and thank the remarkable kaiako at "Waterview School" who were the brave and generous co-researchers, co-teachers and co-learners whose work is at the heart of this thesis.

I offer heartfelt thanks to my supervisors, Dr Joanna Higgins, Dr Lex McDonald and Dr Sue Cherrington for the guidance, expertise and care they offered on this $\mathrm{PhD}$ journey. I acknowledge the important role they each played in supporting me to create this work. Special mention must go to Joanna as primary supervisor for walking this path so closely alongside me, and for the friendship that has been forged as a result.

The lines between colleague and friend, and between friend and whanau, are blurred. There is an amazing and widespread community who have supported me to make this thesis possible, and this achievement is as much yours as it is mine. I cannot list all of you who have held the fort for me in my many absences, who have parented in my place, who have offered words of encouragement and advice, who have shared wisdom and jokes, and who have made space for me to do what I needed to do in those times when I chose to prioritise this work. I acknowledge and thank you all. 


\section{Table of Contents}

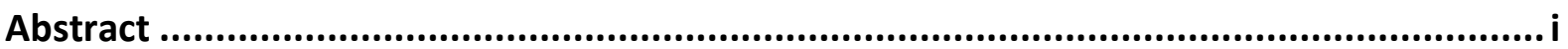

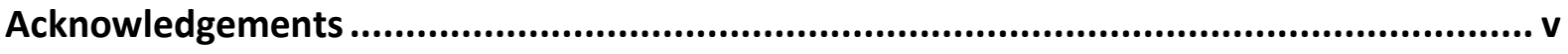

Table of Contents ........................................................................................................... vii

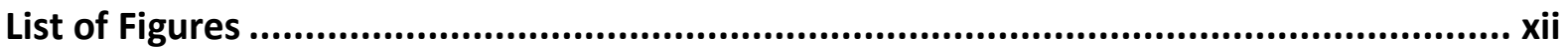

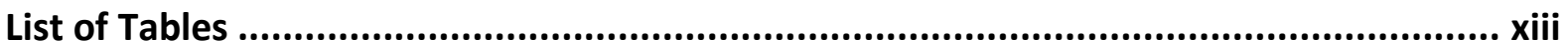

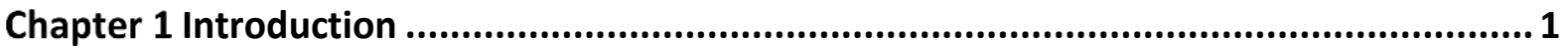

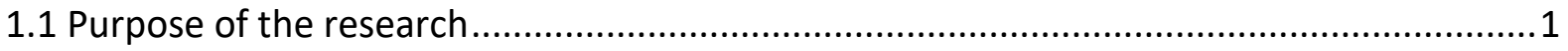

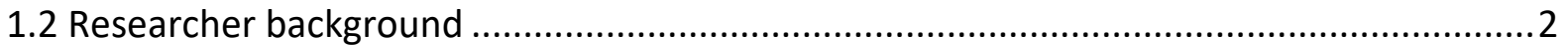

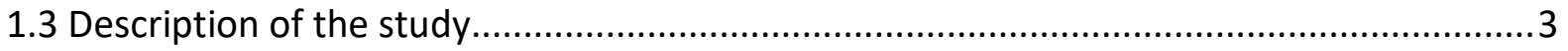

1.4 Rationale for the study: Equitable teaching | learning of mathematics ............................ 3

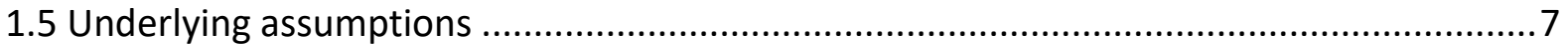

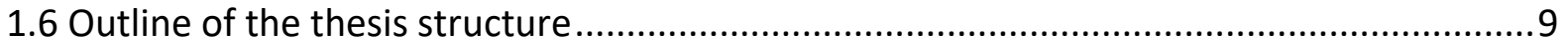

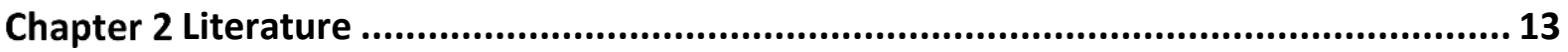

2.1 The role of teacher knowledge in mathematics teaching | learning ..............................14

2.1.1 What knowledge is important for mathematics teaching | learning? ....................15

2.1.2 Connecting knowledge and practice: Why teacher knowledge is important ........17

2.1.3 Teacher learning as epistemological: Generating knowledge as local theory .......20

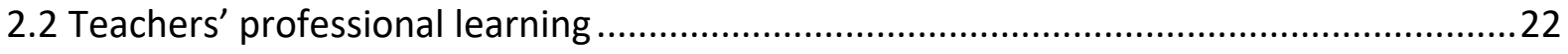

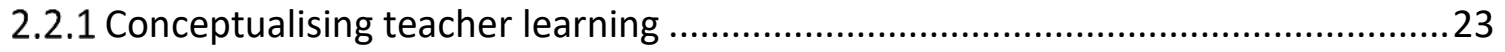

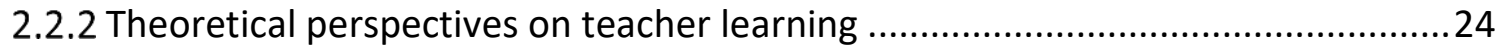

2.2.3 'Effective' teacher learning: Linking teacher and student learning .......................25

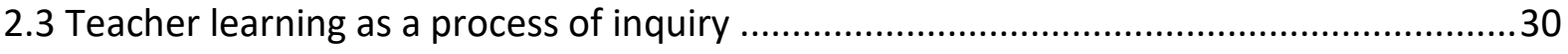

2.3.1 Teacher inquiry as knowledge-building cycles ...................................................30

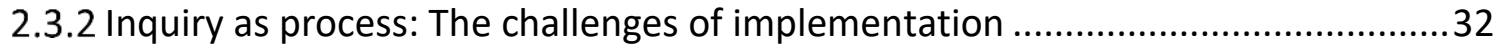

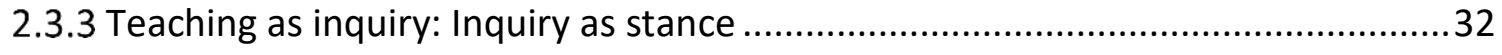

2.3.4 Teacher learning as the development of adaptive expertise................................33

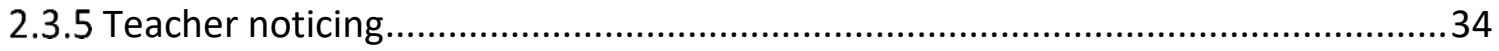

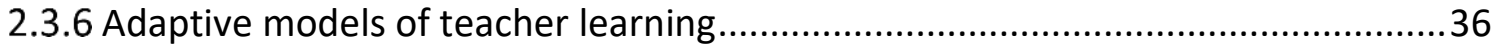

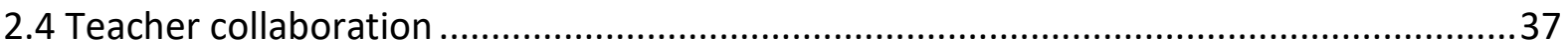

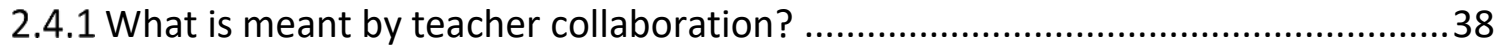

2.4.2 Community as a site for teacher collaboration .................................................... 39

2.4.3 Teacher learning within community ................................................................. 40

2.4.4 Connecting community and inquiry: Teachers' collaborative inquiry.....................42

2.5 Affordances of teachers' collaborative inquiry: Inside the 'black box' .............................44 
2.5.1 A focus on content: What is shared in teachers' collaborative inquiry? .45

2.5.2 A focus on dialogue: How do teachers engage with content? .............................48

2.6 Co-teaching as an arrangement for teacher learning...................................................51

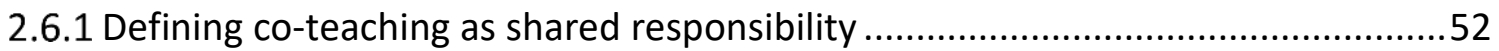

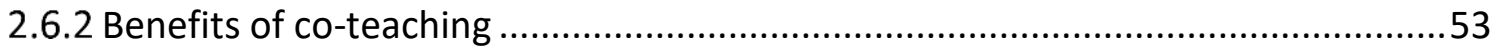

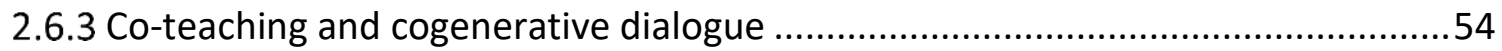

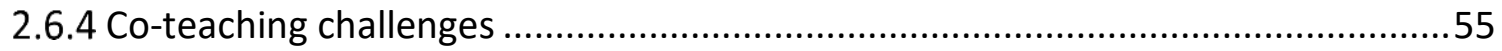

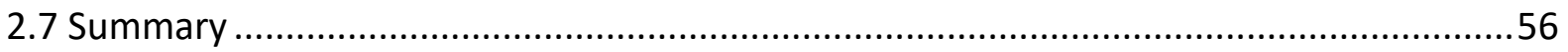

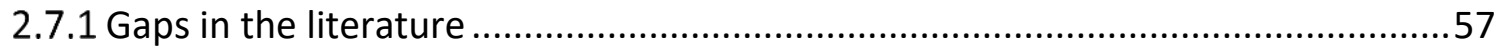

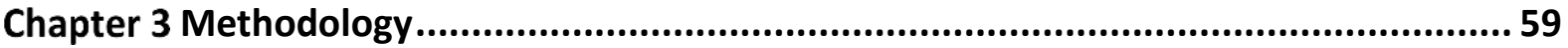

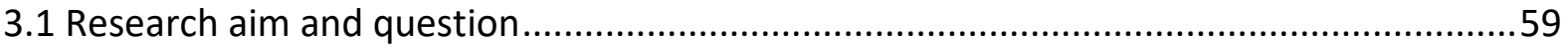

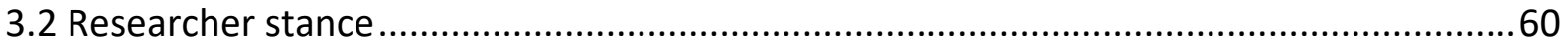

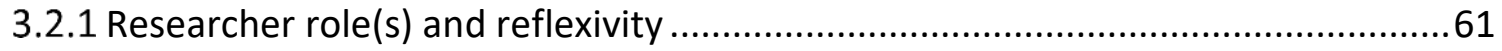

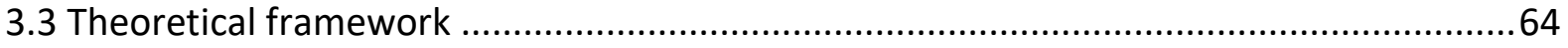

3.3.1 Theoretical approach: Cultural-historical activity theory ..................................65

3.3.2 Theoretical pluralism: Multiple theoretical tools .................................................67

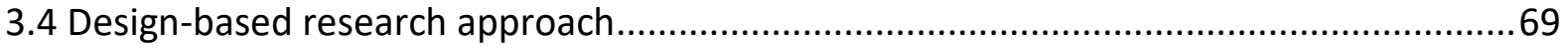

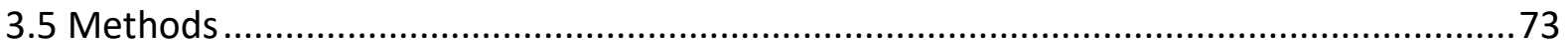

3.5.1 Research site selection and recruitment of participants .................................... 73

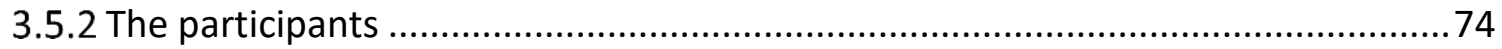

3.5.3 Data sources and data gathering methods.......................................................... 75

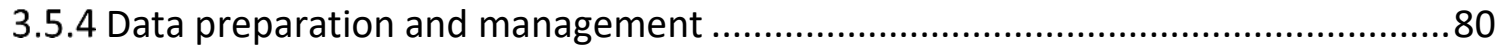

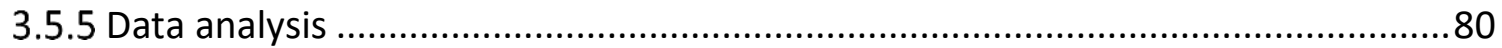

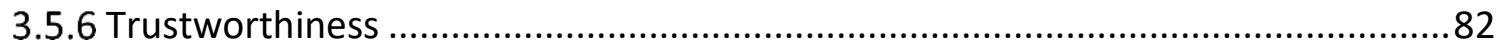

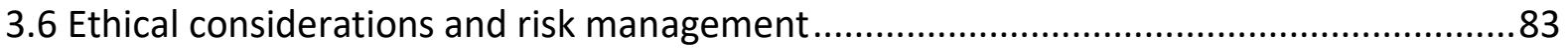

3.6.1 Negotiating entry and developing research relationships .................................84

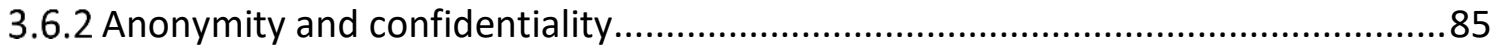

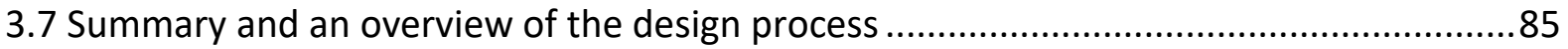

Chapter 4 Setting the scene: Collaboration in mathematics teaching | learning prior to the

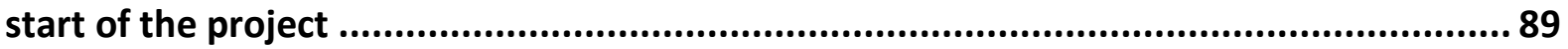

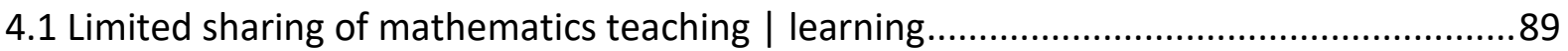

4.2 Designing staff meetings to expand teachers' access to other's practice.......................92

4.2.1 Promoting a sense of shared purpose ............................................................... 92

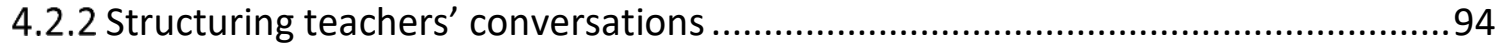

4.2.3 Sharing expert knowledge across curriculum boundaries.................................95

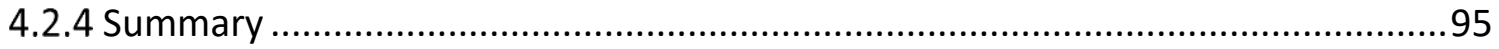


4.3 Activity system 1: Sharing teaching ideas in staff meetings. .96

4.4 Discussion: Contradictions within the activity of sharing ideas at staff meetings .99

4.4.1 Grouping practices promote individualised mathematics teaching. 101

4.4.2 Teachers' access to resources for expanding classroom practice 101

4.4.3 The value of shared practice as a resource for teacher learning: What and whose expertise is valued and why? 103

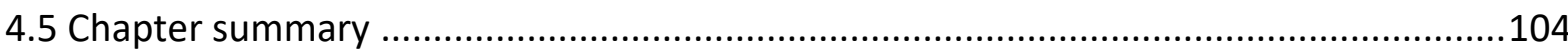

Chapter 5 Design phase 1: Negotiating the object and sharing video ............................ 107

5.1 Getting underway: Early design elements are researcher-specified..............................108

5.1.1 An overview of early design principles ............................................................. 108

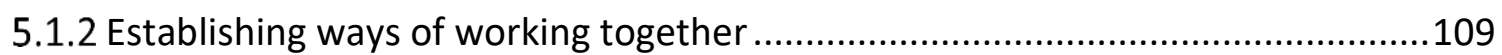

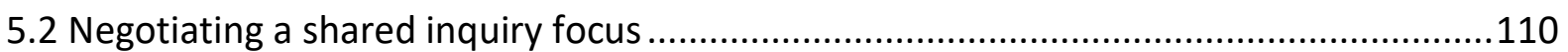

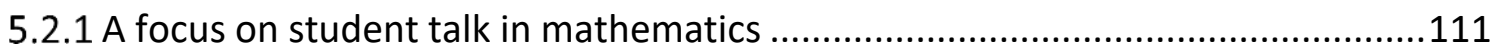

5.2.2 What teachers meant by 'student talk' in mathematics .....................................112

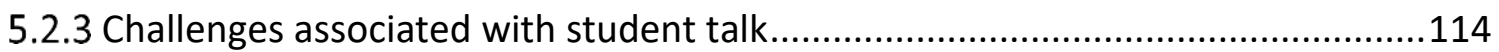

5.2.4 A teacher's role in student talk: "You're not there to pat their backs" ................116

5.2.5 Structuring teachers' conversations expands and deepens thinking ...................118

5.3 How to share the work of implementing new pedagogies ..........................................121

5.3.1 Introducing the idea of video-recording mathematics lessons ............................122

5.3.2 Developing guidelines for using classroom video............................................123

5.4 Implementing new pedagogies and reflecting on classroom video ..............................125

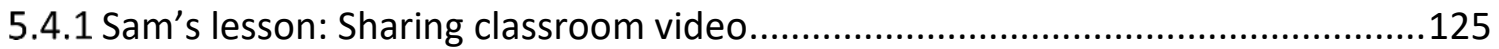

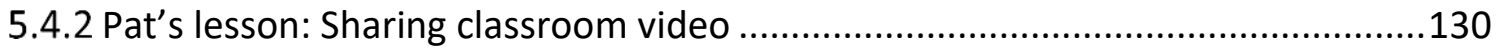

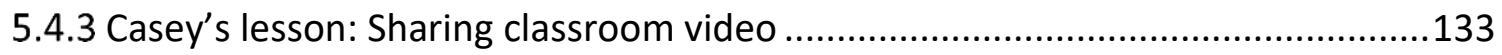

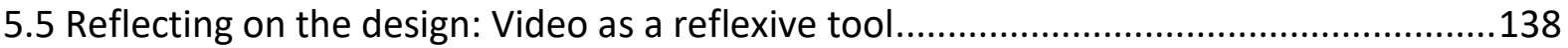

5.6 Activity system 2: Reflecting together on videos of classroom practice ........................140

5.7 Discussion: Contradictions within the activity of reflecting together on classroom video

5.7.1 Diverse and shifting ideas about student talk [Runaway object?] ...................... 145

5.7.2 Beyond sharing: Structuring conversations to engage with difference ................145

5.7.3 Teacher as 'explainer' and teacher as 'facilitator' ..............................................147

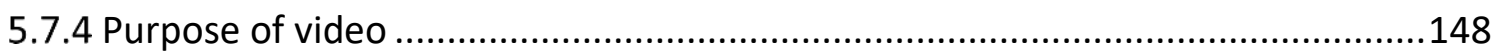

5.7.5 The influence of expertise on teachers' conversations .......................................149

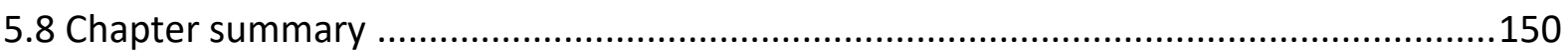

Chapter 6 Design phase 2: Co-teaching as an arrangement for teachers' shared work ... 153

6.1 Co-teaching as an innovation: The birth of an idea..... .154 
6.2 Developing and trialling co-teaching as an innovation: First experiences .157

6.2.1 Pat and Raewyn co-teaching in Pat's classroom.

6.2.2 Pat + Kris co-teaching in Pat's classroom.

6.3 Contrasting co-teaching and appraisal observations

6.4 Co-teaching as a feature of the teachers' collaborative inquiry: Enacting, sharing and discussing co-teaching with colleagues

6.4.1 Casey and Pat co-teaching in Casey's classroom ................................................165

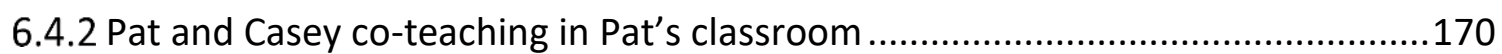

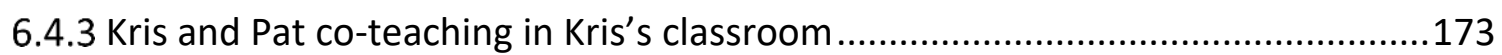

6.5 The three phases of co-teaching: Co-planning, co-instruction and co-reflection...........175

6.5.1 Co-planning for student and teacher learning................................................175

6.5.2 Co-instruction: A flexible arrangement for teaching mathematics together ........178

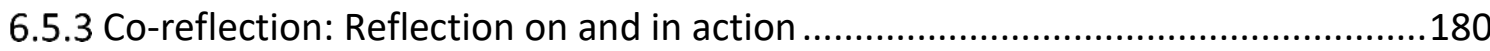

6.6 Co-teaching as part of a bigger picture: An emerging model for teachers' collaborative

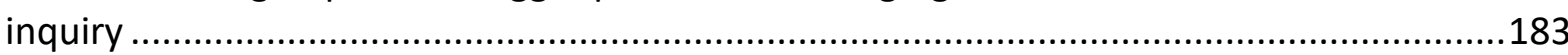

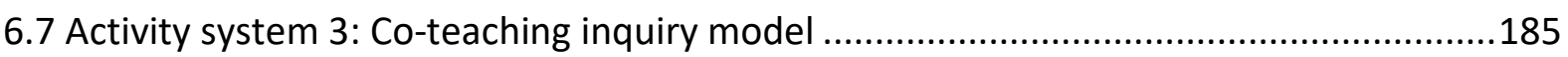

6.8 Contradictions within the activity: The affordances of co-teaching inquiry for teacher

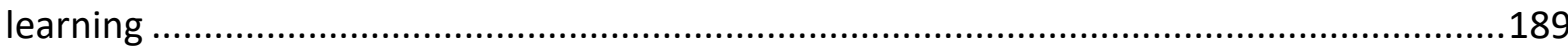

6.8.1 Relationships: "I don't wanna work with you if it's 'look at me" "........................191

6.8.2 Accountability and trust: Productive relationships "have to be earned" ............195

6.8.3 Engagement in robust, learning-focused dialogue ..............................................199

6.8.4 Reciprocal responsibility for one's own and others' learning ............................204

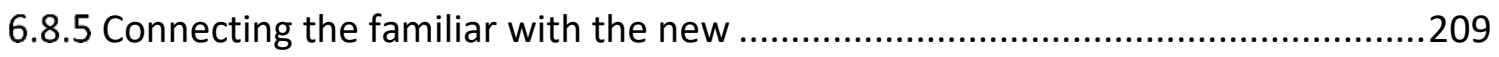

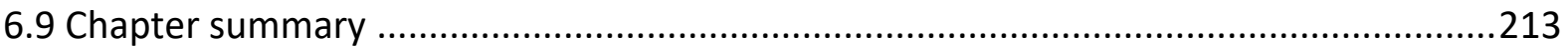

Chapter 7 Restructuring teachers' work: Teacher learning as adaptive, transformative and

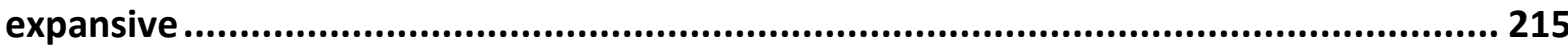

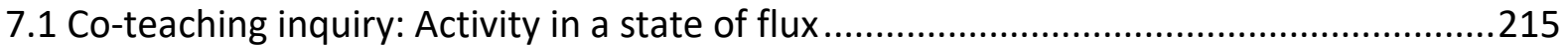

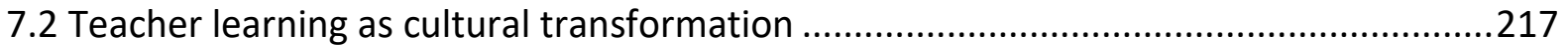

7.3 Expanding teachers' access to resources within three fields of practice ........................219

7.3.1 Enacting shared practice: The familiar meets the new ......................................219

7.3.2 Conversations about practice: Cogenerative dialogue ........................................221

7.3.3 The complexity of co-teaching sharpens teacher noticing .................................225

7.3.4 Teacher learning within shared practice: Talking | Enacting | Noticing ..............228

7.4 Opening space for new ways of working: The mechanisms of change .........................231

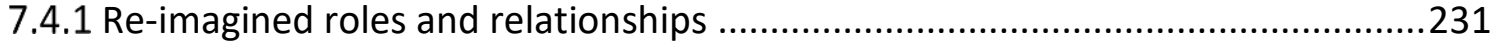

7.4.2 Shared responsibility for student learning: The emergence of the collective .....234 


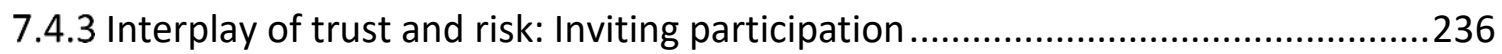

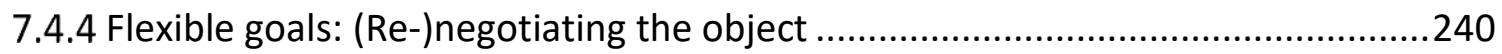

7.5 Engaging with difference: Co-generating knowledge...............................................24

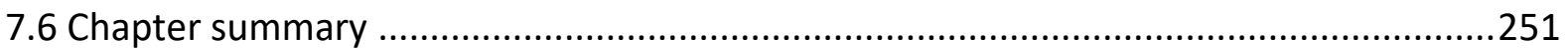

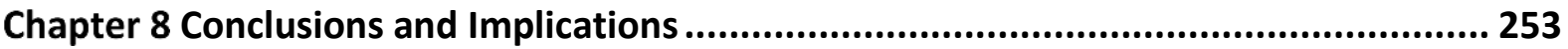

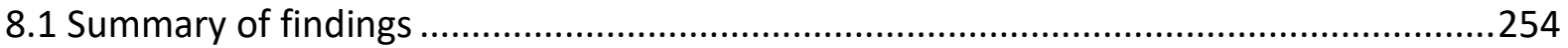

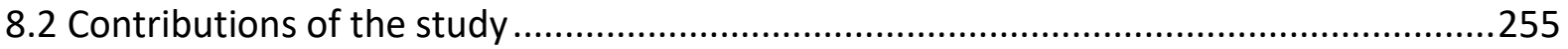

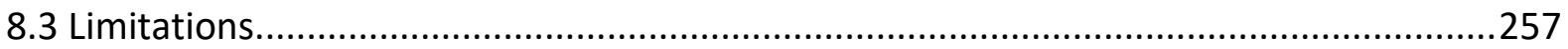

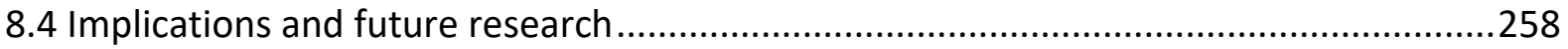

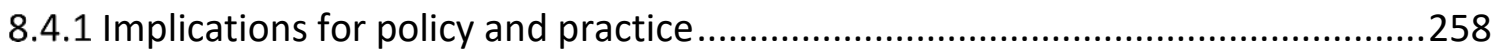

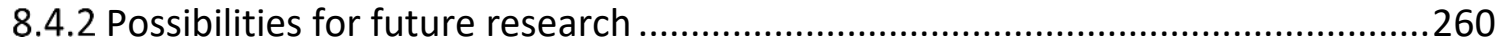

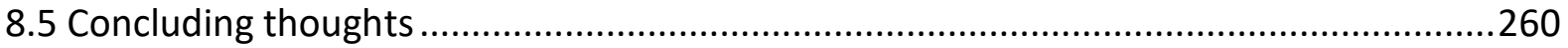

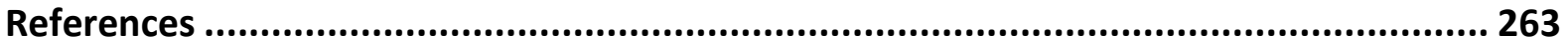

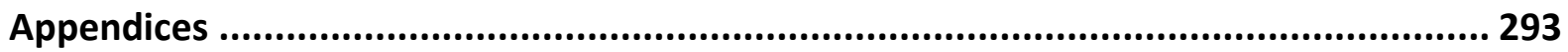

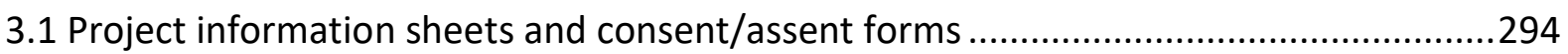

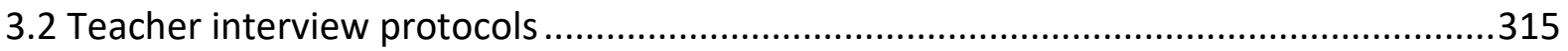

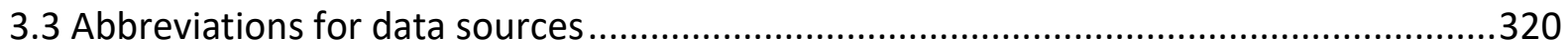

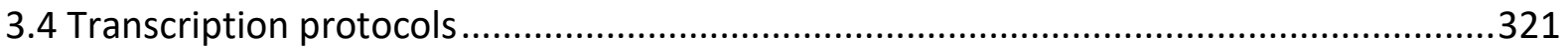

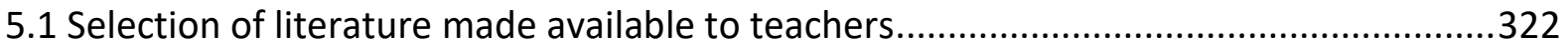




\section{List of Figures}

Figure 2.1. Outline of literature surveyed in Chapter 2 ...................................................13

Figure 2.2. Cycle of teachers' pedagogical reasoning and action (Shulman, 1987) ...............18

Figure 2.3. Interrelatedness of domains of mathematical knowledge. ...............................21

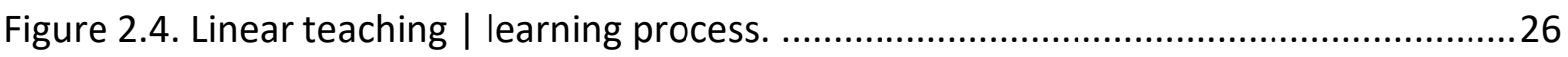

Figure 2.5. Characteristics of effective professional learning (Desimone, 2009)...................27

Figure 2.6. Professional inquiry and knowledge-building cycle to promote valued outcomes

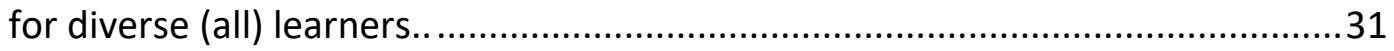

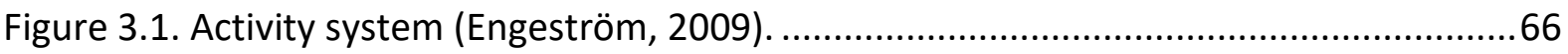

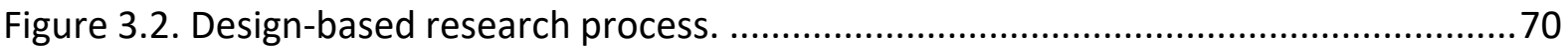

Figure 3.3. Integrating an inquiry and knowledge-building cycle with the research baseddesign process

Figure 4.1. Activity system 1: Teachers' collaborative activity prior to the study involving sharing classroom practice at staff meetings.

Figure 4.2. Contradictions within the teachers' collaborative activity prior to the study: Sharing classroom practice at staff meetings.

Figure 5.1. Overview of key design phases and collaborative inquiry activity.

Figure 5.2. Activity system 2: Reflecting together on classroom video.

Figure 5.3. Contradictions within the teachers' collaborative activity in design phase 1 : Reflecting together on classroom video.

Figure 6.1. Overview of key design phases and collaborative inquiry activity....... .153

Figure 6.2. Co-teaching cycles within teachers' collaborative inquiry. 184

Figure 6.3. Activity system 3: Co-teaching inquiry model. 187

Figure 6.4. Contradictions within the co-teaching inquiry activity in design phase 2: Coteaching inquiry model.

Figure 7.1. Interconnected fields of teachers' co-teaching inquiry practice

Figure 7.2. Restructuring mathematics teaching | learning within interconnected fields of co-teaching practice. 


\section{List of Tables}

Table 2.1 Characteristics of Professional Learning that Influences Achievement....................28

Table 2.2 Definitions and Core Characteristics of PLCs...........................................................40

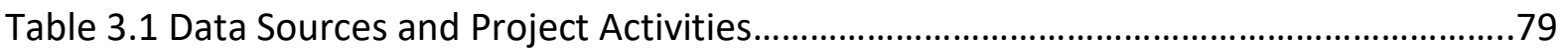

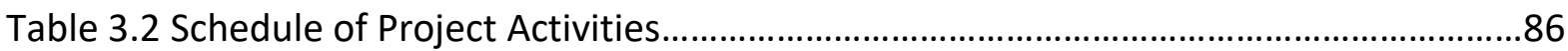




\section{Chapter 1 Introduction}

Achieving equity in mathematics teaching | learning is a complex undertaking and remains an enduring and important challenge (Jorgensen, 2014). Growing calls for reform in mathematics classrooms that are aimed at meeting the needs of $21^{\text {st }}$ century learners presume a reconceptualisation of the teacher's role and associated shifts in expectations for teachers' classroom practice (Darling-Hammond \& Bransford, 2005). Calls for mathematics education reform encapsulate a vision of ambitious mathematics teaching | learning that involves learners' active engagement in mathematical inquiry and argumentation and necessitates a radical shift for teachers; a shift that is challenging to achieve (Hunter, 2010). Against such a backdrop, this study is premised on a view that teachers' work in collaborative contexts is a productive site for teachers' professional learning wherein such shifts might be opportuned.

\subsection{Purpose of the research}

The central purpose of this study was to investigate the collaborative activity of a group of teachers who were aiming to strengthen mathematics teaching | learning in the context of their day to day work in a New Zealand primary school. The overarching aim was for the researcher and the group of teachers to co-design and participate in enacting a model for collaborative teacher inquiry, and to investigate participants' perceptions of, and actions taken during, the experience. The study addresses the research question:

How does participation in collaborative inquiry generate teachers' knowledge for mathematics teaching | learning?

The focus of the exploration was on appreciating the critical contradictions that arose and actions that were taken as participants designed and participated in collective, goal-directed activity. The research sought to account for the affordances within such activity, described by Little (2003) as "the ways in which the practices of the group open up some opportunities [for teacher learning] and constrain or close off others" (p. 939). Implicit in the research question is how changes in teachers' knowledge, 
beliefs, and practices for teaching | learning mathematics are revealed in how they talk about mathematics teaching practices.

\subsection{Researcher background}

This study is informed by my practice as a teacher educator with a focus on primary mathematics education, and as a former primary teacher and mathematics support teacher (MST), a specialist role aimed at raising achievement for learners identified as well below the then national standard for mathematics achievement (Ministry of Education, 2017). The motivation for this research stems from my interest in, and wonderings about, the complexity of teaching mathematics well, and serves as a response to two interrelated contradictions that arose within my work as a primary teacher. Firstly, during my study towards a Master of Education between 2002 and 2006, and my training for the MST role, I became increasingly aware of the affordances of structuring collaborative, inquiry-oriented interactions amongst learners in my classroom. In contrast, I began to question the effectiveness of many approaches to professional learning for teachers through which it appeared there was little if any likelihood of transforming classroom practice. A pivotal moment when this contradiction was starkly realised for me was listening to a lecture about student engagement and noting the irony of how motivated yet completely disengaged I was.

The second contradiction involved the often individualised nature of teachers'

work - including the arguably widespread expectation that one teacher is held accountable for the learning of one group of students. In contrast, my own experiences of teaching included job-sharing in a number of roles including as Assistant Principal, classroom teacher and in the MST role. I was struck by the way in which these collaborative contexts and engaging in a shared endeavour opened possibilities for learning whereby activities such as shared decision-making and planning, co-teaching, and joint assessment required us to make our practice explicit and available for scrutiny, and to justify it. I was struck by the potential for such interactions to be transformative and self-sustaining and became interested in what conditions and actions might encourage or impede this in a wider collegial context. Together, these 
experiences fuelled my interest in exploring how teacher learning might be promoted by designed approaches to teacher collaboration.

\subsection{Description of the study}

This thesis reports on a study carried out in a New Zealand primary school over two terms of a four-term school year; that is approximately six months. The research took a participatory, design-based approach and involved working with a group of four teachers as the primary participants, one of whom withdrew partway through the study's duration. The research design and methodological approaches used are elaborated on in Chapter 3 Methodology.

\subsection{Rationale for the study: Equitable teaching | learning of mathematics}

Inequity is an important and persistent problem in education. There is disparity in educational achievement amongst different groups of students internationally and in New Zealand, and addressing inequity remains a priority for our education system. Within the social, cultural-historical and policy context of the problem of inequitable opportunity for learning, this thesis explores the central role of the teacher in students' educational success in mathematics. Addressing the inequitable teaching | learning of mathematics is an educational imperative both internationally and for New Zealand (OECD, 2012). The problem of educational underachievement for students is specifically framed here as a problem of opportunities for teachers' ongoing learning.

Over the last 20 years, New Zealand learners have been consistently measured as achieving significantly higher than the OECD average, however the range of scores from the lowest to the highest achieving students is the widest amongst the top performing countries (Nusche, Laveault, MacBeath, \& Santiago, 2012). Accordingly, the reduction of achievement disparities within and among schools, and improving education outcomes for all students, are consistently noted as education priorities. In the Ministry of Education's annual Statements of Intent which outline four-year plans to deliver on education goals and priorities, equity of educational achievement has been highlighted as a national education priority since at least 2010 (Ministry of Education, 2019b). The greatest differences in achievement among different groups of 
learners can be seen to occur within schools rather than between them, suggesting that differences in achievement might be influenced at classroom level. Promoting the professional learning and development of teachers is a key lever for addressing disparities in educational achievement. New Zealand's education system is one of the most devolved in the world, with significant trust and personal accountability placed on teachers for the effectiveness of their practice. Until recently, a key policy approach to addressing diverse learning needs within our education system has been centred on the development of assessment and evaluation approaches with particular attention being given to groups of students for whom the system can be seen to be underperforming. However, there is a need to strengthen both the identification of, and the response to, groups at risk of underachievement (OECD, 2012).

The problem of inequity in mathematics achievement among different groups of learners, particularly in New Zealand's primary classrooms, provides the impetus and rationale for this study. It reflects a school reform agenda that aims to address gaps in achievement and produce the greatest gains for those students most at risk of underachievement. Internationally, the inequitable achievement of different groups of students is increasingly seen as a school performance issue (OECD, 2012) focused on the need for changes in teaching to meet increasingly diverse student needs (DarlingHammond, Wei, Andree, Richardson, \& Orphanos, 2009). At the heart of such an agenda is the political and economic imperative for transformative professional learning for teachers that can develop the knowledge and skills necessary in a rapidly changing education scene. As Stetsenko (2008) argues:

The notion of transformative practice is inexorably linked to ideals of social justice and emancipation as pursuits of common humanity .... Arguably, such an emphasis is highly consistent with the challenges now facing researchers and practitioners of education given the rapidly globalizing world where communities are interrelated and the tasks facing them worldwide ((2008, p. 474).

School reform efforts have primarily focused on the development of teachers who are seen to have the single largest system-level impact on student achievement (AltonLee, 2003). Accordingly, in this study disparities in mathematics achievement between different groups of learners in New Zealand is framed as a problem of effective professional learning for teachers premised on the idea that teachers' 
professional learning can "make dramatic differences [...] for students who have traditionally been under-served by education" (Alton-Lee, in Timperley, Wilson, Barrar, \& Fung, 2007, p. xx). Reform goals for mathematics teaching | learning require shifts in fundamental aspects of teacher practice such as classroom roles and patterns of discourse, however, teaching has proven resilient to change and such shifts are complex and difficult to achieve (Spillane, 1999).

Equity is identified as an underlying value of the New Zealand curriculum (Ministry of Education, 2007) and should be reflected in "every decision relating to curriculum and every interaction that takes place in school" (p. 10). Nevertheless, evidence points to a growing achievement gap between different groups of students including, in particular, those from different cultural and socio-economic backgrounds. For instance, national standards data show that Pasifika learners' achievement levels remain lowest of all identified ethnic groups, marginally below New Zealand Māori and significantly below all other groups (Ministry of Education, 2019a). Increasing attention towards such measures can be counterproductive, however. For instance, Turner, Rubie-Davies and Webber (2015) in their study of 15 teachers in five Auckland schools found that secondary mathematics teachers had lower expectations for Māori and Pasifika students' achievement than for their European and Asian peers, and that they attributed student underachievement to perceived deficiencies in their family circumstances such as uneducated parents and a lack of home support for their learning. High teacher expectations have been shown to impact positively on student achievement (Good, 1981, 1987). Conversely, low teacher expectations, which are more closely associated with indigenous and minoritised students than their European counterparts, have been seen to contribute to student underachievement (Turner et al., 2015). The New Zealand curriculum has an explicitlystated principle of holding high expectations and supporting and empowering "all students to learn and achieve personal excellence regardless of their individual circumstances" (p. 9). As Cobb argues in his foreword to Anthony and Walshaw's (2007) Effective Pedagogy in Mathematics/Pāngarau Best Evidence Synthesis Iteration $(B E S)$ which was focused on pedagogy that impacts positively on student outcomes, it is important to make a distinction between categorisations of students by ethnicity in 
order to assess equity within the system while avoiding stereotyping and attending to the complexity of identity when seeking to explain inequities in diverse children's learning opportunities.

This study was initially intended to focus on promoting the mathematics achievement of Pasifika ${ }^{1}$ students in part because this is a group for whom mathematics achievement is consistently measured as significantly lower than that of European students (May, Cowles, \& Lamy, 2013; Young-Loveridge, 2010). Despite the significance of this problem the literature remains very limited. There is an emerging body of literature exploring effective approaches for raising the achievement of Pasifika students in New Zealand generally (Fletcher, Parkhill, Fa'afoi, Taleni, \& O’Regan, 2009) and in mathematics in particular (e.g. Averill, 2012; Hunter \& Anthony, 2011), however, approaches to raising the mathematics achievement of Pasifika students remains a significantly under-researched area. Given that there are very few studies focused on specific pedagogical approaches to raise the mathematics achievement levels of Pasifika students, promoting equitable learning opportunities for these students constitutes a "strategic research site [which is] particularly illuminating for our understanding of how knowledge grows in teaching" (Shulman, 1986, p. 8). In the absence of an established body of knowledge specifically addressing this problem, teachers are required then to develop their own approaches opening opportunities to explore teachers' pedagogical innovations which can reveal important understandings about how they learn to teach.

The study takes up "the problem of how classroom teaching practice comes to be known shared and developed among teachers through their out-of-classroom interactions" (Little, 2003, p. 913); in this case through designed processes for collaborative interaction among teachers of mathematics within the context of their school. An explicit goal of the project was to transform practice through research and so the focus was on designing an intervention to support teachers to improve teaching and learning (Tobin, 2014). The study is based on the underlying conviction that

1 The term Pasifika, in accordance with Hunter and Anthony (2011), refers here "to a multi-ethnic, heterogeneous group of people who originated from the Island nations in the South Pacific" (p. 103). 
teachers' learning can be enhanced by collaboration with colleagues, and specifically aimed to investigate how teachers' collaboration can support teachers to promote mathematics learning for diverse (all) learners. There is a growing consensus that collaboration is a core component of professional learning that promotes teachers' knowledge and practice (Desimone, 2009) and student learning (Timperley, Wilson, Barrar, \& Fung, 2007). In New Zealand, Pasifika students are over represented in schools with low socio-economic student populations (May et al., 2013) and collaborative professional learning has been identified as a crucial influence for promoting high student achievement in such schools (Darling-Hammond, Wei, Andree, Richardson, \& Orphanos, 2009).

\subsection{Underlying assumptions}

The use of teaching | learning rather than just teaching is used to deliberately position the teacher as learner and to emphasise the reciprocal nature of teaching and learning. Such a notion is captured in the term ako, a Māori term that means both to teach and to learn. A focus on teaching | learning rather than teaching and learning encapsulates the idea of teaching and learning as having a dialectical relationship shown by the use of the Sheffer stroke "whereby two mutually exclusive but reciprocal terms are combined together" (Roth \& Lee, 2007, p. 197). Powietrzynska (2015) describes dialectics as "constructs in social fields that are constituent of a whole and do not exist independently - existence of one presupposes the other" (p. 72). In other words, learning and teaching are assumed to constitute one whole whereby without learning, teaching cannot be said to have occurred and similarly teaching can be said to fundamentally involve learning.

In this study, the teachers' learning through collaborative inquiry is viewed through a socio-cultural lens and framed by an ontological assumption that knowledge for mathematics teaching | learning is generated across multiple mathematical, social and cultural planes. The study brings together ideas related to teacher inquiry (e.g. Timperley, Kaser, \& Halbert, 2014) and professional learning communities (PLCs) (e.g. Hipp \& Huffman, 2010). Teachers' inquiry is assumed to be a socially constructed activity, mediated by social, cultural and historical tools 
(Vygotsky, 1978) in which learning is not limited to what is in individuals' minds but rather occurs within interactions among people. The study takes an epistemological position that teacher learning occurs both in formal, planned contexts, and in the everyday informal experiences of teachers in the broader context of their work and lives. It is assumed that teachers' collaborative inquiry is a situated practice connected with the interrelated practices of teaching and talking about teaching mathematics. This thesis explores potential disconnections among teachers' knowledge, practices and discourse and aims to shed light on how designing for teachers' collaborative inquiry might strengthen these connections.

An overarching aim of this study was to explore how a group of teachers in a New Zealand primary school might collaboratively inquire into their practice with the ultimate objective of promoting improved mathematics learning for students they had identified as at risk of underachievement. A number of assumptions about the nature of effective mathematics teaching | learning underpin the study, informed by research findings such as those reviewed by Anthony and Walshaw (2007) in their BES. Such pedagogical practices can be described as ambitious in that they are premised on high expectations for the mathematics learning of all students (Cobb, 2007). The chapters that follow trace the argument that what teachers know impacts upon what they do in the classroom and thus upon the ways in which their actions are able to promote, or indeed constrain, student learning.

The thesis aims to explore processes for teacher learning that can strengthen teachers' mathematics teaching | learning to promote improved opportunities for student learning. The next chapter surveys literature that addresses the question of what teacher knowledge is important for mathematics teaching | learning alongside why such knowledge is important; what is the intersection of teacher knowledge and practice? An aim of this study is to contribute to a more nuanced view of the nature and complexity of mathematical knowledge for teaching by exploring these interrelationships in depth within the context of teachers' collaborative work towards improving diverse (all) students' achievement. Conceptualisations of teachers' professional learning are explored with a particular focus on notions of teacher inquiry, collaboration and community. The focus is on the opportunities that teachers 
have to generate important knowledge of teaching | learning in mathematics, and the mechanisms and processes of teacher learning, through the day-to-day work of teaching. To this end, the study aims to answer Koellner and Jacobs' (2015) call for additional research into adaptive models of professional development; that is models that are "designed to be readily responsive or adapted to the goals, resources and circumstances of the local PD context" (p. 51).

\subsection{Outline of the thesis structure}

Chapter 2 Literature presents literature that underpins and informs the thesis. It discusses key terms and locates key concepts. The chapter begins by exploring the role of teacher knowledge in mathematics teaching | learning and connects this to notions of teacher learning as knowledge generation. Teachers' collaborative inquiry describes the activity that was the focus for this study, and thus the chapter aims to draw together literature pertaining to teacher collaboration and to teacher learning as a process of inquiry. Teachers' collaborative inquiry is then conceptualised and the affordances of teachers' collaborative inquiry for teacher learning are discussed. Literature on co-teaching as an arrangement for teacher learning is outlined and the chapter concludes by outlining gaps in the literature that are of relevance to the study.

Chapter 3 Methodology outlines the methodology for the study beginning with the aims of the research. My stance as a researcher is examined and the philosophical underpinnings of research decisions are explained. Implications for the participatory nature of the research and the role of reflexivity are then examined. The theoretical approach to the study is outlined including the use of cultural-historical activity theory as an overarching theoretical framework (Engeström, 2015), and the use of multiple theoretical tools within that to analyse and explain salient features of the activity. A rationale is given for the design-based research approach used and the associated methods are explained including those relating to the research site and participants, data gathering, preparation and analysis methods and considerations pertaining to issues of trustworthiness. Ethical considerations are then outlined including those relating to negotiating research relationships and protecting the 
privacy of participants. The chapter concludes with a discussion of the limitations of the research design and then details a timeline of research activities.

\section{Chapter 4 Setting the scene: Collaboration in mathematics teaching |} learning prior to the start of the project outlines findings related to how the teachers described collaboration in their mathematics teaching | learning work prior to the beginning of the study. It provides a starting point for understanding how the design for teachers' collaborative inquiry developed over the period of the study.

\section{Chapter 5 Design phase 1: Negotiating the object and sharing video} presents findings from the initial phase of designing teachers' collaborative inquiry approach as the project got underway. It focuses on the first of two distinct phases of design during which the group negotiated an overarching focus for their collaborative inquiry and then shared and discussed video excerpts from mathematics lessons in their classrooms.

\section{Chapter 6 Design phase 2: Co-teaching as an arrangement for teachers'}

shared work describes how co-teaching emerged as a core component of the teachers' collaborative inquiry approach. It examines events relating to the emergence and refinement of the co-teaching arrangement that became an important element of the teachers' collaborative inquiry activity. Findings are outlined in relation to the characteristics of the group's co-teaching inquiry activity that had emerged at the end of the study period.

Chapter 7 Restructuring teachers' work: Teacher learning as adaptive, transformative and expansive discusses how the teachers' joint work in the context of their co-teaching inquiry activity appeared to support the collective generation of knowledge for mathematics teaching | learning. The chapter discusses the central theme of engagement with differences as reflexive objects and catalysts for the ongoing transformation of the teachers' work. The discussion centres on the cogeneration of knowledge for mathematics teaching | learning within multiple parallel layers of collaborative inquiry.

Chapter 8 Implications and conclusions provides a summary of the findings and concludes the thesis. It considers the research question and the extent to which 
this study was able to answer it. The significance of the study is evaluated in relation to implications for policy and practice. This is followed by a critical examination of the limitations of the research findings and recommendations for future research. 


\section{Chapter 2 Literature}

There are fundamental assumptions about the nature of mathematics teaching | learning and the professional learning of teachers that underpin this research. This chapter presents a survey of related literature that examines the nature, conditions, and processes for teacher learning in the context of teachers' day-to-day work. The field is broad, however, and many concerns and issues explored in the literature remain outside of the scope of this thesis. The literature surveyed provides justification for focusing on teacher learning in the context of mathematics teaching | learning generally, and for focusing on teacher learning through collaborative inquiry. Figure 2.1 provides an outline of the literature reviewed in this chapter.

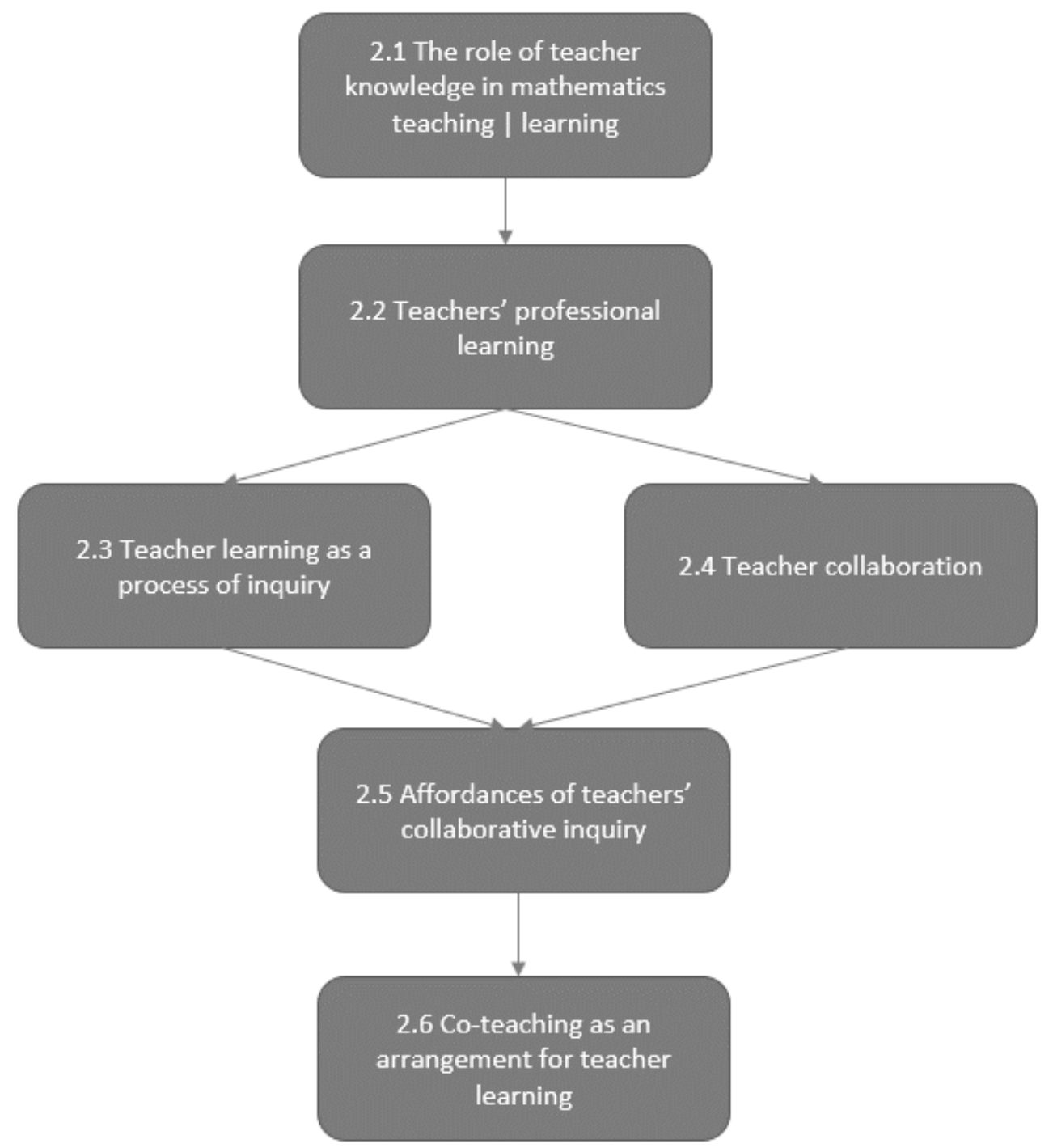

Figure 2.1. Outline of literature surveyed in Chapter 2. 
The chapter begins by examining the nature and role of teacher knowledge for achieving equity goals in the teaching | learning of mathematics. It establishes a rationale for a focus on teacher learning as complex and generative and knowledge production as the co-generation of local theory in the context of teachers' work. This section provides the background for the remainder of the chapter. Section 2.2 outlines literature pertaining to the nature of teachers' professional learning including the importance and challenge of linking teacher learning to student learning. It examines characteristics of effective and adaptive models of teachers' collaborative inquiry and the resources that mediate teacher learning. Teacher learning as a process of inquiry is explored in section 2.3 which explores the notion of teachers' professional learning as the development of adaptive expertise. Literature pertaining to the role of collaboration in teacher learning is examined in section 2.4. Collaboration is examined within the broader context of PLCs with a focus on the notion of inquiry community. Together, sections 2.2 to 2.4 provide a rationale for the study's focus on teachers' collaborative inquiry as an approach to teacher learning. Section 2.5 then explores the affordances of teachers' collaborative inquiry as mediated activity and section 2.6 surveys literature relating to co-teaching as an arrangement for teacher learning. The final section provides a summary and identifies gaps in the literature surveyed.

\subsection{The role of teacher knowledge in mathematics teaching | learning}

The issue of teachers' knowledge is relevant to this thesis because what teachers know and believe about mathematics fundamentally influences what they do in their classrooms (Adler \& Ball, 2009). It is widely accepted that teacher knowledge is important for high-quality mathematics teaching (Bobis, Higgins, Cavanagh, \& Roche, 2012) and this section examines conceptions of teacher knowledge and the complexity of teacher knowledge for mathematics teaching | learning, with a focus on knowledge-of-practice whereby,

knowledge generation and knowledge use are regarded as inherently problematic. That is, basic questions about knowledge and teaching-what it means to generate knowledge, who generates it, what counts as knowledge and to whom, and how knowledge is used and evaluated in particular contexts-are always open to discussion (Cochrane-Smith \& Lytle, 1999, p. 272). 


\subsubsection{What knowledge is important for mathematics teaching / learning?}

The knowledge required for teaching mathematics is substantial, complex and evolving (Ball, Thames, \& Phelps, 2008), and is relational and mediated by affective factors (Bobis et al., 2012). In a study examining the impact of teachers' knowledge on the quality of their mathematics instruction, Hill, Ball and Schilling (2008) concluded that attending to equity in mathematics instruction requires mathematical content knowledge for teachers to choose appropriate examples and contextualise these, and to make mathematical processes explicit to students. Chick, Baker, Pham and Cheng (2006) argued that teachers require an understanding of the complexities of mathematics content from a teachers' perspective, which goes beyond knowledge of content alone. In his seminal paper, Shulman (1986) described teachers' content knowledge as the "missing paradigm" (p. 6) in research on teaching, arguing that a balanced view with a combined focus on pedagogical and content knowledge is needed. He later distinguished among six categories of content knowledge: general pedagogical knowledge, curriculum knowledge, pedagogical content knowledge, knowledge of learners, knowledge of educational contexts, and knowledge of educational ends, values and purposes (Shulman, 1987). Shulman argued that the key to understanding teachers' knowledge lies at the point where content and pedagogical knowledge meet, where teachers put their content knowledge to use in their instructional practice. This notion of pedagogical content knowledge, the "special amalgam of content and pedagogy that is uniquely the province of teachers, their own special form of understanding" (Shulman, 1987, p.8), has been emphasised by researchers, policy makers and practitioners (e.g. Baumert et al., 2010; Hill et al., 2008). Ball, Thames and Phelps (2008) drew on their studies of mathematics teaching practice, and survey measures of content knowledge, to propose six domains of mathematical knowledge for teaching comprising subject matter and pedagogical content knowledge. Chick (2009) used a framework of 18 separate aspects of pedagogical content knowledge to examine the complexity of knowledge needed for teachers to choose examples that afford student learning in the context of understanding and teaching decimals. Highlighting the intersection between the knowledge domains of content and students, Hill, Ball and Schilling (2008) identified 
four additional sub-categories of knowledge: common student errors; students' understanding of content; student developmental sequences; and common student computational strategies.

Efforts such as these to define domains of teacher knowledge illustrate the complexity and scope of knowledge required for mathematics teaching, particularly regarding pedagogical content knowledge. Moral and democratic purposes of education shape what teachers need to know and be able to do and this study is based on the premise that teachers' access to important knowledge is essential for achieving equity goals (Bransford, Darling-Hammond, \& LePage, 2005). Of interest is the importance of teacher knowledge for the successful teaching and learning of mathematics, especially for those students who are underachieving (Alton-Lee, 2012). Sullivan, Clarke and Clarke (2009) surveyed primary and secondary mathematics teachers in Australia about their use of mathematical tasks and concluded that all six domains of mathematical knowledge for teaching categorised by Ball and colleagues (2008) are important if teachers are to implement tasks in ways that afford opportunities for student learning, especially in challenging topics. In a study examining the impact of teachers' knowledge on the quality of their mathematics instruction, Hill and colleagues (2008) concluded that attending to equity in mathematics instruction requires mathematical content knowledge for teachers to choose appropriate examples and contextualise these, and to make mathematical processes explicit to students.

Given the overarching goal of raising mathematics achievement for diverse (all) students, cultural knowledge is of interest in this study. Ball and colleagues (2008) identified a need to understand the cultural specificity of teachers' mathematical knowledge needs, however Bobis and colleagues (2012) in their review of Australasian research spanning 2008 to 2011 note that it is a little explored area. Meaney, McMurchy-Pilkington and Trinick (2012), in their review of research on the mathematics learning of indigenous students, warn that assuming particular groups of students share the same mathematical experiences, understandings and skills is problematic. Furthermore, in their paper reporting on knowledge sharing between an indigenous Australian community and researchers and teachers from Sweden, Papua 
New Guinea and New Zealand, Owens and colleagues (2011) emphasise the 'locatedness' of the cultural knowledge needed for teachers to understand the social and cultural contexts in which their students learn mathematics. Similarly, Jacob (2011), in her study exploring teachers' knowledge for teaching indigenous Australian students, describes the complexity of knowledge needed to assess and build on the mathematical language and understandings children bring with them into the classroom, and to make connections between the mathematics of home and school. In a study exploring students' and teachers' views about heritage cultures in mathematics teaching and learning, Averill (2012) found that mathematics was seen as separate from culture and teachers did not respond to students culturally through the contexts of mathematical tasks. Furthermore, devising and using culturally linked mathematical tasks posed many challenges for teachers and there is an urgent need to develop teachers' knowledge to this end. As Hunter and Hunter (2017) point out "providing equitable access for all students to participate in the mathematics discourse of the learning experience substantially increases the demand on teachers to understand the culture of their students" (p. 9).

\subsubsection{Connecting knowledge and practice: Why teacher knowledge is important}

The interrelatedness of content knowledge and instructional decision-making was found by Bobis and colleagues (2012) to be of importance and this intersection of teachers' mathematical knowledge and teaching practice is elaborated in this section. The notion of mathematical knowledge for teaching | learning is an extension of that used by Ball and colleagues (2008) and forefronts the role of the teacher and their use of different aspects of their knowledge of mathematics. It assumes that teachers use knowledge to make professional judgments and complex decisions with high stakes outcomes for students (Bransford, Darling-Hammond \& LePage, 2005).

Shulman (1987) conceptualised teachers' pedagogical reasoning and action as a cyclical process as illustrated in Figure 2.2 below. Such a cycle suggests that teachers' understanding of important mathematics content impacts on their pedagogical decisions and actions, and subsequently on students' opportunities to learn. For instance, Choppin (2011) described how aspects of a teacher's pedagogical content 
knowledge supported her to use challenging mathematical tasks in ways that enhanced students' mathematical reasoning.

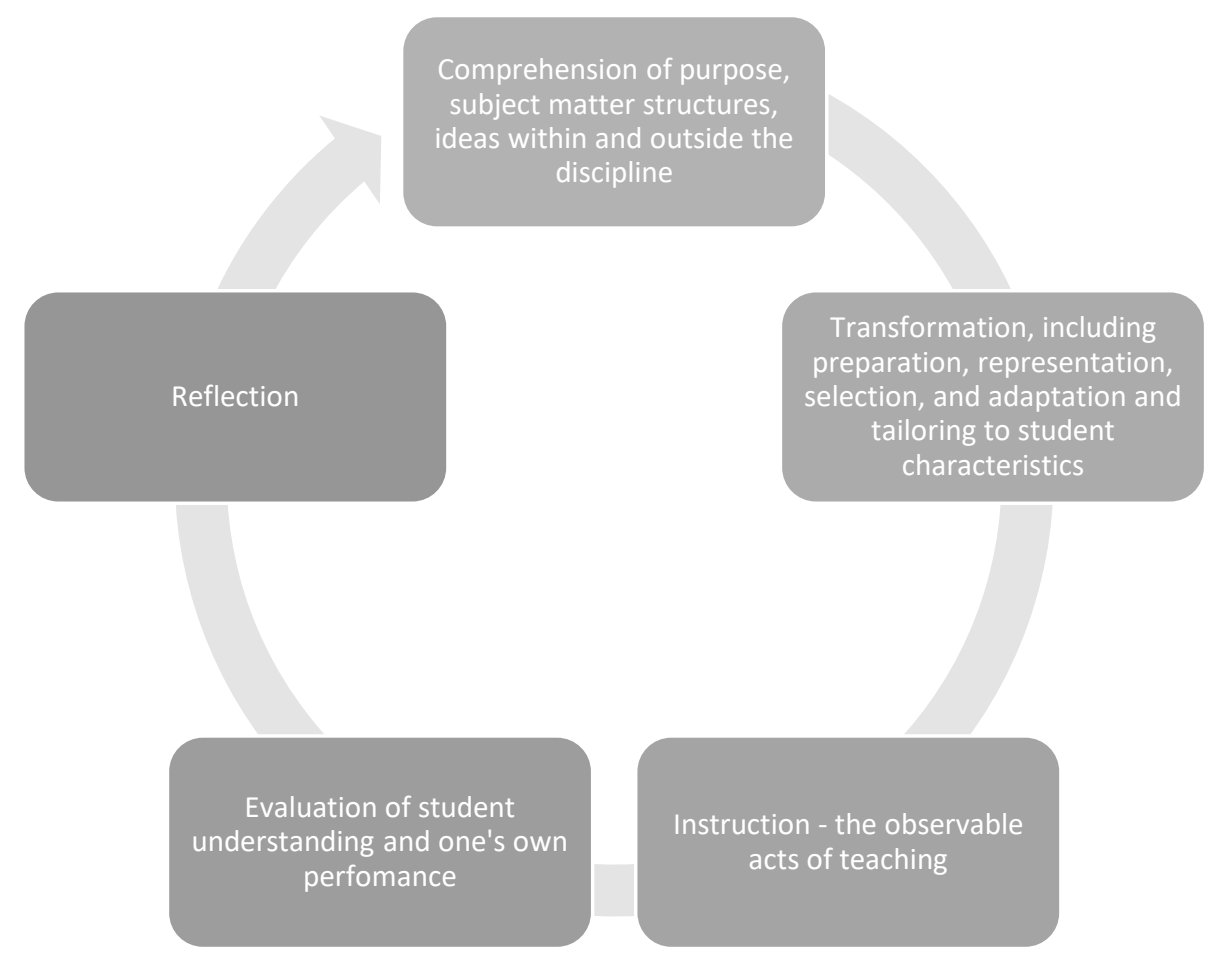

Figure 2.2. Cycle of teachers' pedagogical reasoning and action (Shulman, 1987)

The more comprehensive a teacher's knowledge base, the better informed their teaching decisions will be (Koellner et al., 2007) and the more dynamically they will teach (Brophy, 1991). In a study comparing the content knowledge of mathematics teachers in the United States and China, Ma (1999) observed that the depth, breadth and thoroughness of teachers' subject matter knowledge influenced their teaching and consequently the achievement of their students. The depth of teachers' subject knowledge fundamentally impacts on the range of instructional strategies and conceptual representations upon which they can draw; the connections they can make between topics and levels, and between mathematical concepts and their representations; their ability to respond to student conceptions, misconceptions and errors; and the accuracy of their mathematical explanations and language (Ball et al., 2008; Baumert et al., 2010; Hill et al., 2008). Anthony and Walshaw (2007), in their BES of effective mathematics pedagogy, concluded that teachers require sound content knowledge in order to appreciate the understandings students are 
demonstrating in their mathematical thinking and work, and to make decisions about their learning trajectories. Furthermore, where teachers had inadequate content knowledge, they both missed opportunities to understand and build on their students' prior learning and provided instruction and feedback that impeded rather than supported learning.

In their synthesis of research findings linking teachers' professional learning to student outcomes, Timperley and colleagues (2007) reported a focus on teachers' mathematical content knowledge, pedagogical content knowledge and knowledge of students' mathematical thinking and understanding were necessary but none was sufficient to impact on student learning. Using examples drawn from the practice of medicine, Darling-Hammond and Bransford (2005) argue that it is the professional responsibility of teachers to draw on both current knowledge of practice in their field, and on local knowledge of their students, to exercise professional judgment; that this is the essence of what it means to be a professional. Furthermore, Bobis and colleagues (2012) note an increasing awareness that knowledge is influenced by the social and cultural contexts of teaching and mediated by teachers' beliefs about and attitudes and orientations towards mathematics. For instance, Hill and colleagues (2008) found that the relationship between a teacher's mathematics knowledge and the quality of her mathematics instruction appeared to be mediated by her belief that learning should be fun whereby her emphasis on fun constrained the learning opportunities available for students. Beswick, Callingham and Watson (2011) explored a single construct of teacher knowledge which included the various categories conceptualised by Shulman (1987) and Ball and colleagues (2008) in addition to teacher confidence and aspects of teachers' beliefs about mathematics and mathematics teaching and learning. Their findings suggest that there is value in exploring holistically the complexity of teacher knowledge alongside detailing various elements of that knowledge. They also suggested that teachers need only to be able to locate important pedagogical content knowledge rather than always having it to hand. This is likely to be problematic however in a situated context whereby teachers are responding 'in the moment' to events as they take place during mathematics lessons. 
Drawing on the findings from Anthony and Walshaw's (2007) BES of pedagogy in mathematics that makes a difference for student learning, Cobb (2007) outlines a pedagogical system comprising a conducive emotional environment; the nature of instructional tasks; the mathematical tools and representations chosen; and classroom discourse. He emphasises the complexity of mathematics teaching | learning and takes a focus on the interrelatedness of each of the system's components. Similarly Sullivan (2008) points out in his editorial for the Journal of Mathematics Teacher Education that teachers' knowledge, orientations and actions interact in complex ways to promote mathematics learning and "[i]t all has to come together" (p. 433).

\subsubsection{Teacher learning as epistemological: Generating knowledge as local theory}

The literature surveyed above suggests that relationships among different elements of teachers' knowledge, and the depth and specificity of their understandings, mediate teachers' reasoning and actions in ways that afford or constrain student learning. Together, the studies cited above point to the dynamic and reciprocal interrelatedness of teachers' knowledge of students and their thinking, of mathematical subject matter, and of how best to represent the subject matter. Figure 2.3 below serves as a summary of sections 2.1.1 and 2.1.2 and suggests that different aspects of teachers' knowledge for mathematics teaching may inform one another in complex ways. An increasingly comprehensive understanding of the nature and influence of what teachers know is emerging, however what is less well defined in the research literature is how teachers develop such knowledge, in particular the specific processes and mechanisms involved, and this has been highlighted as an important area for further study (Baumert et al., 2010). 


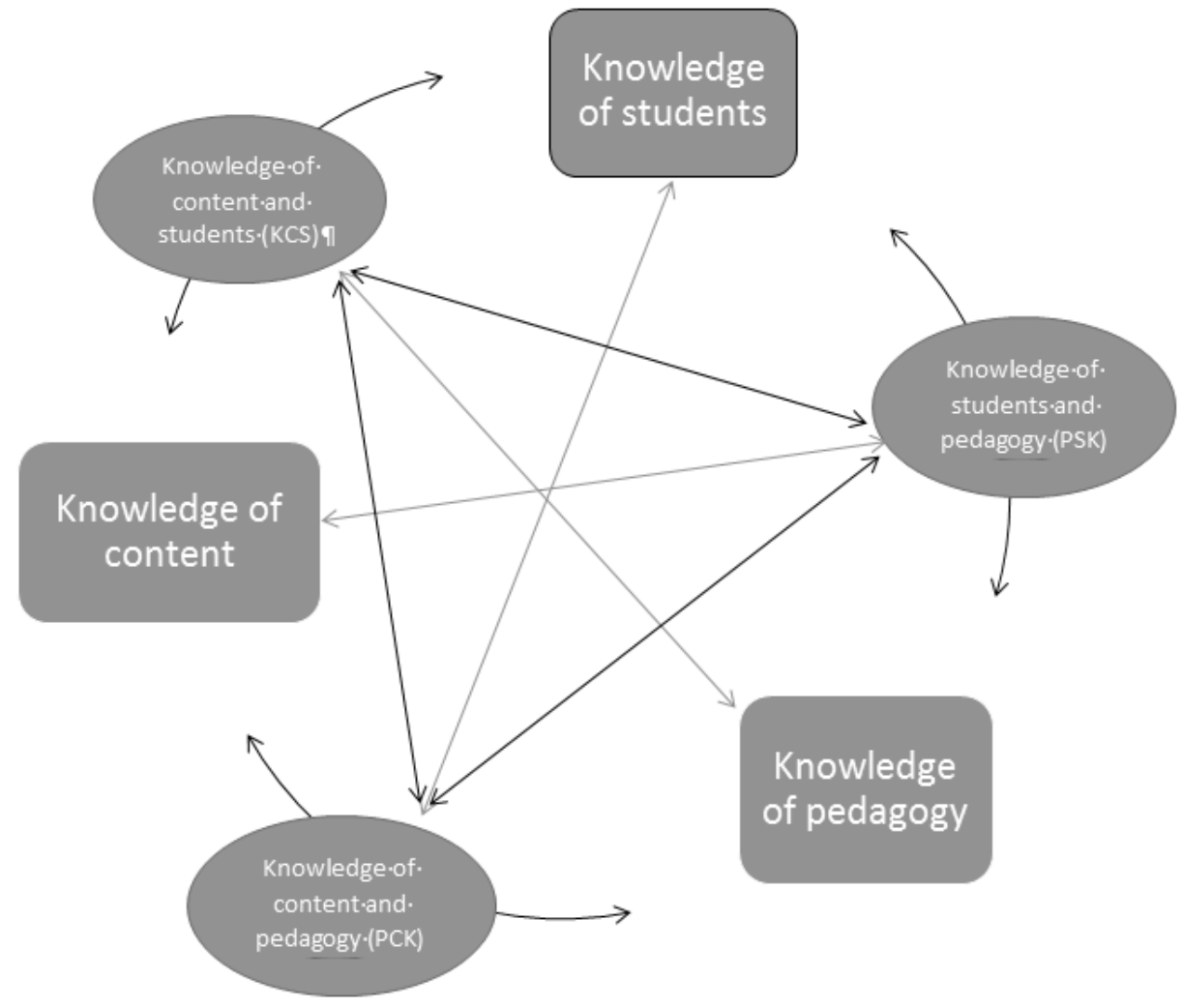

Figure 2.3. Interrelatedness of domains of mathematical knowledge.

Shulman's (1987) Cycle of teachers' pedagogical reasoning and action which is illustrated on page 18 suggests that the knowledge teachers require for teaching, in this case the teaching of mathematics, constitutes a complex and dynamic system that is continually being generated within the enactment of teaching. Using examples drawn from the practice of medicine, Darling-Hammond and Bransford (2005) argue that it is a professional responsibility of teachers to draw on both current knowledge of practice in their field, and on local knowledge of their students, to exercise professional judgment; that this is the essence of what it means to be a professional. These authors point out the complexity of teaching and learning involves a moral purpose that requires that teachers,

know a great deal about how to achieve their goals for [students] in situations that are unpredictable and non-routine, that they be able to enact what they understand in practice, and that they be able to continue to learn from their colleagues and their students about how to meet new challenges (p. 13). 
A stance taken in this thesis is that of knowledge co-generation as the production of local theory, an epistemological undertaking that occurs within the teaching | learning activity of teachers (Kincheloe, 2011). Of interest here is how teachers' knowledge might mediate teachers' reasoning and actions to afford or constrain student learning and thus potentially open space to expand teachers' learning. In thinking about such a conceptualisation of teacher knowledge, the notion of teachers' knowledge of themselves, of the epistemologies they bring to their mathematics teaching, might be thought of as a meta-knowledge. That is teachers' knowledge of their thinking, beliefs, assumptions and emotions about mathematics teaching and learning is viewed as an overarching conception of teachers' knowledge.

Cochran-Smith and Lytle (1999) distinguish among three conceptualisations of teacher learning: knowledge-for-practice, formal knowledge and theory generated and codified by university-based researchers; knowledge-in-practice, that which is embedded in the practice and reflections of teachers; and knowledge-of-practice which assumes that teacher knowledge is generated within inquiry communities as teachers purposefully problematise, interrogate and interpret both their own practice contexts and the knowledge and theories of others. The perspectives taken in this study draw on this third conceptualisation of knowledge-of-practice whereby "knowledge making is understood as a pedagogic act - constructed in the context of use, intimately connected to the knower, and ... inevitably a process of theorizing" (p. 273). This contrasts with an 'evidence-based' view of teacher learning and practice that positions teachers as users rather than creators of knowledge about teaching and learning (Cochran-Smith \& Lytle, 2009). Collaborative practitioner inquiry opens space for local knowledge production (Skattebol \& Arthur, 2014) and this is elaborated on in upcoming sections.

\subsection{Teachers' professional learning}

The notion of teachers as experts and professionals makes central the connection between teachers' knowledge and their learning. Implicit in the preceding section is the notion that shifts in goals for teaching and learning typically require associated shifts in approaches to teaching and learning (Darling-Hammond \& 
Bransford, 2005) and this is a key assumption underpinning this thesis. Thus, it is assumed that promoting increasingly equitable outcomes for learners requires shifts in the pedagogical practices of teachers; put simply the need for teachers to do something different in order to opportune different opportunities for their students. Disparity in mathematics achievement among different groups of learners is framed here as a problem of the professional learning opportunities afforded teachers. This is premised on evidence that teachers' professional learning can "make dramatic differences [...] for students who have traditionally been under-served by education" (Alton-Lee, in Timperley et al., 2007, p. xx).

\subsubsection{Conceptualising teacher learning}

The wide-ranging contexts and largely serendipitous nature of teacher learning contribute to a lack of clarity and coherence around what is known in this field (Kennedy, 2016; Wilson \& Berne, 1999). Guskey (2002) describes professional development as "systematic efforts to bring about changes in the classroom practices of teachers, in their attitudes and beliefs, and in the learning outcomes of students" (p. 381). Similarly, teacher learning is described by Fishman, Marx, Best and Tal (2003) as "changes in the knowledge, beliefs and attitudes of teachers that lead to the acquisition of new skills, new concepts, and new processes related to the work of teaching” (p. 645). Terms such as 'professional learning' and 'professional development' are closely interwoven and often used interchangeably in the literature. The term 'professional learning' is an overarching term that encompasses both the deliberately planned-for events that are often described as professional development, and the wide-ranging situations, experiences and opportunities from which teachers may learn (Timperley et al., 2007). Following Cochran-Smyth and Lytle (1999) the term 'teacher learning' is used in this thesis to both capture a complex and broad view of the multiplicity of events that might constitute learning opportunities for teachers, and also to forefront the learning of teachers as a primary focus for the research. In accordance with this conceptualisation of professional learning is the view that teachers' learning is continuously evolving and an integral part of teachers' day-to-day work (Desimone, 2009). 


\subsubsection{Theoretical perspectives on teacher learning}

Teacher learning literature is underpinned by two broad theoretical perspectives: cognitive theories of learning as the acquisition of knowledge; and situated theories of learning as participation in practice (Cobb \& Bowers, 1999). Sfard (1998) argues that the although these contrasting perspectives are essentially incompatible, they inform one another by each providing a position from which to critique the other. Additionally, Eteläpelto and Collin (2004) suggest that exploring the interactions and relations between the two perspectives is fruitful for understanding professional learning in complex contexts. A cognitive, individual and relatively fixed view of knowledge as existing in the minds of teachers remains somewhat prevalent in conceptualisations of teacher learning. For instance Baumert and colleagues (2010) refer to pedagogical content knowledge as being "picked up" and "conveyed to" teachers (p. 168). Such a perspective assumes a dualistic relationship between thought and action whereby teacher learning is assumed to involve gaining new knowledge and subsequently transferring what is known into classroom practice; that is, as the product of learning (Ellis, Edwards, \& Smagorinsky, 2010). McDonald (2009) argues that transfer, described as "the degree to which past learning and new learning is repeated in similar and new situations" (p. 630), is a fundamental concept in all teaching and learning and is frequently either explicitly stated or implied as an important intended outcome of teachers' professional learning. The notion of transfer often implies transferring knowledge from the learning context to the practice context in contrast with situated perspectives whereby learning is assumed to occur within practice contexts. Bransford and Schwartz (1999) offer an alternative view of transfer as preparation for future learning whereby what is known or learned in one context "guides noticing and interpretation" (p. 92) in another.

The emergence of social perspectives on teacher learning was noted by Bobis and colleagues (2012) who observed growing interest in the situated nature of teachers' knowledge and the influence of social and political contextual elements. A socio-cultural perspective can be distinguished from more generally socially situated views of learning and provides a productive theoretical and methodological foundation for the analysis and design of teacher learning (Ellis et al., 2010). Drawing 
on the work of Vygotsky, the authors suggest that such a perspective assumes that teacher learning is both socially situated and uniquely experienced. As such, the social context provides opportunities to act within, and shape, a system in continual flux. A situated view of teacher learning assumes that improving teacher learning requires changes in teachers' work. That is teachers' work is an important context for their learning and so to effect changes in learning there must be change in the nature of work; these are interdependent (Hodkinson \& Hodkinson, 2004). Accordingly, Cobb (2007) pointed out in his foreword to Anthony and Walshaw's BES that the practice context must be viewed as an important site for teachers' ongoing professional learning as it is an important mediator of how learning experiences can transform practice.

One notable example in New Zealand is the Numeracy Development Project (NDP), a large-scale professional development project which succeeded in improving teacher knowledge and practice, and raising student achievement (Higgins \& Parsons, 2009). The success of the professional development programme lay in the integrated design and use of pedagogical tools focused on core project ideas within the context of teachers' classroom practice. Another related example is the Developing Mathematical Inquiry Communities (DMIC) programme which was designed to address the persistent disparity of achievement for Māori and Pasifika students in mathematics (Hunter \& Hunter, 2017). Anthony, Hunter and Thompson (2014), for instance, trace one teacher's learning journey as he worked to develop a mathematical inquiry community in his classroom and they highlight the multiple and interrelated opportunities for learning that were occasioned within a classroom-based intervention. This thesis takes an explicitly socio-cultural perspective, and this is further elaborated in Chapter 3.

\subsection{3 'Effective' teacher learning: Linking teacher and student learning}

Teachers' professional learning is a complex and dynamic system encompassing multiple, interrelated influences which need to be understood in relation to each other if outcomes are to be explained (Opfer \& Pedder, 2011). Notions of teachers' professional learning as 'effective' generally assume a relationship, directly or indirectly, with improved student learning. Increasing the effectiveness of teachers' 
classroom practice is assumed to represent an interim step in a linear learning process that has improved student learning as the ultimate goal, as illustrated in Figure 2.4 below.

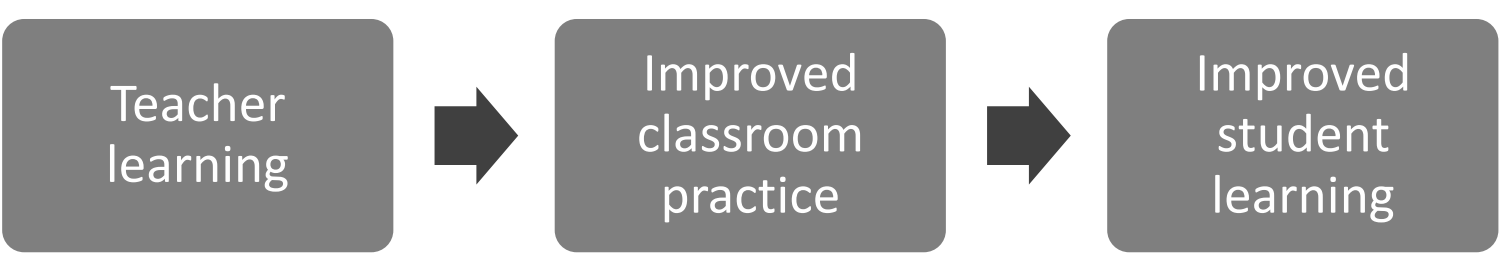

Figure 2.4. Linear teaching | learning process.

This study is premised on a theory of improvement that suggests that improving teachers' practice is an important lever for improving the learning of students whereby teachers' classroom practice influences the potential of students' classroom experiences to impact their learning outcomes. For instance, in a study involving job-embedded professional development with a focus on improving the "rigor and quality of students' classroom experiences in mathematics" (Hintz et al., 2013, p. 7), the authors reported steady improvements in teacher practice and student learning. An unstated assumption in that study was that improvements in the quality of students' classroom experiences would promote improvements in their learning. It is argued in this study that improving teaching constitutes an improvement in students' classroom experiences. Research relating to the learning processes of teachers highlights both the complexity and limited theorisation of teacher learning and supports the view that substantive changes in teaching and learning are difficult to achieve (Timperley et al., 2007). Desimone (2009) contends that a consensus is forming on five core elements of professional learning that can shift teachers' practice, the first step in the teacher learning process illustrated in Figure 2.4 above. These are illustrated in Figure 2.5 below. 


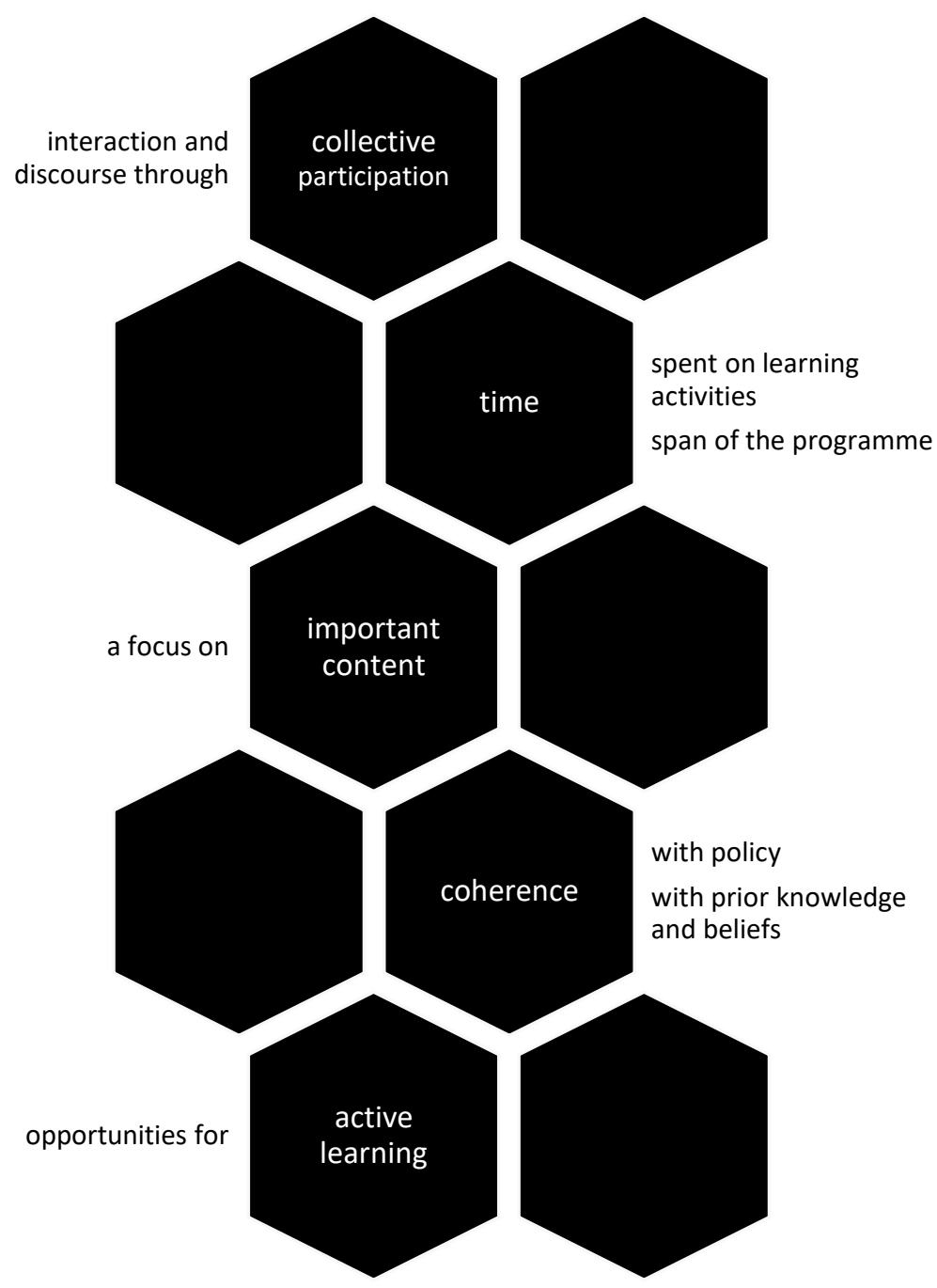

Figure 2.5. Characteristics of effective professional learning (Desimone, 2009)

There is a paucity of studies making explicit links between teachers' professional learning and outcomes for learners (Kennedy, 2016; Timperley et al., 2007). DarlingHammond and Richardson (2009) reviewed studies that made links between teacher learning and student impacts. They concluded that improvements in student achievement were promoted by professional development that was concentrated, sustained over time and situated in teachers' day-to-day work; explicitly focused on student learning; connected with important content; clearly aligned with the priorities and goals of the school; and supported the building of productive professional relationships amongst teachers. In their BES, Timperley and colleagues concluded that teachers engaging in professional learning can substantially influence student 
achievement and they identified key characteristics of such learning and these are summarised in Table 2.1 below. Timperley and colleagues concluded that little is understood about change processes involved in teacher learning and their conclusions in this regard represent conjecture rather than definitive findings. This is a gap that this study aims to address.

Table 2.1

\section{Characteristics of Professional Learning that Influences Achievement}

\section{Contextual factors}

- extended time for learning

- the availability of expertise

- teacher engagement

- challenging problematic discourses

- participation in a professional community

- coherence with policy directions and research evidence

- active involvement of school leaders

\section{Content of programmes and activities}

- strong integration among different components

- clear links between teaching and learning and between teachers and students

- a focus on assessment

- promoting sustainability through understanding theory and developing inquiry skills

\section{Nature of learning activities}

- the variety, content, sequence and alignment of activities

- the opportunity to discuss and negotiate understanding including engaging existing theories of practice

- student-focused activities

\section{Learning processes}

- improving the impact of teaching is challenging for teachers

- the development of new understandings and skills is required - activating prior knowledge is necessary but insufficient for teacher change

- new understandings can sometimes align with current practice and at other times create dissonance

- developing teachers' capacity to co- and self-regulate learning supports sustained improvement

(Timperley et al., 2007) 
Garet, Porter, Desimone, Birman, and Yoon (2001) point out that relatively few studies provide empirical evidence explicitly linking teachers' learning and practice with student learning apparently contradicting the notion that improved student learning is the ultimate goal of teacher learning. Furthermore, efforts in the literature to connect teacher learning with improved student learning are paradoxical. In the teacher learning literature, students' learning outcomes are simultaneously conceptualised as a source of data that informs teacher learning; a domain of knowledge that teacher learning is aimed at developing; and an end-point as the ultimate purpose of teacher learning. Student learning is at once a tool that mediates the activity of teacher learning, and both an object and an outcome towards which teachers' learning activity is directed. In other words, gaining a better understanding of students and their learning can be an explicit goal of teacher learning in the first instance (an object) and as teachers are engaging in activity aimed at improving student learning (an outcome), evidence of student learning informs the actions they take (a tool mediating the activity). Thus, as teachers come to better understand students and their learning, they are more able to notice changes (or a lack of change) in students' learning outcomes and can adjust their practices in light of what they have noticed. This paradoxical relationship between teacher and student learning underpins notions of teacher learning as a process of inquiry and this is explored in section 2.3 that follows.

This section has outlined characteristics of teacher learning that promote strengthened teacher knowledge and practice and support improved student learning. Kennedy's (2016) review exploring how professional development improves teaching found that such characteristics on their own unreliably predict the success of professional development programmes. This study draws on these characteristics to inform underlying principles for a design for teacher learning. The following sections focus on two aspects of teacher learning which continue to be of particular interest to researchers, policy makers and practitioners. These are the notion of teacher learning as a process of inquiry and the value of teacher collaboration for teacher learning, particularly in connection with the notion of a PLC. A conceptualisation of teachers' 
collaborative inquiry integrating notions of inquiry and of teachers' collaboration in community, is then discussed as a phenomenon of particular interest in this study.

\subsection{Teacher learning as a process of inquiry}

Conceptualising teacher learning as an epistemological undertaking involving ongoing cycles of knowledge building through inquiry addresses a paradoxical relationship between student and teacher learning. As Darling-Hammond and Bransford (2005) suggest, "learning how to teach allows teachers to better use their knowledge of what to teach" (p. 26, emphasis in original). Notions of teacher inquiry build on Schön's (1983) notion of reflection-in-action as epistemology of teacher practice. Teacher inquiry is variously conceptualised as practitioner research (e.g. Cochran-Smith \& Lytle, 2009), pedagogy (e.g. Aitken \& Sinnema, 2008), formative assessment (e.g. Mason, 2009), and professional learning (e.g. Timperley, Kaser, \& Halbert, 2014), with a multiplicity of connections made among the various notions. Jaworski (2003) highlights multiple parallel levels of inquiry in a teaching | learning context, drawing on Dewey's observations of education as essentially continuous. In the context of education, inquiry can characterise the learning of students, the practice and learning of teachers and teacher educators, and the work of academics researching teaching and learning. This study draws on notions of teaching as inquiry whereby teaching involves constant processes of learning from and in practice (Mason, 2009; Ministry of Education, 2007), and inquiry as a stance teachers take in their practice (Cochran-Smith \& Lytle, 2009) as outlined in the following sections.

\subsubsection{Teacher inquiry as knowledge-building cycles}

The notion of teacher inquiry is prevalent in the New Zealand education policy environment. The New Zealand curriculum outlines a view of teaching as a cyclical model of inquiry whereby "effective pedagogy requires that teachers inquire into the impact of their teaching on their students" (Ministry of Education, 2007, p. 35) and the Education Council (2017) requires that teachers "inquire into and reflect on the effectiveness of practice in an ongoing way, using evidence from a range of sources" ( $\mathrm{p}$. 18). In their professional learning and development BES, Timperley and colleagues (2007) argue that teachers' inquiry should be grounded in problems of practice, be 
aimed at deepening pedagogical content and assessment knowledge, and engage teachers' existing theories to both build on them and challenge them. The inquiry and knowledge building model was further developed by Timperley, Parr and Bertanees (2009) who suggest that the cycle's complementary focus on both student and teacher learning goals promotes self- and co-regulatory learning and thus supports sustainability. Fullan (2006) argues that sustained processes of instructional improvement require deep cultural change towards teachers continuously taking the role of learner, with their professional learning fundamentally connected to their work.

A subsequent iteration of the knowledge building cycle (shown inFigure 2.6) focused attention on promoting the learning of under-served students (Alton-Lee, 2012) and was thus of particular interest in this study. Section 3.4 provides an explanation of how the professional inquiry and knowledge building cycle that is illustrated above broadly paralleled the design-based methodology employed in this study and provided a framework for the collaborative teaching inquiry in which participants engaged.

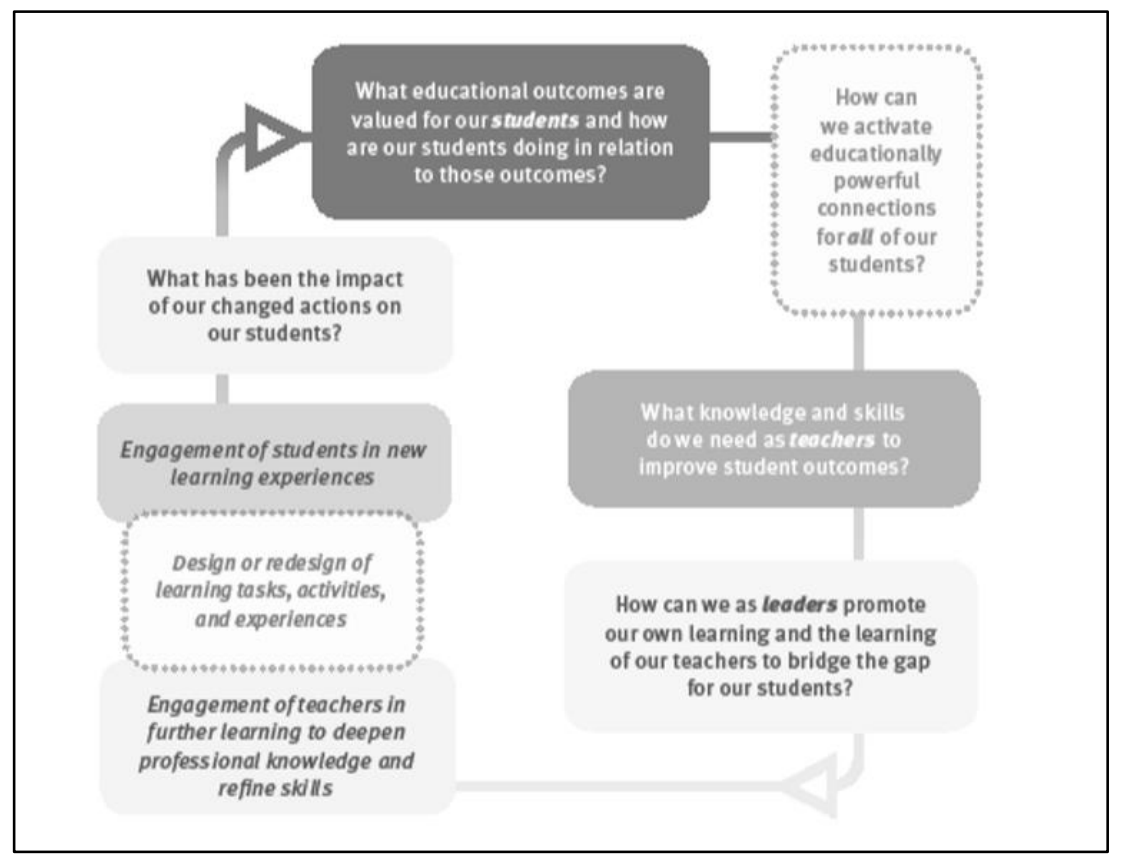

Figure 2.6. Professional inquiry and knowledge-building cycle to promote valued outcomes for diverse (all) learners. From "The Use of Evidence to Improve Education and Serve the Public Good" presented at the Annual Meeting of the American Educational Research Association, Vancouver, Canada. Copyright 2012 by Adrienne Alton-Lee. Reprinted with permission. 


\subsubsection{Inquiry as process: The challenges of implementation}

Despite the interest in teacher inquiry, there are a number of challenges to implementation and genuine inquiry is rarely realised (Le Fevre, Robinson, \& Sinnema, 2015). Sinnema and Aitken (2011) found that two years after implementation, the teaching as inquiry model in the New Zealand Curriculum was poorly understood, few teachers engaged with research evidence to inform their inquiries, and there was limited progress towards embedding inquiry in teachers' practice. Similarly, a national review by the Education Review Office (2012) found that teachers' inquiries tended to focus on areas of teacher interest rather than learners' needs, and on what was already known rather than on sources of new knowledge. Benade (2015) argues that teacher inquiry requires critical reflection in collaborative contexts whereby teachers are pressed to make public and examine their assumptions and beliefs. Le Fevre and colleagues distinguish between genuine and pseudo-inquiry, characterising genuine inquiry as involving open-mindedness, an openness to learning that involves a willingness to critically examine one's existing views in light of new evidence. They argue that genuine inquiry, particularly in the context of difference or disagreement, is relatively rare. Parr and Timperley (2015) cite Fullan's observation that "although words travel well, their underlying concepts and thinking may not" and they identify a clear need, particularly at a school level, for "defining, and strengthening capability for what is involved in inquiry" (p. 35). Teachers need opportunities to develop the skills of inquiry in order to sustain professional learning and associated achievement gains for students (Timperley et al., 2007). This study aims to address that need.

\subsubsection{Teaching as inquiry: Inquiry as stance}

Viewing professional learning as an inquiry and knowledge building cycle aligns with Cochran-Smith and Lytle's (1999) conception of teacher learning as the development of "knowledge-of-practice". They distinguish this from "knowledge-forpractice" referring to knowledge generated by researchers for teachers to use, and "knowledge-in-practice" indicating the craft knowledge assumed to be embedded in the practices and reflections of expert teachers. Taking a knowledge-of-practice perspective of teacher learning, "knowledge making is understood as a pedagogic act constructed in the context of use, intimately connected to the knower, and ... also 
inevitably a process of theorising" (pp. 272-273). Viewing mathematics teaching as fundamentally involving teacher learning aligns with Ma's (1999) finding that teacher and student learning develop reciprocally and simultaneously and teachers' learning of mathematics content occurs largely as they are engaged in its teaching. From such a perspective, inquiry can be seen as a process that teachers enact in the work of teaching, rather than something that is done as an end in itself.

The notion of teaching as inquiry aligns with the position articulated by Jaworski (2014) that "developing as a teacher requires one to be a learner, and the overt stance of being a learner-teacher is a research stance” (p. 2). Such a perspective somewhat contradicts the inquiry processes such as the one depicted in Figure 2.6 whereby engagement in teacher learning appears to be framed as an event within the inquiry process. Teaching as inquiry suggests that to learn as a teacher does not involve inquiry, but that it fundamentally is inquiry. Accordingly Bobis et al. (2012) suggest that "understanding teachers' thinking about their own knowledge and its perceived impact on teaching practices is paramount to improving the professional learning of teachers" (p. 335). Cochran-Smith and Lytle (2009) discriminate between teachers doing inquiry and becoming inquirers, and they propose the notion of teachers' inquiry as stance. They describe inquiry as an identity that teachers adopt as they engage in practice, and this is a perspective explicitly adopted in this study.

\subsubsection{Teacher learning as the development of adaptive expertise.}

Bransford, Darling-Hammond and LePage (2005) suggest that it is important for teachers to become "adaptive experts who are prepared for effective lifelong learning that allows them continuously to add to their knowledge and skills" (p. 3). Conceptualising teacher learning as the development of adaptive expertise underpins notions of teacher inquiry and contradicts a common conception of teacher learning of a teacher's movement along a trajectory from novice to expert whereby expertise is assumed to increase efficiency as novices learn to recognise patterns with fluency and develop memory schema that support them to deal with complex tasks (Bransford, Derry, Berliner, \& Hammerness, 2005). Increasingly complex classroom contexts require teachers to be perpetual problem-solvers (Larrivee, 2000). Bransford and colleagues argue that efficiency as an outcome of experience, and as a characteristic of 
expertise, is oriented towards the removal of problems rather than promoting the sustained problem-solving that is required by teachers responding to complex and unpredictable classroom events. In contrast, they argue, the development of adaptive expertise requires teachers to become increasingly critical thinkers able to reflect on, evaluate and learn from their teaching. In comparison with the speed, accuracy and automaticity characteristic of routine expertise, Hatano and Oura (2003) describe flexibility, innovation and creativity as characteristic competencies of adaptive experts. They suggest that in the context of solving problems in the domain of their expertise, adaptive experts may apply schemas in more adaptive or finely tuned ways; better understand and be able to modify or invent procedures, respond to contextual change in flexible ways and cross domain boundaries to find solutions. Such a view is consistent with Bransford and Schwarts' (1999) argument that transfer in teacher learning can be usefully viewed from a perspective of preparation for future learning whereby the focus shifts from what is transferred directly, to evidence of productive learning trajectories and the increased sophistication that teachers as learners might bring to future activities thus supporting future learning possibilities. Conceptualising teacher learning as the development of adaptive expertise aligns with a view of teaching as involving applying knowledge in increasingly flexible and fine-tuned ways; understanding, adjusting and devising classroom actions; responding adaptably to changes in the teaching context; and finding solutions to practice problems from outside of their immediate practice context. Characterising teaching as involving perpetual problem-solving within complex contexts is a perspective that fundamentally underpins this thesis.

\subsubsection{Teacher noticing}

Mathematics teaching | learning is unpredictable and contingent and teacher noticing is central to notions of teaching as inquiry whereby teachers are required to notice, interpret and respond to classroom events as they occur. Noticing generally refers to paying attention to and making sense of specific phenomena, with reference to classroom events (Sherin, Jacobs, \& Philipp, 2011). Teacher noticing in mathematics has been described as a "hidden practice of in-the-moment decision-making that is needed to respond to children's ... strategy explanations” (Jacobs, Lamb, \& Philipp, 
2010, p. 197), a conceptualisation that is related to Schön's (1983) notion of reflectionin-action. Jacobs and colleagues conceptualise the professional noticing of children's mathematical thinking in terms of a set of interrelated skills comprising attending to the mathematical details in students' strategies; interpreting students' understandings as apparent in their strategies; and the reasoning teachers use in deciding how to respond to students' understandings. These authors found that such noticing is challenging and not a routine skill in which adults are inherently competent; noticing is learned through a combination of practice experience and professional learning. Deborah Ball (2011), in her foreword to a volume on mathematics teacher noticing, emphasised the specialised and sometimes unnatural nature of teacher noticing, in particular noticing children's thinking in a domain one knows well. She points out that a "paradox of expertise is that ideas that seem obvious are not so to the learner" (p $\mathrm{xxi}$ ), perhaps suggesting that the more extensive the teacher's knowledge of the subject, the more difficult it can be to interpret students' understandings (and misunderstandings). Furthermore, she points out, teacher noticing "is not purely neutral attention, but culturally shaped perception" ( $\mathrm{p} x \mathrm{xi}$ ) and teachers must notice selectively and with awareness of how cultural experience shapes perceptions and understanding.

Teacher noticing is an important element of reflective practice and teacher reflection is key to strengthening teaching as teachers make sense of teaching | learning experiences and in turn use these to inform their future practice. Jacobs, Philipp and Sherin (2011) point to the benefits of seeing noticing as an important focus for inquiry suggesting that "noticing is a critical component of mathematics teaching expertise and thus a better understanding of noticing could become a tool for improving mathematics teaching and learning" (p. xxvi). Drawing a connection between noticing and reflection, Jaworski (2003) argues that critical intelligence, a kind of 'metaknowing', emerges from an increased awareness of classroom issues. Thus, she suggests, critical reflection outside the classroom promotes more explicit awareness of the classroom conditions and events within practice which in turn leads to the possibility for expansions in action and shifts in practice. Drawing attention to 
the role of challenging the taken for granted in teachers' practice, Larivee (2000) describes critical reflection as involving:

a deep exploration process that exposes unexamined beliefs, assumptions, and expectations ... Reflective practitioners challenge assumptions and question existing practices, thereby continuously accessing new lens to view their practice and alter their perspectives (p. 296).

Critiquing the notion of teaching as inquiry, Benade (2015) argues that collaboration is a necessary condition of teachers' work if they are to make their theories of action explicit and open to challenge, yet inquiry cycles tend to presuppose teachers' inquiry as an individual rather than collective process as implied by the use of language indicating a first-person perspective. Collaborative critical reflection can lead to future noticing in the moment thereby allowing for the possibility of alternative decisions and actions (Mason, 2009). This aligns with a complex view of teaching and suggests an increased capacity for teachers to notice both elements of the teaching activity itself and the impacts of their teaching (Jaworski, 2003). That is, an expanded capacity to notice both the activity itself and its shifting goals as shifts in student learning outcomes are realised. Jaworski (2008) suggests that reflecting critically with colleagues on aspects of past practice can support the development of enhanced noticing within future practice thus influencing classroom actions and potentially changing practice, an interaction. Such a view provides a compelling rationale for a focus on teacher noticing in the context of teacher learning through inquiry and answers Jaworski's (2003) call for further research to test related theoretical claims and gain improved insights into the associated processes of teacher noticing within inquiry activity.

\subsubsection{Adaptive models of teacher learning}

Taking a view of teachers' professional learning activity as an integrated system, Koellner and Jacobs (2015) argue that while different models of professional development may share common characteristics such as those described in section 2.2.3 above, an important distinction is where they fall on a continuum from highly specified to highly adaptive models. They describe adaptive models of professional learning as underpinned by general principles rather than specified characteristics, 
and flexibly evolving in response to local contexts. The notion of inquiry as adaptive professional learning activity is captured in Timperley and colleagues' (2014) spiral of inquiry. The authors suggest that use of the framework could accelerate the emergence of, and facilitate links among, innovative practices in diverse settings. Such models can support incremental and important impacts on teachers' knowledge and practices, and potentially on student achievement. For example, Koellner and Jacobs found that participation in the Problem-Solving Cycle (PSC), a school-based model of professional development aligned with reform principles and situated in practice, supported teachers to attend to their students' mathematical thinking and make productive pedagogical decisions in response. Examples of adaptive models of teacher professional learning that are underpinned by the notion of collaborative inquiry include Japanese lesson study (Lewis, Perry, \& Hurd, 2009), video clubs (van Es \& Sherin, 2008), and teacher work groups (Horn \& Little, 2010). Highlighting the flexible and negotiated nature of adaptive models of teachers' professional learning, Koellner and Jacobs suggest that such approaches remain under researched owing to methodological challenges inherent in researching and making claims about impacts on teachers' knowledge and practice and student achievement. Furthermore, although teaching as inquiry is an approach to teacher learning that is inherently adaptive, apparently inquiry-oriented models of teacher learning can be prescriptive while masquerading as adaptive.

\subsection{Teacher collaboration}

Collaboration is a construct that is of particular interest in this study with a focus on the role of collaboration in teacher learning. There is currently a great deal of interest in teacher collaboration within education settings internationally and in Aotearoa New Zealand. One of six professional standards for teachers in New Zealand is to "use inquiry, collaborative problem-solving and professional learning to improve professional capability to impact on the learning and achievement of all learners" (Education Council, 2017, p. 18) and it is elaborated on thus: "Inquire into and reflect on the effectiveness of practice in an ongoing way, using evidence from a range of sources ... and engage in collaborative problem-solving and learning-focused collegial discussions" (p. 18). The Education Review Office (2016) in New Zealand highlights 
mahi tahi, described as "the unity of a group of people working towards a specific goal or on a specific task, often in a hands-on fashion ... the business of working together collaboratively in the pursuit of learner-centred education goals" (p. 15), as important across all domains in their framework of indicators of effective practice for improvement and learner success. The ERO indicators identify collaboration as essential for improvement in schooling, citing Fullan, Rincón-Gallardo and Hargreaves (2015) who argue that "collaboration focused on the improvement of teaching and learning is one of the highest-yielding strategies to boost student, school and system performance" (p. 8).

\subsubsection{What is meant by teacher collaboration?}

Collaboration is widely discussed yet rarely explicitly defined within teacher learning literature, and the term has a wide variety of uses within education (Cook \& Friend, 2010) and across many academic domains (Dillenbourg, 1999). For instance, there is a growing body of research exploring teacher collaboration within digital spaces, collaboration between general classroom teachers and educators with specialist roles such as librarians or special education teachers, between teachers and subject experts, and multi-agency collaboration in education settings however such collaborations are all outside of the scope of this thesis. The focus on collaboration in this study is on the real-time and face-to-face interactions of general classroom teachers within the context of their work.

In seeking to define teacher collaboration, an important distinction is made by Kelchtermans (2006) between collaboration which refers to what teachers do together and collegiality which refers to the quality of teachers' relationships with one another although the two are mutually constitutive and reflective. Friend and Cook (2014) define interpersonal collaboration as "a style for direct interaction between at least two coequal parties voluntarily engaged in shared decision making as they work towards a common goal" (p. 6). This definition is limited in that the focus is on shared decision-making rather than shared activity. Furthermore, the notion of coequal parties perhaps suggests an ideal to aspire to rather than a characteristic of collaboration per se. Thomson (as cited by Thomson \& Perry, 2006) offers the 
following definition drawn from his work in civil government in the United States and with a focus on collaboration among institutions:

Collaboration is a process in which autonomous actors interact through formal and informal negotiation, jointly creating rules and structures governing their relationships and ways to act or decide on the issues that brought them together; it is a process involving shared norms and mutually beneficial interactions (p. 23).

Such a definition is more useful as it highlights the complex, dynamic and unpredictable nature of collaboration. It is important to note that shared activity is not necessarily collaborative (Cook \& Friend, 2010), an idea that aligns with Little's (1990) observation that teachers' shared endeavours range from the sharing of stories and ideas to interdependence in what she terms "joint work" (p. 519). What often masquerades for collaboration can be simple division of labour whereby teachers take individual responsibility for aspects of their work rather than jointly engaging in it, for instance, by dividing groups of students for instruction rather than engaging in joint instruction of one group.

\subsubsection{Community as a site for teacher collaboration}

Teacher collaboration is generally understood to be an element of teachers' community (e.g. Shulman \& Shulman, 2004) and interest in community as a component of teacher learning can be traced to Lortie's (1975) observations of individualism in teachers' work and consequent resistance to development. In their seminal work, Lave and Wenger (1991) introduced the notion of communities of practice in which learning is socially situated and conceived of as the development of identity through a process of legitimate engagement in practice. Wenger (1998) further elaborated on this notion describing a learning community in which learning is a central focus of activity and where the community is a context for both the acquisition and generation of knowledge simultaneously. There is ongoing attention in policy, practice and research to the notion of community as a core element of teachers' professional learning and the PLC is a widely adopted notion in practice (Horn \& Little, 2010). The PLC has no agreed definition in the literature (Stoll \& Louis, 2007) nevertheless definitions of a PLC can be seen to converge on a number of core characteristics as illustrated in Table 2.2 below. 
Table 2.2

Definitions and Core Characteristics of PLCS

\begin{tabular}{|c|c|c|}
\hline $\begin{array}{l}\text { "a group of people who take an } \\
\text { active, reflective, collaborative } \\
\text { learning-oriented, and growth- } \\
\text { promoting approach toward the } \\
\text { mysteries, problems and perplexities } \\
\text { of teaching and learning" } \\
\text { (Mitchell \& Sackney, 2009, p. 30) }\end{array}$ & $\begin{array}{l}\text { "Professional educators working } \\
\text { collectively and purposefully to create } \\
\text { and sustain a culture of learning for all } \\
\text { students and adults" } \\
\text { (Hipp \& Huffman, 2010, p. 12) }\end{array}$ & $\begin{array}{c}\text { "an inclusive and mutually supportive } \\
\text { group of people with a collaborative, } \\
\text { reflective and growth-oriented } \\
\text { approach towards investigating and } \\
\text { learning more about their practice in } \\
\text { order to improve pupil's learning" } \\
\text { (Stoll, 2011, p. 104) }\end{array}$ \\
\hline $\begin{array}{l}\text { - } \quad \text { Shared vision, values and goals } \\
\text { - } \quad \text { Collaborative work culture } \\
\text { - } \quad \text { Collective learning and shared } \\
\text { understanding } \\
\text { - } \quad \text { Reflective practice and } \\
\text { experimentation } \\
\text { - } \quad \text { Knowledge systems and data- } \\
\text { based decision making } \\
\text { - } \quad \text { High trust }\end{array}$ & $\begin{array}{l}\text { - } \quad \text { Supportive and shared leadership } \\
\text { - } \quad \text { Shared values and vision } \\
\text { - } \quad \text { application } \\
\text { - } \quad \text { Shared personal practice } \\
\quad \text { structures and relationships }\end{array}$ & $\begin{array}{l}\text { - } \quad \text { Shared vision and values } \\
\text { - } \quad \text { Collective responsibility for } \\
\text { students and each other's } \\
\text { learning } \\
\text { - } \quad \text { Reflective professional enquiry } \\
\text { - } \quad \text { Collaboration } \\
\text { - } \quad \text { Group and individual learning are } \\
\text { - } \quad \text { Tromoted } \\
\end{array}$ \\
\hline
\end{tabular}

The PLC as an umbrella term remains broadly conceptualised to the point that almost any group of teachers working together is classified as a community (DuFour, 2004; Grossman, Wineburg, \& Woolworth, 2001; Hord, 2009). The term PLC is applied to varied activities and arrangements that describe groups of teachers working together to support their professional learning and strengthen their pedagogical practice. Examples of such groups include study or reading groups (Gersten, Dimino, Jayanthi, Kim, \& Santoro, 2010), video clubs (van Es \& Sherin, 2008), quality learning circles (Lovett \& Verstappen, 2004) and teaching teams (DuFour, 2004). Although the specific elements of participants' activity within such groups differentiate them, a common characteristic is that they all involve teachers talking about aspects of their work with a view to strengthening classroom practice.

\subsubsection{Teacher learning within community}

The value of teachers engaging interactively with their colleagues in professional learning within the context of their work (Desimone, 2009) and in 
particular the notion that community represents effective conditions for improving teacher practice and raising student achievement (Eaker \& Keating, 2012) are widely accepted. McDonald (2009) argues that teacher collaboration focusing on key content and student learning, and building on teachers' experience is a key strategy for promoting transfer in teacher learning whereby what is learned is enacted in teachers' classroom practice. PLCs are productive contexts for teacher learning that can promote improved student learning (e.g. Owen, 2015; Timperley et al., 2007) and that have the equitable teaching | learning of all students at their heart. This is captured by DuFour, DuFour, Eaker and Karhanek (2004) who suggest that a central question addressed by PLCs is "What happens in our school when, despite our best efforts, a student does not learn?" (p. 7).

PLCs can provide support for teachers managing the unpredictable nature of mathematics teaching and the uncertainties produced in a reform-oriented pedagogical system that centres on student reasoning (Cobb, 2007). In other words, teachers working to adopt complex new pedagogical approaches have access to additional support for improving the effectiveness of their classroom practice within a community. Timperley and colleagues (2007) found that professional communities which promoted improved student achievement supported teachers to develop new understandings of teaching and learning and focused on the analysis of evidence of student impacts. In a study that aimed to account for specific processes and occurrences of teacher learning within PLCs, Owen (2015) observed that changes in teachers beliefs and values were strongly supported by working in teams characterised by the development of shared values, collaborative work, a focus on students, shared accountability, and distributed and supportive leadership. Participation in PLCs supported teachers to change classroom practice enabling teachers to develop new teaching approaches and sustain innovative practices. Furthermore, school cultures shifted with schools becoming more open to change and to investigating new teaching approaches, and increasingly engaging in reflective conversations including about challenges that arose. Across three case study schools, teachers reported changes in practice and improved learning for students, including achievement, social skills, 
emotions, independence and creativity. Owen found that a key impact of effective PLCs is the improved well-being of students and teachers.

Despite strong interest in teacher community, some researchers remain cautious in their support for a view that a PLC represents a productive arrangement for promoting teacher learning and raising student achievement. Collaboration within a community can be counterproductive for teachers (Alton-Lee, 2008), has been associated with neutral and negative student outcomes (Timperley et al., 2007), and can be constrained by what Little (2003) describes as the community's "horizons of observation" whereby the voices and epistemological perspectives of certain groups are privileged. The actions of school leaders can also serve to afford or constrain teacher learning through collaboration, as the context of teachers' work is structured and restructured (Hintz et al., 2013). Furthermore, it is not clear what learning processes are at work within teachers' community. Dillenbourg (1999) argues that collaboration is neither a method nor a mechanism for learning but a situation in which particular interactions are expected to occur. These interactions then trigger learning mechanisms that generate learning effects and thus how to promote such interaction is of primary interest and is the focus of the study reported in this thesis. How communities enact collaboration is mediated by structures within the activity, in this case the shared work of teachers. When we design tools to increase collaboration, the focus of our interest is on the most salient characteristics of the collaboration in relation to the activity's structures.

\subsubsection{Connecting community and inquiry: Teachers' collaborative inquiry}

This study's dual focus on teacher learning through inquiry and the role of teacher collaboration within community come together in the interrelated notions of teachers' collaborative inquiry within inquiry communities. Collaboration in the context of teachers' work can provide a repository of practice ideas to be shared amongst teachers (Lewis et al., 2009), catalyse changes in teachers' practice (DarlingHammond et al., 2009), and sharpen teachers' perceptions of important phenomena (Hunter \& Back, 2011). Focusing on professional learning as the primary object of teacher community, Levine (2010) distinguishes among four conceptions of teacher community: communities of practice; communities of learners; teachers' professional 
communities; and inquiry communities, and interrogates the goals, products and mechanisms for teacher learning within such communities. He describes inquiry communities as foregrounding "the role of systematic inquiry conducted with the support of colleagues as a means of improving teaching and learning in schools" (p. 112). Highlighting mechanisms for learning he describes systematic teacher inquiry as characteristic of inquiry communities whereby teachers "articulate questions, problems and dilemmas" and knowledge is developed through the structured analysis of data "and/or conversations which generate new, revised, or more explicit understandings" (Levine, 2010, p. 122). Similarly differentiating an inquiry community from other forms of community, Jaworski (2008) describes co-learning inquiry as "people learning together through inquiry" (p. 311) highlighting the reciprocal nature of such learning. In teacher learning literature, collaborative inquiry can denote a participatory research design characterised by collaboration among teachers, researchers and others such as professional development facilitators.

Jaworski (2003) traces connections between notions of collaborative inquiry as research and as teacher development, and notes that collaborative inquiry approaches have been shown to be powerful in promoting the "kinds of thinking that lead to development" (p. 7). An example is Parr and Timperely’s (2015) project involving researchers, professional development facilitators and teachers working together to promote literacy achievement. They found that working collaboratively to raise evaluative capacity afforded modest gains for students but significant learning for policy makers, schools and professional development facilitators. As will be described in Chapter 3, this study adopts a research approach consistent with the notion of research as collaborative inquiry and there is a simultaneous focus on teachers' collaborative inquiry, a notion of teaching as an inquiry-focused activity enacted in collaboration with colleagues. Collaborative inquiry entails participatory research aimed at transforming practice, and can be seen as a hybrid activity directed at multiple outcomes simultaneously thus surfacing a number of tensions and opportunities (Jaworski, 2003). Of particular importance to this study is that teachers' collaborative inquiry has been linked to improved teacher knowledge, for example 
through lesson study (Hunter \& Back, 2011), and to gains in student learning in mathematics (Ingvarson, Beavis, Bishop, Peck, \& Elsworth, 2004).

Calls for continued investigations into the professional learning of mathematics teachers in situated and collaborative contexts remain prevalent in the literature (Hill et al., 2008). The preceding survey of the literature suggests that there is increasing understanding of the conditions for and characteristics of effective professional learning opportunities for teachers, and some apparent consensus on the value of collaboration within a community for teacher learning. There is support in the literature for the notion of teachers' inquiry community as a promising approach to teacher learning within the context of their day-to-day work. Less is known however about how teachers learn; the specific processes and mechanisms involved. There remain many inconsistencies between the characteristics of teachers' professional learning and the teacher change that results, and it is necessary to account for the mechanisms and processes that interact to produce learning in order to explain, rather than just state, the effect (Opfer \& Pedder, 2011). In accordance with Levine's (2010) description of an inquiry community, the sections that follow outline literature pertaining to groups of teachers working together to inquire into and improve mathematics teaching | learning. Such a description encompasses groups of teachers working together in range of activities and arrangements for instance in video clubs (van Es \& Sherin, 2008) and PLCs (e.g. DuFour et al., 2004; Owen, 2015), and through lesson study (e.g. Doig \& Groves, 2011; Hunter \& Back, 2011). Of interest in reviewing this literature was how the teachers' collaborative inquiry promoted, and constrained, their learning, and literature pertaining to this is explored in the following sections.

\subsection{Affordances of teachers' collaborative inquiry: Inside the 'black box'}

Despite the interest in teacher community there is a scarcity of research that gets inside community to account for the mechanics and processes of teacher learning. For instance, Timperley and colleagues (2007) in their professional learning and development BES identified this as a gap in the literature, a problem they framed as a "black box" of teacher learning. In focusing on processes of collaborative teacher learning in this study, the notion of affordances can be used to examine how learning 
is enabled or constrained through the use of various tools. Little (2003) describes affordances as "draw[ing] attention to the various resources made available to learning through talk, gesture and concrete objects, while acknowledging the uncertainty of learning in practice" (p. 920). Broadly following Kennedy (2016), the sections that follow explore the literature in relation to the affordances of what teachers share as they engage in collaborative inquiry (section 2.5.1), and how teachers interact and engage with what is shared (section 2.5.2).

\subsubsection{A focus on content: What is shared in teachers' collaborative inquiry?}

What is shared, including the nature of classroom observations and representations of teachers' practice (e.g. Little, 2003); the nature of the mathematics being taught (Perry \& Lewis, 2009); the availability of students' thinking (e.g. Fishman et al., 2003); and evidence of student achievement (e.g. Ingvarson et al., 2004), mediate what learning opportunities are provided or limited by collaborating. For instance, in the context of a year-long video club van Es and Sherin (2008) found that viewing video excerpts from their own and colleagues' mathematics lessons enhanced teachers' understanding of students' mathematical thinking, and supported teachers to recognise the value of students explaining their ideas in mathematics classes. The teachers viewed video excerpts that were selected by the authors to illustrate students' thinking, including students' explanations, questions, confusion or discussion about mathematics ideas that emerged within lessons. The authors concluded that different video clips afforded different opportunities for teacher learning with some providing greater access to student thinking than others. There were also differences depending whether teachers were discussing video excerpts from a colleague's classroom or their own.

\subsubsection{Learning across and from difference}

The diversity of experience, knowledge, and expertise different teachers bring to a community mediate their collaborative activity and the resources made available to community members for their learning. People's diverse lived experiences are a powerful resource for learning within community (Bransford \& Schwartz, 1999). In the context of a 2-year study of collaborative inquiry involving early childhood educators and academics, Skattebol and Arthur (2014) found that a heterogeneous group of 
practitioners working across difference was an important aspect of the professional transformations experienced by participants. This was thought to be related to the need to explain their thinking across a diversity of expertise which "sparked provocative lines of intellectual engagement" (p. 12). They found that engaging with others from outside their everyday fields of practice illuminated that despite taking critical stance towards their own practice, views of their practice still constituted personally constructed realities and their wider collaboration afforded opportunities to "further question orthodoxies in their thinking" (p. 9). The involvement of 'outsider' colleagues, such as teacher educators and researchers, was important to sustain and enhance teachers' inquiry efforts. The collaborative inquiry "made inroads that challenged academic/practitioner and theory/practice binaries and introduced possibilities for new locally produced knowledge and new hybrid identities" (p. 10) in particular shifting the researchers' identity from the previously imagined critical friend to one of "resource gatherers and co-learners" (p. 10) and there was a blurring of boundaries between insiders/outsiders in the knowledge production process. Furthermore, insider status both enabled access to data that is otherwise unavailable while at the same time creating limits in terms of a taken for granted insider view of the practice space and phenomenon under scrutiny. Highlighting the importance of difference in expertise, in contrast to privileging an expert role, it was observed that participants moved in and out of their different fields of expertise and were required to apply a high level of metacognition to the problems presented by others.

\subsubsection{Learning from student learning}

Student learning provides feedback to teachers as teaching is enacted (Fishman et al., 2003) and as such is integral to the inquiry process. Examining student thinking is a specific focus of Japanese lesson study in which students' solution strategies are recorded in detail and discussed (Doig \& Groves, 2011) and in their year-long study of four schools in England and the Channel Islands, Hunter and Back (2011) reported that teachers' knowledge of mathematics was deepened through the process. Drawing on findings from their Cognitively Guided Instruction (CGI) professional development programme, Carpenter, Fennema and Franke (1996) argue that developing understandings of students' mathematical thinking can support teachers to broaden 
their own mathematical knowledge. The CGI approach involves the use of a framework to unpack students' thinking and has similarities to that of New Zealand Ministry of Education's (2008a) number framework. The number framework is a core component of the Numeracy Development Project, a national professional development programme for teachers of mathematics aimed at the enhancing student learning through enhancing teachers' professional capacity. In the context of Cognitively Guided Instruction (CGI), Carpenter and colleagues described how teachers' understanding of students' thinking supports an integrated view of mathematics teachers' knowledge by: providing access to students' mathematical representations on which teachers can build; exposing teachers to students' strategies that challenge and expand their own; and requiring teachers to examine and question their pedagogical knowledge as they consider how to integrate new understandings of student thinking into their pedagogical approaches. This work shows reciprocity between the teachers' use of knowledge in examining student thinking and the possibilities this affords for the expansion of teachers' knowledge. Furthermore, an ongoing cycle of teacher and student learning emerges whereby teachers learning about their students' thinking and applying this knowledge in their teaching generates new understanding of their students' thinking (Franke, Carpenter, Levi, \& Fennema, 2001). Kazemi and Franke (2004) found that as teachers struggle to make sense of students' strategising they are increasingly able to both recognise their students' learning trajectories and position themselves as mathematical thinkers.

Underpinning teacher inquiry cycles is the notion that improving student outcomes can act as a catalyst for teachers to engage in practices that promote ongoing improvements in learning (e.g. Ingvarson et al., 2004). Nevertheless, Little (2003) concluded that teachers examining students' work together is not sufficient to provide opportunities for teacher learning. Little argues that mediating factors include how the work is used, how teachers represent their classroom practice in their talk, and the normative aspects of professional dialogue. Pointing out the importance of teachers engaging with their existing theories of practice in light of evidence of the impacts of that practice on students, Timperley and colleagues (2007) have asked the question “How can teachers' existing theories be engaged, debated and challenged 
during professional learning opportunities in ways that ensure ongoing theory improvement?" (p. 201).

Assessment data as a measure of student outcomes used both as a tool for teacher learning and a measure of its impact need to be examined to surface underlying assumptions about the value of the mathematics assessed. Meaney et al. (2012) suggest, for example, that a Western view of mathematics with a focus on number can create a deficit view of students whose strengths are in other aspects of mathematics rather than recognising strengths which can be built upon. This may be of significance in the context of teachers inquiring to raise the achievement of particular groups of students. Furthermore, Benade (2015) argues that the data on which such inquiry is based should extend beyond that generated in the school setting and that the field of inquiry extend beyond that of the classroom.

\subsubsection{Learning from mathematical tasks}

Mathematical tasks provide mathematical content for student learning and are a tool for the learning of teachers (Zaslavsky and colleagues, as cited in Doig \& Groves, 2011) however tasks elicit students' thinking unequally implying the need to strategically choose tasks for teachers to examine student thinking together (Perry \& Lewis, 2009). Hunter (2007) found that teachers' collaborative examination and coconstruction of tasks assisted a deeper understanding of the mathematics involved and supported teachers' responsiveness by helping to anticipate and plan for the range of solution strategies and erroneous thinking that may emerge. In Japanese lesson study, teachers engage in considerable research into the mathematics involved in tasks, and the expected responses of learners in contrast with many other countries, including New Zealand, where it is not normal practice to engage in such detailed examination of mathematical content (Doig \& Groves, 2011).

\subsubsection{A focus on dialogue: How do teachers engage with content?}

Taking a focus on collaborative inquiry emphasises the critical role of professional dialogue in teachers' shared work. Teachers need opportunities to articulate and evaluate their knowledge of mathematical content (Bobis et al., 2012). During a 10-day professional development programme for mathematics and science 
teachers in Australia, teachers reported that opportunities to discuss new learning supported them to make the transition from thinking about ideas to thinking about how they might be applied to enhance teaching (McPhan, Pegg, \& Horarik, 2008). The work of change is challenging, however, and requires teachers to question the status quo including questioning their own and others' theories and enactment of practice. In their professional learning and development BES, Timperley and colleagues (2007) found that many studies reporting improved outcomes for students involved engaging teachers with existing theories of practice, described as "personal theories that consist of particular beliefs and values; related knowledge, skills and practices; and desired outcomes" (p. 197). The authors found that effective professional learning required teachers to consider their current practice in relation to student outcomes and then develop new evidence-based theories aimed at improving those outcomes.

Interrogating the theories underlying teachers' practice can be constrained by teachers' reluctance to expose problematic aspects of their current practice for fear of negative consequences (Le Fevre, 2014). As Hunter (2007) suggests, teachers' interactions are a key element in transforming teachers' beliefs and attitudes, providing opportunities for reflection on habits of practice, and opening up possibilities for changed practice. Nevertheless, teachers' interactions can both promote and constrain opportunities for learning (Little, 2003) and teachers' professional conversations are not equally productive for their learning. Factors promoting teachers' open engagement in conversations about their practice included the level of respect among participants, their commitment to shared decisions, and the validity of any data that is shared (Robinson, Hohepa, \& Lloyd, 2009).

In an elementary school in the United States, Kazemi and Franke (2004) documented interactions within a workgroup of ten teachers examining students' mathematical work. They found that teachers' choices about what to share mediated what ideas were made public and thus shaped the nature and direction of the group's work. Choices about what was shared were informed by the combined influence of teachers' individual and shared experiences. In an Australian study focused on collaborative practitioner research in early childhood education settings, participants noted that stories documenting the processes of shifting pedagogy are rare owing to a 
reluctance to make visible what is not working and thus risk exposing weaknesses in one's practice (Skattebol \& Arthur, 2014). Exposing "gaps" in practice or knowledge involves risk-taking however, as Gallo-Fox (2010) points out, not exposing such gaps also represents a risk for which the consequences may be more significant.

Nevertheless, where teachers are reluctant to expose problems of practice it suggests an inclination towards hiding gaps for self-protection and that this takes precedence over exposing and resolving gaps to mitigate risks to students.

Group norms associated with conflict in teachers' shared activity can be both an inhibitor and promoter of professional learning. The cultural norms of a group are made up of assumptions, beliefs, values, expectations and habits, and dictate "the way we do things around here" (Eaker \& Keating, 2012, p. 4). Timperley and colleagues (2009) note several challenges to teachers' engaging at a deep level in collaborative inquiry including the role of norms of collegial interaction influencing teachers' willingness to challenge colleagues' thinking. Jaworski (2008) suggests that when shared norms of practice serve to preserve the status quo, inquiry is not necessarily a "normal" way of being for teachers' communities of practice thus constraining the shifts in teacher knowledge and practice needed to change student outcomes. She argues that it is necessary, though not always comfortable, to critically question one's practice while engaging in it and highlights the notion of 'critical alignment' whereby participants essentially align themselves with existing norms within the various communities in which they practice, while taking a critical view of that alignment. She argues that this metacognitive awareness is what distinguishes inquiry communities from communities of practice. Accordingly, Skattebol and Arthur (2014) suggest that there is a need for narratives of change processes including detailing the factors that constrain criticality and transformative practices within the realities of the practice context.

Examining an episode of the work of a school-based PLC, Allen (2013) observes that where norms of collegiality characterise a group's interactions and validation, rather than critical reflection, is the primary work of a community, critical questions are shut down and thus constrain teacher learning. He traces the catalyst for a focus on validation to the 'outside forces' of policy, including those aimed at accountability 
measures, suggesting that ownership of the group's purpose influences the processes they engage in. Describing teachers' experiences of collaborative teacher learning in an Australian secondary school, Andrews and Lewis (2002) reported dialogue that was messy, challenging and uncertain as participants worked to reconcile differences. The dialogue enabled teachers to articulate their otherwise tacit knowledge and challenge their co-participants' ideas and beliefs. A promising way to promote such conversations was suggested by Levine and Marcus (2010) who reported on a case study of a small secondary school whose teachers engaged in different types of collaborative activity throughout the week. Levine and Marcus tentatively concluded that providing intentional structures and deliberately planned areas of focus might help to counteract conflict-avoidance norms by permitting or requiring teachers to make details of their practice public and take collective responsibility for aspects of each other's work.

The connections between teachers' beliefs and practice are reciprocal and cyclical and teachers' beliefs influence both their practice and their orientations to their own learning (Opfer \& Pedder, 2011). Timperley and Alton-Lee (2008) suggest that when the prior knowledge and beliefs of teachers are not explicitly engaged with, teachers may reject new learning as inconsistent with what they believe, or overly assimilate in that they believe their practice is already aligned with the new approaches suggested. For instance, when evaluating teachers' use of inquiry to inform teaching in New Zealand schools, the Education Review Office (2012) concluded that "the expectation that something different may need to happen for identified students to 'accelerate' their progress is not widely held or understood" (p. 21). This aligns with Mitchell and Sackney's (2011) contention that reflection and critical inquiry are required if teachers are to meaningfully respond to disturbances to the status quo whereby one's actions impact on the teaching | learning conditions and outcomes of all others.

\subsection{Co-teaching as an arrangement for teacher learning}

This section draws on a growing body of literature examining co-teaching as an arrangement for teachers' professional learning and practice in a range of contexts 
including pre-service teachers on practicum co-teaching with experienced teachers, general classroom teachers co-teaching with expert special education teachers, preservice and in-service teacher educators co-teaching with classroom teachers, practitioners with expert knowledge of content co-teaching with classroom teachers, and newly graduated teachers co-teaching with more experienced colleagues and mentors.

\subsubsection{Defining co-teaching as shared responsibility}

A widely accepted definition of co-teaching is that of Cook and Friend (1995) who describe it thus: "Co-teaching occurs when two or more professionals jointly deliver substantive instruction to a diverse, blended group of students in a single physical space" (p. 2). In the context of special education and mainstream classroom teachers working together, these authors outline six models of co-teaching ranging from one teacher teaching and the other observing, to what they call team teaching in which both teachers are actively involved in jointly delivering instruction at the same time. This notion of team teaching aligns with how co-teaching is conceptualised in this study. Active joint engagement in teaching contrasts with a view of co-teaching as a shared teaching arrangement in which the teaching task is divided up and teachers take responsibility for different aspects of the lesson, or different groups of students. Murphy and Scantlebury (2010) describe co-teaching as "two or more teachers teaching together, sharing responsibility for meeting the learning needs of students and, at the same time, learning from each other" (p. 1). Their definition shifts the emphasis from delivery of instruction to the learning of both students and teachers. Similarly, Roth and Tobin (2004) argue that building collective responsibility for classroom events is amongst the most important elements of co-teaching praxis and can be seen where teachers take individual action to advance the learning of students and thus enact collective responsibility through individual action. Following Roth and Tobin, who describe co-teaching as "teaching at another teacher's elbow and taking shared responsibility for all parts of the lesson" (p. 161), co-teaching is assumed in this study to include processes of co-planning, co-instruction and co-reflection. 


\subsubsection{Benefits of co-teaching}

Summarising their volume on co-teaching in international contexts, Scantlebury and Murphy (2010) highlight a number of benefits of co-teaching for both teachers and students, including gains in students' learning and achievement, the expansion of the learning environment to include multiple perspectives and, as a consequence, more democratic teaching | learning spaces and enhanced equality, more inclusive environments supporting enhanced student participation and contribution and increased student ownership of learning. They suggest that important learning processes include the opportunity to reflect collaboratively on one's own practice and that of colleagues; the role of teachers' accountability to one another in compelling teachers to "up their game"; the expanded opportunities for teachers to practice in diverse classrooms; increased risk-taking; and the reciprocal validation of co-teaching partners. Scantlebury and Murphy further argue that student learning is extended by the expansion of the range of expertise and resources available to them where there are two or more teachers co-instructing.

Co-teaching expands the resources available for teachers to support both the learning of their students and their own learning. As teachers engage in co-teaching, the actions of each teacher become accessible to the other as resources that can be appropriated into their own teaching repertoire and teacher learning through coteaching can include both conscious action and unconscious appropriation of new approaches to teaching (Roth \& Tobin, 2002). For instance, as part of their collaborative and job-embedded professional development model, Hintz et al. (2013) described a process of participatory coaching. Experts co-taught with, or modelled for, teacher learners using in-the-moment coaching to provide opportunities that "highlight the decisions teachers face - things that typically go un-discussed" (p. 9). Such a process involves first noticing and then engaging with, through discussion, important instructional decisions. From multiple studies of co-teaching in the context of science education, Roth and Tobin conclude that expanded learning opportunities for teachers from co-teaching are consistent outcomes of co-teaching pairs with varied combinations of experience and expertise. 
Sustained improvement is an important challenge to address in relation to the professional learning of teachers (Timperley et al., 2007). Owen (2015) found that processes of co-teaching, including teachers planning, instructing and observing, assessing and reflecting together, supported the development of a learning culture oriented towards ongoing improvement, and built momentum for sustained efforts towards educational change. Furthermore, teachers who have experienced co-teaching as part of their pre-service teacher education later actively seek collaborative relationships with colleagues in their new teaching roles (Juck, Scantlebury, \& GalloFox, 2010). This suggests that improvements in teaching | learning that are promoted by co-teaching have the potential to be self-sustaining.

\subsubsection{Co-teaching and cogenerative dialogue}

Co-teaching appears to promote professional dialogue about practice that is critically reflective and has the potential to transform learning environments. In their introduction to their book on co-teaching in international contexts, Murphy and Scantlebury (2010) suggest that "co-teaching provides a structure for reflection on theory, praxis and practice" (p. 3). Similarly, Carambo and Stickney (2009) observed that when employed as a structure for the pre-service practicum, co-teaching occurred as an intersection of diverse cultural fields and promoted reflection that was "scholarly and informed by multiple perspectives" (p. 400), conditions that they argue are difficult to replicate for practising teachers. These authors suggest that even collaborative reflection on teaching episodes after the fact "cannot replicate the depth of understanding that emerge[s] when two teachers cohabit the classroom and cooperate on the variety of actions needed to successfully teach [a science lesson]" (p. 438). They argue that collaborative reflection-in-action (Schön, 1983) is able to "foster an affinity for reflective practice" (p. 440), however it is seldom a feature of the practice of experienced teachers owing to the complex work demands of the teaching role. Tobin and Roth (2005) in their work with science teachers found that interactions among teachers, students and the researcher promoted a deeper examination of classroom life leading to increased awareness of teachers' practice and generating possibilities for improving the quality of that practice and consequently improving student learning. Roth and Tobin (2004) describe such interactions as co- 
generative dialogues involving the collective generation of local theory in relation to classroom events leading to changes in practice that can be enacted by teachers in future teaching episodes. Carambo and Stickney (2009) point out that co-teaching is often associated with cogenerative dialogues which they describe as discussions amongst stakeholders in an educational context about the teaching and learning that is occurring, structured such that "no one person's voice is privileged and participants generate local theory and knowledge focused on teaching and learning" (p. 6). In relation to pre- and in-service teachers working together, Carambo and Stickney suggest that co-teaching and cogenerative dialogues serve as a vehicle for the transformation of learning environments by providing "transformational tools inside the classroom [and] produc[ing] a more adaptive environment" (p.391), explicitly shifting ownership of teaching and learning from individuals to the collective.

A key difference between the co-teaching approach and other adaptive models of professional learning is that the actual teaching is a shared experience whereas in the case of video clubs and lesson study, for example, the collaboration centres on observations or representations of one teacher's practice. The co-teaching experience simultaneously affords teachers' in the moment reflection and response to events as they unfold in the lesson, and diverse perspectives against which to test one another's interpretations of those events.

\subsubsection{Co-teaching challenges}

There are fiscal and staffing implications related to having multiple teachers in classrooms nevertheless it is possible to imagine flexible and creative solutions for meeting the resourcing challenges (Carambo \& Stickney, 2009). Darling-Hammond and Bransford (2005) point out the mismatch between the way schools are organised and the demands of teaching and learning arguing that "both side of the reform coin: better teachers and better systems" (p. 5) need to be attended to simultaneously. Furthermore, they point to developing the capacity of teachers to work on improving practice as members of collaborative communities as one way to do this. However, solution strategies require the support of management in fundamentally rethinking how schools are organised and resources are distributed. This can be difficult to achieve when teachers who have experienced co-teaching, for instance, might 
advocate for it but may not be able to articulate its benefits in compelling ways to management who are required to balance competing demands on their professional attention and the resources they are responsible for managing. A contributing factor may be the dearth of evidence in the form of narratives of change processes which detail the factors that constrain criticality and transformative practices within the realities of the practice context (Skattebol \& Arthur, 2014). A challenge that is not brought to light is difficult to address.

\subsection{Summary}

The foregoing survey of the literature serves several purposes in informing the study undertaken. First, it explores the complexity of teachers' knowledge in the context of teaching | learning mathematics in primary classrooms and engenders questions about the nature, conditions, and processes for teacher learning in the context of their day-to-day work. The review outlines a perspective of knowledge coproduction as the generation of local theory; that is, teachers' practice is viewed as an epistemological undertaking. The chapter establishes the context for the central problem of the thesis: How might a group of teachers in a New Zealand primary school collaboratively inquire into their practice with the ultimate objective of promoting improved mathematics learning for students they had identified as at risk of underachievement? The thesis explores a perspective of teachers' professional learning as the development of adaptive expertise and examines characteristics of adaptive models of teachers' collaborative inquiry and the resources that mediate teacher learning. The review of the literature gives reasons to explore teachers' collaborative inquiry in the context of primary mathematics classrooms in order to broaden understandings of the mechanisms at work when teachers learn in the context of joint practice.

As discussed throughout this chapter, teachers learning in collaboration with colleagues in the context of their day-to-day work can promote shifts in classroom practice that are expected to impact positively on the learning of diverse students. The term collaborative inquiry describes the activity that was the focus of this research and is used to align the activity with the notion of teaching as inquiry and to forefront the 
role of teachers' joint engagement in this activity. Elements of teachers' collaborative activity are interrelated in complex ways and it is the tensions, contradictions and resistances between and among elements of the activity system that are of interest in this study.

\subsubsection{Gaps in the literature}

There is considerable interest in teacher inquiry in collaborative contexts, nevertheless there remains a need for further research to answer the question how does participation in collaborative inquiry generate teachers' knowledge for mathematics teaching | learning? For instance, Carambo and Stickney (2009) call for research to investigate ways to "reintegrate reflective practice into the lives of practising teachers" (p. 440). Despite a growing body of literature focused on coteaching there appears to be little or no literature examining co-teaching arrangements between teaching colleagues in the course of their day-to-day work where the focus is on promoting their professional learning. This study, and the approach to collaborative inquiry that emerges from it, align with the call of Scantlebury and Murphy (2010) for policy makers to embrace co-teaching and cogenerative dialogue "as central to future developments in education" (p. 391). 


\section{Chapter 3 Methodology}

This chapter describes the perspectives and approaches that underpin the study design. First, my stance as a researcher is explained, followed by an outline of the theoretical approach taken. The participatory nature of the research is fore-fronted and the multiplicity of the researcher role(s) is examined. Cultural-historical activity theory is outlined as a theoretical and conceptual tool and the multi-theoretical, pragmatic approach is explained. The research approach is described including the methods used, the research site and participants, approaches to data collection, preparation and analysis, and a discussion of trustworthiness. Ethical considerations are outlined, and limitations of the study design are described. The chapter ends with an overview of the chapters that follow.

\subsection{Research aim and question}

The research approach is fundamentally informed by the problem the research aims to address and the associated questions it sets out to answer. As outlined in section 1.1, the study aimed to answer the following research question:

How does participation in collaborative inquiry generate teachers' knowledge for mathematics teaching | learning?

The overarching purpose of the study was to work with a group of teachers to codesign and participate in enacting a model for collaborative teacher inquiry with a focus on appreciating the critical contradictions that arose in the activity, and actions that were taken. The research sought to account for the affordances within such activity, including how space for teacher learning was opened up and constrained. In seeking to answer the research question, the aim was to understand participants' experiences of the collaborative inquiry activity including how teachers identified valued educational outcomes in mathematics; how participants described their experiences of collaborative inquiry; what contradictions arose within the teachers' collaborative inquiry activity and what actions were taken to resolve these; and how participants described any impacts of the collaborative inquiry on mathematics teaching | learning. Implicit in the research question is how changes in teachers' 
knowledge, beliefs, and practices for teaching | learning mathematics are revealed in how they talk about mathematics teaching practices for and with diverse students.

\subsection{Researcher stance}

Philosophical perspectives underpin any research, whether explicitly or not, and fundamentally impact on choices made in the design and enactment of any research activity. Denzin and Lincoln (2011) and Kincheloe (2007a) raise the ontological question of what it means to be human, implying the subjectivity of the lived, human experience and multiple perspectives on reality. This is a subjective, relativist perspective which assumes that those who experience a phenomenon create multiple meanings or "realities" of it (Ponterotto, 2005). A sociocultural perspective was taken in this research in that it was intended to appreciate the multiple, socially and culturally constructed realities of participants' experiences (Schoen, 2011). A critical lens was applied aimed at grounding the research on the importance of difference, including the role of power within and among different realities (Kincheloe, 2007b).

A qualitative approach was chosen in keeping with the intention to capture the complexity of the research context and in accordance with the notion of qualitative research as bricolage, a metaphor that captures the notion of piecing together the research story from multiple threads. (Denzin \& Lincoln, 2011). Taking an interpretive and critical position assumes subjectivity and necessary interaction between the researcher, research participants and the research context in order to understand the multiple and shifting realities of the lived experience (Ponterotto, 2005). Following Tobin and Ritchie (2012), an interpretive approach meant that research questions and design characteristics were taken as heuristic and were continuously renegotiated. The emerging design was contingent on ongoing and simultaneous analysis, interpretation and reporting back to participants. Taking an epistemological stance that challenges a reductionist view, the position adopted in this study is that "reality is too complex and multidimensional to lend itself to fixed views and reductionist descriptions" (Kincheloe, 2009, p. 109). A socio-cultural approach is informed by the notion that it is impossible for a researcher to stand apart from their epistemological and ontological 
positions and take a value-free perspective, thus requiring reflexivity. As Berings, Doornbos, and Simons (2006) describe, critical researchers are 'reflexivists' who seek to explain the influences of their own and their co-participants values on the meanings constructed in the research. Accordingly this research was anchored in the interpretive and participatory paradigms and took an explicitly appreciative stance, reflecting the "blurring of genres" commented on by Lincoln, Lynham and Guba (2011).

Axiological concerns permeate questions around the impact of researchers' values, the roles participants take in the research process and how these play out, and how research products are used including how the quality of research is judged (Baptiste, 2001). An interpretive and critical approach assumes the influence of researcher values both by seeing bias as a potential means to promote relationships and dialogue, and by promoting an explicit goal for the research to transform the status quo by empowering research participants to take action (Ponterotto, 2005). The research position taken here is grounded primarily in axiological assumptions concerned with equity, caring and social justice, valuing strength and difference as foundations for growth and learning, and privileging community over individual goals. High on my axiological ladder is alleviating the anxiety teachers bring to their teaching of mathematics.

\subsubsection{Researcher role(s) and reflexivity}

A dilemma in posing a research question and defining the parameters of this study, lay within the axiological question of who the research is for. Denzin (2005) puts moral and ethical considerations at the forefront in his argument for indigenous epistemologies to inform critical theory. He calls researchers to participate and listen, and to define ethical and moral principles with their participants. A fundamental challenge with taking such a stance is raised by Tuhiwai Smith (2005) who describes the 'tricky ground' that researchers have to negotiate in terms of our sometimes (perhaps often) conflicting commitments to the traditions of a chosen methodology, the institutions within which we work, our co-participants in the research, and ethical considerations. How does the researcher, for example, work with co-participants such as the teachers in this study to develop ethical guidelines when our employing 
institutions require these to be developed and approved prior to entering the field and engaging with participants? This is a challenge that is born out of indigenous research, but which has relevance for any group of research participants.

Classroom-oriented research activities involving collaborations amongst practitioners and researchers have been found to promote a reflexive relationship that can impact the learning and development of researchers alongside teachers and students (e.g. Hunter, 2007). Reporting their experiences of job-embedded professional development for elementary teachers in mathematics, involving a collaboration amongst researchers, teachers and school leaders, Hintz and colleagues (2013) noted how their identities as competent learners developed through their work together. These researchers formed a growing belief that individuals do not hold the answers but must "build more detailed visions of ambitious teaching through [their] work together" (p. 10). Jaworski (2003) draws attention to the role of teacher educators as practitioners in processes of inquiry aimed at "the big issues in teaching" (p. 7) and highlights the parallels between the teacher educators' own learning processes and those of their students. Hintz and colleagues (2013) similarly note the complexity of the change process and how participants found themselves "being leaders and learners who must be vulnerable, deeply challenged, and learning ambitiously" (p. 9). Such conclusions are premised on a view of practitioners as knowledge creators and of teaching as an epistemological undertaking, a view that informs this study. Accordingly, an emerging research design was developed which allowed space to navigate the research agenda with co-participants, but which was realistically bounded to give the novice researcher the support of structured guidelines. Such an approach aligns with Parr and Timperley's (2015) observation that school-based research aimed at effecting educational improvement "represents a blurring of once clear roles and a changing of expectations, including the function of the research, who participates, and whose knowledge contributes and in what ways" (p. 30). In keeping with the design-based approach to the research (described in section 3.4) a notable characteristic of the researcher role was my gradual withdrawal from active participation and project leadership (see Chapter 5) to more of a 
participant observer role as the teachers took increasing ownership of the inquiry process.

For convenience the term 'researcher' is used to refer to my role in this study, however the roles of teacher participant and researcher are blurred with all of us explicitly describing ourselves as co-researchers and teaching colleagues. In their large national schooling improvement project aimed at simultaneously evaluating a Ministry of Education funded programme while also working with clusters of schools to build capacity, Parr and Timperley (2015) point out that "pressures, choices, and constraints face those engaging in forms of research that combine research as knowledge, application in context, and participative features" (p. 34). Similarly, the role of the researcher in this study was a multifaceted one involving simultaneously taking perspectives as advocate for and critic of the proposed design. As such there is an inevitable tension which necessitated methods that could surface and question the researcher's tacitly held assumptions (Design-based Research Collective, 2003).

Strategies included keeping a reflective journal, using frequent member checks and engaging in critical and reflective discussions with peers, including supervisors and cohort groups, in order to bring forward my assumptions, biases and possible alternative views (Shenton, 2004). While in the field I routinely recorded my impressions, thoughts and wonderings either in writing or by audio recording. Where possible, immediately after leaving the field I recorded my comments about my experiences and these comments were later imported into NVivo as data sources for analysis. Throughout the course of my $\mathrm{PhD}$ candidature I attended regular meetings of two cohort groups comprising students and academic staff with similar research interests to my own. These meetings supplemented conventional supervision meetings and provided an additional setting in which I could share and test my emerging thinking and underlying assumptions in relation to my researcher role. I maintained contact with research participants after exiting the field thus transcripts were able to be made available to research participants for checking and drafts of research outputs such as papers and conference presentations have been shared with participating teachers. 
The remaining sections in this chapter describe the theoretical underpinnings of the study, the methodology chosen, and the associated methods employed. Ethical considerations and risk management processes are described and limitations of the research approach are discussed. In relation to each of these aspects, researcher decisions and actions are explained and emergent tensions and challenges are discussed.

\subsection{Theoretical framework}

This study approaches teachers' professional learning from a sociocultural perspective which suggests knowledge resides within participation in social activity. Teachers' knowledge is assumed to be rooted in, and identity ascribed through, practice (Jaworski, 2008). From such a viewpoint, knowledge is situated in and can be understood through action (Roth, 2007). Taking a view that a phenomenon is better understood in a process of change rather than as an endpoint (Vygotsky, 1978), teachers' professional learning can be viewed as both part of the process of teachers' practice and as a product of that practice. Thus, in accordance with Vygotsky's theoretical position that the unit of analysis is the collaborative system within which individual and collective learning are developed and integrated (Scrimsher \& Tudge, 2003), teachers engage as learners within a variety of sociocultural contexts, actively constructing knowledge and mutually and reciprocally shaping and being shaped by those environments in which they work. Such a view suggests both individuals and the groups within which they participate have mutually constituted identities.

Furthermore, a focus on teaching | learning encapsulates the idea of teaching and learning as having a dialectical relationship. Powietrzynska (2015) describes dialectics as "constructs in social fields that are constituent of a whole and do not exist independently - existence of one presupposes the other" (p. 72). In other words, learning and teaching are assumed to constitute one whole whereby without learning, teaching cannot be said to have occurred and similarly teaching can be said to fundamentally involve learning. 


\subsubsection{Theoretical approach: Cultural-historical activity theory}

Focusing on teachers' collaborative inquiry, this study situates teacher collaboration within the notion of an inquiry community the conceptualisation of which Jaworski (2003) suggests has theoretical roots in the integration of elements of social constructivist and sociocultural theory. Following Jaworski, this study takes a sociocultural perspective in order to prioritise a view of learning rather than taking a narrower focus on individual learners. Cultural-historical activity theory (CHAT) provides a theoretical lens through which to explore the interrelationships among elements and the contradictions produced within activity (Engeström, 2015); in this case the activity of teachers' learning through collaborative inquiry. Central to sociocultural theory is the idea that all action is mediated by tools and signs (Vygotsky, 1978). Accordingly, CHAT is premised on the idea that learning is socially situated and mediated by conceptual and material artefacts including objects and people, building on a Vygotskian sociocultural understanding of learning as participation in legitimate, everyday activity. Engeström (2009) conceptualises an activity system (illustrated in Figure 3.1 below) as consisting of: a subject or subjects, the people engaged in the activity; an outcome towards which the activity is motivated; an object which is acted upon in order to achieve the outcome; and material and conceptual artefacts or tools which mediate the activity. Action can be seen to be influenced by: the rules or norms that govern activity, both explicitly and tacitly; the community within and for which the activity occurs; and the various roles and responsibilities of participants, referred to as the division of labour, including who performs what tasks (horizontal) and the relative power and status inherent in roles (vertical). The arrows depict the relationships between various elements of the system: the subject can be seen to produce, and the object to consume, the outcome; the subject and the rest of the community engage in reciprocal interactions; and the relationship between the community and object is one of differentiated distribution (the community) and accumulation (the object) of the outcome. 


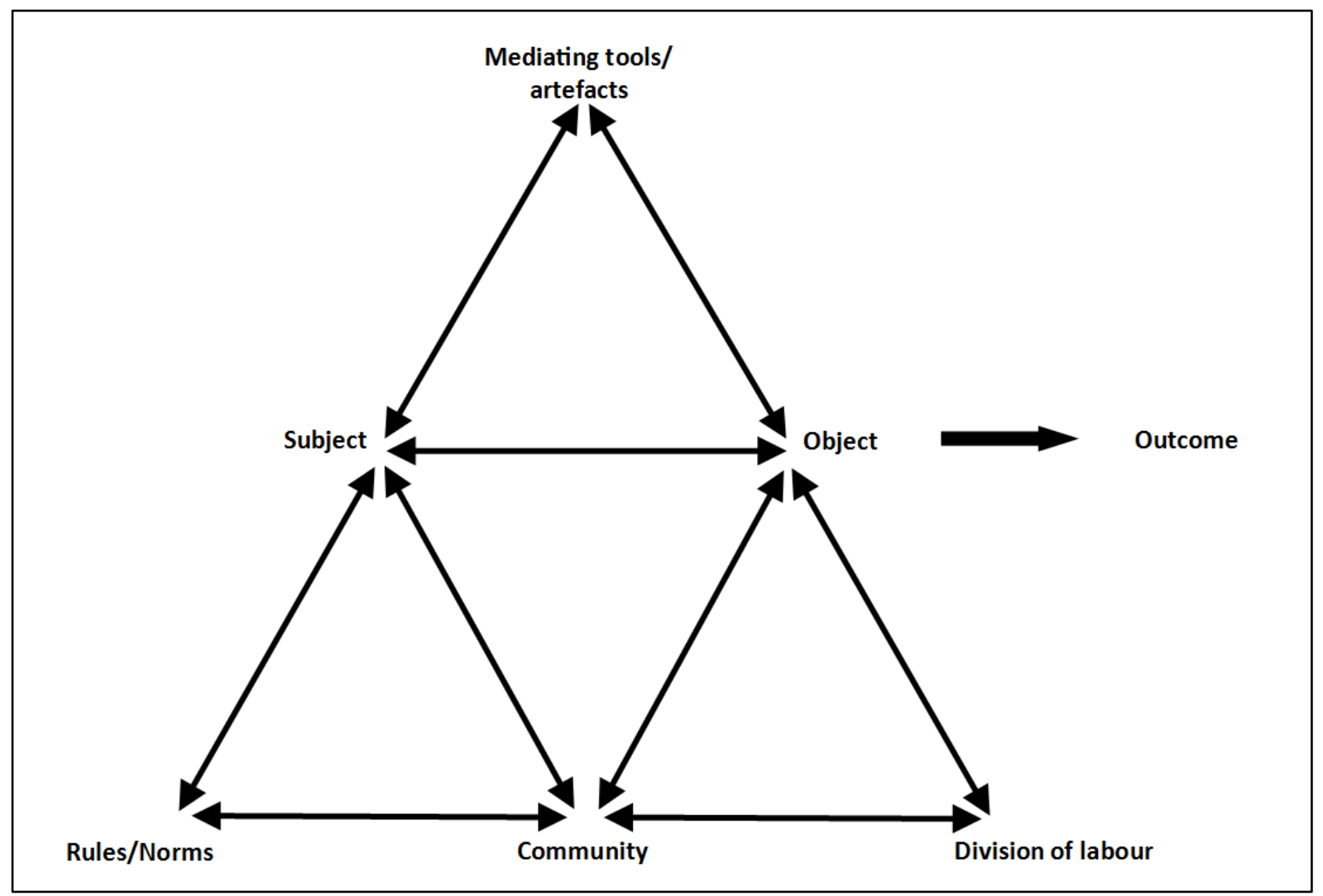

Figure 3.1. Activity system (Engeström, 2009).

In such a system, the activity becomes the core unit of analysis and, according to Roth and Lee (2007),

learning occurs whenever a novel practice, artefact, tool or division of labour at the level of the individual or group within an activity system constitutes a new possibility for others ... leading to an increase in generalized action possibilities and therefore to collective (organizational, societal, cultural) learning (p. 205).

Using CHAT as an analytical framework provides a systematic way to capture the complexity of teachers' collaborative activity (Levine, 2010). The research context of teachers' collaboration can be seen to produce contradictions and challenges that provide the catalysts for change and CHAT enables the researcher to inquire into both the means and ends of professional learning simultaneously. Thus, teachers' collaborative inquiry constitutes the goal-directed activity of interest in this study and the notion of inquiry community will be used to conceptualise generative learning at the level of the activity system. Following Gade (2015) the concept of expansive 
learning activity drawing on shared classroom praxis is employed as a universal concept and activity system is thus taken as the unit of analysis.

\subsubsection{Theoretical pluralism: Multiple theoretical tools}

Within the overarching framework of CHAT, multiple theoretical tools are used to explain salient elements of the activity system. Following Tobin (2012), a key principle of this research is a polysemic (multiple meanings) and polyphonic (multiple voices) approach which avoids deficit perspectives towards difference and privileging the researcher's voice over others. The aim is to capture multiple voices and engage with multiple meanings, and to present nuanced claims alongside the associated contradictions that arise as expected aspects of social life (Sewell, 2005). Difference and sameness are regarded as resources and are interpreted in relation to one another (Tobin \& Ritchie, 2012). What follows is a brief introduction to some of the key constructs employed in theorising teacher learning.

\section{Contradictions and expansion}

Internal contradictions are regarded as the "driving force of change and development in activity systems" (Engeström, 2015, p. xv) and the ways in which the actions of teachers aimed at resolving contradictions opens space for an expanded set of actions (Engeström, 2009) is of particular interest in this study. Social life is characterised by patterns of thin coherence and contradiction (Sewell, 2005), and any new element introduced into an activity system will "generate disturbances and conflicts, but also innovative attempts to change the activity" (Engeström, 2009, p. 57). Thus contradictions within the activity system serve as catalysts for learning as possibilities for action are expanded (Roth \& Lee, 2007).

\section{Structure and agency}

Human agency - the power to act to create one's lived world - is an important notion underpinning a cultural-historical activity perspective. Roth and Tobin (2004) describe agency in terms of the potential to act or the range of possible actions available in a given set of circumstances. Sewell (1992) defines structures as "sets of mutually sustaining schemas and resources that empower and constrain social action and that tend to be reproduced by that social action" (p. 19). He argues that 
possibilities for action are produced in a dialectic relationship between structure and agency and thus mediated by the circumstances in which the activity occurs. In other words, changes in structure effect agency and any change in agency brings about an associated change in structure. The macro structure that is the focus of this study is the school which is comprised of classrooms within which the teaching | learning of mathematics occurs. At the meso level is the notion of an inquiry community including structures that characterise the collaborative inquiry activity of a group of teachers. The micro level involves the interactions of the teachers, including their actions and utterances, as they go about their shared work within and beyond their classrooms.

\section{Individual and collective}

In activity-theoretical terms, the distinction between individual action and collective activity is crucial and is underpinned by the notion of historically evolving divisions of labour (Engeström, 2015). Stetsenko (2008) argues that

"the core of human nature and development has to do with people collaboratively transforming their world in view of their goals and purposes-a process through which people come to know themselves and their world as well ultimately come to be human" (p. 474).

Consistent with Vygotsky, Stetsenko theorises transformative action as both profoundly social and involving the role of individuals as agents whose contributions shape, and are shaped by, social practices. Thus in the context of object-directed activity, individual action and the collective activity can be seen as dialectically related and mutually constitutive.

\section{Affordances and constraints}

The analysis drew on the notion of affordances, that is "the ways in which the practices of the group open up some opportunities and constrain or close off others" (Little, 2003, p. 939), to examine how learning was enabled or constrained through the use of various tools. Specifically, what aspects of, and to what degree of depth and transparency, was teachers' classroom practice made accessible in their collaboration and in doing so how was teacher learning opened up or closed down within that collaboration? 


\section{Emergence and contingence}

Viewed from a socio-cultural perspective, social life is emergent and contingent, and in a constant state of flux (Alexakos, 2015). Consistent with a multiontological perspective, the phenomenon of teachers' collaborative inquiry is viewed in this study as constantly changing; emergent from the activity as it happens, and contingent on what is being learned. Furthermore, research is "refined and changed as new ideas emerge. Outcomes are not oversimplified but are nuanced and viewed as contingent" (Alexakos, 2015, p. 20).

\section{Heuristics}

Following Powietrzynska, Tobin and Alexakos (2014), the notion of a heuristic is used to shed light on how meanings associated with social constructs are brought to light, in this case the construct of teaching | learning mathematics. Heuristics act as reflexive objects, illuminating difference and "provid[ing] a window into both the individual and collective enactments of specific characteristics in a social field" (p. 69) such as a group of teachers working together within a school. Responses to a heuristic and the characteristics represented within it shed light on the phenomenological question 'what is happening here?' and the hermeneutic interpretation of 'why is it happening?' Departing somewhat from the approach of the abovementioned authors, heuristics are used here as a theoretical tool to generate understandings of the phenomenon of teacher learning afforded by teachers' collaborative activity, rather than as a designed intervention specifically aimed at promoting such learning.

\subsection{Design-based research approach}

Design-based research is characterised by a close relationship between developing theory and improving instructional design (Cobb, Confrey, diSessa, Lehrer, \& Schauble, 2003) including impacts on students (Anderson \& Shattuck, 2012). Design experiments are "extended, interventionist and theory-oriented enterprises whose 'theories' do real work in practical educational contexts" (Cobb et al., 2003, p. 13) with theoretically and empirically significant problems of practice as the starting point (McKenney \& Reeves, 2013). Parr and Timperley (2015) argue that such approaches have "strengthened an education research tradition keen to bridge theory and 
practice" (p. 33). Design-based research involving collaboration between teachers and researchers is a promising approach to uncover how the actions of teachers 'play out' in the classroom (2013) and in the context of teachers' professional learning.

Furthermore, this approach allows the creation of "learning conditions which current theory promotes as productive but which may not be commonly practised, nor completely understood" (Design-based Research Collective, 2003, p. 5). Design-based research, with its focus on connecting processes of enacting learning designs with outcomes of interest (Design-based Research Collective, 2003) was thus a chosen as a suitable methodology for this study.

According to Cobb et al. (2003) design studies "entail both 'engineering' particular forms of learning and systematically studying those forms of learning within the context defined by the means of supporting them" (p. 9). Such research involves an iterative cycle of design based on conjectures which are then tested and refined leading to redesign (Reeves, 2006) as illustrated in Figure 3.2 below. In contrast to research approaches that assume findings will be subsequently applied in practice, design-based research "integrates the development of solutions to practical problems in learning environments with the identification of reusable design principles" (Herrington, McKenney, Reeves, \& Oliver, 2007, p. 4090).

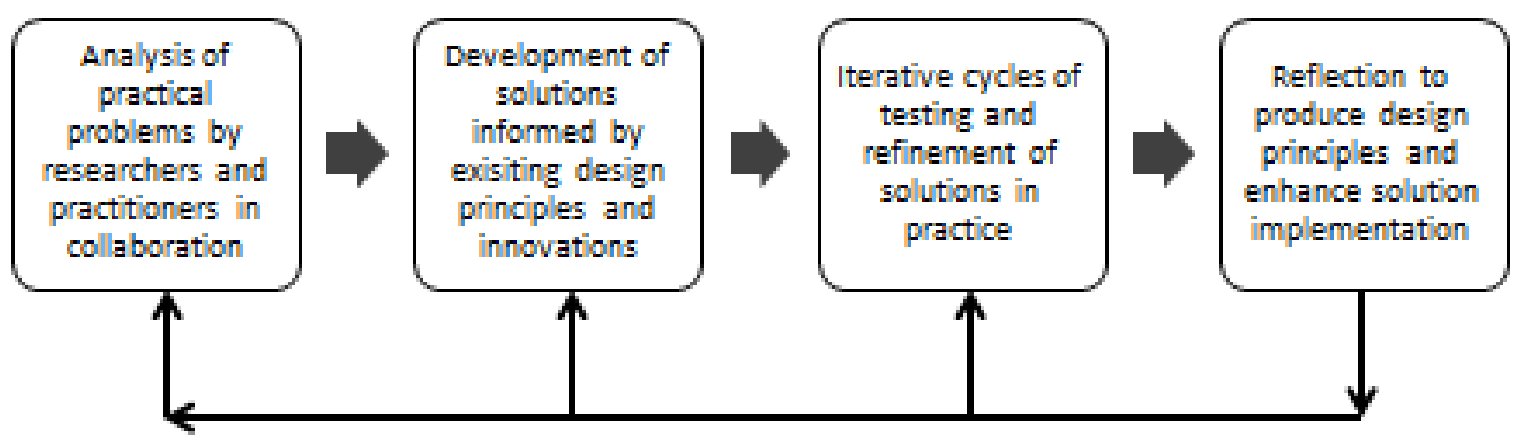

Refinement of problems, solutions, methods and design principles

Figure 3.2. Design-based research process. Reprinted from "Design Research from a Technology Perspective," by T. Reeves, in J. van den Akker, K. Gravemeijer, S. McKenney, \& N. Nieveen (Eds.), Educational Design Research (p. 59). London: Routeledge. Copyright 2006 by Taylor and Francis (Books) Limited UK. Reprinted with permission. 
The design cycle followed in this study aimed to broadly parallel a professional inquiry and knowledge-building cycle that was adapted from Alton-Lee (2012) to forefront teachers' collaboration and is shown in Figure 3.3 below. The project was explicitly designed to support the generation of practice-based pedagogical knowledge and address the research question by documenting the processes involved in the knowledge production. Given the participatory nature of the research, specific aspects of mathematical knowledge in focus would depend on the collectively negotiated professional learning agenda and co-designed collaborative processes. The intention was to design a flexible and adaptive model of teachers' collaborative inquiry, with associated tools to support the model's enactment. In keeping with the design-based approach and in accordance with Engeström's (2015) notion of research as formative intervention, the collaborative activities of the participant group were subject to negotiation and included: reading and discussing research articles; co-planning, coteaching and reflecting together on mathematics lessons; and sharing and discussing excerpts from video recordings of classroom activities. 


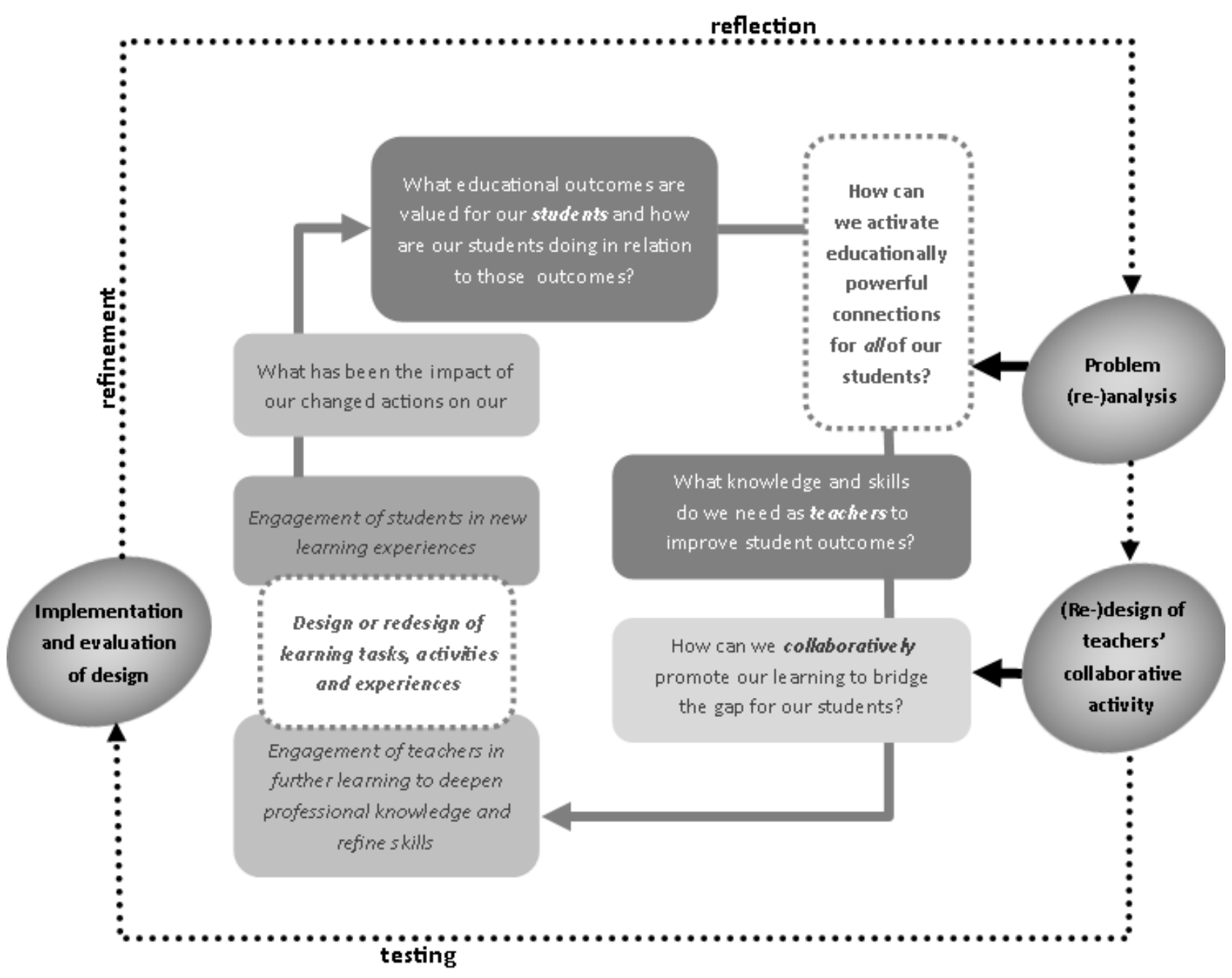

Figure 3.3. Integrating an inquiry and knowledge-building cycle with the research baseddesign process. Adapted from "The Use of Evidence to Improve Education and Serve the Public Good" presented at the Annual Meeting of the American Educational Research Association, Vancouver, Canada. Copyright 2012 by Adrienne Alton-Lee. Adapted with permission.

Design-based research is exploratory in nature (Herrington et al., 2007) and the collaborative and situated nature of the project necessitated a research design that was emergent and adaptive to both the specific goals and related foci negotiated among participants, and the dynamic nature of learning environments. Each iteration of the inquiry and research cycle broadly followed a cycle of three-weekly group meetings with planned episodes of teaching video-recorded between meetings. Selected video excerpts were shared and discussed at subsequent meetings. In this way multiple iterations of the design were allowed for within the scope of the project. Figure 3.3 might be seen to represent a relatively simple and single-level inquiry and design cycle, however the complex reality of teachers' work suggests more emergent and 
multilevel relationships amongst elements of the cycle. The research approach was intended to capture the complexity of the design process and associated products and this is elaborated on in the remainder of this section.

\subsection{Methods}

In taking an interpretive and situated approach which draws on sociocultural perspectives, the intention was to capture the lived experiences of the participating teachers and to interpret the multiple realities of collaborative teacher learning processes through the use of their voices to narrate the experiences (Creswell, 2013). The research methods used were aimed at capturing the voices of participants and gaining a deep understanding of their perspectives on the emerging collaborative relationships and the impacts on teachers' mathematical knowledge for teaching. Broudy's (1970) discussion of what it means 'to know' highlights the importance of proximity to source thus: "Humanistic truth of knowledge involves something other than logical or scientific validity. Perhaps it is authenticity. Authenticity is the property of being genuine, nonfake, as really issuing from the source that claims to originate it" (p. 5).

\subsubsection{Research site selection and recruitment of participants}

The intention was to develop a research relationship with teachers of mathematics in a primary or intermediate school that would be the sole research site. Site selection included the following broad criteria: the school had an identified goal of promoting improved achievement in mathematics, including for Pasifika students as this was the intended focus at the project's outset; the teaching staff could generally be considered "typically" diverse in terms of experience, expertise and enthusiasm for the teaching of mathematics; and the school was within a reasonable commuting distance to allow for an on-going and mutually beneficial research relationship. Two approaches were used to identify a suitable research site: experts within the local mathematics education professional community were approached for suggestions of schools that met the criteria; and the Ministry of Education's (n.d.-c) database of schools was searched. 
The database of schools was filtered to identify primary and intermediate schools that were within a limited geographical region and had a student roll of more than 100 students, at least $15 \%$ of whom identified as Pasifika according to Ministry of Education criteria. Education Review Office (ERO) evaluation reports for each identified school were then scanned to exclude any schools where "the performance ... needs improvement, and there are risks to the education and safety of the students" (Education Review Office, n.d.). Principals of schools identified as meeting the criteria were then contacted via email, provided with general information about the project and invited to contact the researcher to discuss the research further. Three schools expressed interest and face to face meetings were arranged to share further information and answer questions about the project. The nature of the project necessitated a high level of commitment, particularly from teacher participants, and so it was necessary to communicate fully with the Board of Trustees, principal and teaching staff of the school to outline what would be required of participants and to ascertain whether: the goals of the project were aligned with the current needs and goals of the school; the principal and/or other school leaders were likely to consent to actively participating in the project; a sufficient number of teachers was likely to consent to participating; and a suitable time and place would be available for participants to meet regularly for the duration of the project.

The final research site was selected after a series of meetings and telephone and email conversations among the researcher, the principal and two teachers with leadership roles within the school. Formal written consent was given by the principal and Board of Trustees prior to the recruitment of research participants (see Appendix 3.1 for copies of all information sheets and consent forms). Referred to by the pseudonym Waterview School, it was a full primary school located in a largely residential area in Wellington, New Zealand, and had a culturally diverse roll of between 200 and 250 students.

\subsubsection{The participants}

Teachers were invited to a meeting at which information about the project was provided by the researcher and they had an opportunity to ask any questions. Participation in the project was on an entirely voluntary basis and interested teachers 
were provided with an information sheet and written consent form. Four teachers consented to participate in the project although one teacher later withdrew (see Section 6.2). They have been assigned pseudonyms (Casey, Kris, Pat and Sam) and allocated the female gender to protect their identities. They were all experienced teachers with ten or more years of classroom experience, at least three of which were at their current school. The group of teachers included a range of ages and levels of confidence with teaching mathematics. In addition to their classroom teaching roles, they all held additional leadership and specialised roles in a range of areas within the school including one teacher (Kris) who was responsible for curriculum leadership in mathematics.

The four teachers taught in 'single-cell' classrooms with between 22 and 26 students in each, comprising one Year 2 class (6-year-olds), one Year 3 and 4 class (7and 8-year-olds) and two Year 7 and 8 classes (11- and 12-year-olds). During the study, Kris also worked with four students from outside of these classes as part of an intervention for one term. Because students were to be present for classroom observations and video recorded teaching sessions, and examples of student work would likely be discussed, students and their parents were provided with information sheets and opportunities to ask questions about the research. The written assent of students and consent of their parents was attained and 67 of the 102 students who were invited agreed to participate in the study. The school's principal also consented and attended and actively participated in two of the group meetings.

\subsubsection{Data sources and data gathering methods}

It is typical for qualitative research to involve multiple sources of data (Creswell, 2013) and this is a feature of design-based research (Cobb et al., 2003). Teachers' self-reports of their experiences are a frequently used source of data to investigate the impacts of professional learning however this has some important limitations. An alternative approach is a systematic investigation of critical components of the professional learning experience, with the identification of what counts as 'critical' being contingent on the theoretical framework underpinning the professional learning design. The adaptive nature of the professional learning design highlighted the importance of documenting the events and processes of the teachers' 
professional learning (Koellner \& Jacobs, 2015). Accordingly, a primary data source in this study was the use of digital audio recording supplemented by video recording to capture the planned collaborative activities of participants, such as meetings and shared reflection sessions.

The inquiry group which was made up of the researcher and four (later three) teacher participants met approximately three-weekly from late term two (June) to late term four (December). Six of the seven meetings were held after school for up to one and half hours, with the exception being second meeting which was held in the July school holidays for approximately three and a half hours. During these meetings, the group shared and reflected on teaching episodes, read and discussed literature, and planned future classroom and project activities (see Table 3.2 for a detailed schedule of project activities). Audio and video records of teachers' collaborative activities were used to capture what resources were made available for learning within the specific talk and artefacts shared by teachers, providing a clearer view than interview or survey data alone (Little, 2003). Recording group meetings served to capture a phenomenological perspective on the social structures that afforded and constrained individual's actions within the collective activity.

Semi-structured face-to-face interviews were conducted by the researcher with each participating teacher. These were used to elicit the participating teachers' tacit perceptions and opinions and also provide opportunities to gather historical information (Creswell, 2013). The interviews were held at the school during class time, and release was arranged by the school with relieving costs met by me. The interview questions aimed to elicit data that provided illumination of the research questions. The initial interviews focused on the teachers' prior experiences of collaboration in their work and their current perspectives on mathematics teaching | learning and what it means for students to achieve in mathematics, with a specific focus on Pasifika learners in keeping with the intended focus on this group of priority learners. The final interview questions aimed to elicit participants' experiences of the collaborative inquiry activity and focused on the processes and impacts of any perceived changes. Schedules of interview questions used at the beginning and end of the data-gathering phase of the project were provided to the participants at the start of each interview 
and these are attached in Appendix 3.2. The interviews were audio recorded and written notes were taken as a back-up in case of technology failure. Appendix 3.3 provides a key to abbreviations used for data sources.

Prior to the teacher interviews that were conducted at the beginning and end of the data gathering period, a mathematics lesson was observed in each participating teacher's classroom. Audio and video recordings and field notes were taken aimed at capturing routine classroom events with a focus on the actions and words of the teachers. The observations were not intended for separate analysis but rather informed the collection and analysis of data from interviews and group meetings. Although two classroom observations were not expected to elicit sufficient information to draw robust conclusions about the nature or any shifts in teachers' classroom practices (Desimone, 2009), the observations provided the researcher with contextual information that supported both the interpretation of the social meaning of classroom events, and lines of reasoning that were picked up in the interviews themselves and their subsequent analysis (McCutcheon, 1981). Teachers were encouraged, for instance, to reference examples from observed classroom episodes to illustrate or expand on what they raised at the interviews.

An important reflexive tool was the research journal which was analysed as a source of data informing how the my role and background shaped the research (Creswell, 2013). My reflections were captured in written notes during data gathering activities and audio recordings made immediately following these activities. My reflective comments continued to be recorded during the analysis phase of the research in order to surface and capture personal responses to the data as they arose. These data supplemented and were integrated with other data sources such as records of informal communications, material artefacts of students' and teachers' work, and other documents such as teachers' written planning. In particular, email communication between the teachers and researcher were analysed and records of the researcher's informal conversations with teachers were captured in audio recordings or written notes as soon as possible after they had occurred. 
Table 3.1 below outlines the sources of data related to the programme of research activities in the school from entry to withdrawal. In the original research design it was intended to collect weekly reflections from the participating teachers using a format of their choice, for example via email, in a written journal, using audio or video recordings or using a self-chosen template. Of the four teachers, one chose to email weekly reflections, two chose to use a handwritten journal and one chose to use a 'PMI' format - a table used to organise reflections into points that are 'plus' (positives or successes), 'minus' (negatives or challenges) and 'interesting' (points that are neither positive nor negative but are nevertheless considered relevant and of interest). One teacher emailed weekly reflections for four weeks and another teacher provided one written reflection using a 'PMI' framework. It appeared that reflecting in writing constituted a task 'on top' of the teachers' day-to-day work and to impose the expectation that reflections be completed for the purposes of the research was not in keeping with the authentic and negotiated approach to the study. The limited individual reflections also possibly revealed that teachers' intellectual work is largely done in verbal interactions with colleagues and in the absence of this perhaps there is limited opportunity to reflect on one's practice. This is elaborated on in the findings and discussion chapters that follow. 
Table 3.1

Data Sources and Project Activities

\begin{tabular}{|c|c|c|c|c|}
\hline & 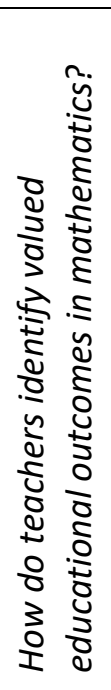 & 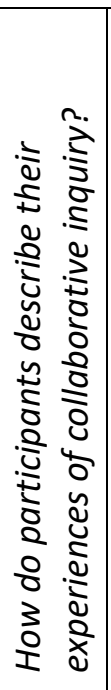 & 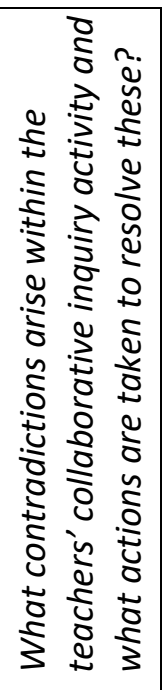 & 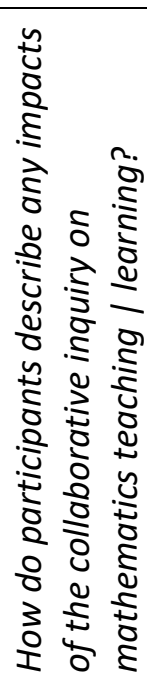 \\
\hline \multicolumn{5}{|c|}{ Entry, exploration and initial design phase } \\
\hline $\begin{array}{l}\text { - Video/audio recordings of collaborative design work } \\
\text { - Field notes } \\
\text { - Material artefacts produced and/or used in teachers' } \\
\text { planned collaborative activity }\end{array}$ & $\checkmark$ & & $\checkmark$ & \\
\hline $\begin{array}{l}\text { - Classroom observations + semi-structured follow-up } \\
\text { interviews }\end{array}$ & $\checkmark$ & $\checkmark$ & $\checkmark$ & \\
\hline \multicolumn{5}{|c|}{ Ongoing implementation and revision of approach to collaborative inquiry } \\
\hline $\begin{array}{l}\text { - Video/audio recordings of collaborative design work } \\
\text { - Field notes } \\
\text { - Material artefacts produced and/or used in teachers' } \\
\text { planned collaborative activity }\end{array}$ & $\checkmark$ & & $\checkmark$ & \\
\hline $\begin{array}{l}\text { - Informal classroom observations and debriefing } \\
\text { conversations }\end{array}$ & $\checkmark$ & $\checkmark$ & & $\checkmark$ \\
\hline - Teachers' written reflections & & $\checkmark$ & $\checkmark$ & $\checkmark$ \\
\hline $\begin{array}{l}\text { Records of informal communications e.g. emails, } \\
\text { conversations with participants outside of scheduled } \\
\text { meetings }\end{array}$ & & $\checkmark$ & $\checkmark$ & $\checkmark$ \\
\hline $\begin{array}{l}\text { - Supplementary data sources - related to negotiated } \\
\text { focus and designed processes for the collaborative } \\
\text { inquiry activity, may include: video and/or audio } \\
\text { recordings of classroom teaching; classroom } \\
\text { observation and/or discussion notes, material } \\
\text { artefacts of teachers' and/or students' work }\end{array}$ & & & $\checkmark$ & $\checkmark$ \\
\hline \multicolumn{5}{|l|}{ Future planning and exit } \\
\hline $\begin{array}{l}\text { - Video/audio recordings of collaborative future } \\
\text { - } \text { planning work } \\
\text { - } \quad \text { Material notes } \\
\end{array}$ & $\checkmark$ & & $\checkmark$ & $\checkmark$ \\
\hline $\begin{array}{l}\text { - Classroom observations + semi-structured follow-up } \\
\text { interviews }\end{array}$ & $\checkmark$ & $\checkmark$ & & $\checkmark$ \\
\hline
\end{tabular}




\subsubsection{Data preparation and management}

Audio recordings of teacher interviews and inquiry-related conversations, including all group meetings, were transcribed by the researcher using NVivo software (initially version 10 and later version 11). Transcribing is an act of representation, that is "a transcript is a text that 're'-presents an event; it is not the event itself. Following this logic, what is re-presented is data constructed by a researcher for a particular purpose, not just talk written down” (Green, Franquiz, \& Dixon, 1997, p. 172). Thus decisions about what to include and exclude ascribe and give (or constrain) access to particular meanings, for instance, pauses, hesitation, or incomplete utterings convey messages that can influence interpretations of meaning when included or omitted from the written record. Intelligent verbatim transcripts (Hickley, n.d.) were prepared with the aim of providing an account that was both easily readable to support participant access for review and sufficiently detailed to capture the flow of the conversation (see Appendix 3.4 for the transcription protocols used). Video records of the teachers' conversations were then viewed alongside the transcripts and notes made of additional context-related and visual details such as gesture and facial expression where these suggested meanings not apparent in the audio transcript. Audio and video recordings of classroom observations and the researcher's field notes were used to develop detailed descriptions of classroom events.

\subsubsection{Data analysis}

The preparation of data for analysis involves interpretation and as such cannot be separated from the analysis itself (Charmaz, 2006). Design-based research involves interaction between the collection and analysis of data in that one informs the other iteratively and cyclically (Cobb et al., 2003), and so data analysis began in the field as data collection was on-going. Taking a view of teachers' professional learning as the generation of knowledge of practice, participants can be seen as engaging in oral inquiry through rich conversations (Cochran-Smith \& Lytle, 1999). Thus data analysis started in the field whereby interpretations were jointly constructed within group interactions. Between the three-weekly meetings of the inquiry group, I listened to audio recordings and made detailed notes. Noteworthy events and broad emergent themes were identified and used to inform subsequent discussions. In this way the 
analysis was made in collaboration with participants and used both to interpret events that had occurred and plan for future activity. Initial themes and patterns emerging in the data were able to be fed into subsequent design iterations for participants to use to refine the conjectures upon which the emergent design was based. The group's collaborative reflection on the data and our ongoing analysis served to sharpen my research focus and also to focus the teachers' attention on their practice decisions and actions, promoting adaptations to their practice in subsequent iterations of the inquiry.

The contingent nature of learning required that, on exit from the field, the data corpus be analysed retrospectively (Cobb et al., 2003). Using NVivo software as an aid to data management and analysis, a thematic approach was taken (Braun \& Clarke, 2006). Content analysis was used to identify broad themes arising from what was said in the interviews and during group meetings. This involved coding meaningful 'chunks' of speech ranging from parts of a sentence to several sentences in length, as the meaning unit for analysis (Graneheim \& Lundman, 2004).

As Saldana (2013) points out coding is an interpretive process involving both decoding, that is making meaning of the data, and encoding or assigning "a summative, salient, essence-capturing, and/or evocative attribute for a portion of ... data" (p. 3). For this study, coding began during the data preparation process, after the initial teacher interviews and two of the meetings with participants had been fully transcribed, and continued simultaneously with ongoing data preparation. Coding interview and group meeting transcripts involved ascribing both theoretically-derived and data-derived codes. Inductive codes were derived from the data using an opencoding approach (Corbin \& Strauss, 1990) involving recursively coding meaningful portions of data and writing analytic memos to gradually develop increasingly clearly defined codes and patterns of relationships among them in order to identify themes. Deductive codes were developed from the elements of the CHAT framework as illustrated in Figure 3.1. The CHAT framework was used as a conceptual tool to analyse the emerging themes in terms of the different elements of the activity system and any identified contradictions among them including the nature and impact of any actions taken to resolve them. 
CHAT was thus used as a framework to both design and analyse the structures and processes of the collaborative inquiry, and its associated tools. As such, it was particularly important to note and account for data that departed from any dominant patterns (Braun \& Clarke, 2006). As Saldana (2013) argues, the process of analysis can be seen as primarily aimed at identifying patterns and consistencies in the data, nevertheless any inconsistencies can, perhaps paradoxically, constitute the pattern. Furthermore, patterns must be identified in order for that which diverts from the pattern, including the contradictions specifically being examined in this study, to be apparent.

Throughout data preparation and coding processes, the writing of analytic memos enables researchers' ongoing reflection on their thinking in relation to participants, processes and phenomena of interest and thus acts as a heuristic to provoke further thinking (Saldana, 2013). As data for this study was transcribed and coded in NVivo, emerging thoughts and observations were recorded in memos as they occurred in line with Saldana's (2013) advice to immediately stop and write a memo "whenever anything related to and significant about the coding or analysis of the data comes to mind" (p. 42). Tesch's eight steps of coding (as cited in Creswell, 2014) provided a framework for coding the data, with particular attention being paid to the need to "[g]et a sense of the whole" (p. 198). In particular, at the completion of the data preparation stage, the data set was repeatedly read in its entirety, actively searching for additional meanings and patterns.

\subsubsection{Trustworthiness}

Related to data analysis, trustworthiness is an important concern of the research design because the integrity of the process for producing data determines the usefulness of any conclusions drawn from them (Cobb et al., 2003). Building on the work of Guba (1981), Shenton (2004) describes four categories for judging the trustworthiness of qualitative studies: credibility, concerning the extent to which a true picture of the phenomenon under scrutiny is presented; transferability, concerning the extent to which research findings can be applied to alternative contexts; dependability, concerning the extent to which the work could be repeated by another researcher; and confirmability, concerning the extent to which the findings 
represent the ideas and experiences of participants rather than the preferences and characteristics of the researcher.

Specific strategies used to enhance the trustworthiness of this research were drawn from Creswell (2014) and Shenton (2004) and included: using multiple sources of data from which to identify and justify themes; making findings available to participants for checking and feedback; using rich, thick descriptions in communicating research procedures and findings; making my role as researcher and inherent biases explicit, particularly through the use of a reflective journal; spending a prolonged time in the field including being on site regularly throughout the data gathering period; and explicitly communicating discrepant cases in the data. Attention has been paid to recording the criteria and evidence used for any inferences made (Cobb et al., 2003). Furthermore, iteration and collaboration inherent in design-based research contribute to the alignment of theory, design, practice and measurement over time and thus support the quality of research findings (Design-based Research Collective, 2003). Researching alongside practitioners as co-researchers extends the diversity of experience and expertise being drawn on and, as Cobb and colleagues (2003) argue, supports the development of varied interpretations of the data thus strengthening the analysis. Authenticity criteria outlined by Tobin and Ritchie (2012) and adopted in this study include ontological authenticity whereby it is expected that participants will change their ontologies and thus valuing difference and others' perspectives is an important consideration in designing and carrying out the research. Tobin and Ritchie also outline authenticity criteria related to beneficence including attending to issues of social justice and equity in relation to who benefits directly from the research, and protecting the agency of stakeholders other than the authors of the research to determine for themselves what is transferable to their own settings.

\subsection{Ethical considerations and risk management}

Qualitative research, by nature, is founded on values and ethics and these permeate decisions made throughout the research process (Baptiste, 2001; Denzin \& Lincoln, 2011). Participatory research situated in work contexts needs to account for multiple communities each with "its own epistemological and power agenda" (Gibbs, 
Costley, Armsby, \& Trakakis, 2007, p. 366). Creswell (2014) outlines an extensive range of ethical issues and strategies to address them which provided practical guidance for this project and a number of ethical considerations that were particularly pertinent to this study are described below. Of particular relevance to research in a New Zealand schooling context are the researcher's obligations with regard to the Treaty of Waitangi which is a founding document that positions New Zealand as a bicultural nation with indigenous Māori and non-Māori as equal partners (TomlinsJahnke \& Warren, 2011). There is thus a need to pay attention to "reciprocity, equity and benefit sharing" (Hudson \& Russell, 2009, p. 65). While such a stance is of particular importance when researching with Maori, it provides a strong foundation for ethical research more generally.

\subsubsection{Negotiating entry and developing research relationships}

An emerging research design was used which allowed space to navigate the research agenda with co-participants, but one which was realistically bounded to give the novice researcher the support of structured guidelines. In particular, the exploratory phase of the research provided sufficient time and opportunity to surface participants' shared and individual goals. It was necessary to outline the time and workload commitments involved and to reinforce that participation was voluntary and participants had the right to withdraw at any time up to the end of the initial data collection phase of the research. The challenge of extracting data pertaining to individuals meant that although participants could withdraw at any time however data that had been collected would remain part of the dataset.

Parr and Timperley (2015) comment on the importance of relationships and the need to "build trust [...] while challenging one another to affect improvement" (p. 35). The concept of whanaungatanga which refers to ideas of connectedness and relationships within a family-like structure (Bishop, 1999), provided a foundation for trust, reciprocity and productivity and required me as a researcher to personally invest in the research. The criterion that the school be within commuting distance both aimed to increase the likelihood that prior collegial connections with participants existed and supported an extended and on-going relationship beyond the data 
gathering activities of the research. Additionally, exiting the field involved negotiating 'next steps' in the teachers' on-going collaborative inquiry.

\subsubsection{Anonymity and confidentiality}

Anonymity and confidentiality are important ethical considerations and are concerned with protecting the privacy of research participants (Christians, 2005). Anonymity in the context of this research is problematic in that others within the research setting would know who the participants were. In terms of confidentiality, although participants discussed, observed and viewed records of each other's practice, it was important that specific contributions that were not otherwise made available to the group not be connected with individuals either in the context of research activities or any research outputs. To this end, specific details of events or utterances that occurred during interviews, classroom observations or one-to-one communications were not shared by the researcher in the larger group. Confidentiality was further addressed by assigning pseudonyms and obscuring identifying details in research accounts (Creswell, 2013), including by providing composite descriptions of the participating teachers and by making expectations of confidentiality explicit in participant information and during group interactions.

\subsection{Summary and an overview of the design process}

In summary, the theoretical and methodological underpinnings outlined in this chapter offer support for the research approaches taken in this study, aimed at capturing and understanding the complexity of teachers' work and predicated on an ontological stance of theorising and generating knowledge from experience and in practice. The methods employed are tools for exploring teachers' learning through collaborative inquiry and at the same time serve as pathways by setting in motion learning processes.

As stated at the beginning of this chapter, the overarching purpose of the project was for the researcher and a group of teachers to co-design and enact an approach to collaborative teacher inquiry. Chapters 1 to 3 have provided a theoretical and empirical foundation for the study. Chapters 4 to 6 that follow together trace the design process from the start to the end of the project and accordingly the findings 
discussed in Chapters 4 to 6 largely follow a chronological sequence of project activities. Table 3.2 below outlines the timeline and nature of project activities over the data gathering period during which the design for the teachers' collaborative inquiry was developed.

Table 3.2

Schedule of Project Activities

\begin{tabular}{|c|c|c|}
\hline Project stage & Key activity details/events & Who was involved \\
\hline $\begin{array}{l}\text { Initial data } \\
\text { gathering }\end{array}$ & $\begin{array}{l}\text { Initial teacher interviews and classroom observations } \\
\text { 9-17 June, } 2014 \\
\text { - Video- and audio-recorded observation of a mathematics } \\
\text { lesson in each classroom } \\
\text { - Individual semi-structured interview with each teacher }\end{array}$ & $\begin{array}{l}\text { Teachers: } \\
\text { - } \quad \text { Casey } \\
\text { - } \quad \text { Kris } \\
\text { - } \quad \text { Pat } \\
\text { - Sam } \\
\text { Interviewer/ } \\
\text { observer: } \\
\text { - } \quad \text { Raewyn }\end{array}$ \\
\hline \multirow[t]{2}{*}{$\begin{array}{l}\text { Setting up the } \\
\text { inquiry } \\
\text { (Design phase } \\
1 \text { : Problem } \\
\text { analysis and } \\
\text { solution } \\
\text { development) }\end{array}$} & $\begin{array}{l}\text { Group meeting \#1 - Monday 30/6/14 (Week 8, Term 2) } \\
\text { After school - approx. } 1 \text { hour } \\
\text { - Group kawa (meeting protocols) agreed } \\
\text { - Shared inquiry focus discussed - student talk identified } \\
\text { - Raewyn distributed a selection of readings (list) } \\
\text { - } \quad \text { Agenda for upcoming meeting to be held in the school } \\
\quad \text { holiday }\end{array}$ & $\begin{array}{l}\text { Casey } \\
\text { Kris } \\
\text { Pat } \\
\text { Sam } \\
\text { Raewyn }\end{array}$ \\
\hline & $\begin{array}{l}\text { Group meeting \#2 - Friday 18/7/14 } \\
\text { During school holidays - approximately } 3 \text { hours } \\
\text { - Reading (Anthony and Walshaw, 2007, pp. 72-81) and } \\
\text { engaging in a structured discussion - student talk in } \\
\text { mathematics } \\
\text { - Exploring teachers' perceptions of mathematics teaching I } \\
\text { learning with student talk as the object - using CHAT as a } \\
\text { framework } \\
\text { - Identifying the use of 'talk moves' (Chapin \& O'Connor, } \\
\text { 2007) as a specific aspect of teachers' practice to be } \\
\text { developed } \\
\text { - Teachers agree to video mathematics lessons and select } \\
\text { excerpts to share at future group meetings }\end{array}$ & $\begin{array}{l}\text { Casey } \\
\text { Kris } \\
\text { Pat } \\
\text { Sam } \\
\text { Dale } \\
\text { Raewyn }\end{array}$ \\
\hline $\begin{array}{l}\text { Sharing video } \\
\text { as a window } \\
\text { into teachers' } \\
\text { classroom } \\
\text { practice } \\
\text { (Design phase } \\
\text { 1: Testing and } \\
\text { refinement; } \\
\text { Reflection) }\end{array}$ & $\begin{array}{l}\text { Group meeting \#3 - Monday } 4 / 8 / 14 \text { (Week 2, Term } 3 \text { ) } \\
\text { After school - approximately } 1 \text { hour and } 40 \text { minutes } \\
\text { - 'Round robin' sharing - what has been happening in } \\
\text { - } \quad \text { Inthematheduction classrooms? } \\
\text { - Sharing of classroom video excerpts for group discussion } \\
\text { (Sam and Pat) } \\
\text { - Agreement for Raewyn to observe or co-teach and reflect } \\
\text { with teachers prior to next meeting }\end{array}$ & $\begin{array}{l}\text { Casey } \\
\text { Kris } \\
\text { Pat } \\
\text { Sam } \\
\text { Dale } \\
\text { Raewyn }\end{array}$ \\
\hline
\end{tabular}




\begin{tabular}{|c|c|c|}
\hline $\begin{array}{l}\text { Inception of } \\
\text { co-teaching } \\
\text { innovation } \\
\text { (Design phase } \\
\text { 2: Problem } \\
\text { analysis and } \\
\text { solution } \\
\text { development) }\end{array}$ & $\begin{array}{l}\text { Group meeting \#4 - Monday } 25 / 8 / 14 \text { (Week } 5 \text {, Term } 3 \text { ) } \\
\text { After school - approximately } 1 \text { hour and } 5 \text { minutes } \\
\text { - 'What's on top?' - sharing a 'wow moment' including Pat } \\
\text { - describing co-teaching with Raewyn } \\
\text { - Sharing of classroom video excerpt for group discussion } \\
\text { (Casey) }\end{array}$ & $\begin{array}{l}\text { Casey } \\
\text { Kris } \\
\text { Pat } \\
\text { Raewyn }\end{array}$ \\
\hline \multirow{3}{*}{$\begin{array}{l}\text { Enacting and } \\
\text { reflecting on } \\
\text { co-teaching as } \\
\text { a feature of } \\
\text { the teachers' } \\
\text { collaborative } \\
\text { inquiry } \\
\text { (Design phase } \\
2: \text { Testing and } \\
\text { refinement; } \\
\text { reflection) }\end{array}$} & $\begin{array}{l}\text { Group meeting \#5 - Monday 15/9/14 (Week 8, Term 3) } \\
\text { After school - approx. } 1 \text { hour and } 20 \text { minutes } \\
\text { - Sharing a video excerpt from a co-taught lesson (Pat and } \\
\text { Kris) } \\
\text { - Defining co-teaching - initiated by Kris } \\
\text { - Planning for Casey and Pat to co-teach }\end{array}$ & $\begin{array}{l}\text { Casey } \\
\text { Kris } \\
\text { Pat } \\
\text { Raewyn }\end{array}$ \\
\hline & $\begin{array}{l}\text { Group meeting \#6 - Monday 20/10/14 (Week 2, Term 4) } \\
\text { After school - approx. } 1 \text { hour and } 20 \text { minutes } \\
\text { - } \quad \text { Reflecting on co-teaching experiences } \\
\text { - Discussing transcript from Group meeting \#5 } \\
\text { - Planning for a second round of co-teaching in pairs }\end{array}$ & $\begin{array}{l}\text { Casey } \\
\text { Kris } \\
\text { Pat } \\
\text { Raewyn }\end{array}$ \\
\hline & $\begin{array}{l}\text { Group meeting \#7 - Monday } 1 / 12 / 14 \text { (Week } 8 \text {, Term 4) } \\
\text { After school - approx. } 1 \text { hour and } 12 \text { minutes } \\
\text { - Reflecting on co-teaching experiences } \\
\text { - Sharing a video excerpt from a co-taught lesson (Pat and } \\
\quad \text { Kris) } \\
\text { - Future planning - including considering a proposal to apply } \\
\quad \text { for funding to extend the project }\end{array}$ & $\begin{array}{l}\text { Casey } \\
\text { Kris } \\
\text { Pat } \\
\text { Raewyn }\end{array}$ \\
\hline $\begin{array}{l}\text { Final data } \\
\text { gathering }\end{array}$ & $\begin{array}{l}\text { Final teacher interviews and classroom observations } \\
27 \text { November - } 5 \text { December, } 2014 \\
\text { - Video- and audio-recorded observation of a mathematics } \\
\text { lesson in each classroom } \\
\text { - Individual semi-structured interview with each teacher }\end{array}$ & $\begin{array}{l}\text { Teachers: } \\
\text { - Casey } \\
\text { - Kris } \\
\text { - Pat } \\
\text { Interviewer/ } \\
\text { observer: } \\
\text { Raewyn }\end{array}$ \\
\hline
\end{tabular}

There is some crossover between the activities outlined in the three chapters that follow whereby the co-teaching idea, which is central to the final design product, first emerged and began to be developed. At the same time, the teachers' activity remaining largely focused on recording and sharing video from their individual classroom practice. Later, the teachers incorporated the use of video into their coteaching inquiry activity, adding to the blurred lines that delineated the two design phases. As such, the findings outlined in the following two chapters trace the iterative process of refining aspects of the teachers' collaborative inquiry approach, including the ongoing process of developing shared understandings of, and solutions for, 
problems of practice; productive arrangements, processes and tools for the teachers' work together; and the principles underpinning the designed collaborative inquiry approach. 


\section{Chapter 4 Setting the scene: Collaboration in mathematics teaching | learning prior to the start of the project}

This chapter provides a starting point for understanding how the design for teachers' collaborative inquiry developed over the period of the study. It outlines how the teachers described their opportunities for, and experiences of, collaboration in their mathematics teaching | learning work prior to the beginning of the study. It draws on data from initial interviews with the teachers and presents findings related to teachers' prior experiences of collaboration in their work. These findings then informed subsequent project activities.

\subsection{Limited sharing of mathematics teaching | learning}

Data from interviews at the start of the project suggested that collaborating with colleagues was a normal part of practice for these teachers. The teachers' prior experiences of collaborating with their colleagues were largely positive and productive. Despite seeing collaboration as involving extra work, all three teachers described working with colleagues as an arrangement that was conducive to their own learning and the learning of their students. Casey commented:

There's I have to say extra work but ... I don't see it as a negative because I see it as learning for me and it's having to think in a sort of concise way of what the needs are so hopefully as a result the pupil concerned will make progress. [C-Int\#1]

Similarly, Pat described how having colleagues with different experiences and expertise on hand to bounce ideas around with could:

Bring you out of your comfort zone and ... it's really helpful for the students as well because ... not everyone learns the same way and so you have to look for different ways [to teach]. [P-Int\#l]

The teachers saw collaboration as a fundamentally reciprocal process whereby as contributors they also expected to benefit. For instance, Casey described how she willingly shared her expertise with others because:

I'm hoping they'll all collaborate with me ... you know all of us sharing it's not just me. [C-Int\#l] 
Although the teachers had positive and productive prior experiences of collaborating in their work, it appeared they rarely collaborated with colleagues in their mathematics teaching. This was despite a flexible curriculum and established practices in the school of team-wide and school-wide shared planning in a range of curriculum contexts. New Zealand's national curriculum document (Ministry of Education, 2007) specifies achievement objectives by learning area and student yearlevel, and provides the flexibility for individual schools to design local curricula aligned with these. Waterview School's local curriculum included a common programme overview for mathematics teaching whereby all classes focused on the same strand of the curriculum at the same time. This approach provided a common curriculum focus that potentially allowed for shared planning and professional learning at the team and school level, nevertheless, shared planning in mathematics teaching learning was limited:

What goes on in each and every single classroom is very different because apart from the informal conversation of "what are you doing?" there's not a structured time ... of planning [together]. [K-Int\#l]

Teaching teams might decide to have a shared focus on an aspect of the mathematics curriculum as part of each term's integrated school-wide student inquiry topic. For example, a topic involving food preparation might include a focus on measurement. However, it was unusual to specifically include mathematics activities in the detailed unit plans, and where mathematics was included the associated planning was at a relatively surface level:

We put mathematical concepts on our unit plan ... but we probably don't do it in the sense of a deep level. We'll go "here's the curriculum" and we'll drop it in there. We plan four activities that every class is gonna do but maths isn't one of those. [K-Int\#l]

Informal arrangements for teachers to collaboratively plan and teach mathematics appeared to be limited to occasional serendipitous opportunities to share ideas. For instance Casey, who had previously taught in a flexible space where she often combined classes with another teacher, described how this teaching arrangement involving high levels of collaboration did not fully extend to mathematics: 
We collaborated ... a lot more over our planning because we were together. That was great collaboration because we all had ideas that sort of fed off each other and kind of complemented each other, you know one was more details one was organiser, it kind of fell into place. We've missed it this year ... the togetherness ... cos teaching can be lonely. We certainly didn't do the maths together, we kept our maths and our reading separate because the children were different stages but we could discuss things. [C-Int\#1]

Generally, it appeared that teachers talking with colleagues about mathematics teaching | learning was relatively uncommon as highlighted by an event that appeared to generate an unusual level of interest from other teachers and their students. Kris' class had been working in groups to calculate the volume of topsoil needed to replenish school gardens. The class had constructed a cardboard model of a cubic metre and were using it outside to make sense of their measurements. This attracted the interest of students and teachers from other classes:

With the cubic metre there was general interest in what was happening so they [teachers and students from other classes] wanted to talk to me about it. [K-Int\#1]

To be engaging in mathematics teaching | learning outside the relative privacy of the classroom was unusual and this, with the obvious 'hands-on' nature of the task, had created some interest and sparked conversations with other teachers.

Although formal sharing of mathematics planning and informal conversations about mathematics practice were uncommon, there were some planned opportunities for teachers to share their classroom practice during weekly staff meetings. For these staff meetings, mathematics was only one of many possible foci and the schedule of meeting topics was determined by the principal in consultation with other school leaders. At the beginning of the year, approximately four months before the start of the project, Kris had become the designated lead teacher for mathematics. She was responsible for overseeing mathematics teaching | learning in the school and had taken over responsibility for planning and leading the mathematics-focused staff meetings. Previously, these meetings had often involved teachers sharing in 'round robin' fashion whereby each teacher had a turn at showing and talking about aspects of their mathematics teaching, with limited opportunity for teachers to interact and interrogate one another's practice. During the final group meeting, Casey recalled the 
staff meetings "when people report on their inquiry, some of those dreary things that we sit and listen to" [GM\#7] prompting laughter from the others in apparent agreement. Taking these previous experiences as a starting point, the following section outlines two recent mathematics-focused staff meetings that had provided opportunities for teachers to share their mathematics teaching | learning.

\subsection{Designing staff meetings to expand teachers' access to other's practice}

During the school term prior to the start of data gathering, Kris had planned and led two staff meetings in which teachers shared ideas for, and descriptions of, their classroom practice in mathematics. The focus for staff meetings at Waterview School was largely influenced by management priorities and Kris, as leader of mathematics, had the primary responsibility for identifying the focus for mathematicsfocused staff meetings. The meeting focus was informed by Kris' performance appraisal observations of teachers' mathematics lessons and considerations of the development needs she had identified. Kris' role gave her access to and responsibility for collecting and responding to evidence of teachers' classroom practice whereby she conducted observations in each classroom and then co-constructed feedback with each teacher. Records of the observations and the associated feedback were then provided to and discussed with the school's management team comprising the principal and other school leaders, and informed decisions about the professional learning needs of staff and associated foci for staff meetings.

In planning for the staff meetings, Kris made a number of explicit design decisions aimed at addressing some of the perceived limitations of previous staff meetings and promoting teacher collaboration. The following sections draw on the teachers' recollections of these staff meetings.

\subsubsection{Promoting a sense of shared purpose}

The focus of the first of the two staff meetings was on sharing details of intervention strategies teachers were using in their classrooms to enhance the learning of their 'target' students. These were students that the teachers had identified as requiring additional support to succeed in mathematics learning: 
The aim was to sharpen people's focus cos we do really well identifying our target students but since we've been doing that, which has been two years, the intervention kind of has just sat there for the whole year; it hasn't evolved it hasn't grown. [K-Int\#1]

Teachers were expected to reflect on the impacts of their intervention strategies on the target students' learning and adjust their teaching approaches where student learning improvements fell short of the teachers' goals:

[Teachers] were given the opportunity to stop think look at have they have they got those kids to where they should be or have they achieved what the intervention was cos actually you might need to sharpen your focus and move your need or move your intervention to address it better. [K-Int\#l]

During the meeting, Kris had pressed teachers to take a specific focus on the mathematical content their intervention was aiming to develop and explicitly connect this with what they knew about the identified students. She described using a 'honeycomb' exercise in which teachers identified an aspect of content to focus on, such as students' knowledge of number:

So number knowledge went in the middle and around the comb I put all of the needs that my target students had relating to number knowledge. It showed that they [teachers] knew the people [students] in their group and then on the back they chose one of those needs so it was again really focussed [K-Int\#1]

The teachers then 'speed-dated' whereby they rotated and had the opportunity to comment on each other's honeycombs. In planning the meeting, Kris had several explicit aims in mind, including to develop a sense of shared purpose and to create opportunities for unproductive practice to be challenged:

That sense of we're all in this together; we're all experienced teachers we should all be able to offer ideas, lend resources that type of thing and then to go "if it's not working don't keep doing it" but somebody else might have an idea of what has worked in their class [K-Int\#1]

During the two weeks following this meeting, the teachers were tasked with implementing one of the ideas that had emerged and then sharing their experience at a second staff meeting. Kris noted a sense of shared endeavour at the end of that first meeting:

It felt really good, it felt really we were on the same team, we were all kind of [encouraging] each other to do really well. [K-Int\#1] 
Casey suggested that sharing practice at staff meetings provided an opportunity to hear about others' practice. For her, this prompted future informal conversations with colleagues about resources and ideas that they might be interested in using in their own classrooms:

Hearing what other people have been doing has been interesting and I've certainly had follow-up conversations with a couple of staff about things that I could show them that I've got. [C-Int\#1]

Such conversations were focused on offering ideas and resources, often aligned with Casey's expertise in teaching English language learners, for example ideas of ways to build English language learners' vocabulary of mathematics terms.

\subsubsection{Structuring teachers' conversations}

An aim of the second meeting was to provide teachers with an opportunity to make their practice public in order that they could celebrate their successes:

They had a two-minute window at the next meeting to say what the need was, what the activity to support the need was, and any recommendations that they would make ... so it gave people that floor of sharing and celebrating. [K-Int\#l]

Kris highlighted the opportunity to celebrate success as particularly important:

[A teacher] was so excited to be sharing the progress of what her students had made from two weeks previous and kind of linking it all together. [K-Int\#1]

Having a limited timeframe for teachers to share was an explicit structure that had two distinct aims: to create excitement by promoting a sense of urgency; and to fairly distribute the time available by constraining teachers whose voices might otherwise dominate. Kris suggested that past staff meetings had been characterised by people "blowing their own trumpets" and "prattling on and on and on" and she assumed responsibility for the allocation of time, not fully trusting teachers to self-regulate. She saw this as being about respect:

Maybe because I don't like people prattling on and on and on and on about their own [work] because we'd all like that opportunity. I respect that. I don't do it so why do you, you know? [K-Int\#1] 


\subsubsection{Sharing expert knowledge across curriculum boundaries}

For the second meeting, the identified focus was strategies to develop students' mathematical language. There was an upcoming school-wide topic connected with the statistics strand in the curriculum and Kris saw this as involving a high level of content-specific language. The staff meeting was intended to link with a previous literacy-focused staff meeting on vocabulary development and a particular resource for the teacher learning at this meeting was the recognised expertise of Casey who was the teacher with responsibility for supporting EAL students' learning:

So by including her on it ... hopefully for people creating this picture of "actually what I'm doing in literacy I can do in maths or I can do my maths in literacy with the language" that type of thing, so that was really powerful. [K-Int\#1]

The contribution of Casey as EAL teacher was seen as extending the teachers' access to ideas and material resources for their classroom practice by way of providing links to online resources, for example. This was particularly aimed at resourcing teachers to respond to identified student needs:

She [Kris] asked me to do a bit on maths vocabulary because two of the teachers have vocabulary as a need for their maths target students. [C-Int\#1]

\subsubsection{Summary}

In planning these two staff meetings, Kris purposely employed strategies aimed at maximising the affordances of the activity for teacher learning. She explicitly structured the teachers' interactions and thinking, leveraged the resource of Casey's EAL expertise and made explicit connections among the teaching | learning of mathematics and other aspects of the teachers' work. The use of a graphic organiser, the honeycomb, was an explicit structure intended to support the teachers to focus their thinking on these particular aspects of their students' learning. This demonstrated an ethic of care for both the students and the mathematics which Anthony and Walshaw (2007) found to be characteristic of teachers who created productive mathematical experiences for diverse students. Kris saw the teachers' collaboration at these staff meetings as powerful in relation to her goals of establishing a sense of shared purpose and supporting teachers to challenge problematic teaching 
practices. Identified outcomes from the meetings included strengthening teachers' interpersonal relationships and their sense of shared responsibility for the learning of all students, alongside developing students' specific mathematics content knowledge and mathematical vocabulary.

Implicit in Kris' approach was the expectation that if changes in student outcomes are to be achieved, teachers would need to adapt their practices. Underlying such an expectation was an assumption that teaching is adaptive and practice is emergent and should be adjusted over time. Furthermore, Kris appears to believe that all children can experience improvements in their learning outcomes and the responsibility for achieving this rests with the teachers' practice. This is in contrast to a deficit view whereby teachers may attribute student achievement challenges as associated with student characteristics such as innate ability or constraining personal circumstances, and thus outside of teachers' ready influence. It can be seen in later sections how Kris' beliefs and the principles underlying her designed interactions for the staff meetings shaped the design of the teachers' collaborative activity going forward.

\subsection{Activity system 1: Sharing teaching ideas in staff meetings}

Sharing ideas for mathematics teaching | learning in staff meetings marked a starting point for considering the design of teachers' collaborative inquiry activity. Overall, the design process was fluid and was both informed by, and followed on from, participants' past and ongoing experiences in multiple contexts. Thus, it is important to make explicit a starting point for analysing the activity. This chapter has drawn on data from the initial teacher interviews and described the teachers' collaborative activity during the initial stages of the design process. In this section, mathematicsfocused staff meetings are presented as an activity system and in later sections this activity system is discussed in relation to the decisions made and actions taken as the group designed an approach to collaborative teacher inquiry.

Figure 4.1 on the following page depicts the teachers' sharing of practice at mathematics-focused staff meetings as an activity system. 


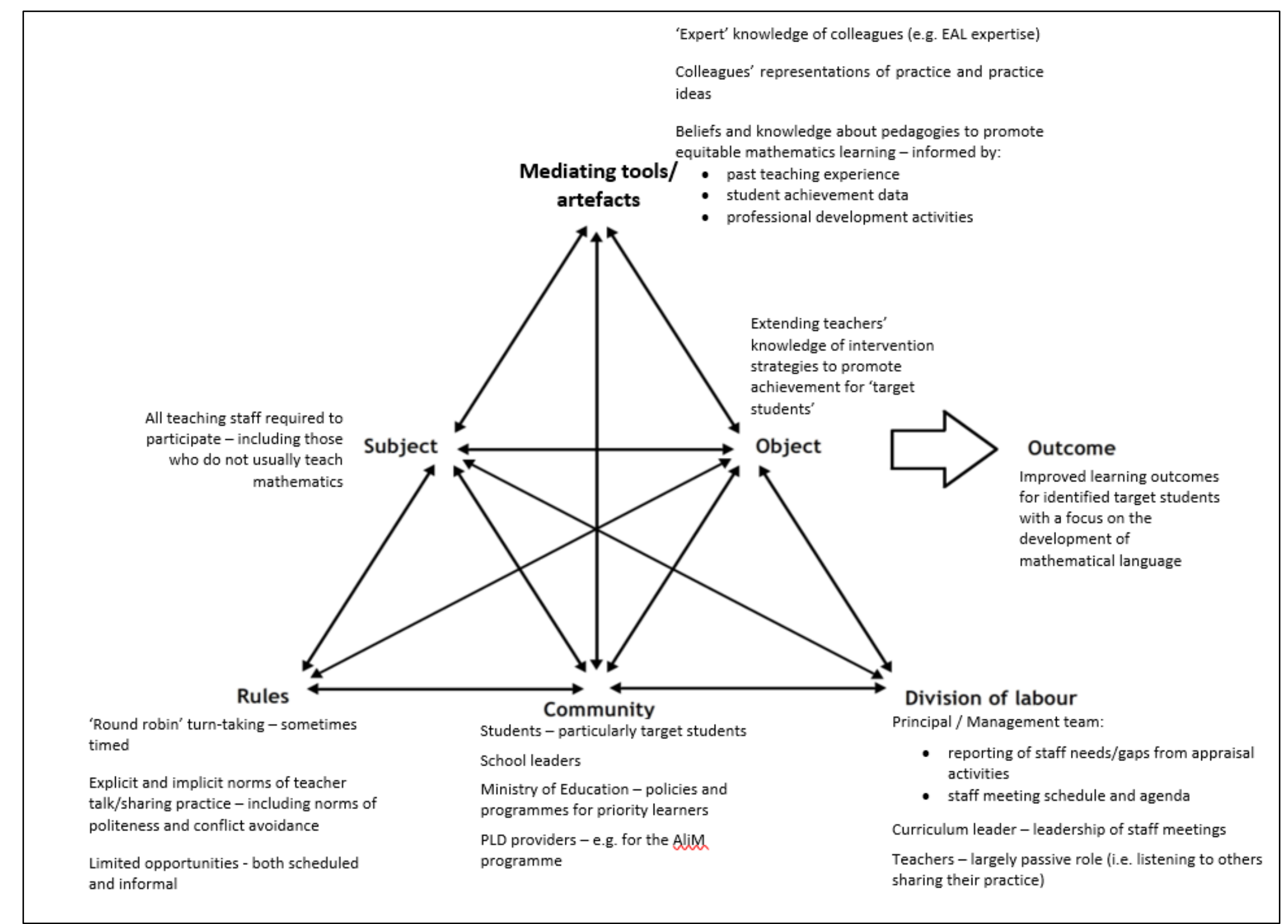

Figure 4.1. Activity system 1: Teachers' collaborative activity prior to the study involving sharing classroom practice at staff meetings. 
In relation to the two mathematics-focused staff meetings, the subjects of the activity were teachers of the school, including those who did not teach mathematics. The object was to devise, and later enact, in-class intervention strategies to support target students who had been identified as under achieving in mathematics, with the intended outcome of improved educational outcomes for the identified students. The primary tools were teachers' ideas for, and representations of, classroom strategies, including verbal descriptions of practice and classroom artefacts. The teachers' intervention strategies were informed by past teaching experience, student achievement data, and professional development activities such as coaching, attending courses and reading. In some cases, teachers had specific expertise to draw on such as Casey's knowledge of strategies to support EAL learners. Explicit hierarchies in the form of designated leadership and expert positions, defined the division of labour in the activity. For instance, as the lead-teacher of mathematics Kris enacted different roles and had considerably more autonomy in mathematics-related staff meetings than her colleagues. The social norms of teachers talking and sharing practice, such as norms of politeness and conflict-avoidance, and explicit discussion protocols such as timed turn-taking acted as rules, alongside decisions about the allocation of time for teachers to collaborate. The teachers' collaboration was situated within the community of teaching colleagues at one school and was associated with cultures related to their particular school and to the teaching profession more generally. The wider community included identified target students and their families who had an interest in their learning achievements, support staff such as teacher aides who may be involved in implementing support strategies in the classroom, and school leaders for whom student achievement was the ultimate responsibility. Casting the net wider still, the community also included the Ministry of Education who specified policies and provided resources for accelerating the achievements of priority learners in mathematics, and the PLD providers who delivered related programmes such as the Accelerating Learning in Mathematics (ALiM) project (Ministry of Education, n.d.-a). Ways of working and being for each of these community groups shaped the teachers' collaborative activity. In section 4.4 that follows, the activity system is used to illustrate contradictions that emerged as the teachers engaged in this collaborative activity. 


\subsection{Discussion: Contradictions within the activity of sharing ideas at staff meetings}

Prior to the study, sharing mathematics teaching | learning was infrequent for the teachers and occurred in two main contexts: professional development staff meetings and informal conversations. Where teachers did engage in shared activity, a number of contradictions emerged and these are represented in Figure 4.2 which is reproduced from page 97 . Dotted arrows have been added to show the inner contradictions that were apparent within the teachers' shared mathematics teaching | learning activity and these are labelled as (1, 2, 3, 4, and 5, on Figure 4.2 on the following page. The inner contradictions that emerged in the activity at this stage in the design process are then discussed in the sections that follow. 
'Expert' knowledge of colleagues (e.g. EAL expertise)

Colleagues' representations of practice and practice ideas

Beliefs and knowledge about pedagogies to promote equitable mathematics learning - informed by: participate - including those who do not usually teach mathematics

Rules

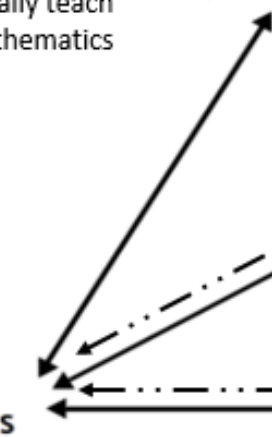

'Round robin' turn-taking - sometimes timed

Explicit and implicit norms of teacher talk/sharing practice - including norms of politeness and conflict avoidance

Limited opportunities - both scheduled and informal

Mediating tools/ - past teaching experience

artefacts $\quad$ student

- professional development activities

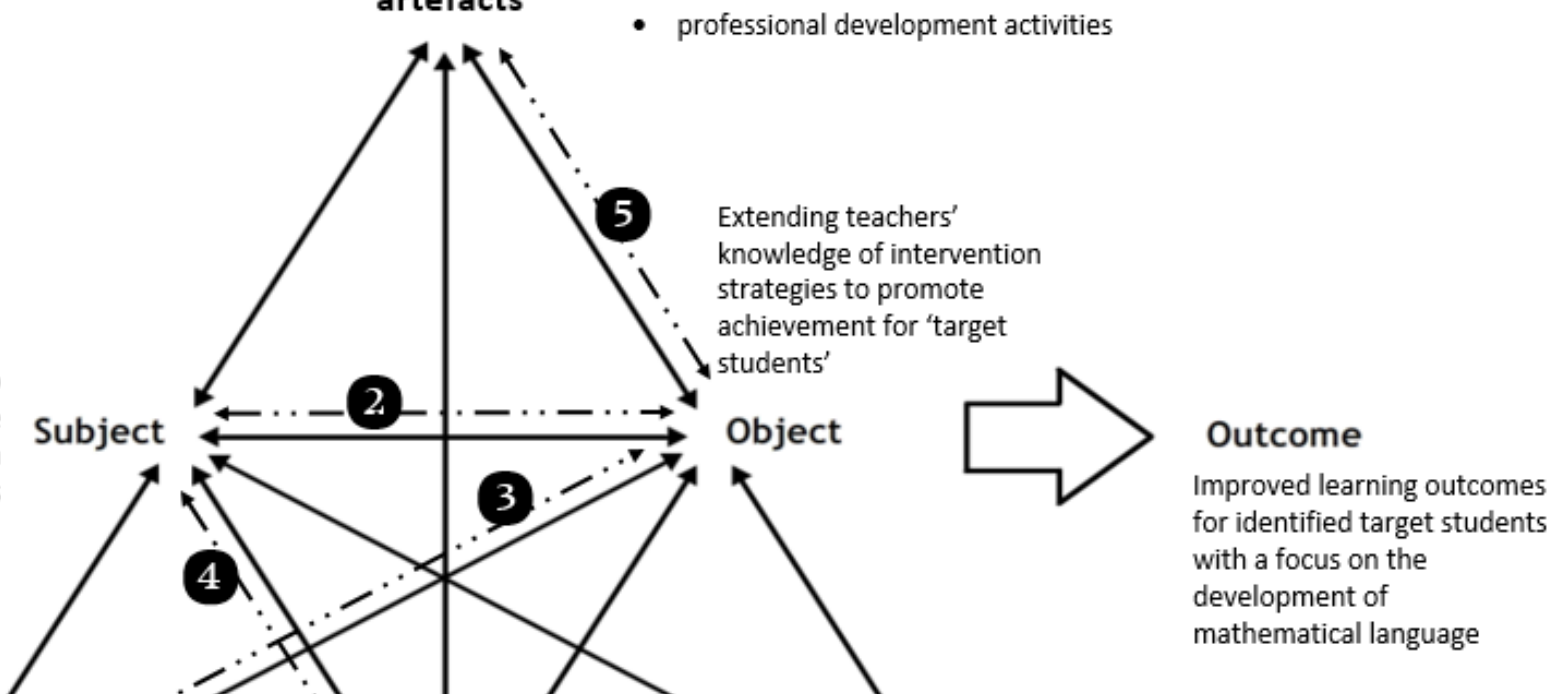

o

Community

Students - particularly target students

School leaders

Ministry of Education - policies and

programmes for priority learners

PLD providers - e.g. for the AliM

programme
Division of labour

Principal / Management team:

- reporting of staff needs/gaps from appraisal activities

- staff meeting schedule and agenda

Curriculum leader - leadership of staff meetings

Teachers - largely passive role (i.e. listening to others sharing their practice)

Figure 4.2. Contradictions within the teachers' collaborative activity prior to the study: Sharing classroom practice at staff meetings. 


\subsubsection{Grouping practices promote individualised mathematics teaching}

Contradiction 1 [division of labour $\leftrightarrow \rightarrow$ rules] relates to the individualisation of the teachers' work in mathematics in contrast to other aspects of their teaching. Outside of the learning area of mathematics, the teachers described structures that supported them to engage in shared planning and teaching, such as regularly planning integrated units of work as a teaching team. Implicit and explicit norms of sharing practice were apparent in many domains of the teachers' work. Despite experiencing collaboration in their teaching as positive and productive, it was rare for these teachers to share the work of mathematics teaching. For instance, Casey described how she had actively collaborated with another teacher in a shared classroom space however for mathematics and reading their teaching remained an individual activity. The relative privatisation of the teachers' mathematics teaching | learning appeared to be mediated by their beliefs about effective pedagogy, including for Casey the belief that students needed to be separated for instruction into groups based on levels of achievement. In New Zealand primary schools, the pedagogical practice of grouping children for instruction in mathematics is prevalent and largely unquestioned, premised on the notion that targeted instruction is required to meet students' individual needs (Higgins \& Eden, 2015). The prevalence of such grouping practices appeared to promote the individualisation of mathematics teaching. It was assumed that each group had specific instructional needs unique to them thereby bounding the teaching | learning activity to a narrow interaction between small groups of students and their teacher. It appeared that, in line with prevailing beliefs about small group instruction in mathematics, Casey and her teaching partners believed that each group of students had a specific set of unique teaching | learning needs which limited the possibilities for teachers to share their planning and teaching.

\subsubsection{Teachers' access to resources for expanding classroom practice}

On occasions when teachers shared aspects of their mathematics teaching practice in staff meetings, opportunities to learn from one another were constrained. Contradictions 2 [subject $\leftrightarrow \rightarrow$ object] and 3 [rules $\leftrightarrow \rightarrow$ object] pertain to the challenges teachers had accessing the practice ideas that their colleagues shared in 
staff meetings which in turn constrained the teachers' opportunities to expand their own repertoires of classroom practice. These challenges related to the ways and the extent to which teachers made their practice available to others in the staff meetings. Contradiction 2 pertains to the first of two staff meetings during which the teachers had a short time to present details of specific intervention strategies they were using in their classrooms. A focus for the meeting was on demonstrating the range of intervention strategies that had been implemented throughout the school. For the teachers, previous opportunities to share their practice appeared to be experienced as more of an accountability exercise than an opportunity to learn from one another, mediating both what teachers chose to share and how their colleagues engaged with what was shared. They saw themselves as passive members of an audience while their colleagues each took a turn to talk, sometimes at length, about classroom practice that was largely irrelevant to others.

Connected with contradiction 2 , contradiction 3 relates to the protocols for sharing practice ideas at staff meetings. As described above, time-limited turn-taking positioned the teachers as passive participants in the activity which largely involved listening to colleagues describe their practice. There was little, if any, opportunity to engage with and interrogate specific strategies, for instance to identify and discuss further those that might be used productively in a different classroom setting. In relation to contradictions 2 and 3, the teachers' actions towards the object, the ways in which they were able to extend their repertoires of intervention strategies for target students, were mediated by the accessibility of others' practice as a resource to inform their own. The teachers were primarily listening to others' stories of practice which Little (1990) observed is not only unlikely to impact classroom practice but also serves to reinforce the notion of teachers' work as individual whereby the stories were focused on what $I$ do in my classroom with my students. The teachers' actions were thus constrained in relation to when and what spaces for seeking support for mathematics were available to them in the context of these staff meetings. 


\subsubsection{The value of shared practice as a resource for teacher learning: What and}

\section{whose expertise is valued and why?}

Kris, as mathematics lead teacher, identified the focus for the staff meetings and teachers chose the specific details of their classroom practice to share. At the first of the two staff meetings, teachers identified an intervention strategy they were using to address the learning needs of identified target students and chose what details to share. Related to the challenge of teachers accessing one another's practice as a resource for their learning, contradictions 4 and 5 pertain to what teachers chose to share and the value of teachers' shared practice to support their colleagues' learning. Kris had a pivotal role in setting the agenda for staff meetings and thus had significant agency in terms of both bounding the content of what was shared and establishing some explicit protocols of how it was to be shared. She had specified an overarching focus on mathematical language because during her classroom observations she had identified this an aspect of teachers' practice that needed strengthening. Contradiction (4) [community $\leftrightarrow$ subjects] relates to a tension between the motives of the teachers in sharing their practice in the staff meetings and those of the school's management team. Kris' motives in having teachers share intervention strategies appeared to be aimed promoting self-reflection on the effectiveness of their individual practice. Thus, sharing classroom strategies with colleagues could be seen as an accountability mechanism whereby teachers were asked to articulate and justify their interventions in terms of the perceived impacts on their target students. Furthermore teachers, including Kris, were cautious about sharing teaching challenges because there was a risk of being judged negatively. As such, it was likely that teachers hid rather than surfaced any challenges they were experiencing in the classroom thereby constraining the opportunity to reflect on and work together to improve aspects of practice that were problematic.

Related to 4, contradiction 5 [tools $\leftrightarrow$ object] highlights a likely tension between the teachers' choice of what they would share, and the potential of the chosen intervention strategies for enhancing the development of students' mathematical language. One intended purpose of sharing at staff meetings was to extend each teachers' practice ideas however, paradoxically, the aspect of practice that 
teachers were sharing had been identified as particularly weak for some teachers. As such, the classroom examples that teachers shared were unlikely to be the most productive models of practice possible.

Furthermore, limited opportunities for the teachers to influence or interrogate the purpose of staff meetings mediated the learning goals of the activity. School leaders decided on staff meeting content and the teachers had little agency to specify the object of the staff meeting activity and most teachers were not directly involved in conversations to decide on staff meeting goals. As such there was no forum for those goals to be challenged, justified or agreed upon thus limiting the responsiveness of staff meetings to the development needs of each teacher and the range of perspectives that could be brought to the question of what the staff meetings were aiming to achieve. As Timperley and colleagues (2007) point out, shared goals are essential for teachers to engage in productive inquiry as this involves recognising and responding to discrepancies between what is intended and evidence of what is actually occurring. The staff meetings provided limited opportunity to address Alton-Lee's (2012) question "what educational outcomes are valued for our students and how are our students doing in relation to those outcomes?" (p. 17) which is aimed at teachers explicitly attending to the object of their shared activity, the identification of valued outcomes as shared goals to work towards, and the evidence that informs those goals. In the absence of shared goals teachers are more likely to lack professional vision, the capacity to notice those elements of practice that are particularly valued (Van Es \& Sherin, 2008), and assume that their own practice is not in need of change.

\subsection{Chapter summary}

This section has outlined the teachers' experiences of collaborating in mathematics teaching | learning prior to the start of the project which had been largely informal and infrequent. The teachers' collaboration was generally directed at the sharing of teaching ideas and materials. Often an offer or request for help would be made where one teacher was identified as having expertise and others saw a related need either in their students or their pedagogical practice. In relation to their classroom practice teachers were held responsible for the learning of their own 
students. Other teachers had an opportunity during the staff meeting to offer suggestions however, it was not expected that all teachers would necessarily do so and in this respect the teachers defined their own roles by the actions they took or didn't take. The group sharing took a 'show and tell' approach and teachers were actively involved when it was their turn to share and mostly passive otherwise. In pairs, teachers then had opportunities to contribute ideas and receive feedback in relation to one another's intervention strategies, presumably drawing on their experience and knowledge of practice to do so. Casey and Kris had additional roles which were connected with identified school-wide leadership positions they held. Casey was invited to lead a workshop focused on mathematical language at the start of the second staff meeting because of her particular expertise as the lead teacher of English as an additional language (EAL) and her considerable experience in this area. Recognition of expertise played a role in teachers seeking help informally from others and where teachers felt they had particular expertise they were prepared to offer ideas to others.

Prior to the start of the project, Kris had initiated changes to the way teachers engaged with one another's practice during staff professional development meetings focused on mathematics. She introduced explicit structures during the staff meeting aimed at strengthening teachers' interactions by limiting teacher passivity, focusing the thinking and sharing of the teachers on particular aspects of their practice, and enhancing opportunities to interact and contribute to one another's thinking about and planning for practice. Thus, Kris' actions in her lead role supported increased opportunities for teachers to expand their practice repertoires. Nevertheless, the teachers' access to one another's practice remained limited to what teachers chose to share and how they represented their practice in a context removed from the actual practice itself. Furthermore, the sharing of practice appeared to involve a simple exchange of ideas whereby robust evidence of effectiveness was unlikely to be considered. There remained a contradiction between the goals for teachers sharing their practice and the affordances of teachers' stories of practice as a resource for them to extend their own repertoires of practice ideas. 
In the following chapter, the project activities of the group are described in relation to the process of designing the teachers' collaborative inquiry approach from the starting point that has been described in this chapter. The focus is on key catalytic events that shaped the collaborative inquiry approach that emerged at the end of the project. 


\section{Chapter 5 Design phase 1: Negotiating the object and sharing video}

Having set the scene, attention turns to the process of designing and beginning to enact an approach to teachers' collaborative inquiry aimed at strengthening their mathematics teaching | learning. This chapter describes findings in relation to the design of the teachers' collaborative inquiry approach as the project got underway and focuses on the first of two distinct phases of design as illustrated in

Figure 5.1 below. The figure outlines the two design phases that emerged as the group enacted and refined their collaborative inquiry throughout the study and shows how findings in relation to each of the phases are organised in the chapters that follow.

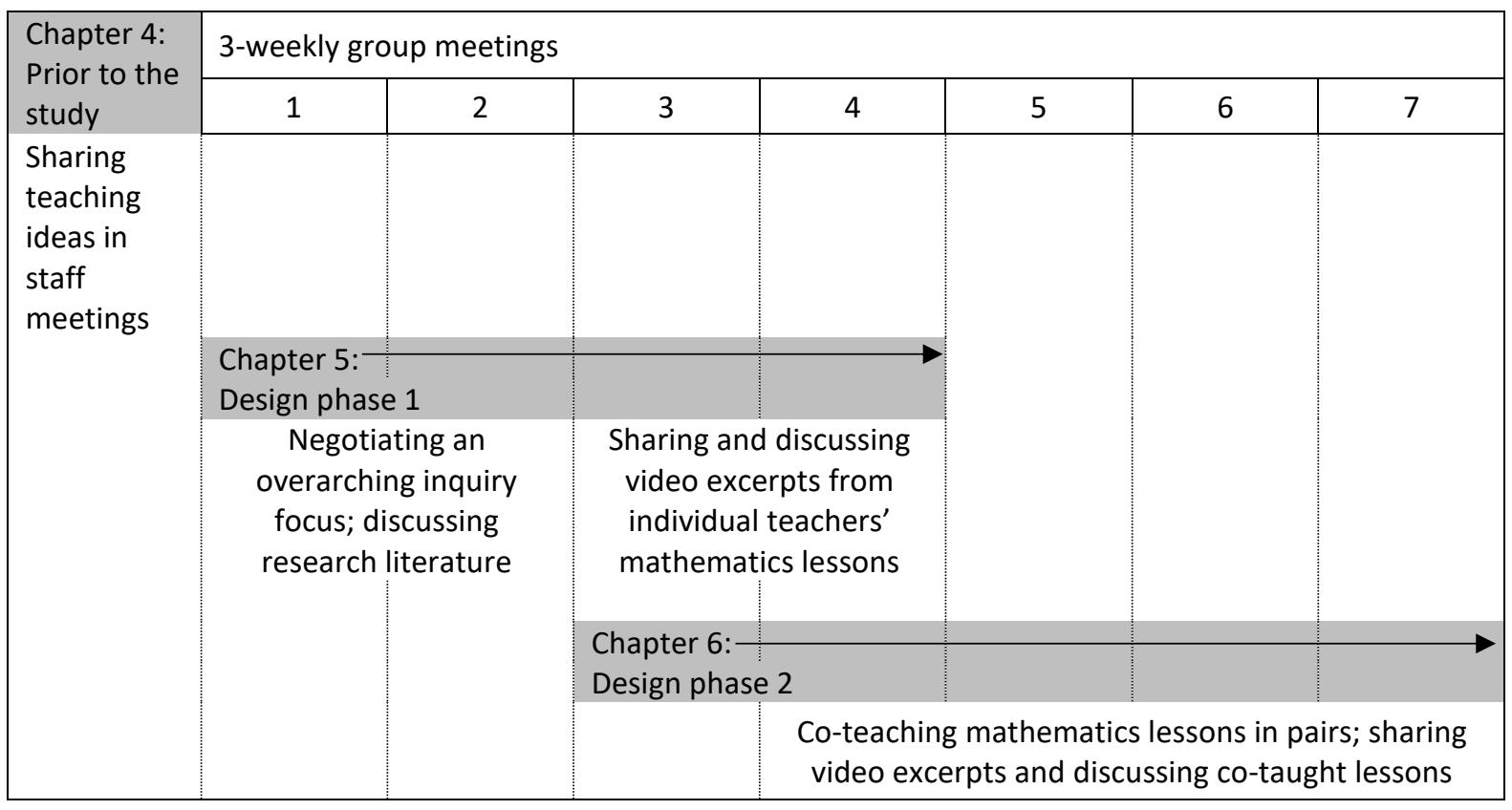

Figure 5.1. Overview of key design phases and collaborative inquiry activity.

During the first phase of the design, the teachers met three-weekly, initially to identify a focus for their inquiry with reference to research literature and then, from the third group meeting, to share related aspects of their practice with reference to self-chosen video excerpts from their classrooms. During phase 1, the teachers' collaborative inquiry approach developed from the starting point of sharing teaching 
ideas in staff meetings, to a collaborative inquiry approach that featured using classroom video as a tool for reflection on, and development of, teachers' practice. Drawing primarily on data from audio recordings of group meetings one to four, the emerging characteristics of the inquiry approach, and key events in the ongoing process of refining its design during this first phase, are identified and discussed. Firstly, early design principles and ways of working together are articulated, and the process for negotiating the group's shared inquiry focus is described, including how a structured discussion of research literature informed the teachers' thinking. A rationale and principles for sharing classroom video are identified and three instances of sharing and discussing video excerpts from participants' classrooms are described and analysed. The teachers' activity during this first design phase is then depicted as an activity system and contradictions that emerged in the teachers' collaborative inquiry activity are outlined and discussed.

In describing project activities, 'the group' refers to the group of participating teachers, and 'group meetings' refer to three-weekly scheduled project meetings that the teachers, myself and sometimes the principal attended as co-participants. As the design process began, discussions during the first two group meetings centred on purposes for, and approaches to, working together.

\subsection{Getting underway: Early design elements are researcher-specified}

In the early stages of the project I had a central role in planning and leading the group's first meetings and specifying aspects of our approach to working together. My involvement particularly influenced our early work together, which in turn influenced later events. This section outlines and provides some rationale for elements of the early design including how we worked together, to what ends, and why.

\subsubsection{An overview of early design principles}

At the outset, principles that underpinned the group's approach to collaborative inquiry were largely specified by me and were informed by research evidence pertaining to teacher learning, as well as by my previous experiences including as a participant in, and facilitator of, planned professional learning experiences. These principles included that the activity be research-informed, directed 
at collectively identified goals, appropriate for the local context, and have a primary focus on student learning. Literature outlined in Chapter 1 informed the initial design and, as previously articulated, an overarching goal of the project was to engage teachers in inquiry activity aimed at strengthening their capacity to engage diverse students in productive mathematics learning.

The primary site for teacher learning was expected to be the conversations that occurred during regular group meetings which would provide a forum for sharing and co-constructing ideas about classroom practice. In keeping with the overarching inquiry cycle I had considered it important that discussions about mathematics teaching | learning were informed by research evidence. I saw it as part of my role to provide access to appropriate literature. The research of scholars such as Anthony and Walshaw (2007), Hunter (2010), Carpenter, Fennema and Franke (1996), Boaler and Staples (2008) informed ideas about what constituted effective, equitable mathematics teaching | learning and this centred on discourse-oriented approaches to solving rich, cognitively challenging problems. I identified research articles, professional readings and policy documents that I considered pertinent to the group's work, including several that related to the theme of talk in mathematics that had emerged across the four classroom observations and interviews (see Appendix 5.1 for a list of selected literature made available to teachers as potential inquiry resources). It was not an expectation that the teachers read all or even any of these materials outside of our meetings, however they were made available and the teachers were invited to read any they were interested in.

\subsubsection{Establishing ways of working together}

The initial group meetings were largely planned and organised by me and at the beginning of the first group meeting, participation protocols were explicitly negotiated and mutually agreed upon. Explicitly negotiating group protocols was a move I had initiated in response to a previous experience of facilitating a professional development workshop for a group of teachers. The workshop had been challenging in that some teachers' actions had compromised others' opportunities to engage. A colleague had later pointed out that negotiating agreed group norms may have helped and I had realised that although this was an explicit aspect of my practice when 
working with children it had not previously occurred to me to do this when working with teachers. Thus, the development of group norms was introduced as a solution to a problem that had emerged in a previous context removed from this activity. Referred to by the group as our $k a w a^{2}$, the protocols were recorded on a chart which was then displayed and often referred to, particularly at the beginning of group meetings. The group's kawa specified expectations related to timeliness, confidentiality, equitable opportunity to contribute, and participants' dual roles as teachers and co-researchers. The kawa also included the importance of sharing food and of starting each meeting with a reflection, highlighting well-established norms for any gathering of people at Waterview School. The negotiation of a group kawa is introduced here as it influenced the design and enactment of the teachers' shared activity at several stages throughout the duration of the project. The negotiation of the kawa is discussed further in section 6.8.1.

\subsection{Negotiating a shared inquiry focus}

Much of the activity during the first two group meetings centred on identifying and analysing a shared focus for the teachers' inquiry and was largely focused on the problem analysis phase of the inquiry cycle. The first group meeting was held after school and was aimed at developing some preliminary ideas about the nature and purpose of our work together, including eliciting ideas for an overarching inquiry focus. The second meeting was held during school holidays and at three hours duration was the longest of the project. During this second meeting, the inquiry focus was discussed in more detailed with reference to teachers' current classroom practice and to a selected reading. The group's initial approach to collaborating in their inquiry into mathematics teaching | learning was agreed upon. This section outlines data relating to the negotiation of a focus for the teachers' collaborative inquiry activity over the first two meetings.

2 Kawa usually refers to the protocols of the marae (Keane, 2013). The term's use here is not presumed to reflect the rich cultural understandings of the notion of kawa for Māori from whom the term has been borrowed. 


\subsubsection{A focus on student talk in mathematics}

In keeping with Alton-Lee's (2012) inquiry and knowledge building cycle, the question "what educational outcomes are valued for our students and how are our students doing in relation to those outcomes?" was inherent in the teachers' negotiation of a shared focus for their inquiry (see Figure 3.3). I had originally intended the focus to be on mathematics teaching | learning of Pasifika students for whom the school had specified targets in line with the government's national standards reporting requirements. However, although this was not explicitly discussed, the teachers maintained their previously-established focus on the group they referred to as 'target' students who were identified according to learning needs rather than by cultural identity.

During the first group meeting, when I prompted the teachers to think about a possible inquiry focus, the importance of student talk in mathematics was raised by Kris:

I was thinking talk.... kids being able to articulate- not even using the right words but having the confidence for them to speak and how do we ensure that we're getting the best out of our kids?... Talk underpins everything ... talking and articulating thinking. [K-GM\#1]

Talking about mathematics had emerged as a theme in data from interviews and classroom observations that had occurred prior to this first group meeting. For instance, when I had observed in classrooms, I noticed that each of the teachers had deliberately attended to the language demands of mathematics tasks. Pat had introduced vocabulary prior to teaching related mathematics content and the other three teachers had explicitly modelled or given feedback about the use of precise mathematical terms, for example making explicit the distinction between a cube and a square. I had noticed the teachers' explicit attention to mathematical language partly because I was surprised that this was such a consistent characteristic of each teacher's practice:

It's fascinating because when I had that chance to observe you in your classes ... talk was the thing that really struck me.... You all have really different approaches to student talk in the classroom and yet there were common patterns, for example about making language explicit, that really struck me. [R-GM\#1] 
The importance of developing consistent practices in each classroom appeared to be one of the drivers for focusing on talk.

During their second meeting, the group engaged in a structured discussion in two smaller groups, and then came back together to share their thoughts. Using activity theory as a framework to think about student talk in the context of mathematics classroom, Kris, Casey and Pat had been discussing student talk from the perspective of teachers, and Sam, Dale and myself had been discussing it from the perspective of students. Kris suggested:

One thing that is really important is to have a kind of universal language that's used ... so that if Casey's children come to me for maths one day, that I can still promote that student talk because they'd be used to me saying "well we are going to re-voice" or "we're going to repeat" or "we're going to".... That's a really important focus too, that we've got to be comfortable and have that really good understanding ourselves so that it can be beneficial to our community of learners, not just our class. [K-GM\#2]

The other group had shared a similar view to that of Kris' group above:

Sam raised that same sort of idea and linking it to your approach to literacy and consistencies across classrooms ... maybe engaging in this kind of collaborative inquiry helps build that as well because you're gonna be developing a language together and then, hopefully, in various ways that's going to be shared as well.... We put consistency up there around providing structures for talk. That idea of that explicitness that you have talked about but also raised the idea of there being consistencies across classrooms to facilitate the students as they transition [to a new class each year]. [R-GM\#2]

Both groups had suggested that co-constructing consistent teacher practices was a worthwhile goal for the group's work together. Developing consistent practices in relation to student talk was aimed both at avoiding the possibility of teachers' actions being at odds with one another and directed at competing objects, and at supporting students to work productively with different teachers.

\subsubsection{What teachers meant by 'student talk' in mathematics}

The teachers were generally in agreement about the importance of student talk in mathematics and our discussion during the first group meeting culminated in a general agreement that mathematics talk was a focus of interest for our inquiry. We 
resolved to discuss this in more depth at the second meeting which was to be held during an upcoming two-week school holiday break.

Student talk is a very broad idea but it might be something really useful to think about ... exploring in a bit more depth or with a bit more focus. [R-GM\#1]

Kris observed that people may have different perspectives and suggested that in preparation for the next meeting each person should take some time to consider what they meant by the notion:

I wondered too whether to get the ball rolling for that Friday if we were able to come with quite a clear idea of what maths talk is to ourselves so that we have a similar understanding cos what I might deem to be talk in maths might be not the same as what other people's are, and if we're heading down a talk road for example I don't wanna be heading off [laughs] one way and you guys go in the other. [K-GM\#1]

She appeared to recognise that naming student talk as a focus for the group's inquiry did not necessarily mean that there was a shared understanding of what it might mean for students to talk about mathematics, and that there was a need to clarify the focus in order for the teachers to be directing their activity at a common object.

During the first two group meetings, the teachers shared examples of student talk in their own mathematics classrooms. The range of examples suggested they each had different perspectives on the purposes of students talking in mathematics. For instance, Casey saw student talk as:

A way of measuring understanding ... being able to articulate what you actually mean so to convey that meaning also shows understanding. [C-GM\#1]

For Casey, student talk was a mode through which others could access and judge a student's mathematical understanding. Similarly, Pat saw student talk in mathematics as primarily focused on students explaining their mathematical understandings and, in connection with this, having access to the necessary mathematical language to do so:

We talked about language being very important ... I have a lot of boys at the moment who are good with numbers and have no idea how to apply it and no understanding what it actually means and if you asked them to explain it they wouldn't know how to. They'd be able to write it down and give you an answer but have no idea on how to explain it. [P-GM\#1] 
Pat appeared to see talk in mathematics as students being able to translate numerical processes into words. Sam described how even when students were able to articulate a process they had used to solve a problem they often described a learned procedure without necessarily understanding the mathematics involved in it:

They just couldn't articulate any of the strategies they had been taught ... they need to be able to explain how that process works and they still don't understand that you know. They say "oh you take three here and put three over here", they have no sense of what those numbers mean. [S-GM\#1]

Sam appeared to see student talk as primarily about explaining the steps of a mathematical procedure for someone else to follow:

They [students] can listen to someone else about how they got that idea but they don't know how they got that idea; they can listen to someone explain it and they can follow the steps of how they did it and they'll go "well do you understand how they did it?" and they're like "nah" because they don't seem to be able to think that way.... Sometimes kids can't see how someone else has got it because it just does not make sense to them how they did it ... like if [students] are explaining something they're kids who are very capable and do explain it very well, those kids who don't have that knowledge who are struggling can't follow it, they can follow the steps but they don't understand how it works. [S-GM\#2]

From this perspective, some students are positioned as "knowers" and "explainers" of mathematics and others as the recipients of that knowledge. Sam suggested that the explanations provided by "very capable" students may not be able to be followed or fully understood by those who are "struggling" due to their limited confidence:

I'm not saying that they can't be taught, my point was the confidence is something I notice about my kids that was mentioned in here that they just give up. [S-GM\#2]

Sam is referring here to an excerpt from Anthony and Walshaw (2007) that the group were reading and discussing during the second group meeting (see section 5.2.4 below).

\subsubsection{Challenges associated with student talk}

Talk in mathematics, particularly for identified target students, was typically viewed as problematic and the teachers raised several challenges for students in relation to talk in mathematics. These included lacking confidence to speak during 
mathematics classes, having limited mathematics vocabulary, difficulties understanding others' explanations, and insufficient prior knowledge or a limited range of strategies to contribute to discussions. Teachers also recounted how students who had appeared to understand what had been taught during a mathematics lesson could not then explain the mathematics in an assessment situation. For instance, despite the explicit attention to students' mathematical language, several of the teachers noted being surprised by the performance of their students on items in 'GloSS' tests (Ministry of Education, n.d.-b), an interview-based assessment tool used extensively in New Zealand primary schools. Sam recounted that:

Something I noticed with doing the GloSS testing is that quite a few of my kids ... were just completely relying on algorithms as opposed to actually being able to explain. They just couldn't articulate any of the strategies they had been taught. [S-GM\#1]

She described how students appeared to demonstrate an understanding of decimal numbers in a practical task where they could not previously explain their understanding during a GloSS interview:

They were actually all able to do it quite confidently and I was sitting there going "this is really interesting" because they couldn't do it in another context but ... they could completely understand it in [the practical task] and I was thinking "this is gonna be really hard for you from what I've noticed about the GloSS testing". [S-GM\#1]

Promoting student talk was seen by the teachers as an explicitly mathematical goal and how teachers responded to students' challenges with mathematics talk appeared to relate to their different perspectives on the purpose of talk in mathematics. For instance, Pat described how the difficulties that some of her students were experiencing with talk in mathematics illuminated gaps in their knowledge and she saw this as supporting her to better know her students:

It's also knowing where your student is at as well ... I know I'm having problems with a couple of my kids in my class who I assumed that they know this and I'm teaching them this ... it's almost like you're teaching them $\mathrm{D}$ and you expect them to know what $C$ is and you're teaching $D$ to get along but they're still stuck on $\mathrm{A}$ and they missed those steps and ... they still don't even understand what you've actually said before. [P-GM\#2] 
She was describing how gaps in her students' understandings of previously taught concepts were not apparent unless they had opportunities to explain their thinking.

\subsubsection{A teacher's role in student talk: "You're not there to pat their backs"}

What teachers saw as the purposes for talk in mathematics appeared to also shape how they saw their own role in students' talk. References to literature and the introduction of explicit conversation structures supported the group to focus their discussion on a teacher's role in relation to students' talk in mathematics. For instance, Sam recalled reading an article several years ago during a staff professional development meeting and she suggested that the kind of mathematics talk described in it could be a goal for this group:

I think being able to get them to the ideal stage of what that article was talking about would be brilliant.... These kids were talking about maths with each other without any help from the teacher and the patterns of how they spoke and it helped them to really unpack what they were doing. It was like teaching them the language of maths. [S-GM\#1]

She suggested that students talking "without any help from the teacher" might represent a worthwhile inquiry goal but also suggested that "teacher talk has to help don't we have to model?" Sam largely saw the teacher's role as offering accurate mathematical explanations for students:

I can be halfway through talking about something and then go "where was I going here?" and I've just completely misled all these children, and you can see their faces going "oh yeah, yeah" but they do that nod thing where they're like "yeah, yeah we understand you" [others agree] and you're like "ooh I hope you didn't". [S-GM\#1]

Sam raised the importance of teachers' content knowledge in their productive use of talk in mathematics, particularly in relation to anticipating and responding to students' misconceptions:

To actually practice what you might say so that you can give them the opportunity to discuss and get to an answer or a conjecture before you jump in too quickly to correct the error ... so I need to know about what common misconceptions there are and what sort of questions I could ask to prompt them to another understanding and I also need to know when actually there is nothing I can say that is going to make that move and when I need to say actually this is because of this. [S-GM\#2] 
Sam expressed a range of views of the teacher's role in students' mathematics talk from a central role as content expert and primary 'explainer', to a peripheral role as observer whereby students engage in conversations independently of the teacher, drawing on previously taught language and modelled talk.

At the second group meeting the group read and discussed a section entitled Mathematics teaching for diverse learners involves respectful exchange of ideas from Anthony and Walshaw's (2007) effective pedagogy in mathematics BES (pp. 72-81). I had chosen this reading because it synthesises research covering a range of aspects of the broader topic of mathematical talk with a focus on pedagogy that impacts positively on learning. In other words, the BES articulated research findings that made explicit links between teacher actions and student learning. Furthermore, this reading explicitly includes teachers among its intended audience and so it was considered accessible and relevant, and addressed the chosen focus with sufficient breadth and depth. Referring to the BES excerpt, Kris described how the reading reinforced her own recent shifts in thinking about the value of hearing and attending to students' ideas in mathematics:

That really challenged me from where I've been to where I've come from, and now having someone else kind of talking about valuing student ideas and what that actually means ... it wasn't that it was a new idea or anything but it was a challenge.... They'd said you're not there to pat their backs [noises of agreement from others] you know? And so that was a real shift in practice I think for me. [K-GM\#2]

Kris' focus here was on students' mathematical ideas whereas Pat and Dale appeared to share a different perspective on student talk, focusing more on the teachers' role in explicitly teaching students how to talk, including how to ask questions, in mathematics:

So the questioning, how to do it, cos you know it's one thing to say it but another thing to model that, and we [Dale and Pat] talked about using speaking frames and ... even perhaps having key words within it like place value ... so being really explicit with it. [P-GM\#2]

Pat seemed to be talking about the language that teachers might use with students, and students' understanding of that language: 
There's also the breakdown of their learning intention as well ... there's no point of writing it down when they have no understanding of what those words mean. [P-GM\#2]

In relation to the teacher's role in student talk, Casey raised a contradiction that had arisen for her when she had read an article that I had distributed during the first group meeting:

It says "'students ask one another for information, evaluate one another's ideas and monitor each other's work ... our teacher role has changed from giving information to facilitating students' learning'" (Anthony cited in Scanlan, 2013, p. 2) and I didn't actually understand what that meant. To me it was just rhetoric, education speak and I'm just thinking of my [target] students ... how are they going to be? [C-GM\#2]

What Casey was quoting here appeared to contradict her understanding of the teacher's role, particularly from the perspective of a deficit view of students whose achievements have not met expected levels. From this viewpoint, Casey believed that she had students who could not yet do complex mathematics and instead needed her direct instruction. She appeared to assume that some students would not be able to engage in the kind of mathematical discourse that was described in the BES excerpt.

\subsubsection{Structuring teachers' conversations expands and deepens thinking}

Building on Kris' approach to staff meeting conversations, and my own practice as a classroom teacher and professional learning facilitator, I provided explicit structures for some of the group's early interactions. In particular, the teachers' discussion of the BES excerpt was explicitly structured and this shaped the conversation and influenced the thinking that was generated. When introducing the BES reading during the second group meeting, I had suggested an approach that involved using two different coloured highlighter pens:

The idea would be to pick out say if it's in yellow things that are either strengths or current practice now for you in your classroom ... and the pink might be things that are new ideas, maybe different from what you do and maybe challenge your thinking and your practice or kind of spark some new thinking. [R-GM\#2]

This approach was aimed at surfacing some of the tacitly held beliefs underlying each teacher's classroom practice, and inviting the teachers to identify and engage with new 
and possibly contradictory ideas about the role of student talk in mathematics. Independent reading of the BES excerpt was followed by each person sharing with a partner what they had individually highlighted. I encouraged the teachers to think about the important aspects of student talk that they wanted to focus on promoting and why, particularly in relation to their knowledge of their students. After ten minutes of sharing in pairs, there was an extended 25-minute discussion of the article in the larger group during which Casey explained how a conversation with Kris had afforded her an opportunity to both connect with her own practice and envisage how she might extend it. As described in section 5.2.4 above, Kris had been talking about the challenge of learning how to really value students' ideas. Kris had made explicit connections among the reading, her classroom practice and previous professional learning opportunities as a participant in the Accelerated Learning in Mathematics (ALiM) project (Ministry of Education, n.d.-a). Casey had responded:

I think that's probably what we do in the juniors. We might say good boy or well done but a step further ... that's what Kris was explaining to me so it made sense and I asked how she did it. [C-GM\#2]

Identifying what teachers saw as challenges in their own practice in relation to the article they were reading had prompted a conversation whereby Kris' experience was made available as a resource for Casey's thinking about her own practice. In that way, an opportunity emerged for the two teachers to interrogate their own and each other's practice ideas.

In response to a point made in the reading, Sam suggested that students with a limited range of strategies are more inclined to lack the confidence to persevere with a challenging task:

What I notice about my students in my target group [is] they've only got a certain amount of strategies they can do in their head and then they just don't know what to do next ... whereas the other kids who do have a [few] more strategies are able to continue on and so it's that confidence to continue to take a risk and because they're not sitting on the edge or willing to push past the edge of their knowledge they're not building anymore. [S-GM\#2]

Casey challenged Sam's comment above saying:

That's where that sharing [comes in] so that they hear everyone else's ideas and you revoicing those ideas maybe broadens that. [C-GM\#2] 
Sam then countered Casey's point suggesting that less capable students are unable to understand the explanations given by their more capable peers and Kris responded, saying:

What's exciting when you do it at a whole class level, when you give the opportunity to rephrase what's been said, [is] that you get [student] and then you get someone who's a little bit lower who understands it and then someone a bit lower than them and that has this waterfall effect of that actually given the time the whole class can understand it because it's been digested so many different ways and different ways of speaking it so it is quite an exciting thing to happen. [K-GM\#2]

Here, Casey and Kris appeared to have quite different perspectives to Sam on the job that students' explanations were doing in the mathematics lesson. For Sam, a mathematical explanation was the articulation of a series of steps to follow in order to find a solution to a given problem. She appeared to believe that students who had deficits in their mathematical knowledge or who lacked confidence were not able to access the explanations of their more advanced peers. In contrast, Kris and Casey appeared to see students' explanations as providing multiple, scaffolded opportunities to access mathematical ideas and that making a student's mathematical explanation public was a useful resource for the learning of other students. Furthermore, this exchange also suggested a shift in Casey's view away from her earlier position of seeing the teacher's role as primarily that of explainer.

What these data show is that engaging with research-informed evidence and using an explicit protocol to shape the teachers' thinking and subsequent discussion, supported the teachers to surface and, importantly, to interrogate some of their beliefs and understandings in relation to their practice. This allowed the conversation to shift from a focus on productive mathematical talk as a valued outcome for students, to a focus on the object of the teachers' activity; that is the pedagogical practices that might promote the outcome. The research article served as a resource to expand the teachers' thinking about student talk, including the nature and purpose of mathematical practices such as explaining and justifying mathematical ideas. Working to make visible students' mathematical thinking represents an important and challenging goal for teachers (Anthony et al., 2014). The teachers' conversations connecting students' mathematical talk to teachers' pedagogical practice thus further 
opened their ideas about practice for the scrutiny of others. As Levine and Marcus (2010) observed in their study, explicit structures for their discussion supported teachers to surface and make public details of their practice. Furthermore, incorporating such structures appeared to illuminate and expand teachers' thinking whereby several contrasting views of the nature, importance and role of student talk were surfaced. There were several occasions where one teacher challenged an idea that was different from her own, including ideas from the reading and those shared by her colleagues. When such challenges were raised, further elaboration of the teacher's thinking was prompted.

\subsection{How to share the work of implementing new pedagogies}

As the group settled on the overarching teacher inquiry focus of promoting student talk in mathematics, discussion turned to how teachers could work together towards this object. As described previously, the group's activity was explicitly linked to the inquiry cycle and the process of designing an approach to collaborative teacher inquiry centred on the question of "How can we collaboratively promote our own learning to bridge the gap for our students?" (See Figure 3.3). The first two group meetings had provided an opportunity to articulate and refine aspects of the initial design that had been largely conceived by me prior to the start of our work together, and that had informed meeting agendas, the design of activities, and the selection of materials used in the early stages of the project. The first phase of designing the teachers' collaborative inquiry activity, and how the design was enacted, are elaborated on in this section.

In formulating initial design ideas, two key principles were drawn on that broadly underpin situated, inquiry-focused and adaptive approaches to teacher learning. Firstly, attention was given to opening teachers' practice up to scrutiny as a resource for all participants' learning. Secondly, student thinking was the intended focus for teachers' thinking about their practice. The design particularly drew on principles underlying Cognitively Guided Instruction (Carpenter et al., 1996) and Japanese Lesson Study (Lewis, Perry, \& Hurd, 2009) by making explicit an intended focus on student thinking rather than on teacher performance in reviewing and 
reflecting on classroom events. Attention to students' mathematical thinking supports teachers to extend and deepen their own mathematical understandings. Accordingly, a feature that emerged in the first phase of design was broadly similar to that of a video club in which teachers developed new understandings of classroom interactions through viewing and discussing classroom video (van Es \& Sherin, 2008). In our study, teachers volunteered to video-record a mathematics lesson, review the video recordings and self-select an excerpt for the group to reflect on at subsequent group meeting. This section outlines how the idea of sharing video emerged as an early design feature, and what protocols and principles were developed to guide the group discussion of classroom video clips.

\subsubsection{Introducing the idea of video-recording mathematics lessons}

Kris first suggested video-recording mathematics lessons during the second group meeting when the teachers were discussing how to attend to what they perceived as gaps in individual students' knowledge. Pat suggested working one-toone with a student who was struggling in a group situation:

Pat: You could start with that group and then let them have a go and then have him by your side, that's something I'm gonna be trying.

Kris: You could get him to video the lesson for you.

Kris' suggestion was not picked up for discussion at this time however, and Kris did not elaborate on what she specifically saw as the purpose of videoing a lesson. Nevertheless, she appeared to see video as a tool for supporting Pat to meet the identified needs of one of her target students. Video-recording mathematics practice as part of the teachers' collaborative inquiry activity was raised by me later in the meeting in relation to the idea of teachers trialling 'talk moves' to promote and orchestrate mathematical discussions in their classrooms (Chapin \& O'Connor, 2007). I wondered how the teachers might work together to introduce this new practice:

That sort of raises that questions of what does this collaborating look like ... and some of the elements that I thought could be part of a collaborative design could be about videoing your own practice ... and then selecting a couple of those episodes, selecting something that happens in your classroom as you're trying these strategies that you could share and could become our discussion the next time we got together. [R-GM\#2] 
During a turn in the conversation lasting over five minutes, I had outlined the reasons for suggesting using video excerpts, including articulating some of the underlying principles:

One of the things around the videoing is that it gives people a view into another classroom, and to really be able to sort of pull apart what's going on for those students in that classroom really sharpens teachers' perceptions of what's happening for students if the focus is on student thinking not on teacher performance. [R-GM\#2]

In contrast to my intended focus on students' thinking rather than teacher actions, Sam responded that sharing classroom videos for the group to discuss would be a useful source of feedback on her practice:

If you want to get something out of this experience of thinking about my practice and I want to know whether I'm actually doing good practice then I need to provide evidence of what my practice is or isn't. [S-GM\#2]

This perhaps reflects an implicit norm whereby teachers expected their classroom actions to be scrutinised to inform judgements about the adequacy of their instruction, for example in the context of classroom observations by school leaders as part of a performance appraisal process. In contrast, Kris saw video as providing access to multiple perspectives on one's own practice, saying "it's that whole thing of this is what I see but do you see what I see?" [K-GM\#2] Kris had previously discussed with the Dale, the principal, the idea of using video as an approach to teachers sharing classroom practice at staff meetings:

I've had a similar conversation with Dale ... we've talked about for the intervention feedback this time sharing or that they have to video themselves and analyse their video. [K-GM\#2]

It was not the usual practice for these teachers to video themselves teaching, nevertheless using video to support teachers' professional development was not an entirely new idea for the group and appeared to have authenticity in the context of the teachers' work.

\subsubsection{Developing guidelines for using classroom video}

Drawing on their past experiences of having classroom practice observed and scrutinised by colleagues, and of watching and critiquing video clips of other teachers' 
practice, the teachers suggested there needed to be explicit guidelines for the use of video in their work together:

I'm happy to have video recording as long as there are sort of like ground rules as in the purpose of actually recording and that we always keep that in mind ... and so the conversation that we do have is solely based on that not on anything else that may've happened. [P-GM\#2]

Pat, Sam and Casey had previously attended a series of professional development workshops in which video was shared and discussed. They recounted how they had not understood the purpose for viewing the clips, and how the discussion had often focused on the personal characteristics of the teacher. Pat saw being explicit about the purpose as important to protect teachers from a potentially negative experience:

Some of us just get a bit anxious about these things whereas if we're actually just saying this is what we're looking at and this is what we're trying to achieve. [P-GM\#2]

Pat later joked that she would video her 'teacher wait time' for thirty seconds and share that, perhaps further illustrating her anxiety about having video clips of her practice scrutinised. The teachers suggested that critiquing one another's practice needed to be done with care and this was reiterated when Casey described an instance of having her practice observed and critiqued by a professional development facilitator known to some of the teachers. Sam suggested that the facilitator was not adequately trained:

I don't think [facilitator] has actually been trained in doing that in a nice way and that's why I think it's such a traumatic experience for people because that could actually be a really good experience but it's not run right. [S-GM\#2]

Informed by their reflections on past experiences, the teachers were stating an important design principle for them, that of purposeful, learning-focused discussions of their practice that protected one another's emotional well-being. This aligned well with a research-informed principle of explicitly focusing on student thinking, rather than on the teacher, when viewing and discussing video excerpts. The opportunity for teachers to choose whether or not they would share videos, and having an explicit purpose and expected focus, together served to mitigate some of the negative emotions the teachers were anticipating. As Pat commented at the fifth group meeting 
after having shared several video excerpts with the group, "they just seem to get easier and easier."

\subsection{Implementing new pedagogies and reflecting on classroom video}

At the end of the second group meeting, the agreed object for the teachers' inquiry activity was promoting productive student talk in mathematics. A particular focus was on teachers explicitly aiming to implement talk moves, a set of instructional teacher moves comprising 'revoicing' or restating students' contributions to mathematics discussions, asking students to repeat another student's idea, eliciting student reasoning by asking students if they agree with a peer's thinking and why, asking students to elaborate or 'add on' to another's thinking, and using wait time (Chapin \& O'Connor, 2007). Over the six-week period covering group meetings three and four, each of the four teachers recorded video of their mathematics teaching and Sam, Pat and Casey each shared selected excerpts for discussion with the group. Sharing was voluntary, and it was intended that teachers self-select excerpts from their own videos to share, with the expectation that teachers would make purposeful selections with their own and their colleagues' learning in mind:

Watch your own video of what happens for kids in your classroom and select something that you think the group could learn from ... something that has that focus on student talk and in this case we're talking about trying out talk moves ... cos this is about our learning, it's not about feedback ... but it's about using each other's and our own practice as a resource for each other's learning. [R-GM\#2]

The sections that follow draw on conversations during group meetings in which teachers shared self-selected excerpts from video recorded mathematics lessons and these were viewed and discussed by the group. Each section includes an example of one teacher sharing a video excerpt from their classroom which is then discussed by the group. Each example is followed by an analysis of the themes emerging from the group's conversation about the video excerpt.

\subsubsection{Sam's lesson: Sharing classroom video}

Sam volunteered to be the first to share video from a mathematics lesson she had taught, and she had selected two excerpts to share during the third group 
meeting. They were both from a lesson in which Sam was working with a group of her identified target students who were solving a problem involving finding the number of dots on four dominoes missing from a domino set. A large screen in the classroom showed an image of the incomplete set of dominoes for the students to refer to.

Example 5.4(A) Reflecting on "completely doing the wrong thing"

When Sam was introducing the two video excerpts, she recalled a point in the lesson where she felt there had been a missed opportunity to use talk moves to extend her students' thinking:

I'm working with my target group. We're working on a problem together and I was aiming to reframe and get them to practice trying to use some talk moves with them ... and then the second one if we get to it is less than five seconds and it's just me completely doing the wrong thing [laughs] which I thought was a really good one because as soon as I thought about it afterwards it was like "why did you do that?" and I thought it would be a good example of the opportunity that I could've used ... those [talk moves] but I didn't ... and it wasn't until I was lying in bed thinking about what I'd show you guys that I was like "oh yeah that was really stupid".

After showing the clip to the group, Sam reiterated the actions she had taken in the lesson and further described what she should have done and why:

I just get up and say "oh you've got lots of different answers let's try and do it with multiplication" [laughter] when I should've just said "can someone show us?"... When I did it I was like "ahhh that was so silly." ... What cracked me up the most was like the whole idea was for them to have different ideas and I went "once you've all got ideas I'm gonna show you" [laughs].

The laughter of the group appeared to be empathetic and Kris and Casey's comments suggested that Sam's experience was familiar to them:

Kris: But that's that desperation that sometimes when you have that hidden agenda when you're teaching like that you have a plan that you want to get to a certain point and you wanna get there and you don't, you're not gonna stop.

Casey: You want them to know it.

Reflecting on the lesson and describing what she would do differently next time, Sam articulated the mathematical practices she wanted students to be engaging in: 


\begin{tabular}{|c|c|}
\hline $\begin{array}{l}\text { I woul } \\
\text { do the } \\
\text { answe }\end{array}$ & $\begin{array}{l}\text { Id get them to present how they did it because it's then when you can } \\
\text { e whole challenging, reasoning their answer, "I don't agree with your } \\
\text { r", or "I think this". }\end{array}$ \\
\hline $\begin{array}{l}\text { Getting stude } \\
\text { kind of conve } \\
\text { appeared to b } \\
\text { first place anc } \\
\text { the main opp }\end{array}$ & $\begin{array}{l}\text { ents to a point in the lesson where the students could engage in this } \\
\text { ersation appeared to be a central goal for Sam. However, the students } \\
\text { se having difficulty understanding how to approach the problem in the } \\
\text { d were thus struggling to get to the "big conversation" where Sam sees } \\
\text { ortunity for learning: }\end{array}$ \\
\hline $\begin{array}{l}\text { I need } \\
\text { them } t \\
\text { minut } \\
\text { enoug } \\
\text { which } \\
\text { spendi } \\
\text { There }\end{array}$ & $\begin{array}{l}\text { to move them to that part of the conversation quicker, I need to move } \\
\text { to having made up an idea of what it's gonna be within the first three } \\
\text { es as opposed to I got there at the eighth minute which doesn't give me } \\
\text { h time to have that big conversation which is the most important, } \\
\text { actually happened within two minutes but should've been probably } \\
\text { ing the most of the time about it and we could've easily have done that. } \\
\text { was no reason why we couldn't have got there faster. }\end{array}$ \\
\hline When Dale a & sked about what learning was intended for the students in this task \\
\hline $\begin{array}{l}\text { Sam did not a } \\
\begin{array}{l}\text { What } \\
\text { do and } \\
\text { what it } \\
\text { with e }\end{array}\end{array}$ & $\begin{array}{l}\text { articulate a mathematical goal for the students but explained: } \\
\text { they are learning to do is to clarify what the problem is asking them to } \\
\text { d then come up with a conjecture to solve the problem ... so understand } \\
\text { th says and then find an answer and then be able to prove your answer } \\
\text { vidence. }\end{array}$ \\
\hline $\begin{array}{l}\text { For this task, } \\
\text { counting the }\end{array}$ & $\begin{array}{l}\text { she had not anticipated that several students would use a strategy of } \\
\text { dots one-by-one and this was picked up by Dale: }\end{array}$ \\
\hline Dale: & $\begin{array}{l}\text { So you were surprised by their responses, those three who were } \\
\text { counting the pictures? }\end{array}$ \\
\hline Sam: & $\begin{array}{l}\text { I was like "oh my God" [laughing] and I sort of thought maybe you } \\
\text { could skip count them ... the one to one I was just like "oh my God } \\
\text { we're gonna be here forever" [others making noises of agreement] and } \\
\text { that wasn't the main aim, the main aim of the problem was actually to } \\
\text { figure out what was missing not how many but ... they needed to know } \\
\text { how many were there in order for them to answer the problem. }\end{array}$ \\
\hline $\begin{array}{l}\text { On reflection, } \\
\text { successfully w } \\
\text { they had solve }\end{array}$ & $\begin{array}{l}\text {, Sam recognised that she could have asked the students who had } \\
\text { worked out how many dots there were to explain it to the others how } \\
\text { red it, instead of providing her own explanation: }\end{array}$ \\
\hline
\end{tabular}

I would get them to present how they did it because it's then when you can do the whole challenging, reasoning their answer, "I don't agree with your answer", or "I think this".

Getting students to a point in the lesson where the students could engage in this kind of conversation appeared to be a central goal for Sam. However, the students appeared to be having difficulty understanding how to approach the problem in the the main opportunity for learning:

I need to move them to that part of the conversation quicker, I need to move them to having made up an idea of what it's gonna be within the first three minutes as opposed to I got there at the eighth minute which doesn't give me enough time to have that big conversation which is the most important, which actually happened within two minutes but should've been probably spending the most of the time about it and we could've easily have done that. There was no reason why we couldn't have got there faster. do and then come up with a conjecture to solve the problem ... so understand what it says and then find an answer and then be able to prove your answer with evidence.

counting the dots one-by-one and this was picked up by Dale:

Dale: So you were surprised by their responses, those three who were counting the pictures?

I was like "oh my God" [laughing] and I sort of thought maybe you could skip count them ... the one to one I was just like "oh my God we're gonna be here forever" [others making noises of agreement] and that wasn't the main aim, the main aim of the problem was actually to figure out what was missing not how many but ... they needed to know how many were there in order for them to answer the problem.

On reflection, Sam recognised that she could have asked the students who had successfully worked out how many dots there were to explain it to the others how they had solved it, instead of providing her own explanation: 


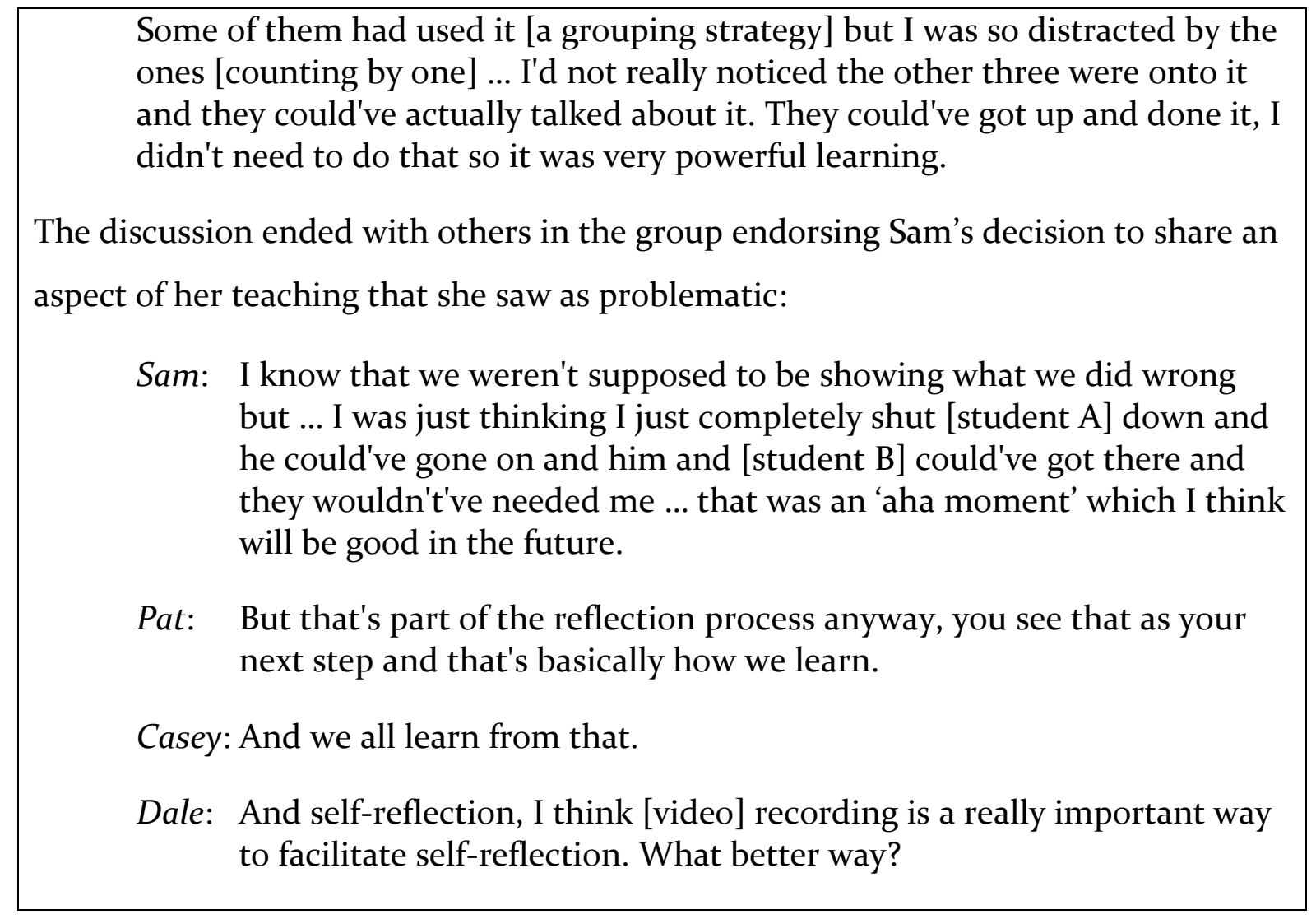

Choosing video excerpts to share with colleagues had provided a purpose for Sam to reflect on her teaching after the lesson, characterised by Schön (1983) as reflection-on-action. Sam had intentionally chosen an excerpt where she saw her practice as problematic in order to make public what she saw as a missed opportunity to promote students' mathematical talk in her lesson. She described failing to notice that a group of students could have provided a mathematical explanation of a solution strategy to others who were struggling to solve part of a problem. Her primary goal in providing her own explanation to the students was to expedite that part of the lesson and move to discussing the students' solutions, perhaps illuminating a conflict between having mathematics learning goals for the lesson in terms of the mathematical understandings that might be developed, and the performance aspect of producing answers (Boaler, 2016) and sharing how they were arrived at. Sam appeared to see the main purpose of talk in this instance to be aimed at sharing rather than developing solution strategies, perhaps missing an important role of talk in students' mathematics learning. In other words, she saw that the students who were struggling to solve the problem and were counting the dots one-by-one were going to take a long time to get to a solution and were thus delaying the opportunity for the group of 
students to engage in the discussion which Sam saw as the primary aim of the lesson. She did not appear to connect this missed opportunity for student talk with the mathematical purpose of that talk, that is with the missed opportunity to have students engage with and make sense of the mathematical ideas in the task (Anthony \& Walshaw, 2007).

During the group's discussion of the video excerpt, Sam reflected and provided detailed commentary on her teaching and, to some extent, her students' responses. The questions she was asked by her colleagues were mostly aimed at clarifying aspects of her practice and there was an apparent assumption that this was an opportunity to provide her with feedback. She was both asked about and offered suggestions for what she might do next time, indicating a focus on Sam's individual learning rather than that of the group. For the most part, Sam's practice was not challenged and where challenges were raised Sam didn't appear to pick up on them. For instance, when I pressed Sam to think about how the mathematics in the problem provided the purpose for having the conversation, she did not appear to pick up on this point and reiterated the need to get to the conversation about solutions more quickly.

The discussion offered Sam opportunities to reflect in detail on her practice, however both in thinking about her selection of an excerpt to share and during the group discussion, the learning opportunities for the other teachers appeared more limited. There was little evidence of teachers making explicit connections between the video and their own classroom practice, and where these connections were made this appeared to be primarily to provide support by showing empathy with Sam.

Furthermore, despite the stated focus on noticing student thinking, the other teachers' questions and comments were primarily directed at Sam's practice and although Sam herself described some of the student impacts she had noticed, these were at a relatively shallow level and were not interrogated by the group. This is perhaps a missed opportunity for the teachers' learning in that the impacts of Sam's practice were not sufficiently scrutinised to inform the other teachers' thinking about their own practice. 


\subsubsection{Pat's lesson: Sharing classroom video}

Immediately following the discussion of Sam's video in Example 5.4(A) above, Pat shared an excerpt of video from a mathematics lesson in her classroom. She had been working with a group of her target students who were solving the problem "I had 24 lollies and I ate $3 / 4$ of them. How many lollies did I eat altogether?” A pedagogical move used by Pat involved getting the students to draw a picture to help them to solve the problem and explain their thinking.

Example 5.4(B) Interrogating an innovative practice: "A picture paints a thousand words"

Introducing the video excerpt, Pat articulated the mathematical ideas and practices that were the intended focus of the lesson:

[The students] were learning about fractions of sets and we did focus on wait time but we also incorporated some of the other strategies as well cos I wanted them to be able to not just repeat but also clarify what they were thinking and to be able to share with a buddy.

She has chosen the clip to highlight the students' use of wait time:

Hopefully you'll be able to hear the discussions that the children have and also them being able to wait and actually think about what they were going to say cos that was one of the things I wanted them to learn.

After the group had viewed the video excerpt, Pat described how she thought the students had done a good job of:

Trying to take those opportunities to wait but also to be able to process and communicate with another person they did very, very well particularly when they came to talk about their pictures that they were drawing.

She then went on to describe in some detail several students' approaches to solving the problem:

Some actually drew columns, some drew circles. Oh [student] actually did the circles and wrote the number four inside because he knew that there was gonna be a four but the others actually did little lines inside.

Pat's observations about her students were focused on their talk about the pictures they had drawn to represent the problem, and how the talk elicited representations and descriptions of the mathematical ideas the students were engaging with, for example: 


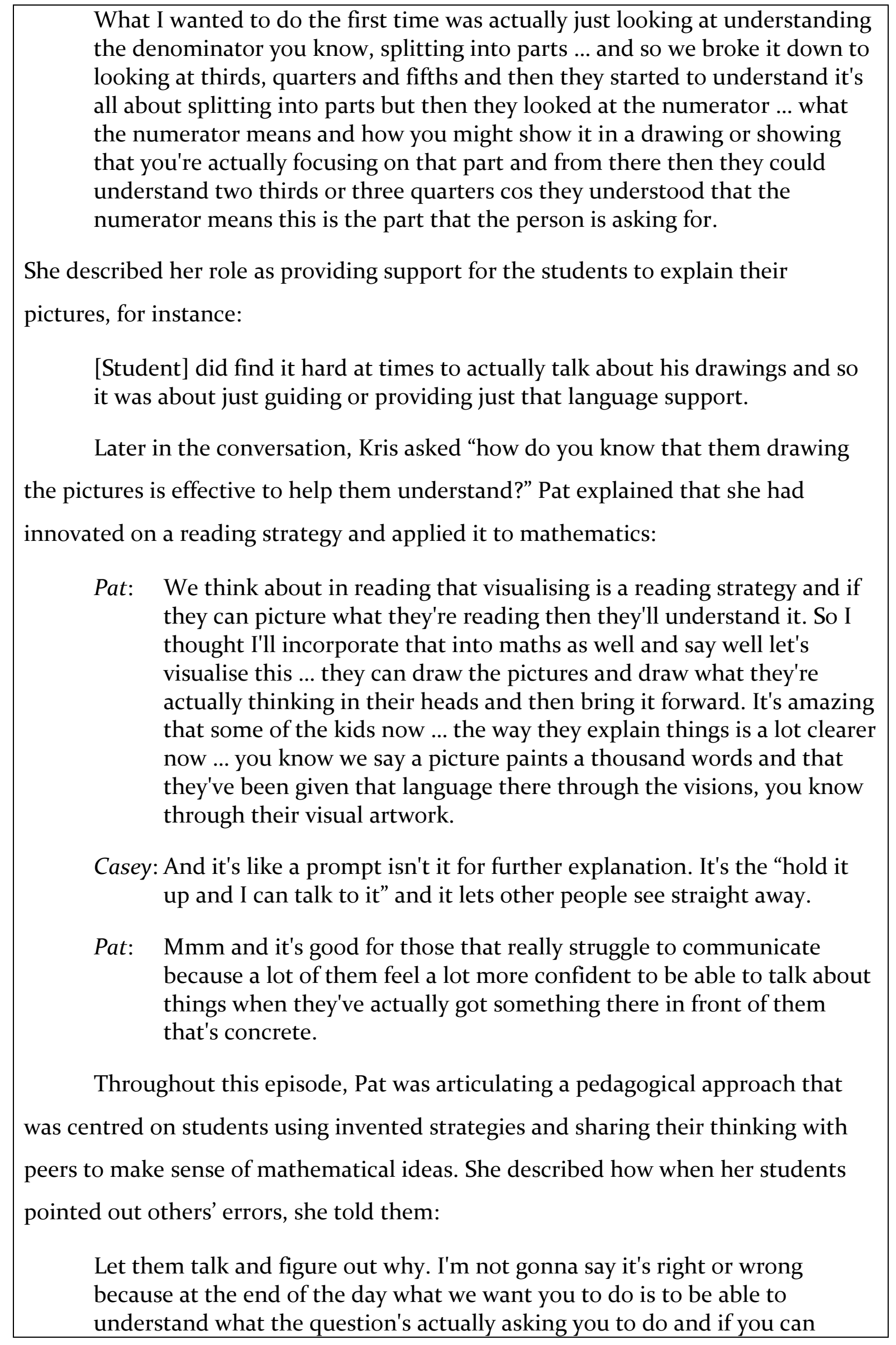




figure out those kind of procedures and you know put them in place and
explain what you were thinking hey that's okay.
Sam endorsed the value of students' drawings in exploring mathematics problems
and eliciting explanations:
I think there's quite a bit of power in getting them to create a visual drawing
because when you look at it you can see what they haven't described and you
can prompt them and say “well what's happening in this part here ... what
does that mean?" and then you're sort of putting a press on how much they
know.
Sam's suggested response to gaps that might be apparent in a students' explanation
of their drawing appears to contrast with Pat's perspective somewhat in that Sam
makes central the teacher's role in the conversation.

On several occasions during the discussion, Pat was pressed to justify her pedagogical actions including being asked how she knew the use of visual representations was an effective pedagogical move, how she knew the students were ready to reason without concrete materials and whether it was Pat or the students who had made this judgement, and where this lesson sat in a sequence of lessons. Pat responded to these questions with descriptions of her practice and thereby publicly articulated what would otherwise be individual and private reasoning about why she did what she did. Sharing the video appeared to prompt Pat to describe her practice in detail including in relation to the mathematical ideas being explored, the mathematical practices of the students and specific pedagogical moves she made. Where other group members pressed her to justify aspects of her practice, her descriptions were deepened. The other teachers primarily engaged with Pat's practice through her descriptions rather than in reference to the video itself and as such sharing the video appeared to act as a catalyst and frame of reference for the conversation, rather than directly a resource for the other teachers' learning.

At the beginning of the discussion, Pat had outlined mathematical and pedagogical goals for the lesson and her descriptions of the lesson were largely focused on the students' rather than on her own moves. This is perhaps partly because Pat appears to see the talk moves as student moves that she is teaching the students to use 
when discussing mathematics tasks with a partner, rather than seeing them as teacher moves through which the students' mathematical discussions are orchestrated by the teacher. Taking student actions as the primary focus appears to support the group's interrogation of the teaching episode because it diverts attention away from Pat's actions and so mitigates the risk of questions being received as critical of her practice.

It is interesting to note that the group did not pick up on the students' use of 'wait time' as Pat had intended, but instead the conversation centred on the use of pictures to represent the students' thinking about fractions. Kris' question to Pat about how she knew using pictures supported students' understanding pressed Pat to justify her practice which she did in relation to the students' ability to articulate their thinking. This in turn opened the conversation for Casey to make connections between her expert knowledge of language learning and the students' mathematical sense-making that Pat was describing. Viewing the video excerpt afforded an opportunity to interrogate in detail an aspect of Pat's lesson that would otherwise have remained private, and this expanded the learning resources available to all teachers thus restructuring the activity and expanding the teachers' power to act. In this case, drawing attention to and interrogating how drawing pictures supported students to develop their understandings of fractions opened opportunities for teachers to consider their own teaching practices in light of Pat's approach.

\subsubsection{Casey's lesson: Sharing classroom video}

At the fourth group meeting three weeks after Sam and Pat had shared their videos, Casey shared a video excerpt from a mathematics lesson in her classroom. She was working with a group of eight children while the remainder of the class engaged with tasks independently of her. Casey and her group were seated at a table on which a variety of materials such as tens frames, ice block sticks and Cuisenaire rods were placed. She asked the students what they knew about teen numbers and then she wrote the numeral 14 on a whiteboard and asked them to make it using equipment of their choice. Casey asked the students to explain what they had made, posing questions such as “can you tell me what you've done?" and "tell us what you've used?" The examples below outline two aspects of Casey's lesson that were picked up for 
discussion by the group of teachers: the role of concrete materials used by the students during the lesson, and Casey's approach to facilitating student talk.

Example 5.4(C) Modelling 'expert' practice: "What a great example"

Initiating the group's discussion of Casey's video, Kris drew attention to
Casey's use of materials and suggested this exemplified good practice and could be
shared more widely with the staff:
One thing that I was really impressed with was that you had the materials
but there was variety and I think sometimes, in my own practice, yes I have
resources but I maybe only have one or two options but you were quite- and
the kids knew how to use it.... I thought "wow, what a great example! If I
could just screenshot that part for our evidence". [K-GM\#4]

This was an aspect of practice that for Casey was tied to her expertise as a teacher of junior children:

I think that in the early years you do need to because they are so hands on ... to explore a concept you do need a variety. [C-GM\#4]

Both Pat and Kris identified Casey's use of materials as an aspect of practice they wished to replicate in their own classrooms:

Pat: I'll use a lot more materials thinking about it. So that's what I've learnt, I'll use a lot more materials [and] use them differently.

Kris: $\quad$ Yeah, I'm thinking that was the big thing that kind of screamed out to me as well that - and it's not about having it available but it's about having it used and even though like mine are double your age, the value in that. That actually just because the place value box might be the easiest thing to use, it doesn't mean that somebody doesn't prefer to use the decimats or someone doesn't prefer to use the number.

Raewyn: And the fact that they're using different equipment means that you've got that chance for kids to talk about and understand the connections between the different kinds as well. What's the connection between the 10 frames and the sticks? [GM\#4]

For Casey, using a variety of materials was a response to students' stated preferences:

[Last year] we were doing patterns to ten, our basic facts to ten, and I did ask them at the end which they preferred and why, and they all had a variety of preferences. Not everyone wanted the tens frame, some wanted the rods 


\begin{tabular}{|c|c|}
\hline $\begin{array}{l}\text { becal } \\
\text { what } \\
\text { bette } \\
\text { wortl } \\
\text { [C-G }\end{array}$ & $\begin{array}{l}\text { se they liked the colours and they could identify. It just depends on } \\
\text { zind of a learner you are I suppose. They could remember the colours } \\
\text { whereas some children find it hard to remember what each rod is } \\
\text { so you know, we used to do the staircases every day to remind them. } \\
\text { I\#4] }\end{array}$ \\
\hline $\begin{array}{l}\text { At th } \\
\text { explain thei } \\
\text { was differen }\end{array}$ & $\begin{array}{l}\text { beginning of her lesson, Casey's had asked each student to individually } \\
\text { solution and Pat noted that this was an aspect of Casey approach that } \\
\text { to her own: }\end{array}$ \\
\hline Pat: & $\begin{array}{l}\text { Just wondering, did they have they have an opportunity to share their } \\
\text { thinking with another person? }\end{array}$ \\
\hline Casey & $\begin{array}{l}\text { Well that was the next thing ... I'd write another number and they had } \\
\text { to use a different material and then share it with a partner. }\end{array}$ \\
\hline (1) & $\begin{array}{l}\text { I think that was quite a good way of actually doing it. Particularly if it's } \\
\text { a new concept that you do it individually first and then those ones } \\
\text { who you know that didn't get it then you take them away and the ones } \\
\text { who sort of like know it, then you can give them another number then } \\
\text { they can share it with each other and then you've got that little - it's } \\
\text { almost like you've got your little group within the little group and } \\
\text { then you've actually got teaching to their specific needs and say 'Right, } \\
\text { okay, there's your gap ... just plug it in now and then re-join with the } \\
\text { rest of the group again.' I thought that was quite a smart move } \\
\text { because usually I do sharing out right at the beginning and I'm } \\
\text { wondering whether that might be something I might think about is } \\
\text { getting them to report straight away back to me first. [GM\#4] }\end{array}$ \\
\hline $\begin{array}{l}\text { Pat was sugg } \\
\text { understandi } \\
\text { to provide ac } \\
\text { alternatives } \\
\text { understandi }\end{array}$ & $\begin{array}{l}\text { esting that this approach would allow her to assess each child's } \\
\text { g and withdraw those who had apparent 'gaps' in their understanding } \\
\text { ditional instruction to them. Casey and Kris both suggested } \\
\text { o Pat's ideas about how to respond to students' different levels of } \\
\text { g: }\end{array}$ \\
\hline Casey & $\begin{array}{l}\text { Then you could also strategically place a knowing one with a kind of } \\
\text { an unsure one. }\end{array}$ \\
\hline Kris: & $\begin{array}{l}\text { I'll often say ... if I hear an idea that I think "Hmm, yeah you've got it" I } \\
\text { will say "I heard what you said, do you mind if I ask you to share } \\
\text { back?" just so that it prepares them ... and it also means that they } \\
\text { know that you heard them and you value what they say. }\end{array}$ \\
\hline
\end{tabular}


Pat was also struck by Casey's use of wait time when asking students to repeat what another student had said:

I like how you are patient ... there were times when you asked them to repeat and [a student] stuttered but you waited ... so it's a bit of both really, looking at both repeat and wait and allowed her to feel success for it, that she was able to speak, because I know that sometimes it can be really frustrating. She [student] reminds me a bit of one of the boys in my class ... you just want to say the words for them, but you allowed them to be able to express their thoughts.

Responding to Pat, Casey expressed some dissatisfaction with the lesson:

I wasn't that pleased with it really, I just thought I could have done a bit more - they could have done a bit more because we have got repeating. We've done a bit of that before. It just didn't seem to be enough conversation for them to repeat.

Pat elaborated on what she saw as effective in Casey's practice:

It was almost like you were throwing in a bit of your EAL experience as well where you asked the child to add a bit more and clarify something and I remember seeing that and that's quite important too where actually, where one person said something and you telling someone else to add more information onto it.

I also observed that I thought the students' conversation had "really got at the heart of what place value is all about" and Casey recalled a student who had performed unexpectedly well in a place value task in a recent assessment. The task involved showing the student a strip of five dots and a strip of ten dots, then adding subsequent strips of ten:

[The student is] a bit slow to pick up on things but in the JAM ... I had to wait but then she said 15 ... and she was able to go 25 and 35 and that was a 'wow' moment for me ... there were gaps [in other areas] whereas she seemed to pick up on this, maybe the concept has just resonated with her or clicked into place.

Casey was referring here to the Junior Assessment of Mathematics (JAM), an interview-based assessment tool (Ministry of Education, 2013). The idea that the concept may have "just resonated with" the student suggested that Casey had noticed the student's shift in understanding but perhaps not connected it with the teaching | learning experience and her own pedagogical practices. 
Casey had previously expressed a reluctance to see herself on video, nevertheless at the fourth group meeting she had volunteered to share an excerpt of classroom video with the group. It appeared that discussing the video was seen as a deserved reward for sharing it, and the other teachers' comments and questions were predominantly aimed at reinforcing aspects of the lesson they saw as strengths. The conversation surfaced differences among the teachers in relation to classroom practices and beliefs about pedagogy. For instance, Pat, Casey and Kris were sharing different perspectives on the teacher's role and role of student talk in mathematics learning. They also appeared to have different perspectives on the resources available to students within students' conversations in mixed-ability groups. Pat had suggested providing separate instruction to students who were finding a task challenging, whereas Casey and Kris were suggesting approaches that involved students providing the expertise and support for one another's learning, for example by strategically pairing students to offer learning support to a student who was struggling.

In Paul Cobb's foreword to Anthony and Walshaw's (2007) BES, he describes their findings as outlining a pedagogical system comprising four interrelated elements of effective pedagogy: "a non-threatening classroom atmosphere; instructional tasks; tools and representations; [and] classroom discourse" (p. $\mathrm{x}$ ). During the discussion of Casey's video, the teachers had picked up on and made connections between two key elements of pedagogy: student discourse and the use of representations, in this case using equipment to represent groupings of ten to develop an early understanding of place value. The group recognised that Casey's use of materials to represent teen numbers was an approach that supported students' understanding and both Pat and Kris identified aspects Casey's practice that might strengthen the effectiveness of their own teaching, thus extending both teachers' repertoires of practice ideas to draw on.

The three examples outlined in section 5.4 above illustrate specific instances of Sam, Pat and Casey sharing video excerpts, and the opportunities for teacher learning that were afforded in the group discussions that followed. Section 5.5 that follows explores themes that emerged in data from subsequent meetings when the teachers reflected on their experiences of video-recording lessons and sharing them with the group for discussion. 


\subsection{Reflecting on the design: Video as a reflexive tool}

Viewing and discussing classroom video excerpts provided teachers with a 'way in' to access one another's usually private classroom practice. The process of selecting video excerpts to share, and the subsequent discussion, appeared to provide opportunities to support teachers who were trying new pedagogical approaches. The importance of discussing the videos that were shared was raised by Kris during the fourth group meeting. After Casey had shared her video excerpt with the group, discussion was initially side-tracked however Kris moved to bring the conversation back to Casey's video:

There's such value in the discussion that comes from the videos and Casey deserves that ... if we rush things that then it loses the value of what we're doing. [K-GM\#4]

On the one hand Kris saw the discussion as something Casey deserved in exchange for sharing her practice, and she also recognised a broader collective purpose as affording the teachers an opportunity to deepen their reflections and learn from the videos. Later in the conversation, Kris suggested that the teachers think about what they had each learned from Casey's video:

Maybe we could think about what next for us, in our own teaching from watching Casey's footage ... what can we take from her good practice into our practice or consider when we're planning or assessing?

At the previous group meeting, Kris had engaged in a line of questioning about Pat's video that she was hoping would illuminate for Pat the significance of her practice:

When I was thinking about Pat with the materials and the drawing I was thinking "oh, that was something that happened to me" and so I think that's why I was asking the questions because I was hoping that you'd see what you got on your video, how powerful that is. [K-GM\#3]

During the fifth group meeting, Kris commented:

With those videos ... that was just the vehicle into the discussion, and the discussion actually then prompted you to think about your own practice. I think there was something in Pat's one ... that straight away struck a chord with me and then with Casey, her multiple materials and equipment that could be used struck a chord so it's kind of getting that glimpse in and kind of taking, borrowing stuff. [K-GM\#5] 
The classroom video excerpts were seen to provide resources for teachers to extend and deepen their pedagogical practices and, at the same time, as evidence of effective teaching. For instance, Kris suggested that Casey's video excerpt could be shared more widely with the teaching staff as an illustration of effective practice in mathematics. Sam had earlier suggested that sharing classroom video would, over time, provide evidence of the ongoing impact on students from shifts in the teachers' practice:

My guess is that as time goes on and we video each other we would hopefully notice that there is a difference in who's doing the talking in our classrooms and there's a lot more of these things being heard by the children leading it and the power's more being shared. So, the capturing video and keeping it is powerful and the talking to each other about what we notice and ways we could better include these is maybe the collaborative aspect that we're working on. [S-GM\#3]

Making a similar point at a later meeting Kris commented on a video Pat had shared, saying:

In comparison to your first video where you had showed talk moves to what I witnessed today, they're leaps apart which is really exciting, so they show a journey too I think which is really cool. [K-GM\#5]

Prior research has found that viewing and discussing classroom video excerpts can support teachers to better interpret students' mathematical thinking, including extending both what aspects of classroom events teachers noticed and how they talked about what they noticed (van Es \& Sherin, 2008). In this study, sharing and discussing video from their classrooms provided the teachers with access to one another's practice, including teaching ideas that could be 'borrowed' to extend one's own repertoire. For instance, both Pat and Kris stated that they would follow Casey's lead in providing students with access to a variety of materials to support mathematics lessons. For Kris, using materials was consistent with her own current practice however she saw that attending to students' preferences by providing a range of materials was a way to strengthen it. For Pat, Casey's use of materials contrasted with her own current practice and so served as a potential disruption in that what was viewed as highly effective teaching appeared very different to what was occurring in Pat's own classroom. In other words, what the students were doing, and using, in each 
of the classrooms looked very different and prompted Pat to suggest that she might adopt this easily observable aspect of Casey's practice. For Pat and Kris, extending their use of materials in their mathematics teaching appeared highly congruent with their current beliefs and practices and so this was an aspect of Casey's pedagogy that would be relatively easy to understand and adopt (Timperley et al., 2007), on the surface at least. Nevertheless, like van Es and Sherin found in the early stages of their video club, Pat and Kris' comments about Casey's use of materials tended to be descriptive and non-specific, and largely disconnected from the students' mathematical understandings even when prompted. Such observations on their own are unlikely to deeply engage teachers with their existing practice theories and so Casey's practice of 'using materials' is likely to remain untested and support only superficial changes in Pat and Kris' understandings and resulting enactment of this practice.

\subsection{Activity system 2: Reflecting together on videos of classroom practice}

To date, elements of the teachers' collaborative inquiry activity that emerged in the data as important included negotiating the focus for the group's activity, the roles participants adopted, some of the tools that mediated the activity, and norms and rules that structured the group's work. The group's shared work occurred predominantly in the context of three-weekly meetings, usually held after school, wherein the teachers shared and discussed aspects of their practice. Conversations initially centred on selected research literature and later also on self-chosen classroom video excerpts. To illustrate the interrelationships among these and other elements of their work together, the group's collaborative inquiry activity is presented as an activity system in Figure 5.2 below. 


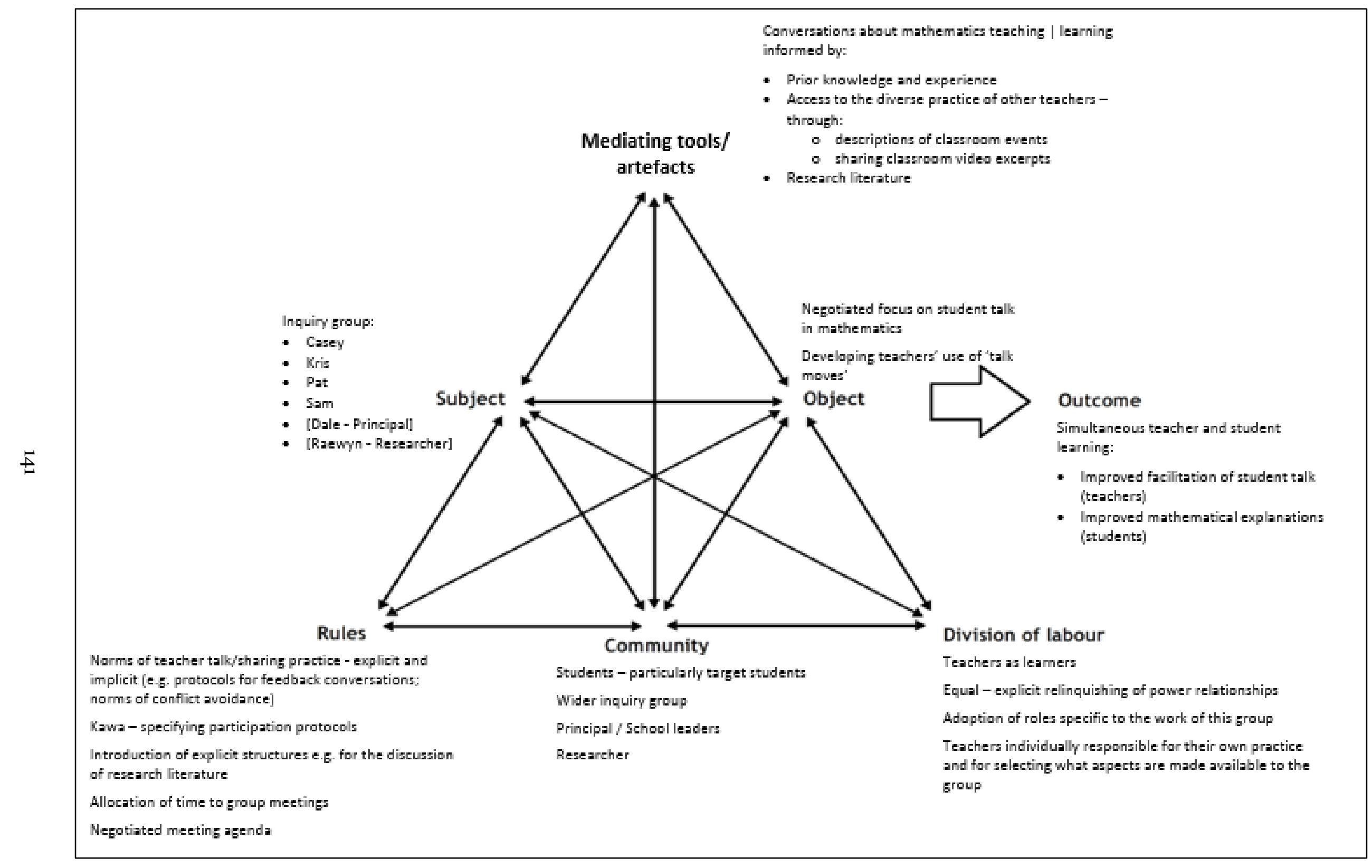

Figure 5.2. Activity system 2: Reflecting together on classroom video. 
In the activity system depicted on the previous page, the subjects of the activity were the four participating teachers, Sam, Casey, Kris and Pat. They were members of three different teaching teams organised by class-level, and as described earlier they taught in single-cell classrooms with their classes spanning a range from Year 2 (6year-old) to Year 8 (12-year-old) students. Although Pat, Casey and Kris had previously worked together as part of a school-mandated PLC, the four teachers were voluntary participants in what was a new group formed specifically for this project. The object, which was negotiated over the course of the first two meetings, was the implementation of talk moves as a pedagogical strategy to promote productive student talk in mathematics. This object was aimed at simultaneous teacher and student learning goals as outcomes, namely improved mathematical explanations as a student learning goal, achieved through the improved facilitation of student talk as a teacher learning goal. The primary tools mediating the group's activity were conversations about mathematics teaching | learning which were in turn mediated by prior knowledge and experience, research literature, and access to representations of one another's classroom practice. Group discussions provided access to other teachers' classroom practice through the sharing of classroom video and descriptions given by teachers of their own practice.

The division of labour associated with this activity was defined by the negotiation of a group kawa which had involved the teachers relinquishing leadership and other roles for the purposes of this work, and explicitly identifying themselves as equal co-learners. Each of the teachers was individually responsible for enacting the teaching of mathematics in her own classroom and choosing how and when to participate in the group's inquiry activities. Each teacher chose what, if any, aspects of her classroom practice were shared with and discussed by the group, for instance Casey initially chose not to share her classroom video with the group although she later changed her mind. Group members adopted roles of their choosing such as Pat who acted as timekeeper in group meetings, and Casey who often took on the role of challenging others' thinking. The social norms of teachers talking and sharing practice, including implicit rules such as norms of politeness and conflict-avoidance, and explicit rules such as protocols for feedback conversations and discussions of 
research literature, acted as rules, again alongside decisions about the allocation of time for teachers to collaborate.

The teachers' collaboration was situated within a community of teaching colleagues and was primarily associated with cultures related to Waterview School. The teachers comprised a subset of the wider teaching staff and were volunteers who had chosen to work together; the wider community can be defined similarly to that for activity system 1 (see section 4.3). There was a group of teachers, some of whom were in the project group, who made up an inquiry team for ALiM, an intervention aimed at accelerating the mathematics achievements of a group of target students from among their classes. Kris was the lead teacher for ALiM in the school and this involved withdrawing students from their classes for additional mathematics lessons. She was being supported by an external facilitator to do this. As co-participant and researcher, I was both one of the subjects of the activity and a member of the wider community in which it took place. The school's principal, Dale, also joined the group for our first three group meetings and so could be considered both one of the subjects and a community member.

\subsection{Discussion: Contradictions within the activity of reflecting together on classroom video}

The first phase of the design for the teachers' collaborative inquiry activity centred on teachers reading research articles together and later selecting and sharing excerpts of classroom video for discussion in group meetings. Contradictions emerged within the group's activity and the activity system diagram from section 5.6 is reproduced in Figure 5.3 with the addition of dotted arrows labelled as $\mathbf{6}, \mathbf{7}, \mathbf{8}, \mathbf{9}$, $(10$ and 11 representing the inner contradictions that were apparent. The inner contradictions that emerged in the activity at this stage in the design process are discussed in the sections that follow. 


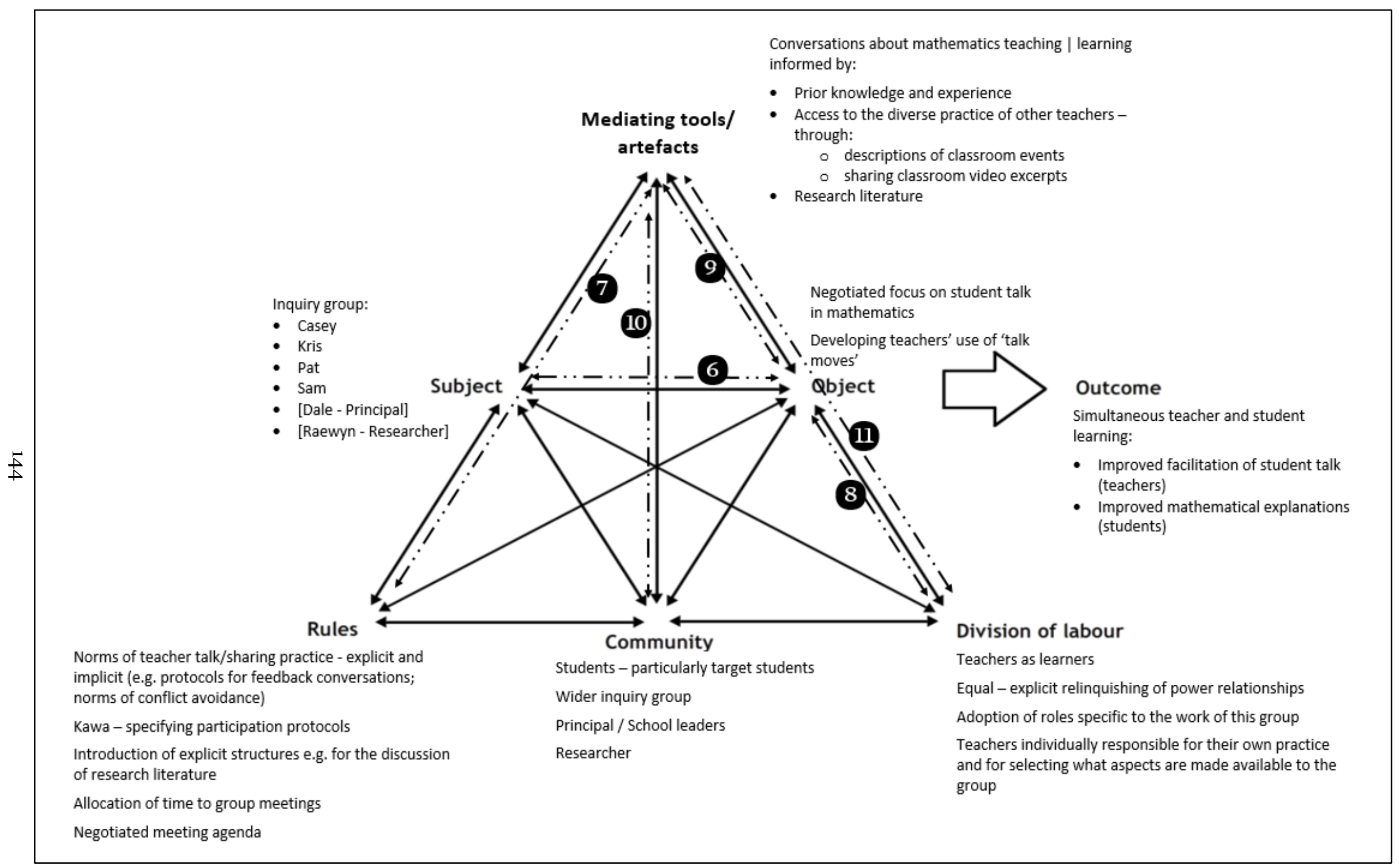

Figure 5.3. Contradictions within the teachers' collaborative activity in design phase 1: Reflecting together on classroom video. 


\subsubsection{Diverse and shifting ideas about student talk [Runaway object?]}

Negotiating the focus for the inquiry elicited sometimes contradictory ideas about practice and created opportunities for teachers' tacit knowledge and beliefs to be made explicit and thus open to interrogation. Contradiction 6 [subject $\leftarrow \rightarrow$ object] pertains to the range of teacher perspectives on an apparently common goal, that of enhancing student talk in mathematics classrooms. During the first two meetings, the primary object of the group's activity was to come to an agreement about a focus for the teachers' collaborative inquiry activity. In other words, the object of the initial activity was to identify the object of the teachers' activity going forward. However, as Kris identified, there was not a consistent or clear view of what was important about student talk or why it was important. The teachers' discussions elicited a range of perspectives on talk in mathematics including the need for consistency in the mathematical language used by teachers and taught to students, and students being able to explain what they were doing and thinking in mathematics. Perspectives on the purpose of talk in mathematics included talk as a mode of direct instruction; talk as performance and a source of evidence of what students know and understand; talk and understanding mathematics talk as a literacy task involving understanding vocabulary and task instructions; and the role of talk in mathematical practices involved in doing and constructing understandings of mathematics. As the teachers worked to specify a shared goal for their activity, they surfaced wide-ranging perspectives on the nature and purpose of student talk in mathematics. Engaging teachers in negotiating inquiry goals provide a forum for surfacing their existing theories of practice, an important prelude to interrogating their practice in light of student outcomes (Timperley et al., 2007) with a view to strengthening the impacts of their teaching on student learning.

\subsubsection{Beyond sharing: Structuring conversations to engage with difference}

Group members' diverse repertoires of knowledge and past experiences, and the literature the group engaged with, informed the teachers' different perspectives about, and their own roles in relation to, student talk and further expanded the teachers' access to diverse practice ideas. Contradiction 7 [rules $\leftrightarrow \rightarrow$ tools] was 
connected to contradiction 6 and related to the different resources that teachers were drawing on to inform their understanding of the role of student talk in mathematics. Multiple contrasts emerged between the teachers' classroom experiences and the views of practice articulated in the research literature the group was reading, nevertheless there was an apparent disconnect whereby these contrasts were not explicitly identified or discussed in the teachers' early conversations. Introducing new 'rules of engagement' whereby contrasting views of practice were explicitly identified and discussed served to expand the conversation as the teachers worked to make sense of and resolve the differences. During the initial group meeting, the teachers' conversation about student talk in mathematics was relatively short-lived and for the most part involved each teacher sharing their perspective independently of the others. Much like in the staff meetings described in the previous chapter, each teacher told separate stories about their own classrooms which were unlikely on their own to support teacher learning (Little, 1990). There was little, if any, engagement with one another's ideas. In contrast, using an explicit structure to engage in a shared reading task appeared to promote an extended conversation during which the teachers interacted with and interrogated their own and one another's ideas about student talk in mathematics. Using different coloured highlighters and explicitly looking for details in the reading that aligned with and challenged the teachers' current practice ideas served to structure their conversations so that they engaged with their existing practice theories and contrasted them with alternative perspectives. Accordingly, their actions were shaped by shifting views in relation to student talk as the object of their shared work. Sewell's (1992) work theorising a dialectical relationship between structure and agency is useful for understanding a shift in the nature of the teachers' conversations. The explicit protocol for reading and thinking about the article served to introduce a new set of rules for engaging with the differences that emerged between each teacher's experiences and the practices that were articulated in the readings and by their colleagues. The activity was thereby restructured in that teachers were pressed to productively engage with these differences and this served to expand the teachers' agency, or power to act, by explicitly encouraging teachers to surface and engage with ideas that promoted challenge. 


\subsubsection{Teacher as 'explainer' and teacher as 'facilitator'}

Throughout the group's discussion of the BES excerpt, beliefs about the teacher's role in mathematics talk were surfaced including providing mathematical explanations and responding to errors, modelling mathematical talk and teaching the language of mathematics, facilitating talk and valuing students' ideas, and observing students' independent talk in mathematics. These visions of practice varied in the possibilities they opened, or constrained, in terms of the ways that teachers' actions might promote valued student outcomes. Contradiction 8 [division of labour $\boldsymbol{\leftrightarrow} \rightarrow$ object] pertained to the emergence of different perspectives on the teachers' role in relation to student talk in mathematics, and how these shaped each teacher's actions towards the object of the group's shared activity, and consequently also the outcome of the activity. How teachers individually understood and acted towards the object, in other words how they used talk moves in their classrooms and how they talked about talk moves, influenced how their collective actions could achieve the intended outcomes. For instance, roles of teacher as explainer and corrector of errors positions teachers as the primary knowers and 'doers' of mathematics and can constrain students' engagement in 'doing' and making sense of mathematics. That is, when teachers offer explanations and correct errors, opportunities for students to engage in sense-making can be shut down. This was illustrated in the video excerpt Sam shared in which she had provided an explanation to students to expedite the lesson, and in doing so shut down the opportunity for other students to provide an explanation. This notion of teacher as explainer positioned students as recipients of mathematics understandings and appeared to illustrate a contradiction for these teachers between how they envisaged their teacher's role and their goal of enhancing student talk in mathematics. For instance, it was an apparent contradiction that alongside her view of teacher as explainer, Sam also saw the importance of giving students opportunities to develop their own thinking, envisaging her role as involving questioning students to challenge their erroneous thinking. Central to Sam's viewpoint here was the positioning of students as learners and teachers as knowers of the mathematics being explored. In contrast, Kris suggested that students needed to also be able to challenge others' mathematical explanations, including those of the teacher "and that 
confidence not only to explain but to question or to go "really?" For Kris, student talk in mathematics was in the context of a conversation in which teachers might be positioned as learners and have their thinking challenged. Thus, how the teachers each viewed their role in the mathematics classroom influenced how they engaged with examples of their own and other teachers' practice in relation to promoting productive student talk.

\subsubsection{Purpose of video}

How excerpts of video were chosen for sharing, and the teachers' different motives for volunteering to share, or even for sharing at all, mediated the learning opportunities that were opened up or shut down in the conversations that followed. Contradictions 9 [tools $\leftrightarrow \rightarrow$ object] and 10 [tools $\leftrightarrow \rightarrow$ community] were related to the use of classroom video excerpts to inform the teachers' shared inquiry. Contradiction 9 pertained to participants' different ideas about how discussing classroom video could support the development and enactment of new classroom practices. The teachers had been prompted to choose excerpts to share that would promote everyone's learning, and it was expected that the discussion would focus on students' mathematical thinking as a resource to inform each teachers' practice. In contrast, discussion of the videos primarily afforded the learning of the teacher who was sharing including by providing feedback and offering teachers a range of perspectives on their teaching. Sharing the video excerpts had pressed teachers to articulate and justify aspects of their practice and Sam had described how thinking about what excerpt to share with the group had prompted her to reflect more deeply about her teaching episode. Sharing practice through video provided access for the teachers to new teaching ideas, such as Pat's use of pictures to help students make sense of problems, and exposed differences in practice that catalysed conversations whereby teachers asked questions of one another to clarify aspects of the practice that was shared. Nevertheless, deep access to diverse practice ideas was constrained whereby the teaching episodes that were shared were described in detail however there was little scrutiny of these beyond the teachers' own descriptions.

Contradiction 10 is closely related to contradiction 9 in that what constrained teachers from sharing and interrogating rich practice dilemmas was in part mediated 
by prior experiences that had shaped the teachers' motives for, and expectations around, the sharing of video. As discussed above, the teachers appeared to see the sharing of video as an opportunity for feedback on their practice however they had previously described risks associated with exposing challenges in their practice. They had also described previous experiences of teachers receiving feedback that were associated with negative judgements about their teaching, for instance in the context of performance appraisal and professional development. Thus, for these teachers, viewing and discussing classroom video was associated with negative consequences and this appeared to influence how they engaged with one another. For both Sam and Casey, discussion of their video excerpts surfaced their descriptions of their own practice and provided them with feedback from the video itself and from their colleagues. In Sam's case, feedback was largely from her own reflections on a problematic aspect of the lesson. For Casey the group's discussion of her video was aimed at celebrating and reinforcing the strengths evident in her teaching. Drawing attention to what is problematic about a teacher's practice, as Sam did, contrasted with the norm of hiding practice challenges and may in part explain the group's reluctance to engage in robust discussion of this excerpt despite endorsing Sam's choice of it. Casey had previously expressed reluctance in relation to watching and sharing video of her teaching, and it appeared that the group acted in part to mitigate the risks associated with sharing by prioritising care for her social and emotional wellbeing. Social norms associated with protecting collegial relationships appeared to constrain the teachers' deep engagement with Sam and Casey's practice as tools to inform the teachers' thinking about their own practice. In contrast, shifting the focus for discussion onto the students, as the sharing of Pat's video had done, appeared to afford more rigorous interrogation of the teaching episode. Observing and analysing the thinking and actions of students is normal day-to-day practice for teachers and thus to question teaching episodes from this perspective is highly normalised and does not pose the risks associated with discussing teachers' actions.

\subsubsection{The influence of expertise on teachers' conversations}

Contradiction 11 [tools $\leftrightarrow$ division of labour] is related to contradiction 10 and pertains to the various roles that group members appeared to adopt within their 
conversations, and the way these opened or constrained the conversations and teachers' access to one another's thinking about their practice. Casey was an experienced junior teacher and teacher of English as an additional language (EAL), and the discussion of her video contrasted with Pat's in ways that appeared to be connected with the group's recognition of her expertise. The discussion of Casey's video centred on a well-recognised aspect of mathematics teaching | learning pedagogy for New Zealand teachers, the use of concrete materials to support students to make sense of number concepts and operations (e.g. Ministry of Education, 2008), and on Casey' use of the 'repeating' talk move. In contrast, Pat's video introduced a pedagogical approach that was relatively novel for the other teachers involving students drawing pictures to make sense of problems they were solving, and then using their pictures as prompts to explain their thinking to others. Positioning Casey as an expert appeared to constrain the group's conversation in that they tended to endorse rather than question Casey's practice, giving her little need to justify her approach. When discussing her apparently less orthodox approach involving students drawing aspects of problems they were solving, Pat was pressed to justify the practice. This prompted a conversational thread in which Casey, Kris and Sam all gave consideration to how drawing pictures might support the development of mathematical understandings. The teachers did not position Pat as an expert practitioner in relation to this aspect of her practice, and thus the discussion opened opportunities for each of the teachers, including Pat, to interrogate the merits of the practice with a focus on how the students did, or might, respond to this pedagogical move. As Hunter (2007) found, the group's conversations afforded possibilities for improved practice whereby eliciting a range of perspectives and practice examples prompted teachers to reflect on taken-for-granted aspects of their own practice. In this case, the conversation about Pat's practice was extended because she was not recognised as having expertise which opened her teaching to questioning by her colleagues.

\subsection{Chapter summary}

This chapter has outlined findings in relation to the teachers' collaborative activity in the first phase of the design process. Throughout the teachers' ongoing 
discussions about the BES excerpt and the classroom videos that were shared, differences in teachers' personal theories of practice were surfaced. During the first two group meetings, the teachers' different perspectives on student talk were made available as a resource for the teachers' collaborative activity and mediated their thinking as they worked to negotiate a focus for their inquiry. Engaging in an explicitly structured discussion of a research article supported the teachers to expand their thinking as they sought to resolve conflicting ideas about student talk in mathematics including those described in the article and by each other. Sharing and discussing video from each other's classrooms afforded opportunities to surface and engage with otherwise private and taken-for-granted aspects of each teacher's practice.

In contrast to their prior experiences of sharing descriptions of practice and practice ideas at professional development-focused staff meetings, reading and engaging in a structured discussion about research literature, and sharing and discussing classroom video, expanded the learning resources available in the teachers' conversations. Contradictions among the teachers' perspectives served to catalyse conversations whereby the teachers attempted to reconcile their different views and practices. Expansion of the activity was made possible where conflicting ideas about practice emerged and were actively engaged with. For instance, Casey was prompted to reconsider how she responded to students' mathematical ideas in light of a conversation with Kris that had highlighted differences between their approaches. As differences were exposed, the teachers' conversations were extended as they were pressed to explain and justify their practice in greater length and depth than they had previously. This enabled diverse ideas about practice to be made available as conceptual resources and reflexive objects for the teachers' thinking about and developing understandings of practice.

Sharing and discussing excerpts of classroom video remained an aspect of the design, however in the second phase of the design process the teachers' collaborative inquiry shifted in focus to featuring co-teaching mathematics lessons in pairs and reflecting on these in the larger group. Recounting the shift in focus from reflecting on classroom video to co-teaching mathematics lessons is largely marked by the closing of this chapter and the opening of the next. In practice, however, the shift occurred 
across an extended period whereby the first co-teaching episode occurred between the second and third group meetings, and teachers continued to share classroom video up to and including at the sixth and penultimate group meeting. Chapter 6 outlines the emergence of co-teaching within the group's work, and describes and analyses examples of the teachers' co-teaching experiences. 


\section{Chapter 6 Design phase 2: Co-teaching as an arrangement for teachers' shared work}

Co-teaching was a key innovation to emerge from the second phase of the design process and was a product of the broader collaborative context in which the research was taking place. This chapter describes the emergence of co-teaching as a core component of the teachers' collaborative inquiry approach and the co-teaching inquiry activity is outlined as it was conceived and enacted by the participants at the end of the study period. This chapter examines events relating to the emergence and refinement of the co-teaching arrangement that became an important element of the teachers' collaborative inquiry activity. Figure 6.1 below (which is reproduced from page 107) highlights how the idea of co-teaching first emerged and began to be developed concurrently with the teachers' activity remaining largely focused on recording and sharing video from their individual classroom practice.

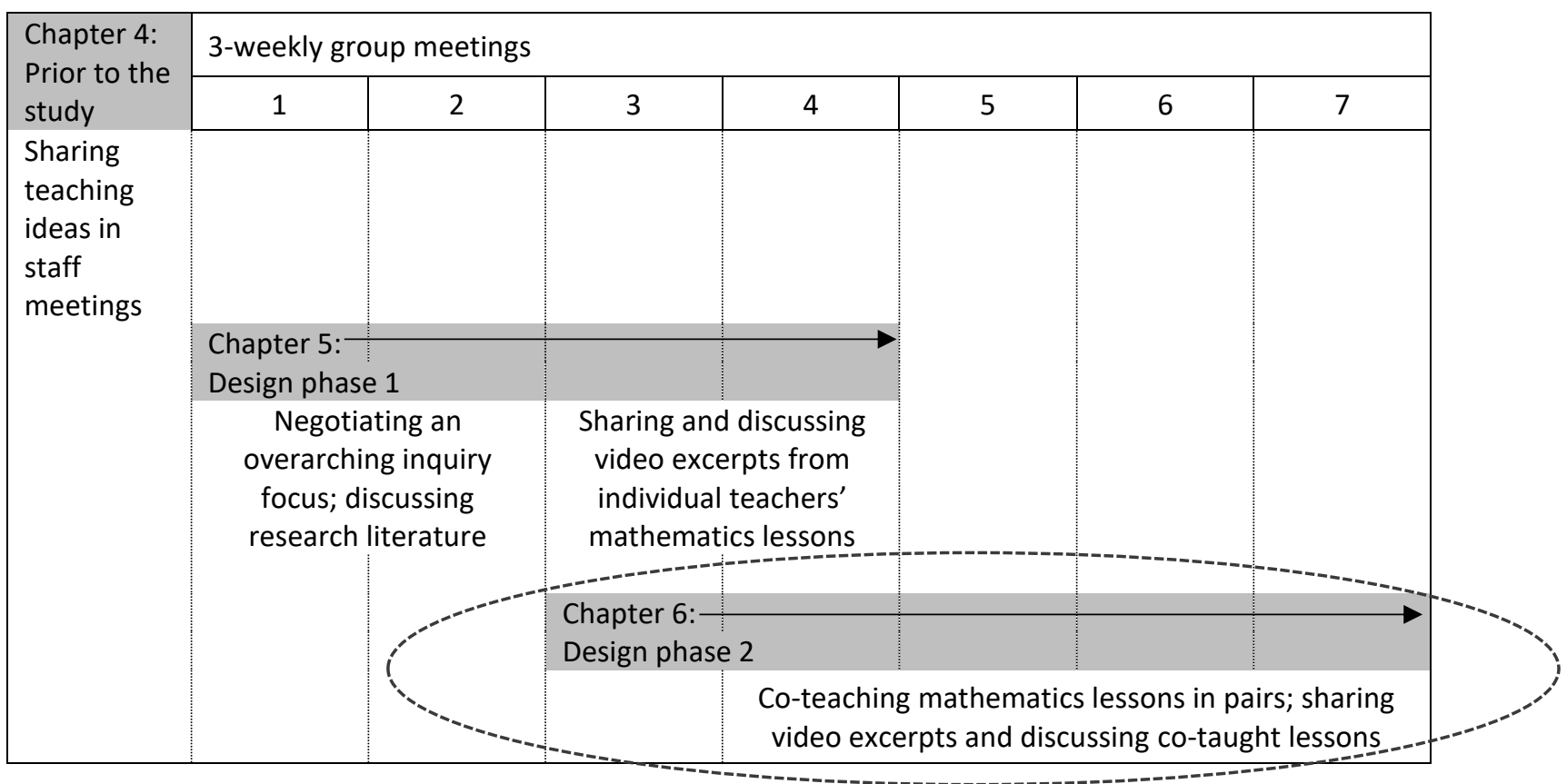

Figure 6.1. Overview of key design phases and collaborative inquiry activity

The aim of the chapter is to illuminate how the idea of co-teaching was sparked and then developed into a key feature of the teachers' work together. Drawing primarily on data from their discussions of co-taught mathematics lessons at three- 
weekly group meetings, the teachers' experiences of co-teaching are described including examples of mathematics lessons that were co-taught by pairs of teachers and then discussed at group meetings. The nature of the co-teaching arrangement is examined, and examples of co-teaching episodes are described from the perspectives of the teachers who were involved. The chapter concludes by describing some of the underlying design principles and characteristics of the collaborative inquiry model that had emerged at the end of the data-gathering period. The role of co-teaching within the teachers' broader collaborative inquiry activity is described, and the coteaching inquiry activity is depicted as an activity system. Finally, the co-teaching inquiry model that emerged at the end of the study is analysed in relation to the affordances of teachers' co-teaching inquiry activity for teacher learning

\subsection{Co-teaching as an innovation: The birth of an idea}

The idea to co-teach mathematics lessons initially arose in response to an informal request for help to address a genuine problem of practice. Kris had encountered students who were struggling with adding decimal fractions and I had suggested introducing decimats, a pedagogical tool which provides students with a representation of decimal place value (see Ministry of Education, 2008, pp. 45-46). Kris had previously tried using decimats with limited success however I had not used them before but believed they had merit and was keen to try them out. We decided to introduce the decimats together; that is, we decided to co-teach a lesson using decimats with a group of students from Kris's class, and then again with a group of students drawn from three different classrooms whose learning Kris was aiming to accelerate in a withdrawal situation. Thus, co-teaching was initially proposed as a way of providing support for Kris to try something new in her practice. An axiological principle underpinning my researcher role was that of reciprocity and mutual benefit and so I had explicitly made myself available as a resource for the teachers' work beyond the context of the study itself. Accordingly, the idea of co-teaching emerged to meet an authentic purpose for sharing the teaching of a lesson. This mirrors Roth and Tobin's (2004) description of a co-teaching arrangement in which two teachers cotaught a science class as a solution to each individual's hesitance to teach the unit alone. In terms of the design cycle, co-teaching emerged as a possible solution to a 
practical problem and was implicitly directed at the question "How can we collaboratively promote our own learning to bridge the gap for our students?" (see Figure 3.3). The emergence of co-teaching as an arrangement for our collaborative activity was contingent on the relationship that existed between Kris and myself both in terms of the reciprocal relationship explicitly established as part of the research design, and how we saw ourselves as equal partners who had something to learn from one another. We had discussed this after these initial co-teaching experiences, between the second and third group meetings:

Kris: $\quad$ I think what helped for us is both of us openly said we've either never used it or we're both weak at it. There was no ...

Raewyn: There was no "I'm the expert here, you're the learner"

Kris: $\quad$ Yeah, and I think that as teachers in general we make somebody better and we make somebody the learner ... I think it's natural in teachers that either somebody leads you or you are leading people.

Our experience of co-teaching a lesson prompted us to consider the possibilities of co-teaching for teacher learning and we both described the experience as "powerful". Reflecting on our co-taught lesson we had shared the view that the coteaching had seemed a productive approach to addressing challenges associated with implementing this pedagogical approach. We were particularly struck by our heightened noticing of the children's thinking during the shared teaching episode. Alongside our explicit aim of trialling a pedagogical approach, the use of decimats to represent decimal place value, we discussed how our co-teaching had student learning as the central focus:

Kris: $\quad$ We would have these side conversations as we went, and ... the starting point was the kids ... and there was that equality of roles.

Raewyn: We had those side conversations that made me think about the way the kids were responding in a way that I probably wouldn't have if I'd just been sitting there teaching it ... I might have been thinking about what $I$ was doing or ...

Kris: $\quad$ The kids' needs were at the centre which allowed the adults to weave together because there's strengths in both. 
Raewyn: Doing it together helped to really explicitly focus on what the kids were doing, and getting out of it, and connecting with, and not connecting with, and that's a real strength.

Kris: $\quad$ I totally agree ... our kind of model puts the child at the centre and what their need is and interestingly that's what's woven over our collaboration today.

We had noted how directing our actions towards explicit learning goals for the students supported us to coordinate our teaching, and we speculated that this would not have been so successful if our focus had been on our teaching. In other words, we believed that if we had directed our attention towards how we would teach together, rather than we what we trying to achieve for these students, we would not have experienced the synergies that we had in these lessons. In other words, we would not have been as 'in tune' with one another's teaching (Roth \& Tobin, 2004).

Shortly after this co-teaching experience, near the end of the third group meeting, I asked the four teachers if I could make an informal visit to their classrooms to observe them teaching a mathematics lesson, followed by an audio-recorded reflective conversation. I suggested this as an alternative to the teachers capturing their reflections individually:

Just to pop into your maths classroom and be a fly on the wall. I'm really aware [of] the challenge of getting regular reflections done and ... I was thinking about my own experience as a teacher and how tricky that is, but the reflection conversations will be really useful ... and just record that "how's it all going?" conversation.

Kris made the alternative suggestion that I might co-teach with, rather than observe, teachers:

Or the other option is, I mean this is putting it out there, is I had Raewyn come in and co-teach with me and actually the power in that for me as a teacher ... that shared responsibility of teaching a lesson was really powerful and it might be able to dovetail into that reflection.

Although we had not previously discussed introducing the option of co-teaching to the other teachers, I had also wondered about doing so and I supported Kris' suggestion:

Let me know if you want me just to sit and be an observer or whether you want me to come in and join in with your lesson.... It was really informal and yet 
powerful in Kris' class so it'd be interesting to see, but totally on the basis of your own preference.

In response, Sam, Pat and Casey all agreed to try co-teaching and it was subsequently arranged via email that I would co-teach a lesson with each of them prior to the next group meeting.

\subsection{Developing and trialling co-teaching as an innovation: First experiences}

As previously discussed, the idea of co-teaching lessons developed from the broader programme of project activities and having co-taught with Kris I subsequently co-taught lessons with Sam, Pat and Casey in each of their classrooms. Kris also cotaught lessons with Pat and Sam as part of their performance appraisals. Shortly after these initial co-teaching experiences, a change in circumstances made Sam unavailable to attend group meetings and so she withdrew from the project. Consequently, the findings from this point draw on data pertaining to the three remaining teachers; that is Pat, Kris and Casey. The examples that follow draw on data relating to two of these co-teaching episodes including how the teachers described and made sense of the coteaching experiences in the context of group meeting discussions.

\subsubsection{Pat and Raewyn co-teaching in Pat's classroom}

The fourth group meeting started with a quick round of 'what's on top' in which teachers shared a 'wow moment' that had happened since the previous meeting. Pat talked about her first co-teaching experience which had been in her classroom with me.

Example 6.2(A) Reigniting the joy of teaching: "I feel inspired again"

Pat started the discussion by saying how much she had enjoyed co-teaching the lesson:

It was a really good experience ... it almost made me spark my teaching again, it was one of those moments where it's like "Oh I feel inspired again' and want to go and do it again ... it was a really enjoyable lesson and the kids enjoyed it too because it was their way of engaging and really thinking about what they're learning ... it was just really great just to see the children enthusiastic about learning about maths. [P-GM\#4] 
The discussion at this group meeting was for the most part limited to Pat's description of the events of the two lessons; there was very little discussion of the episode by the other teachers. Pat's observations were generally focused on student talk with some attention to one student's actions:

We let them talk and let them share their ideas and just let them go ... you can see that they're really starting to listen to each other and starting to talk to each other. One clicked on and he was sitting back and [student] ... had his way of explaining like he didn't want to talk too much but he questioned the others about why they did these things ... almost like, I've introduced it [talk moves] and then I sat back and just let the chaos run ... it was really interesting just to see it just all come out and just the way that they talked to each other and I just sat back and then I did the repeat and I'd said "did you say?" or "you're saying this?" and they were "Ah, maybe that didn't sound right". [P-GM\#4]

Pat's noticing was largely oriented to the ways in which students engaged with the task including some of the challenges they encountered:

Some parts didn't actually come together but [laughs] they were all wanting to learn the maths and that was the key. That no-one was put off. No-one was worried about whether they were getting it right or wrong. A lot of them had a go and started thinking about where they went wrong and that was the great thing about it. You know, we always talked about that it's okay to get things wrong, it's what we do afterwards is what counts and they certainly live that. It's just giving them that bit of power ... but again it is a difficult one to actually hold back because you have to really let it go and sometimes you just feel like "No, you're getting it wrong, jump in, and jump in and direct them" whereas when you you're just used to questioning and repeating what they're saying, then it gives it back to them. [P-GM\#4]

How she described this lesson contrasts with earlier experiences of using talk moves in which the focus for both Pat and her students was on listening rather than talking. Initially Pat had appeared to see talk moves as primarily a tool for monitoring the students' attentiveness:

Tracking to see whether they're being attentive or not and some just get caught out ... I guess for me it's just the attentiveness of them being able to listen has been like tick number one first. [P-GM\#3]

The co-teaching episode appeared to be highly motivating for Pat, particularly in relation to what she saw as the empowerment of her students to engage in 
mathematical thinking and discussion through her use of talk moves. Furthermore, the detail in Pat's descriptions of the students' talk in the example above suggests greatly enhanced noticing compared to her more general comments at the previous group meeting, for instance:

They're doing a lot more talking in terms of the language as well with the use of the talk moves [P-GM\#3].

\subsubsection{Pat + Kris co-teaching in Pat's classroom}

After the group meeting at which Pat had shared the co-teaching episode described above, she went on to co-teach a lesson with Kris. In Kris' mathematics leadership role, she was required to appraise Pat's mathematics teaching. As an alternative to the normal practice of observing Pat's teaching, Kris had offered her the option of co-teaching a lesson together. Pat agreed, perhaps unsurprisingly as she had enjoyed her first experience so much. At the group's fifth meeting, Pat and Kris shared a video excerpt from their co-taught lesson and this is discussed below.

Example 6.2(B) Reflecting on a co-taught lesson: "It did make sense"

The lesson had been predominantly planned by Pat, however she had shared her planning with Kris:

Pat: I emailed Kris yesterday about the lesson and what I had planned and I also said to add anything else, feel free to jump on in, add bits and pieces as we go along. And so there was that understanding right there, right before the lesson started ... she was able to go and prepare bits and pieces as well.

Kris: And then I took stuff into her as follow up for the kids and teacher stuff and I guess I did that to show Pat that I didn't just get an email and say "oh yep, that's great". I wanted her to know that I was committed to what was going on in her classroom. You know, a bit like the decimats, how you [Raewyn] came in and had them laminated ... it wasn't just an experience that you were coming for ... you were contributing to the learning.

Sharing video from the lesson, Pat appeared to have chosen an excerpt to highlight the students' mathematical talk. After viewing the video excerpt, the teachers' discussion centred initially on the task and the students' approaches to solving it, including for example: 


Casey: $\quad$ Referring to a student in the video] so how many has she got, how
many does she start off with, how many counters?
Pat: $\quad$ That's what she's working out.
Casey: $\quad$ Ahhh, she's working it out.
Pat: $\quad$ So they have to figure out what the whole is when half is given ...
$\quad$ Oh, this one here, he just wanted to say something [laughs].
Apparently in agreement with Pat, there is laughter from the group because the
student's explanation appears to be related to the solution only and not to the
problem itself however Kris challenged the assumption that the student "just
wanted something to say" and suggested instead:
But that was him making sense that if it was going back the other way how
many would they each get you know "and if I put down eleven then I'd have
one less" ... it did make sense. [K-GM\#5]
Kris' interpretation of the student's contribution contrasted with how she perceived
his thinking during the lesson:
I'd assumed actually, when I first saw it, that ... he just wanted to participate,
he didn't really have anything to add. [K-GM\#5]
mad been expecting the conversation to take a particular direction which
me from going any further because I thought, "ah, no" [laughs]. [K-GM\#5]
lots of three road, it had led us into multiplicative thinking and I thought if I
mand and didn't notice:

Pat appeared to see sharing her video as primarily an opportunity to make public and celebrate her improved practice and the positive impact it was having on her students. For Pat, sharing this video excerpt was about demonstrating positive outcomes from a professional learning experience rather than providing an artefact to be critically examined as a resource for the learning of the group. This was picked up by Kris and later in the meeting when the group was discussing what they would focus on next she commented: 
If we were going down the video road... we might need to look at supporting us to make sure that we have got video that's informative to others practice ... the video does not necessarily mean that it's a good video. [K-GM\#5]

She was open to continuing to share videos of classroom teaching however suggested that these would need to be carefully chosen to support teachers' learning.

Nevertheless, sharing the video excerpt from Pat and Kris' co-taught lesson had supported a critical discussion of aspects of the lesson. Despite being an active participant in the lesson, sharing the video excerpt had prompted Kris to notice something she had not during the lesson, opening an opportunity to make sense of a student's thinking from a new perspective. Viewing the video excerpt in the group setting, Pat's commentary had drawn attention to the student whose contribution may have otherwise gone unnoticed. Kris then challenged Pat's perspective which focused her comments on the mathematical sense-making of the student, a shift from "what are they doing?" to "how are they understanding the mathematics?" Kris' observation also afforded her the opportunity to reflect on how the student's unanticipated explanation had narrowed her opportunity to respond productively to his thinking at the time.

\subsection{Contrasting co-teaching and appraisal observations}

Being observed in their practice by curriculum leaders was a familiar and regular experience for the teachers. Classroom observations generally involved the curriculum leader watching a lesson and completing an evaluation checklist, followed by a conversation aimed at providing feedback and next steps for the teacher in relation to aspects of the observed practice. Sharing Pat and Kris' co-teaching experience during group meeting five prompted the teachers to discuss some of the perceived benefits of co-teaching, including in contrast with teacher appraisal observations.

Example 6.3(A) Learning from reflecting on and in practice: "It's the shared experience"

Describing their co-teaching experience prior to showing the video excerpt, Pat stated that she had enjoyed co-teaching with Kris and compared it favourably to the experience of being observed and given feedback: 


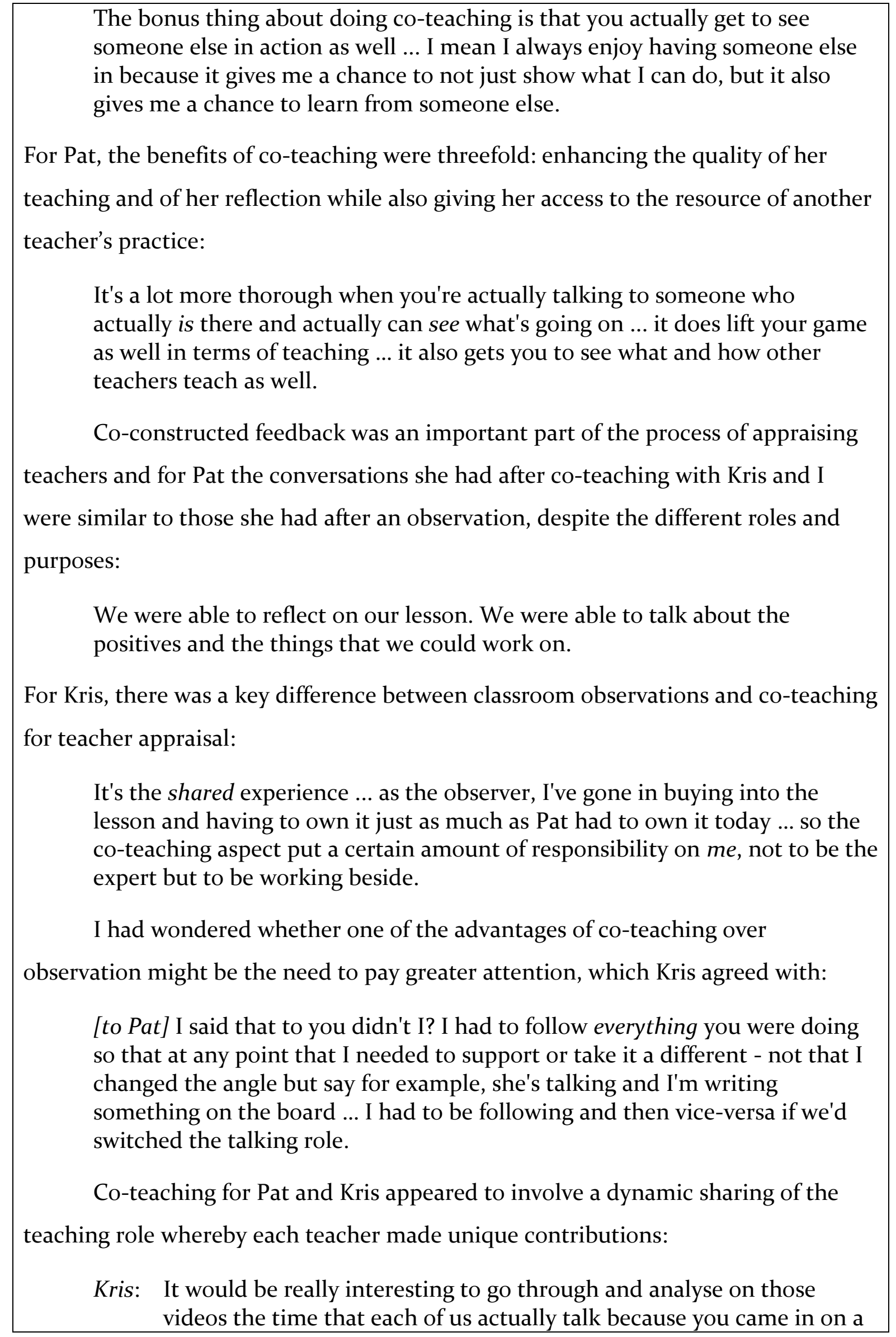




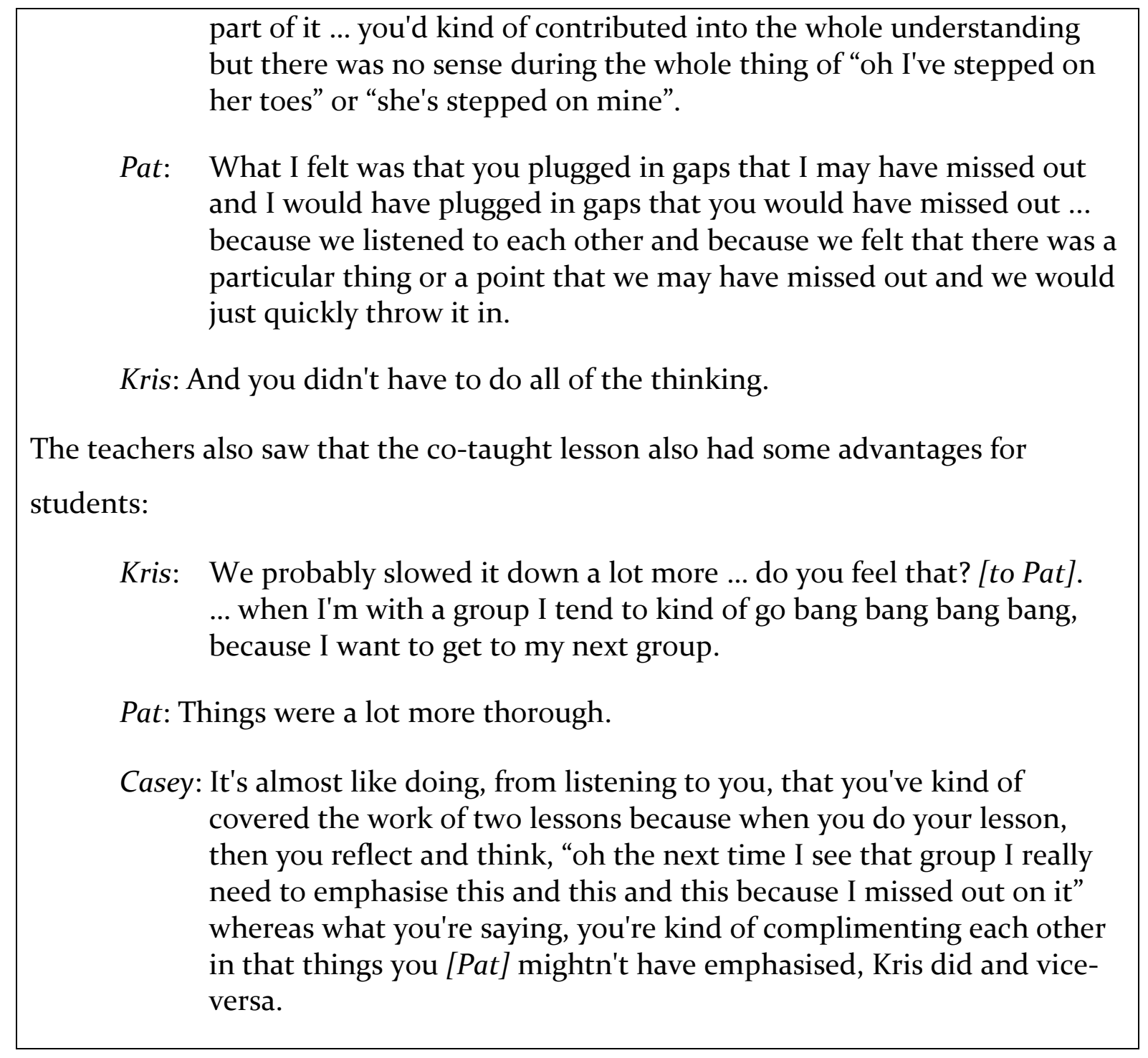

Classroom observations as part of the school's teacher appraisal process had the parallel aims of evaluating the quality of teaching and supporting the development of teachers. The observer, in this case Kris as curriculum lead teacher, took the role of expert and mentor, providing feedback for teachers and helping them to identify "next steps" for their professional development. Kris and Pat's experience of co-teaching for Pat's appraisal appeared to offer some advantages over observing a lesson. Pat enjoyed co-teaching and the experience offered some additional resources for her professional learning including the opportunity to see an expert teacher's practice and to engage in deeper levels of reflection because the experience was shared rather than observed. Co-teaching supported Pat to "lift her game" and teach at her best. It also appeared to expand the opportunities for student learning by slowing the lesson down and 
allowing students to engage more thoroughly with the content. From Kris' point of view, the co-taught lesson gave her deepened access to Pat's practice as a resource to inform both her evaluation of teaching quality and the feedback conversation they had after the lesson. Casey highlighted the expanded opportunity that co-teaching had afforded the Pat and Kris to reflect-in-action (Schön, 1983) and respond immediately to what they noticed about how their teaching impacted on their students.

\subsection{Co-teaching as a feature of the teachers' collaborative inquiry: Enacting, sharing and discussing co-teaching with colleagues}

After Pat and Kris had shared the video of their co-taught lesson and it had been discussed at the group meeting, I posed the question "where to from here?" suggesting that it was time to pause and consider how to build on our work to date. Up to this point, the teachers' inquiry activity had been particularly focused on implementing talk moves as a pedagogical strategy, and as a group we had shared and discussed videos and descriptions of teachers' practice in relation to this goal. Kris, Pat and Casey had each co-taught a mathematics lesson with me, and Kris had co-taught lessons with both Pat and Sam for their performance appraisals. Kris suggested exploring the co-teaching idea further, saying:

My personal opinion is I'd like to ... look at or talk about co-teaching ... because there's that shared experience that I think there'd be a deeper understanding of what's happening in the classroom. Whereas if it's the video ... sometimes you're trying to follow the mathematical kind of learning that at least if you've had a shared experience that you can talk on the run. [K-GM\#5]

For Kris, access to understanding classroom events appeared more limited when sharing video excerpts than when sharing the experience of teaching together where there was an opportunity to talk about what was happening 'in the moment'. In other words as Casey had observed earlier in the conversation, co-teaching supported the opportunity to reflect in, as well as on, practice (Schön, 1983). Furthermore, because the co-taught lesson had already been experienced and talked about by the coteaching pair prior to sharing the video with the wider group, Kris had found that she was more able to focus her attention on how their teaching was impacting on the students. 
Following Kris' suggestion, Pat, Casey and Kris agreed to trial co-teaching in one another's classrooms with me providing the classroom release to allow them to do so. This section examines three lessons, each co-taught by a pair of teachers and then discussed at subsequent group meetings. Sharing the co-teaching episodes at group meetings involved the teachers' descriptions of events during the lesson, and in some cases the group also viewed video excerpts.

\subsubsection{Casey and Pat co-teaching in Casey's classroom}

Having had two experiences of co-teaching in her own classroom, first with me then with Kris, Pat readily volunteered to co-teach a lesson in Casey's classroom. The co-taught lesson was video-recorded by the two teachers and they shared an excerpt of the video at the sixth group meeting. The following two examples illustrate findings from the group's discussion of the co-taught lesson.

Example 6.4(A) Making teacher learning goals explicit: "Just a communication thing"

At the start of the lesson, Pat and Casey had explicitly established a shared purpose and responsibility for one another's emotions:

Casey: The other teacher might be feeling a bit anxious but ... I said [to the students] we were lucky to have you as helping us learn and teaching together and so we established that at the beginning.

Pat: But I also said that I was here to learn as well, and I think it's just, as I said, that reassurance between each other to say that we are on the same page and that I'm not here to critique I'm here as a support person.

Casey: As a learner and the same with me. [GM\#6]

They described how they each had a learning focus for the co-taught lesson:

Pat: What was great is that you also mentioned some of the things that you wanted to try and sort of like notice and work on which sort of automatically made me think okay so how can I support, but ... it wasn't just a learning experience for you, it was also a learning experience for myself as well.

Casey: Definitely for me, definitely. 


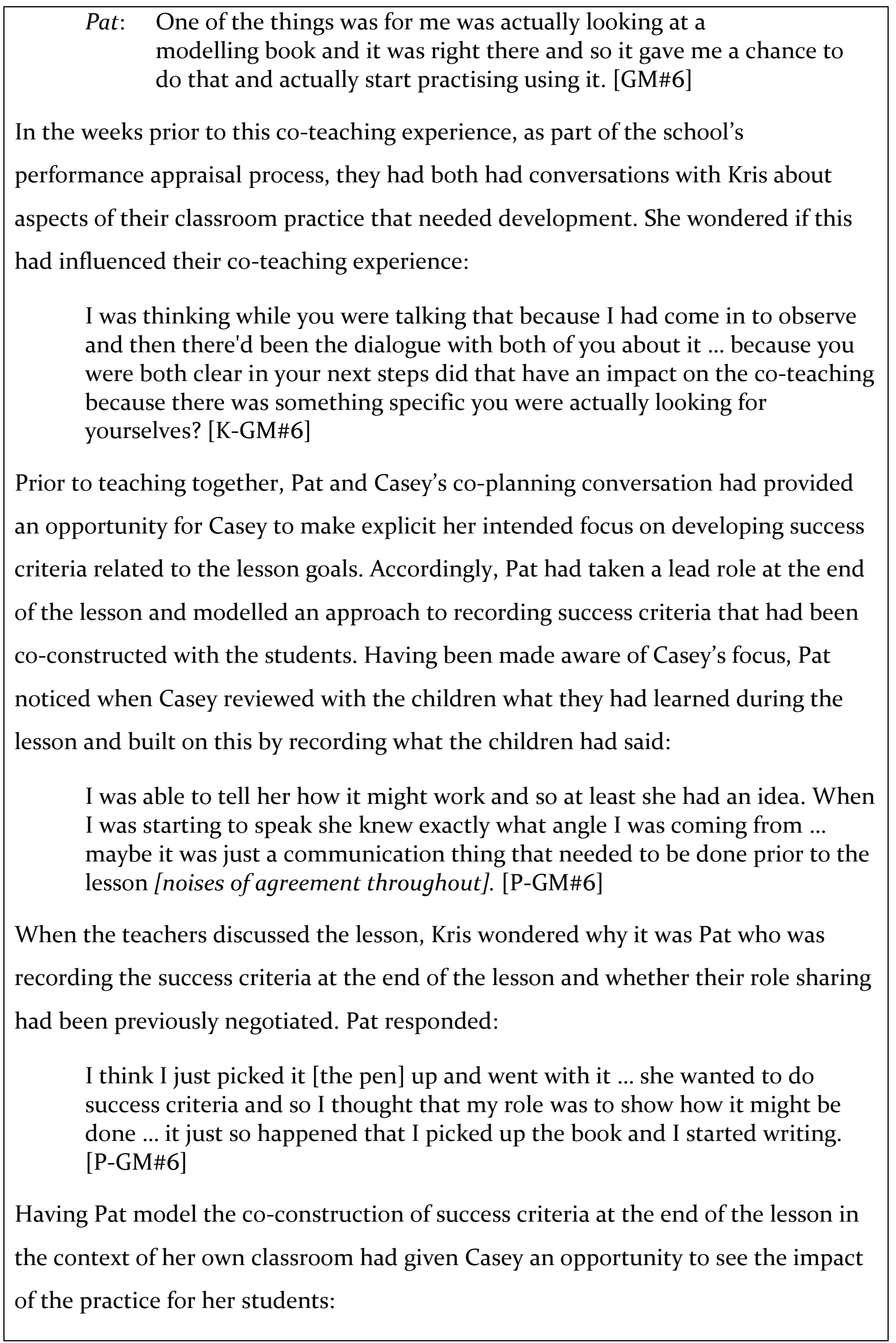




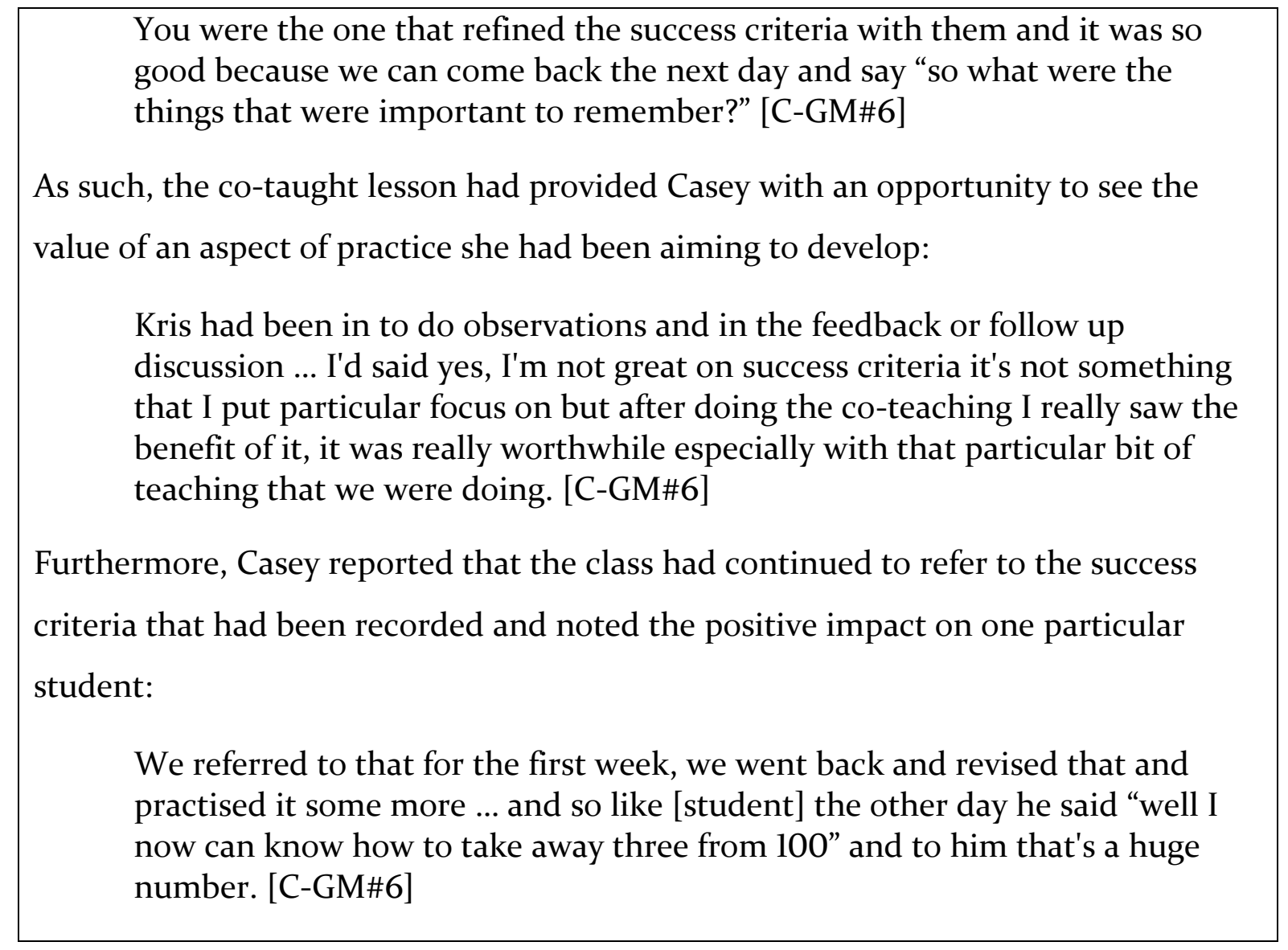

You were the one that refined the success criteria with them and it was so good because we can come back the next day and say "so what were the things that were important to remember?" [C-GM\#6]

As such, the co-taught lesson had provided Casey with an opportunity to see the value of an aspect of practice she had been aiming to develop:

Kris had been in to do observations and in the feedback or follow up discussion ... I'd said yes, I'm not great on success criteria it's not something that I put particular focus on but after doing the co-teaching I really saw the benefit of it, it was really worthwhile especially with that particular bit of teaching that we were doing. [C-GM\#6] practised it some more ... and so like [student] the other day he said "well I now can know how to take away three from 100" and to him that's a huge number. [C-GM\#6]

Co-teaching had allowed for multiple and flexible learning goals for both students and teachers to be attended to simultaneously. In their co-planning, Casey had articulated a learning goal that Pat then actively supported. That is, they had defined a specific object towards which their co-teaching activity would be directed. Furthermore, Pat's expert knowledge was a resource that both teachers were able to draw on as they acted towards the goal, thus influencing the roles each teacher took. For instance, Pat's decision to pick up the pen and act as recorder, provided Casey with access to Pat's practice as an enacted model. For Casey, the practice that Pat was modelling represented a relatively minor adjustment to her usual practice. Furthermore, Casey had an opportunity to see the practice enacted in her own teaching context and described how it had provided a useful resource for her students' ongoing learning beyond the lesson itself. Guskey's (2002) model of teacher change suggests that changes in classroom practice can be the catalyst for changed teacher beliefs where students' learning is positively impacted. In this example, Casey had access to Pat's practice in the context of Casey's own classroom. She had an 
opportunity to observe new practices and their impacts on her own students in her own teaching context, thus expanding the possibilities for her own future practice.

The following example also draws on data from the sixth group meeting and explores an additional theme to emerge from the group's conversation about Casey and Pat's co-taught lesson.

Example 6.4(B) Multiple shifting goals: "Do you know how long that lesson went on for?"

Reflecting on the video excerpt from Casey and Pat's lesson, Kris raised a challenge in relation to the teachers' collective goal of implementing talk moves:

One thing I noticed was that there wasn't a lot of think time happening in the lesson and I wondered about the impact of having two people doing the thinking and the talking through the lesson, what impact that had on the lesson for the learners ... it's something that I felt too that "oh gosh I can really think about what's happening". [K-GM\#6]

Kris observed that having two teachers involved in the lesson might have encroached on the students' thinking time as pauses in one teacher's instruction were filled by the other teacher:

When Pat was writing down there's automatic think time for the children whereas ... you [Casey] were talking, and did that impact on the children's ability to think about what the next success criteria was because they weren't getting that time to think, they were getting Mrs P [Casey] here asking another question?

Pat and Casey both articulated ways in which they had provided think time for the students in the lesson:

Pat: We did do think time ... before they started recording we actually did get them to think about what could be the steps to be successful. We also gave think time in terms of when we're giving them the questions and asked them what to think about and also to explain the question again to someone else.

Casey: That part when they were thinking about now how many fingers would they be showing, they were thinking then. [GM\#6]

Kris wondered if teachers needed to explicitly signal their intentions or risk coteaching partners inadvertently acting in conflict with each other's goals, for 
example where one teacher was aiming to provide thinking time for students, another may feel compelled to keep the lesson moving:

That's one thing that I think could be a real difficulty in co-teaching is that tendency to want to move forward ... "quick we better go [on]". [K-GM\#6]

Pat's heightened tone suggested she might be feeling defensive when she responded with some irony "do you know how long that lesson went on for?... it was full on". Casey agreed saying it "was like two lessons in one”. [GM\#6]

Pat and Casey's responses to Kris' challenge served to elicit their otherwise tacit assumptions about the nature and purpose of think time for students. An apparent contradiction in the example above is that multiple flexible, and sometimes competing, goals are being negotiated simultaneously in a co-teaching session, maintaining the activity in a constant state of flux. For instance, as the teachers' activity is directed towards Casey's goal of specifying success criteria with students, the teachers' overarching goal of learning to use talk moves is in part constrained as space for students to talk gives way to increased teacher talk. At the same time, coconstructing success criteria with students appeared to expand opportunities for student learning related to articulating mathematics understandings as they review what has been learned.

A further contradiction to arise in the example above is the contrast between Pat's stance around the importance of critical feedback for learning, and her apparently defensive response when an aspect of the lesson is directly challenged. Challenging Casey and Pat's practice appeared to promote a fruitful conversation whereby their justifications surfaced otherwise tacit beliefs and understandings about effective pedagogy. Nevertheless, Kris' challenge might have been seen as posing a potential risk to maintaining harmonious relationships amongst group members. How such contradictions were negotiated and served to promote opportunities for teacher learning is explored in later sections. 


\subsubsection{Pat and Casey co-teaching in Pat's classroom}

This section examines a lesson that Pat and Casey co-taught in Pat's classroom and then discussed at the seventh and final group meeting. The discussion was primarily centred on how they had worked together and the lesson itself was not described in detail. Nevertheless, two events of interest emerged from the co-teaching episode and these are discussed below. The first example focuses on Casey's use of concrete materials as a key aspect of her practice.

Example 6.4(C) Using materials: Pat learning from Casey's practice

In preparation for their co-taught lesson, Pat had explained to Casey her
learning intentions for the students. This gave Casey an opportunity to prepare what
her contribution to the teaching might be, and what she might bring with her:
It sort of gave me enough ideas that I came in prepared with some materials.
I didn't know whether we'd use them or not. [C-GM\#7]
During co-taught lesson in Pat's classroom, Pat had the opportunity to observe
Casey's use of concrete materials to develop the students' understanding of
subtraction:
Casey was really good with the materials and she really helped me in terms of
actually showing how to actually use those materials really well, how to use
other materials cos I haven't seen some of them. [P-GM\#7]
Pat saw Casey as providing a model of how to use concrete materials effectively in a
mathematics lesson:
Water in the meeting, Pat described how co-teaching with Casey had taught her
"how to use the materials better". [P-GM\#7]
expertise and so I was actually quite happy that she took a little bit more of a
role there. [P-GM\#7]

Data from video recorded lessons in Pat and Casey's classrooms at the start of the project showed a striking contrast between the two teachers in relation to how they used materials in their mathematics lessons. For instance, in her lesson with a group of learners who were exploring place value of teen numbers, Casey provided a 
wide range of pre-prepared and highly suitable manipulatives such as tens frames, bundled sticks, place value blocks and counters. In contrast, Pat's use of equipment in the lesson I observed at the beginning of the project was limited and unplanned. She initially used no equipment in her lesson with a small group of target students which had focused on multiplication however at one point when she was attempting to explain a concept that a student was struggling to understand, she fetched an abacus and attempted to demonstrate her point with it. At the time I had reflected that the abacus appeared to be a problematic choice for representing the mathematics idea, and Pat had seemed entirely unprepared for using it. Pat had previously commented on Casey's use of materials, resolving to "use a lot more materials and use them differently" in her own teaching. Through the sharing of video, Pat had an opportunity to see examples of, and discuss, Casey's use of materials which had prompted her to consider adopting this aspect of Casey practice into her own teaching repertoire. The opportunity to experience Casey's use of concrete materials in a co-taught lesson, in the familiar teaching context of her own classroom and her own students, positioned Pat as a legitimate peripheral participant in Casey’s practice (Lave \& Wenger, 1991; Roth \& Tobin, 2002) and opened an opportunity for Pat to experience "actions that were, at the time, not part of [her] own range of possibilities" (Roth \& Tobin, 2004, p. 164). For Pat, there is a shift from identifying the use of concrete materials as something that might be developed as part of her practice, to an enacted experience of doing so, perhaps opening possibilities for Pat's future learning (Bransford \& Schwartz, 1999) for instance by sparking her to notice and ask increasingly sophisticated questions about how concrete materials might support her students to develop understandings of mathematics concepts.

A second event of interest that emerged when Pat and Casey were reflecting on their lesson in the final group meeting was related to behaviour management and support for student engagement. The example below outlines how they negotiated their different perspectives of the behaviour of one of the students they were working with. 
Example 6.4(D) Pat and Casey see things differently: "It comes down to relationships"

Reflecting on the co-taught lesson, Pat and Casey appeared to agree that having an additional teacher made it easier to keep children focused. Nevertheless, they had different expectations for the behaviour of at least one of the students in the group:

Pat: The children are less likely to move [laughing] cos there's another set of eyes that are keeping them on task.

Casey: There's me on the video, I'm sure I'm saying "come on [student]" cos [student]'s rolling on the floor, his pen lid has gone under the couch and I'm pulling him in so you probably see me [laughing]... they're on the mat they've gotta be focused

\section{Pat: $\quad$ You know I'm not going to say ... [GM\#7]}

Pat and Casey were talking over one another however Pat appeared to register that Casey's perspective was different to her own. Pat responded to Casey by first affirming Casey's actions:

I saw you doing that and I was like well you know good on you ... but then when you did that once everyone started again I told you a little bit about [student] and about how he works. [P-GM\#7]

Then, explaining how she had shared with Casey her perspective on this student's needs, Pat went on to comment on the importance of co-teaching partners having a trusting relationship in which such conversations can occur without risk of losing face:

For me it comes down to relationships. If you don't have a good relationship with the teacher that you're co-teaching with then you don't have that trust, that sense of yes, we are together on this, then it's not going to work. [P-GM\#7]

Pat and Casey's discussion appeared to surface conflicting beliefs about appropriate student behaviour and illustrates the intertwined notions of trust in, and accountability towards, one another in a co-teaching context. In affirming Casey's action, Pat appeared to be attending to their relationship and had moved to protect Casey's mana. Pat had then surfaced an alternative view of the student's behaviour who Casey had seen as off task and needing to be "pulled in". Pat made her own 
alternative perspective available to Casey as a resource, and to the wider group as a reflexive object. In doing so, Pat was afforded an opportunity to surface and justify her beliefs about what motivates the student's actions, which in turn informed both Casey and Pat's future responses to that student.

This exchange was evidence of the growing trust within the group and illustrates the dynamic interplay between risk and trust and how these influenced and were influenced by relationships among group members. Teacher learning is constrained when teachers are reluctant to expose their practice to scrutiny for fear of negative consequences (Le Fevre, 2014). Where teachers' actions were perceived to involve risk, a successful outcome appeared to reduce the perception of risk and support future action. In prior meetings, teachers had shared video excerpts accompanied by discussion that was encouraging and avoided criticism, and Casey had enjoyed a successful co-teaching experience that she was keen to share and have publicly celebrated by the group. The group's work provided a forum to celebrate teachers' success and this both enhanced the teachers' experience of a successful teaching | learning episode and strengthened the sense of the collective of the group allowing for expanded future possibilities for action.

\subsubsection{Kris and Pat co-teaching in Kris's classroom}

During the final group meeting, Kris and Pat also shared an excerpt of a video from a lesson they had co-taught in Kris' room. The lesson involved adding decimal numbers and the students were using decimats to make sense of the problems posed.

Example 6.4(E) Focusing on mathematics: "It's not point nine ... it's nine tenths"

Kris introduced the teachers' rationale behind choosing this particular video excerpt to share, saying that the student it focused on was "I guess proof of the talk moves working." She drew attention to the mathematical explanation the student had given, and the way in which Pat had responded to it:

Here's [student] who's clearly listened to someone and explained or you know clarified ... why somebody's misconceived the question and then Pat's picked up on the whole factor and then from this point it's not point nine and point seven it's nine tenths and seven tenths is being added. [K-GM\#7] 
Reflecting on the mathematical language the student had used and the clarity of his explanation, Kris noted:

What was great was that Pat hasn't been part of any of the prior teaching ... but he [the student] had explained it in a way that Pat could follow it. [K-GM\#7]

As the teachers continued their discussion Pat described how she had supported the students to make sense of adding 0.9 and 0.7 using the decimats:

We were talking about the parts and he was going to just add on point seven and create more parts where I said "well what does point seven look like and shall we draw another bar and then you can show me that?" and so then they could see the connection of "oh actually I just need to make four bars to make one whole" and then they could see "oh okay well I'll just tag on that little bit there and I've got six left on here so it's one point six". So they can actually see that they're actually trying to make wholes from there ... I said "well let's make them point seven" so they could see that just like how we're adding our counters that they're just shifting over to make one whole. [P-GM\#7]

Kris had described how she had chosen this excerpt to demonstrate the impact of using talk moves and she drew attention to the clarity of the student's mathematical explanation. For Kris, this was an important example to share because this student would not previously have been expected to provide such an explanation. Pat's turn in the conversation illustrates how the student's explanation had opened space for Pat to engage in her own mathematical thinking and sense-making as she worked with the group to build on the student's explanation and apply that to solving the problem. Here, Pat was describing how students had used the decimats to make sense of the numbers and the addition operation, and in doing so she was illustrating how engaging with the student's explanation afforded new ways for her to understand the mathematics content. Responding to Pat's unfamiliar approach to questioning, the student extended his understanding of decimal place value by making an explicit connection between place value and decimal fractions. For the student and teachers alike, a learning opportunity was created whereby the student was given a new 'way in' to understanding decimal fractions and the teachers had to pay close attention to make sense of an unanticipated line of reasoning from the student. It was 
unanticipated because Kris could not anticipate the student's response to Pat's approach to questioning, and Pat did not know the students in Kris' class sufficiently well to anticipate their responses to the task. As Ma (1999) suggests, teachers learn mathematics content as they are engaged in its teaching whereby students' and teachers' learning each supports the other in a reciprocal and simultaneous manner. Ma argues for "a teaching context in which it is possible for teachers to improve their knowledge of school mathematics as they work to improve their teaching of mathematics" (p. 146) and for Pat the co-taught lesson appeared to provide such a context.

\subsection{The three phases of co-teaching: Co-planning, co-instruction and co- reflection}

Consistent with Roth and Tobin (2004), co-teaching, as a feature of the group's model of collaborative inquiry, was conceptualised as comprising co-planning, coinstruction and co-reflection. Alongside the shared instruction of a mathematics lesson, the group saw co-teaching as also involving a shared contribution to planning the lesson, and a shared reflective conversation after the lesson, as described by Kris:

We see co-teaching as being from pre, teaching, reflective say that there's those three phases. [K-GM\#7]

This section outlines findings related to the teachers' experiences of co-teaching as a three-phase process.

\subsubsection{Co-planning for student and teacher learning}

Shared planning prior to a co-taught lesson was considered important preparation for teaching together so that co-teaching partners had a shared understanding of the mathematical content of the lesson and the learning goals for the students, as well as their respective roles in the co-teaching arrangement itself. Knowing what to expect appeared to be particularly important for the teacher who was 'coming in' to co-teach in another classroom. A function of co-planning appeared to be an opportunity for teachers to access important content knowledge prior to teaching at an unfamiliar class level in order to feel confident and prepared for the 
teaching. From the outset, Casey had emphasised the importance of teachers' content knowledge and she saw her contribution in a co-teaching situation as contingent on having an opportunity to engage with the content prior to a co-taught lesson:

I'd like to think that I would have time to investigate the content knowledge first, so we'd have to agree on what the lesson was going to be. [C-GM\#5]

In addition to knowing the content of the lesson, Kris suggested co-teaching partners needed to also share an understanding of the learning goals for the group of students:

Kris: You can prepare yourself for the interaction and it's one thing knowing the content knowledge. Like I said to Pat "oh we're going to be subtracting decimals" and we ended up adding them. The content was there but also I made a point of saying to [Pat] "and these are the reasons why that group is there with me" and also when I led into the lesson that was said again so that the kids were quite clear as well. So that whole pre-conversation is so important to, I think, the success of the lesson that happens.

Casey: Yes, yeah it is.

Pat: Cos otherwise you're sitting there like a bit of a dumbo. [GM\#7] The fear of "sitting there like a bit of a dumbo" was shared by Casey for whom a coplanning conversation prior to teaching with Pat provided openings to actively participate in the co-taught lesson:

I felt quite nervous ... before going in wondering whether I would be just sitting there like a sack of potatoes not knowing what to do, but I think when Pat had sort of filled me in beforehand and so I had an idea what of what we were doing, I think I pretty soon got a sense of where the children were at and what I could come in with. [C-GM\#7]

Casey's short conversation prior to teaching with Pat was instrumental in shaping the lesson. Having an insight into Pat's intentions for the lesson allowed Casey to make a planned contribution to the instruction. This also provided access for Pat to Casey's materials-based teaching approach which expanded the possibilities for Pat's future practice as described previously.

Rather than co-constructing lesson plans together 'from scratch', co-planning was seen as an opportunity for the classroom teacher to inform their co-teaching partner about what was already planned for the day's lesson, and to seek some 
additional input and feedback. As such, lessons were primarily planned by the classroom teacher and were then shared with the teacher who was 'coming in' to coinstruct. Pat suggested that "a really good place for co-teaching is when you do your target groups" whereby planning for co-teaching began with showing your co-teaching partner what you had planned, for example:

This is what I've put down here, this is what I know. Can you come in and we can do it together and just to see if my way is like what you're doing or is there any way I could better myself. [P-GM\#7]

From this perspective, the primary role of the co-teaching partner seemed to be to influence the enactment, rather than the development, of the plan. Nevertheless, in Pat and Casey's experience for example, although Pat had pre-planned the lesson, Casey was able to influence the content and focus of the lesson:

I'd talked about that we were looking at, renaming and subtracting and coming back through there, and you brought up the point about the place values and understanding so you brought up that language thing there. [P-GM\#7]

The main focus for teachers planning together before a co-taught lesson appeared to be on the lesson itself and the intended learning of the students. In addition, conversations prior to teacher together allowed opportunities for coteaching pairs to identify and make explicit their own professional learning goals. For instance, Pat described her conversation with Casey prior to co-teaching in Casey's room:

When we talked [prior to co-teaching] we had a purpose, we knew what we wanted them [the students] to do, we knew what we were going to get out of it. [P-GM\#6]

She suggested that these dual purposes were negotiated collectively rather than being imposed by one of them.

Co-planning was seen to establish the direction of the lesson however the teachers agreed that this needed to be balanced with sufficient flexibility for teachers to be responsive both to each other and to the students:

I think in all our teaching we might be well planned or have good ideas but you still go with the moment don't you? You still pick up on what comes up [C-GM\#6] 
Similarly, Kris suggested that there needed to be a balance between co-planning how the teaching was to be shared, and the flexibility to share the instruction naturally:

It's just an important thing about co-teaching that there's the planning but there's also that if you're too planned ... then it doesn't feel natural. [K-GM\#6]

Co-planning appeared to provide some key resources for the co-taught lessons including discussing the mathematics content prior to teaching, identifying useful lesson materials, and negotiating how to share the teaching role during the lesson. Furthermore, the co-planning and co-reflection aspects of co-teaching appeared to be connected in important ways and this is discussed in section 6.5.3 below.

\subsubsection{Co-instruction: A flexible arrangement for teaching mathematics together}

After Kris, Pat and Casey had all experienced co-teaching with me in their classrooms, and prior to co-teaching with Pat to collect evidence for her performance appraisal, Kris had begun to consider exactly what we meant by co-teaching:

Although I'd said "Yeah co-teaching, I'm open to this concept as part of the appraisal" ... but then I was like "What is this co-teaching?" We hadn't really ever defined it ... all we know is that it's somebody else coming in who's a professional in a teacher capacity ... but I kind of needed to have clear in my head that today, when I entered Pat's room, that we were a team of teachers teaching this maths lesson. [K-GM\#5]

Kris had made an internet search for 'co-teaching' and accessed a document which drew on the work of Friend and Cook (e.g. 1992) and outlined six approaches to coteaching referred to as: one teach, one observe; one teach, one assist; parallel teaching; station teaching; alternative teaching; and team teaching (State Education Resource Centre (SERC), 2004). She suggested that we wanted to avoid a "one teach, one observe" approach:

We weren't going for that thing, that was the model that we trying to keep away from. [K-GM\#5]

We saw co-teaching as involving the shared instruction of a mathematics lesson by two teachers who were both actively involved in the teaching task. That is, both teachers taught the lesson together, as described by Kris:

Team teaching ... is what we headed for whereas I would say the first time that I co-taught with you [Raewyn] it was the one teach, one assist when we were in 
there, yet when we came here [for our second co-taught lesson] we shifted to the team-teach.... Although we had never discussed what co-teaching was going to look like in your room [Pat], I knew enough from what you were saying that you really didn't want me sitting there being this person who ticked boxes; that you wanted me involved in what was happening. [K-GM\#5]

This "team teaching" approach to co-teaching did not preclude the teachers from flexibly arranging how they shared the teaching task according to their particular purposes. This flexibility in arrangements for co-instruction was a particular characteristic of co-teaching for this group and allowed the teachers to be responsive to the needs of students. For instance, during their co-taught lesson in Kris' classroom, Pat and Kris had split the group of students they were teaching into subgroups to attend to identified student needs:

We talked about "well we've got particular skills, let's break the group into a smaller group" and so we trusted each other that I'll look after this one and you look after that one. [P-GM\#7]

During the teaching episode, Pat and Kris had noticed that some of the students they were working with needed further support to understand a particular concept while others were ready to move on in the task. Their decision to divide the group in two and have each teacher work with a subset of the students for part of the lesson was a negotiated response to their in-the-moment reflections, which themselves were contingent on both teachers being actively involved in the teaching of the lesson.

The flexibility of co-teaching arrangements also allowed the teachers to be responsive to their own and their co-teaching partner's needs. For instance, Kris responded to Casey's reservations about co-teaching when she was unfamiliar with the teaching level and mathematics contact knowledge by suggesting:

If you wanted to come and co-teach with me, come in and be the assist person. Don't come and team teach with me. And I'd love you to because you'd do some questioning that would promote thinking which you wouldn't need to have the content knowledge for. [K-GM\#5]

Teachers were able to arrange their co-instruction to be responsive to the teaching context and teachers involved whereby each teacher made a unique contribution. 
The teachers saw co-taught lessons as their joint work and at the same time could identify their individual contributions as illustrated by Casey's comments during the final group meeting:

Remember when we did the success criteria? Now you took it really back to basics and I've kind of used that model because Pat was very thorough and because we came up with that together. I mean that's been on that page and we've [Casey and her class] referred to it. [C-GM\#7]

Casey's reference to what "we did" implies teaching with Pat is a shared practice while at the same time "you took it ..." marks an element of the instruction that she saw as Pat's individual contribution. The co-teaching arrangement created a dual teaching role that was dynamic and alternated between taking an active or more passive role in the instruction. Casey evoked the metaphor of a dance in which partners step up to occupy, and step back to create, space:

I think it's good because when you'd mentioned something and then I came in with something else ... it was almost like doing a dance in a way knowing that you take a step back and this person comes forward and because you are it does give you a bit of time to think about where to next. [C-GM\#7]

While one teacher assumed responsibility for moving the lesson along, the other could stop and think about their next move or the impacts of their last one.

\subsubsection{Co-reflection: Reflection on and in action}

After co-teaching mathematics lessons, teachers reflected together on the experience at two levels, as a co-teaching pair following the lesson, and with the larger inquiry group at our three-weekly meetings. As discussed previously, Kris, as lead teacher of mathematics and responsible for teacher appraisal observations, had offered teachers the opportunity to co-teach a lesson as an alternative to being observed in the classroom. Kris and Pat's reflection after their initial co-teaching episode was framed by an observation checklist that was used to collect evidence for the professional appraisal of teachers:

I had the observation sheets in our talk after and it was actually really powerful because we got to talk about it ... she [Pat] got to identify her next steps through our discussion as opposed to me going "here's the boxes that didn't quite get a tick, can you explain why?" and leaving it at that.... So, although it 
took a little bit longer, we'd had the shared thing where we could say "yeah that happened, or it didn't happen”. [K-GM\#5]

Here, Kris was contrasting the feedback conversation after co-teaching with those she had with teachers after an appraisal observation. Although she had previously described working with teachers to co-construct observation feedback, she saw the reflection after co-teaching as "more powerful" where the two teachers worked together to identify which aspects of practice were effective and which needed strengthening. Referring to her experience of co-teaching with Sam, Kris commented on the importance of reflecting together on the experience of co-teaching:

That opportunity to talk afterwards about it quite quickly is really important. With Sam, we talked about the co-teaching as opposed to the observation ... but that was really important to unpack so that it gave her next steps for her lesson and it also gave me a chance to reflect on what next for my practice. Not what the content was being taught but for my practice. [K-GM\#6]

Casey suggested that it would be useful to develop questions to guide teachers' reflections after a lesson:

You don't necessarily have to look at each question and answer it. Just to get you thinking in a certain way, to get some sort of guidelines for when you say reflect, well what am I reflecting on? [C-GM\#6]

Agreeing with Casey, Kris suggested that a predetermined focus tied to the teachers' learning goals would support reflection to impact positively on their practice:

If people have been given the questions that they're going to be asked or to consider certain points, that the quality of the feedback is more powerful and impacts more on practice. And if it all linked back to that purpose like you [Casey] had success criteria and you [Pat] had the modelling book, that it linked back. When you got together you're able to go "this is what I think worked really well”. [K-GM\#6]

When I wondered if there might be a risk in providing a reflection protocol whereby people might follow it closely and reflect in a narrow way, Casey challenged the idea saying:

But there's also the risk of not thinking too deeply. We could just say "oh look that went really well, I really enjoyed it, thank you" and that's it finished. [C-GM\#6] 
Pat advocated using a common framework for reflection however Kris suggested instead that they each choose their own approach to reflecting on co-taught lessons and then share the different approaches at a subsequent meeting:

Wouldn't it be interesting if that's the model that best suits you [Pat], that's the one you use in your reflection and Casey might have a framework that she particularly relates to and I might have one and that's that reflecting framework and then bringing that in to share, and then we'll have some examples of different frameworks that are workable for teachers. [K-GM\#6]

The group agreed to the more flexible approach suggested by Kris.

Despite the challenge of scheduling opportunities for teachers to meet and talk about their lessons, Pat explained how after her co-teaching experience with Casey, a reflective conversation was a priority:

We were so busy afterwards [but] we knew that was an important link to meet afterwards and so we saw each other in the morning and we both thought we'd just say hello but actually both came together cos we wanted to talk about [the lesson]. [GM\#6]

The availability of release from their classrooms enabled the teachers to restructure their work to provide opportunities for timely co-reflection conversations after cotaught lessons. The importance of scheduling co-reflection conversations when arranging to co-teach was discussed at the penultimate group meeting:

If Raewyn came in for an hour or half an hour or something and it gave you the opportunity to meet together but to have that rich conversation, not on the run. [K-GM\#6]

In addition to reflecting after a co-taught lesson, an important element of the co-teaching approach was the opportunity for teachers to talk about their shared practice as it was occurring:

We didn't just wait til the end to talk, we actually talked to each other all the time, every little piece we did. So, when I was modelling I was talking and saying "what do you think about this?" or she's giving me feedback, I'm giving feedback, so every little thing.... We were able to not just support but share our understanding as well. [P-GM\#6]

For Pat, this ongoing talk during the lesson was about working together to try new approaches and see if they made a difference for learners, an arrangement that Casey described as "the ideal world if you can make it work". [C-GM\#6]. 
In summary, sharing planning to gain a sense of what to expect from the lesson appeared to be an important aspect of the teachers' reflections during and after the lesson. As such, at least some level of co-engagement in the three stages of coteaching, that is co-planning, co-instruction and co-reflection, constituted the coteaching activity. The interplay among the different stages of the co-teaching activity is illustrated by Kris' comment that:

Having that [co-planning] conversation allows you to process things that you can't process at the time when you're in there but you can prepare yourself for that interaction. [K-GM\#7]

The teachers were able to reflect both during and after their co-taught lessons in light of the intent that had been made explicit before teaching.

\subsection{Co-teaching as part of a bigger picture: An emerging model for teachers' collaborative inquiry}

The model of teachers' collaborative inquiry that was emerging at the end of the study retained some of the initial design elements however co-teaching was an important innovation on the initial design and had become a key feature of the approach. Co-teaching is described by Murphy and Scantlebury (2010) as "two or more teachers teaching together, sharing responsibility for meeting the learning needs of students and, at the same time, learning from each other" (p. 1). Similarly, Roth and Tobin (2004) describe co-teaching as “teaching at another teacher's elbow and taking shared responsibility for all parts of lessons" (p. 161). Consistent with these descriptions, the co-teaching model that emerged from this study consisted of pairs of teachers meeting to plan a lesson together, teaching that lesson in one teacher's classroom, then meeting to reflect together after the teaching. The co-taught lessons were video-recorded by the teachers and their shared reflection after the lesson was audio recorded. Video recordings of co-taught lessons were intended as a tool for teachers' reflections and were not collected as data for this study, however excerpts were shared and discussed in subsequent group meetings. Figure 6.2 depicts the teachers' collaborative inquiry model whereby it was envisaged that in each coteaching 'cycle' the teachers would potentially have an opportunity to co-teach twice with two different teachers - once in their own classroom and once in another 
teachers' classroom. The arrows indicate in whose classroom the co-teaching would occur. For instance, in the first co-teaching cycle shown below, Teacher A co-teaches with Teacher B in Teacher B's classroom, and stays in her own classroom to co-teach with Teacher C.

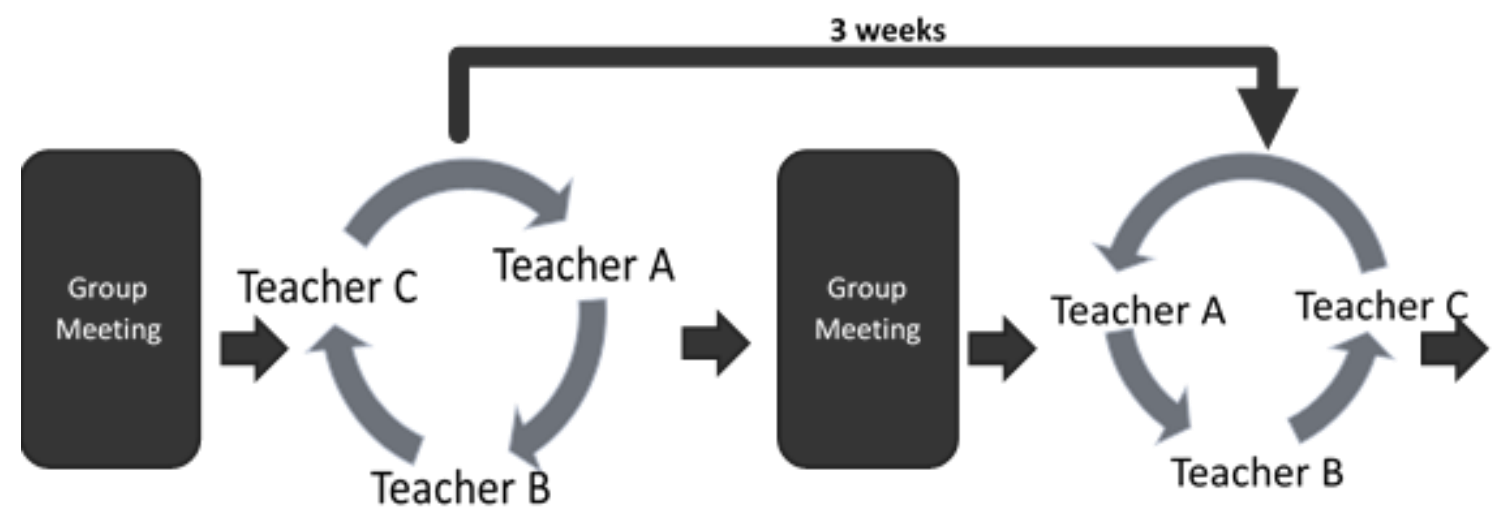

Figure 6.2. Co-teaching cycles within teachers' collaborative inquiry.

In this study, co-teaching a lesson involved the two teachers meeting prior to the lesson to plan together, actively participating in co-instructing the students during the lesson, and meeting after the lesson to reflect together on the lesson. The lesson comprised a single teaching episode and could involve either the whole class or a smaller group of students identified from within the class. There were no specific requirements or explicit expectations of what constituted co-planning and teachers made their own arrangements to meet, often a day or less prior to the lesson. It was generally expected that the co-taught lesson would be a component in the ongoing mathematics programme rather than one designed specifically for the purposes of coteaching. That is, teachers co-taught a lesson that might ordinarily be expected to occur in that classroom as part of the regular mathematics programme. The co-taught lesson occurred at a time normally scheduled for mathematics and the opportunity to co-teach was dependent on the availability of classroom release for the teacher who was working outside of their own classroom. Where possible, teachers were also released from their classroom teaching or other duties to co-plan and co-reflect. I am a fully registered teacher and classroom release for teachers to co-instruct lessons and to meet to reflect together was usually provided by me. At other times, classroom release 
was made possible by asking a colleague to supervise two classes, for example during a school assembly. In some cases, teachers reflected together in the classroom immediately following the lesson, while the students worked on tasks independently of the two teachers.

Between cycles of co-teaching, the group of teachers and I met to share and jointly reflect on the experience. The co-teaching cycle was then repeated in the reverse order. Thus, after two cycles, the participating teachers had opportunities to co-teach in their own and each of their colleague's classrooms, varying where and with whom they co-taught each time. In addition to the three lessons described in previous sections, Kris had also co-taught with Casey in Casey's classroom, a co-teaching arrangement which represented the biggest shift in teaching levels whereby Kris, who normally taught 11- and 12-year-olds, was teaching 6- and 7-year-olds with Casey. Kris and Casey had not shared a video excerpt from this lesson and so the group did not engage in a sustained discussion about it. Nevertheless, aspects of their co-teaching experience were discussed by the teachers in their more general reflections on the collaborative inquiry processes and data from these discussions are drawn on in section 6.8. During the course of the study, Casey had not co-taught a lesson with Kris in Kris' classroom and, as previously mentioned, she had expressed reluctance to do so. Nevertheless, Casey had agreed at the final meeting that she would be prepared to try the experience of co-teaching with Kris in her classroom of much older students and this will also be discussed in the following chapter.

\subsection{Activity system 3: Co-teaching inquiry model}

Co-teaching, as a key characteristic of the inquiry approach, was a design solution that was genuinely cogenerated within the group and not only afforded the teachers' enhanced access to one another's practice, but also fit readily within the dayto-day work of teaching. The teachers' co-participation in the design process meant that as problem solutions and ongoing refinements were developed, there was an understanding of what would 'work' in the practice context.

Figure 6.3 depicts the teachers' collaborative inquiry featuring co-teaching as an activity system. In the activity system depicted above, the subjects of the activity 
were the three remaining participating teachers, Casey, Kris and Pat. Sam, who had participated in the first three group meetings, formally withdrew from the project after the fifth group meeting, however she consented to the continued use of any data collected up to the time of her withdrawal. The stated object remained the implementation of 'talk moves' however the group's collective activity was responsive to classroom events. Increasingly actions were directed at strengthening a range of pedagogical practices aimed at simultaneous teacher and student learning goals as outcomes. For instance, Pat and Casey directed their co-teaching activity at generating success criteria with students which represented an individual learning goal for Casey that could be addressed alongside the collective goal for the group. The focus for individual teachers' learning varied and depended on the specific resources made available in each of the unique sets of circumstances in which the co-teaching occurred. Aspects of one teacher's practice could be picked up as a resource for another teacher's learning and this was influenced by the nature and extent of alignment or contrast with that teacher's current practice. 


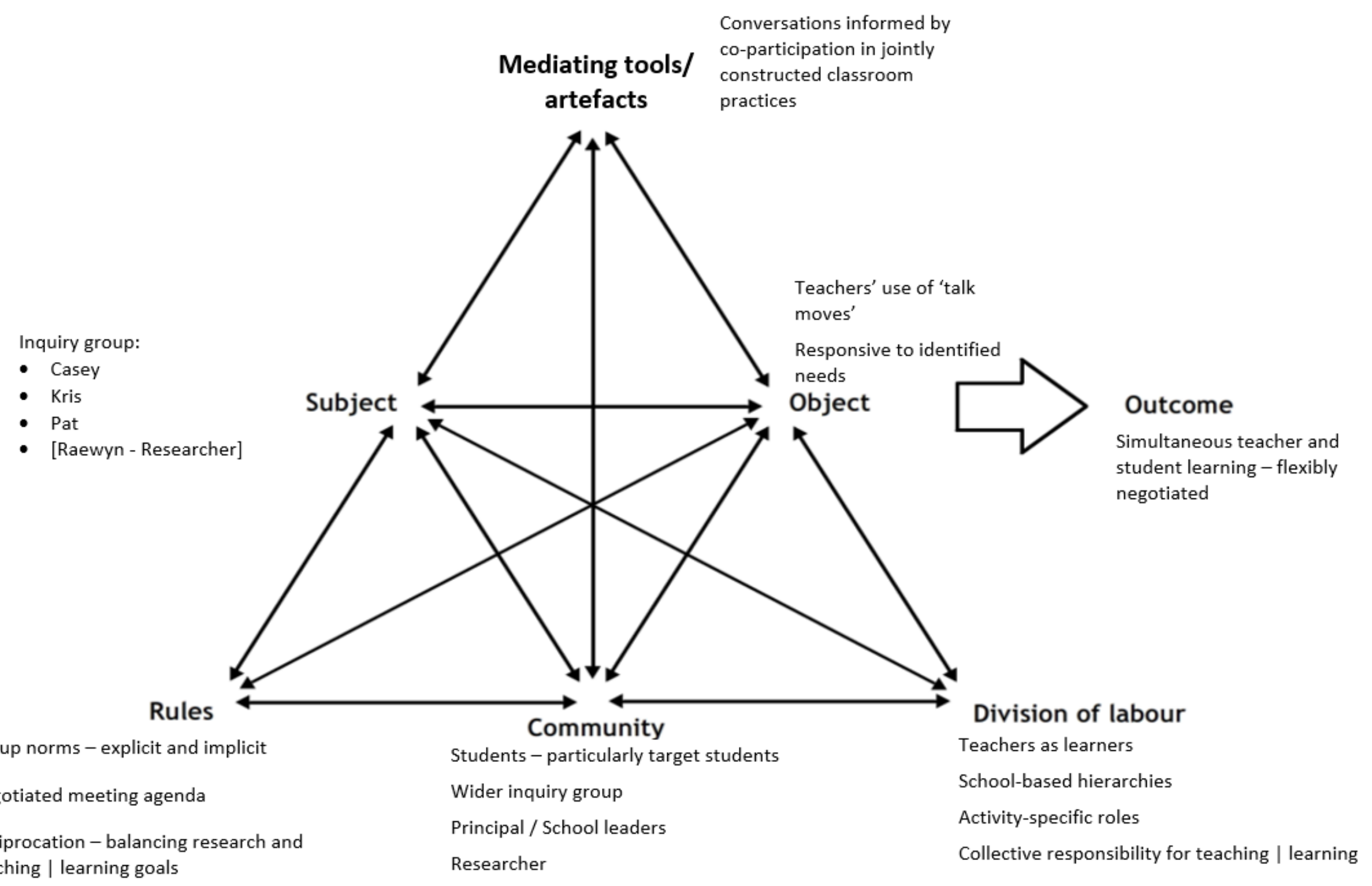

Figure 6.3. Activity system 3: Co-teaching inquiry model. 
The primary tools mediating the groups' activity were conversations about mathematics teaching | learning which were in turn mediated by the teachers' experiences of shared classroom practice. The teachers had access to one another's practice as co-participants in that practice; they experienced the actions of the other teacher as the co-teaching was enacted. Because classroom practice was jointly constructed, the teachers had ready access to the explicit actions of their co-teaching partner. Furthermore, during co-planning discussions, teachers made explicit their teaching approaches and in some cases a rationale for their actions. Co-reflection conversations served as opportunities for teachers to interrogate and make explicit aspects of their teaching that had occurred during the lesson. Sharing classroom video mediated the teachers' thinking about and access to co-teaching episodes. Tools that emerged as a product of the group's collaboration were more readily taken up and incorporated into the teachers' ongoing work in authentic ways than those that were largely designed and introduced from outside the group's activity. For instance, the expectation that teachers record regular individual reflections as part of the project was not realised, and written prompts to support teachers' reflections on video clips and co-teaching experiences were not used; these were both researcher-designed elements of the intended activity.

The division of labour associated with the co-teaching activity continued to be mediated by the group kawa. Characteristic of the co-teaching experience was the teachers' collective responsibility for enacting the teaching of mathematics, and the varying roles that were adopted by each teacher within the experience of co-teaching. The shift from individual to shared responsibility for teaching | learning mediated the ways in which teachers talked about classroom practice, including implicit and explicit conversation norms. These norms, and decisions about the allocation of time for teachers to collaborate, acted as rules mediating the activity.

The teachers' collaboration remained situated within the community associated with Waterview School and the wider educational context, and can be defined similarly to the activity systems depicted in the previous two chapters (see section 4.3 and section 5.6). In section 6.8 that follows, the activity system is used to illustrate contradictions that emerged as the teachers engaged in this collaborative activity and 
examines the affordances of the co-teaching inquiry model for promoting teacher learning.

\subsection{Contradictions within the activity: The affordances of co-teaching inquiry for teacher learning}

Within the teachers' co-teaching inquiry activity, contradictions arose and, as action to resolve these was taken, the activity system expanded. That is, new possibilities for action became available to the teachers as they acted towards their shared goals. The activity system diagram from Figure 6.3 is reproduced on the following page (as Figure 6.4) with the addition of dotted arrows labelled as 121314151617/8 and 19 representing the inner contradictions that were apparent within the co-teaching inquiry activity. With reference to the inner contradictions that emerged in the activity at this stage in the design process, this section aims to capture a complex picture of how the teachers conceptualised and experienced the co-teaching inquiry. Five themes emerged from the data relating to: the relationships amongst participants; values that emerged within and influenced those relationships; the role of dialogue in the teachers' shared work; the reciprocal nature of teaching and learning; and the role of context for learning in practice. The focus is on the affordances of the teachers' collaborative activity, conceptualised by Little (2003) as "the ways in which the practices of the group open up some opportunities and constrain or close off others" (p. 939). The contradictions illustrated in Figure 6.4 above, and the actions taken to reconcile them, are discussed and relate to the ways in which the teachers' inquiry activity developed and opened new possibilities in their shared work. 


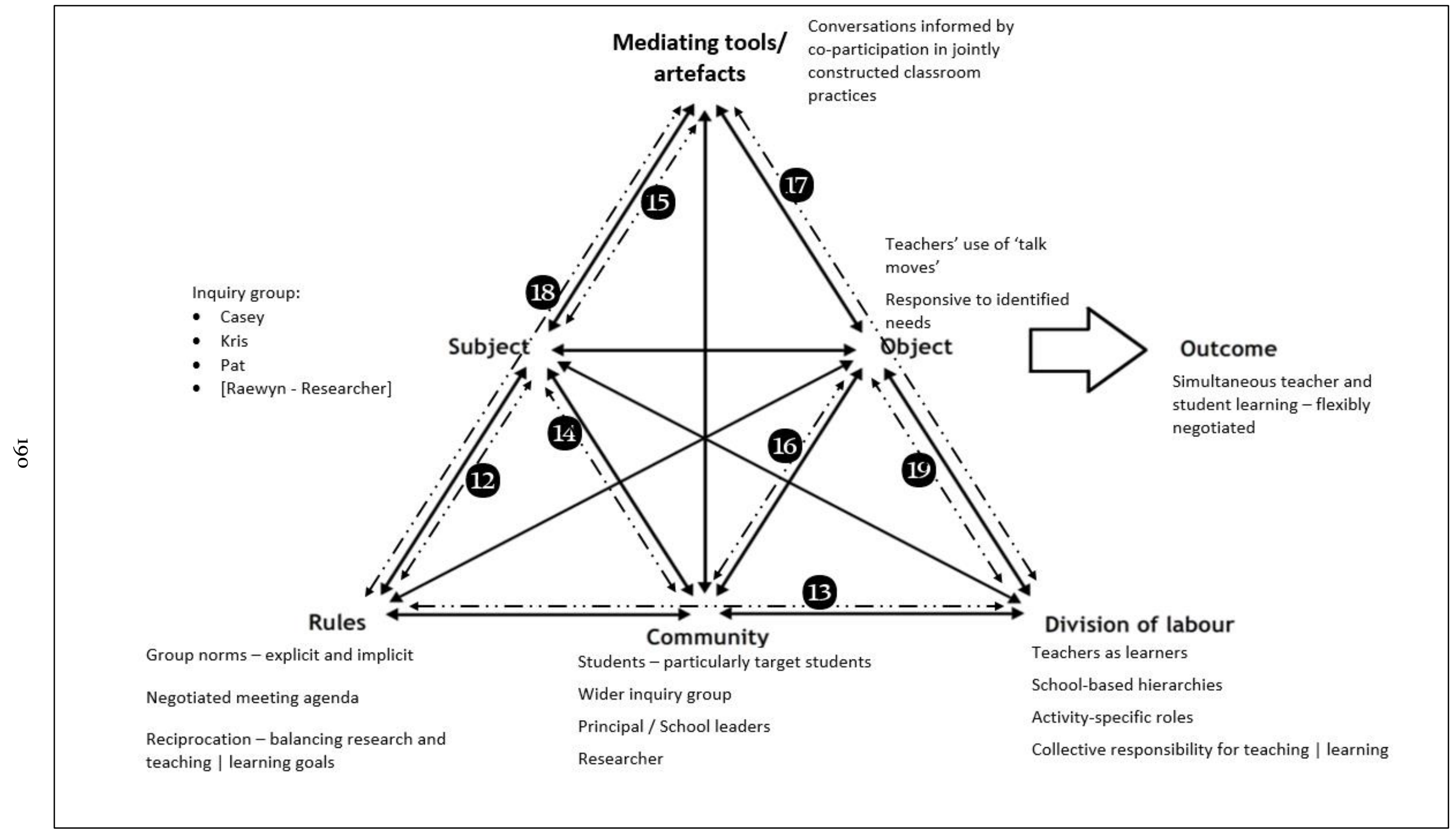

Figure 6.4. Contradictions within the co-teaching inquiry activity in design phase 2: Co-teaching inquiry model. 


\subsubsection{Relationships: "I don't wanna work with you if it's 'look at me"”}

Relationships amongst participants both shaped and were shaped by the group's activity by generating positive emotions and a sense of belonging; shifting teachers' roles; developing a sense of shared responsibility for the outcomes of their work; and strengthening the group's collective agency to participate in important decisions about their work.

Contradiction 12 [rules $\leftarrow \rightarrow$ subject] pertains to the shifting norms of practice from teaching as a largely private and individual undertaking that constrained teachers from sharing the work of mathematics teaching | learning, to a more open practice undertaken publicly and collectively. Working together generated a sense of belonging within the group and the teachers reported a range of positive emotions associated with their co-teaching experiences including increased confidence and enjoyment in their teaching, greater satisfaction with the outcomes of their teaching, excitement about their own and each other's learning, relief that anticipated negative aspects of the experience did not occur, and enhanced enthusiasm for mathematics teaching. Casey described an "oh phew moment" illustrating how their enjoyment of co-teaching appeared to surprise the teachers. Co-teaching contrasted with their prior experiences of making their practice public which had included round-robin sharing at staff meetings which the teachers found disengaging, and appraisal observations which were experienced as intimidating. In contrast, group meetings frequently involved humorous exchanges, gentle teasing and laughter amongst participants. For instance, Pat joked with Casey about "ripping [their video of co-teaching] to pieces" implying that the video excerpt would show problematic classroom practice. What they were actually sharing was a co-teaching episode that gave them a great deal of pride and satisfaction. Pat's comments appeared to acknowledge the extent of Casey's shift whereby at the beginning of the project she refused to even watch videos of herself teaching. It was recognised as significant for Casey that in this episode she was voluntarily sharing video with her colleagues. Kris commented:

I think it captures the group in the sense of how close we are that we're happy to have the hard conversations but also just as happy to laugh and talk and make fun of each other respectfully. [K-GM\#6] 
Joking and laughing together appeared to provide a release for the teachers from the intensity of their busy work day and provided a device for re-forming the collective as the teachers came back together as a group at each three-weekly meeting. As such, joking acted as a mechanism for creating a sense of belonging and appeared to perform functions both of celebrating the teachers' positive experience of working together, and amplifying one another's success by implying a contrast with an alternative, less desirable scenario.

The co-teaching inquiry activity appeared to allow the teachers to renegotiate the roles they saw themselves and others taking in relation to their work, and to shift the nature of relationships that existed amongst colleagues. Contradiction 13 [rules $\leftrightarrow$ division of labour] relates to the disruption to taken-for-granted participation patterns and previously recognised roles within the teachers' shared work. Explicitly negotiating group norms and roles through the establishment of a group kawa promoted shifts in how, and the extent to which, teachers participated productively in the group. The teachers agreed that they were all learners and equal in the context of this work and this was recorded on the chart as "group members are here as teachers and co-researchers". During the early group meetings, the teachers' participation was limited and unequal whereby Kris and I did much of the talking. More equal participation patterns emerged later in the project and the teachers increasingly engaged with one another's teaching practice and in learning-oriented conversations about classroom events. Kris, as lead teacher of mathematics, had noted the importance of her relationship with her co-teaching partners, and of being positioned as a co-participant with an equal status. She saw increased participation as encompassing more than just what or how much each person in the group said. Equal participation was centred on each person's opportunity to contribute ideas and be actively involved in the group's work.

Related to the shifting patterns of participation was that teachers started to share responsibility for student learning beyond their individual classes, and this influenced their work together and supported the ongoing development of increasingly productive working relationships. This was evident in the teachers' coplanning which allowed co-teaching partners to establish common goals and a sense 
of shared ownership of lessons. Working towards a common goal promoted individual accountability and being accountable to a co-teaching partner required teachers to plan more carefully with a focus on both their own and the students' learning. For instance, Kris described feeling accountable to her co-teaching partner for the quality of the mathematics [her emphasis] in relation to her teaching and the students' learning. The teachers started to see their teaching as a shared endeavour, whereas teachers were reluctant to work alongside a colleague who was "showing off" their practice:

I don't wanna work with you if you're "look at me". Whereas if it's "look at us and how we can make a difference to our learners", if we're on that same page ... you actually go "yeah!" [K-GM\#7]

Furthermore, shared responsibility for the teaching of one group of students seemed to redirect attention from the teachers themselves to the impacts of their teaching on their students and the shift in focus to the students' learning, specifically the mathematics, appeared to support the development of productive working relationships.

Contradiction 14 [subject $\bullet \rightarrow$ community] relates to how the teachers' growing sense of a collective identity through their shared work appeared to increase the possibilities for them to participate in important decisions affecting their work. They had expected that they would be released from other meeting commitments to meet and work together on our project however this expectation had not been realised and the project work was in addition to their existing workloads. Time was a scarce resource and so committing to spending time working together signalled the value that teachers placed on the opportunity to reflect together on their practice. They saw the co-teaching inquiry as achieving valuable outcomes that would justify making time available and felt that if Dale, the principal, was able to be convinced that the coteaching approach had potential value for all staff, scheduled staff meeting time might be made available for all teachers to participate in this work in the following year. They saw that as a group they might approach Dale and together make a case for resources to be redirected away from other activities, in this case staff meetings that they experienced as having limited impact on their professional learning and practice, and towards their co-teaching inquiry activity. The teachers felt that school leaders 
and the Ministry of Education, as policy makers and providers of resourcing, would need to be convinced about the usefulness of this work, and that collectively they could advocate for the resourcing they felt was needed. Nevertheless, as mathematics lead teacher Kris felt it was her responsibility and told me during an informal conversation that she had approached Dale about applying for funding to extend the project. She explained that her request was not supported because the school's professional development focus for the upcoming year was on implementing a literacy-based initiative and that she wanted to protect the staff from overly onerous workload demands.

The teachers valued their work together however they experienced their collaboration as involving personal sacrifice (contradiction 15 [subject $\bullet \rightarrow$ tools]). They had limited opportunities to participate in decisions about how their work time was scheduled, and to what ends scheduled time to work together was directed. School leaders made decisions about the timing and agenda for staff meetings, including those with a professional development focus, in line with school-wide priorities they had identified. Arranging to work together outside of these officially scheduled activities, such as making time for group meetings, was seen by the teachers as making a personal sacrifice because the time available was limited and there were many competing demands on it. They saw their shared activity as valuable and accordingly they were prepared to make what they saw as a sacrifice to participate in the project. Nevertheless, they also saw that additional resources, particularly scheduled meeting time and teacher release, would help to maintain the positive outcomes while mitigating some of the additional workload they had been experiencing if their work was to be continued beyond the project. The group's emerging collective identity appeared to expand the possibilities for the teachers to have a say in decisions about how school resources, particularly time, were used and what might be the priorities for teacher learning towards which these resources might be directed. However, the group's collective agency to restructure their work was limited by the resources that they had access to and thus their future co-teaching inquiry activity was constrained. As Fullan et al. (2015) argue, the participation of leaders alongside teachers in activity which is directed at improvement is a high- 
leverage practice, and developing leadership capital at all levels of the school is necessary for the success of school improvement efforts. In this case, although the group advocated strongly for additional resources to continue the co-teaching inquiry activity, Dale, who had not participated in the later stages of the project and so had not experienced the success of the co-teaching inquiry, instead prioritised the resourcing of other activities.

\subsubsection{Accountability and trust: Productive relationships "have to be earned"}

Values such as trust and respect emerged within, and impacted on, relationships amongst group members. Trust, particularly in relation to risk and power, and the teachers' increasing sense of shared accountability in connection with their working relationships, opened up some, and closed down other, possibilities for the group's work. As explored in the previous section, the teachers were able to negotiate increasingly productive working relationships through their co-teaching inquiry activity. They considered positive relationships important for a successful coteaching experience and, despite intentions to engage in co-teaching as equals and as learners, they anticipated that difficult personal relationships would make co-teaching less effective (contradiction 13 [rules $\leftrightarrow$ division of labour]). This expectation was shaped by prior experiences including those of teachers being observed in their practice and engaging in feedback conversations for the purposes of performance appraisal. Comments about personality clashes between some teachers suggested that the teachers saw difficult working relationships as an unavoidable product of incompatible personalities. In contrast, however, co-teaching appeared to create opportunities to reimagine and create increasingly productive relationships. For instance, Kris was able to work productively with a co-teaching partner with whom she had experienced conflict in the past despite initially being sceptical about what her co-teaching partner said about being willing to work together as learners and equals:

Trust has to be earned ... that willingness to open up from that particular person to say, "I need help", that was actually really powerful. That's what collaboration is. [K-Int\#2] 
The co-teaching experience appeared to provide the two teachers with opportunities to demonstrate integrity and earn one another's trust, and perhaps challenged the assumptions each had made about the other. Remaining professional in a challenging relationship involved acknowledging when someone was asking for help and providing help in ways that showed care and upheld the integrity of that person.

Opening practice to the scrutiny of others constituted a risk and required the teachers to trust their colleagues (contradiction 16 [community $\leftrightarrow \rightarrow$ object]). As Kris commented during her final interview, teachers “just don't want that perception of people thinking that you're weak in teaching". Nevertheless, she recalled feeling empowered when she had previously shared classroom video in another context, and she wanted others to have the same experience to have "that sense of celebration, that recognition" [K-Int\#2]. In contrast to the perceived risks, sharing video excerpts with the group appeared to be a positive experience for the teachers. Sharing classroom videos without critiquing them was important in the group's early work and positive experiences appeared to promote teachers' future enthusiasm for sharing. For instance, Casey, who had initially declined even being given a copy of video recorded in her classroom, later willingly shared video clips from co-taught mathematics lessons. She also subsequently shared video clips of her teaching during a whole staff literacy-focused professional development meeting that she had been leading. Sharing video was voluntary in the group; during the negotiation of the kawa it was made explicit that teachers could choose whether and what to share. The teachers were able to articulate a purpose for what they shared rather than feeling compelled to share, and statements like "and this is ... and I'm showing you this because ..." became routine in connection with shared video clips. The teachers felt it was important that they had opportunities to talk about their practice, and that this talk was focused on, and celebrated, students' learning was regarded as a catalyst to support pedagogical change:

[Pat] had this safe group that really acknowledged what she was doing in her classroom and really celebrated the mathematical learning that was going on; that's what I think made the difference [K-Int\#2]

A sense of shared responsibility supported risk-taking by redirecting attention away from the practice of individuals. Co-teaching both supported and pressed 
teachers to engage with new classroom practices and they could take risks and try new pedagogical practices where the responsibility for 'getting it wrong' didn't lie with any one teacher individually. Kris's observation that "you didn't do it but neither did I" [KInt\#2] illustrates how co-teaching redirected attention away from individuals thus minimising the risks associated with having their practice judged by others. She described a mutual sense of accountability between teachers as they co-taught a lesson, invoking an image of each teacher 'having the back' of the other and not wanting to let the other person down. The image of a co-teaching partner 'having your back' was similarly used by Gallo-Fox (2010) to describe the security that co-teaching offered experienced teachers who were experimenting with new pedagogies and attempting to expand their practice. Negotiating shared goals prior to co-teaching promoted trust between the two teachers whereby shared understandings of the pedagogical practices they were aiming to implement influenced how they worked together. Furthermore, when the two teachers had self-identified aspects of their teaching that they wanted to strengthen, the risks associated with these 'gaps' being exposed to others as weaknesses was diffused.

The teachers highlighted the importance of their pre-existing relationships for allowing them to be open to feedback and thus open to the potential to learn from practice. Casey, Kris and Pat had previously worked together in a context in which they "really had a chance to be critical and to be honest" [K-GM\#5]. They suggested that productive professional relationships required them to be both skilled at giving, and open to receiving, critical feedback: "If you can't take the jandal then you'll never make a good co-teacher" [P-GM\#7]. "Taking the jandal” refers to a New Zealand colloquialism that suggests the ability to accept negative or challenging feedback without feeling slighted. Nevertheless, power hierarchies contributed to how feedback was both given and received (contradiction 13 [rules $\leftrightarrow \rightarrow$ division of labour]), and feedback that was delivered without attending to the recipient's emotional response was likely to be counterproductive:

You don't just bark at the teacher and make them feel like they're smaller than you [noises of agreement], they have to understand that we're equal. [P-GM\#7] 
Connected to contradiction 14 [subject $\leftarrow \rightarrow$ community], the teachers were selective about what could, or should, be openly communicated to school leaders suggesting there was some risk and more at stake involved in having their practice or their opinions exposed to management. They were generally reluctant to publicly challenge established school practices. For instance, when one of the school's current professional development practices was described as "dreary" during the final group meeting, the laughter in the group appeared to indicate agreement and I was jokingly asked "can you send that to Dale?" In the case of the comment about "dreary" professional development meetings and other similar instances, it was clear that the teachers would appreciate school leaders knowing how they experienced aspects of their work, however they saw communicating such a message themselves as too much of a risk. It appeared that the involvement of school leaders in conversations about practice constrained teachers from talking openly and when teachers were open about challenges in their classroom practice, they expected different responses from management than they would from a colleague. It was suggested that the way school leaders engaged in conversations and provided professional feedback about practice was more important than the position they held. The teachers felt it was important that feedback about practice that was to be reported to management be discussed directly with the teacher concerned in the first instance, and it appeared that teachers did not fully trust that this would always be the case. Kris shared the group's view that exposing problematic aspects of practice to those in management was a risk for teachers:

If somebody talks critically or honestly about a child [to] senior management ... it becomes a big deal whereas if it's colleague to colleague with no title attached although there might be concern for a child that is no reflection on the teaching that's taking place; now there's two heads together to unpack why is that child stumbling. [K-GM\#6]

Nevertheless, in her role as the lead teacher of mathematics she saw that her involvement in the group gave her insights into the practice of other teachers that helped her to provide support to them as part of her leadership role. It was a contradiction for Kris that she was wary of sharing problems of practice with management nevertheless she believed that school leaders needed to trust teachers to 
have robust professional conversations. She recognised that participating in the collaborative teacher inquiry had given her greater access to the practice of others and that this had supported her in her mathematics lead teacher role; "it's given me eyes on the floor so to speak" [K-Int\#2]. In relation to trusting and being trusted, there was a contradiction between the roles people held and the extent to which teachers were willing to publicly share their practice as a tool for the learning of others (contradiction 17 [tools $\leftrightarrow \rightarrow$ division of labour]).

\subsubsection{Engagement in robust, learning-focused dialogue}

Contradiction 18 [tools $\leftrightarrow \rightarrow$ rules] illustrates a contrast between the teachers' past experiences of appraisal observations and feedback, and the conversations that were part of their co-teaching experience. Connected with contradiction 17, the teachers' emotions appeared to play a role in both the manner and extent to which they engaged in conversations about their co-teaching practice, and therefore the ways in which those conversations mediated activity towards students' and teachers' learning goals. The group's early conversations about their co-teaching experiences tended to focus on celebrating and improving teaching and learning and appeared to promote teachers' ongoing and extended engagement in talk about practice. This contrasted with those that were initiated by school leaders which focused more on feedback and judgements about practice. Co-teaching conversations provided a forum to talk about one's own practice, and access to representations of others' classroom practice, thereby expanding the resources available to teachers for their professional learning and future classroom practice. The group's dialogue afforded opportunities to learn in relation to both what was talked about and how it was talked about. The coteaching inquiry activity expanded opportunities to talk about mathematics teaching | learning which in turn allowed opportunities for teachers to develop robust pedagogical concepts as a resource for their future work. Talk that surfaced, examined and challenged difference expanded both the depth and breadth of teachers' thinking about practice, and created learning opportunities that extended both the conceptual resources they had available to interpret aspects of their work, and teachers' possibilities for their future work (Horn, Garner, Kane, \& Brasel, 2017). 


\section{A forum to talk about practice}

Participation in the co-teaching inquiry activity created new opportunities for teachers to talk about their classroom practice, and to talk about it in new ways. Performance appraisal had previously been one of few contexts for teachers to share aspects of their classroom practice in any detail. In contrast, the co-teaching inquiry was largely characterised by meetings to discuss aspects of the teachers' work and this, alongside co-teaching, was a primary activity of the group. Participation in the inquiry activity increased the extent to which teachers talked about mathematics teaching | learning. This included in relation to talk that occurred both within and beyond the planned co-teaching inquiry activities and involved teachers both within and outside of the project group. Scheduled time to talk was a feature of the co-teaching model that was designed and enacted in the study, and this provided teachers with opportunities to both share descriptions of their classroom practices in mathematics and to celebrate their own and their students' learning. In addition to the talk that occurred as part of the planned aspects of their work together, there appeared to be an increase in the extent to which the project teachers talked informally about their mathematics practice in their day-to-day social interactions. Co-teaching a lesson opened conversations that then carried on outside of the group's planned activities, something that came as a surprise to the teachers given their very demanding workloads. Furthermore, teachers outside of the project were showing an interest in the group's work further extending the reach of the group's conversations about their practice. Thus, for teachers not directly involved in the project, increased opportunities to talk about mathematics teaching | learning were also made available by the boundaries of the group's activity expanding as their work was increasingly made public. This happened indirectly when project teachers' conversations were occurring in public spaces and more directly in contexts such as staff professional development meetings. The teachers noted a growing "passion for maths" that appeared to extend beyond the project group to others who showed an interest in what they were doing. 
Co-teaching included co-planning, co-instruction and co-reflection, as discussed in section 6.5. Before each co-taught lesson, the two teachers met to plan together and after teaching they reflected together on their shared teaching experience. The teachers then also shared details of their co-teaching experience during their three-weekly group meetings. They reported that talking with others afforded opportunities to think about classroom practice in new ways. The example that follows illustrates how teacher learning was afforded by co-planning and coreflection conversations which opened up opportunities for teachers to surface their own beliefs about mathematics teaching | learning and provided access to aspects of others' practice that were otherwise unavailable and unexamined.

\section{Co-planning and co-reflection as opportunities to talk about practice}

The teachers valued having time to talk about their practice and conversations during the co-planning and co-reflecting phases of co-teaching created new opportunities for the teachers to talk about mathematics teaching | learning. The teachers were thus afforded opportunities to make aspects of practice explicit that would otherwise be tacit, and surface their beliefs about what it means to know and do mathematics. Co-planning presented an opportunity to negotiate both student and teacher learning goals for the co-taught lesson, and to explicitly plan teaching approaches towards these goals. For instance, Casey described how co-planning a lesson with Pat had provided a well-timed opportunity to forefront an aspect of practice that had recently been identified as a learning need for her which created an opportunity to focus on that during their lesson and supported a change in her ongoing practice. Similarly, reflective conversations after co-taught lessons were important for both celebrating success and providing feedback. For co-teaching pairs, reflective conversations created opportunities to provide professional feedforward to a co-teaching partner at the same time as identifying one's own future practice goals. Group meetings provided opportunities for the teachers to engage in conversations reflecting on their individual and shared practice.

During several of the group meetings teachers shared excerpts of video recordings of mathematics lessons including those that had been individually and co- 
taught. Some of the teachers' conversations centred on student talk and the use of talk moves, however this was not always the case and the reflection focus emerged in response to events that stood out as important for the teachers involved. For instance, for Casey co-planning and co-reflection created an opportunity to gain support to develop the pedagogical approach of making success criteria explicit with students. The co-planning created a forum for Casey to surface her current practice in relation to the new practice, and co-reflection developed her understanding of how the practice supported the students' learning. Thus, teachers' reflective conversations provided new perspectives from which to view and thus deepen their thinking about their practice:

You've got that chance to hear how dumb your idea is, or how great your idea is, whereas if you don't have anyone to talk to, you think you're wonderful when really you could be really tragic. [K-GM\#4]

Reflecting together on episodes of classroom teaching opened opportunities for teacher learning and what was shared and discussed included a focus on pedagogical practices, students' mathematical thinking and practices, classroom management and grouping arrangements, and aspects of mathematical content. For instance, introducing a video excerpt of the lesson she co-taught with Pat, Kris articulated her reasons for choosing the excerpt and in doing so, she surfaced beliefs about mathematical practices that she valued as important for students to be engaging in, and hence worthy of sharing. These included students attending to others' explanations, engaging with errors, and reasoning mathematically. Highlighting these mathematical practices allowed Kris an opportunity to draw the group's attention to classroom events that align with the discourse-based pedagogical approach the teachers are aiming to develop.

A further example of this is during the discussion of the video excerpt described in Example 6.2(B). Pat's focus was on the mathematical sense-making of the students and the way in which decimats supported their understanding of what it means to add decimal numbers. Sharing the video excerpt at the group meeting appeared to provide a forum for Pat to expand her thinking about the practice she had enacted.

Recounting the episode re-engaged Pat with the mathematics involved in the task and thus afforded an opportunity to extend both Pat's content knowledge and her 
knowledge of students' thinking. This in turn expanded the possibilities for action in Pat's future teaching practice by extending the repertoire of knowledge that can inform her practice decisions.

\section{Reflection-on-action: The limitations of talking about past practice}

There were limitations on the extent to which talking about past practice provided resources for teachers' future practice, including the extent to which teachers could access the practice of others and thus the conceptual resources available for their own learning. For instance, in Example 5.4(B) teachers had an opportunity to access representations of Pat's practice, the mathematics in the task used, and the students' thinking in relation to the task. However, the other teachers did not pick up and engage in a discussion of the mathematics or Pat's practice at this time and Pat's recount of this event is left mostly unexamined by the group. In this case, the teachers' access to Pat's practice was through representations, including through video and descriptions, of classroom events. The learning opportunity that was opened up in the conversation appeared to be mostly limited to Pat whose practice was being shared and for whom a forum for talking about her practice had been provided.

\section{Engaging with difference: Supporting the person and challenging the idea}

Conversations in relation to the co-teaching inquiry were qualitatively different to those related to appraisal in terms of both what was talked about and how the teachers felt about it. Sharing and engaging with one another's different and sometimes conflicting views served to expand the scope of the teachers' conversations. There was an apparent contradiction between the social norm of avoiding challenge and conflict, and the potential learning opportunity made available when practice is problematized and scrutinised (contradiction 18 [rules $\leftrightarrow \rightarrow$ tools]). As the teachers engaged in the inquiry, difference was identified as a strength of the group's collaboration and the three teachers became increasingly likely to challenge one another's different ideas, and to pick up on and engage with conflicting views that were introduced into conversations. They posed and responded to challenges in ways that protected their colleague's wellbeing and the relationships they shared and highlighted the importance of protecting each other's mana (status or authority) and of not "stepping on the toes" of the other teacher. For instance, during a discussion 
about a lesson that Casey and Pat had co-taught, Kris had raised a challenge about the impact on the students' opportunities for think time where there were two teachers in the classroom. She framed her question to soften the challenge she was making to Pat and Casey's practice by directing the question at student impacts perhaps to divert any perceived criticism away from the teachers themselves. Pat had laughed when countering Kris's suggestion that she and Casey may have felt compelled to move the lesson on. Her tone had heightened suggesting she was taking a defensive stance however her laughter had moderated this. Furthermore, Kris's acknowledgement that she only saw part of the lesson and her reassurance that she was not critiquing her two colleagues affirmed her support for them. In her response Casey appeared to endorse Kris's move. Such conversations became increasingly typical of the teachers' discussions about their classroom practice whereby they engaged in challenging and justifying their different approaches to practice.

\subsubsection{Reciprocal responsibility for one's own and others' learning}

The co-teaching inquiry was seen to highlight a reciprocal and mutually constitutive relationship between teaching and learning, a notion that underpins the study. Opportunities for teacher learning were opened up by sharpening teachers' professional noticing of students' mathematics and expanding the teachers' resources to respond. Sharing a teaching role within a mathematics lesson afforded each teacher opportunities to access aspects of the other's practice as a resource for their own teaching. Furthermore, co-teaching as a shared activity provided teachers with access to one another's practice whereby teaching and learning are simultaneous and reciprocal activities. That is, the teachers described how learning was occasioned within the co-teaching activity and afforded each teacher opportunities to both gain feedback on their own practice and access aspects of the other's practice as a resource for their own teaching.

\section{Co-teaching as an opportunity to observe another's practice}

The teachers made their classroom practice available to others in the group through sharing videos of co-taught lessons, engaging in joint practice through coteaching, and talking about experiences in co-teaching pairs and at group meetings. Opening their classroom practice created opportunities for teachers to simultaneously 
gain feedback on their own practice and provide a resource for others' practice.

Specifically, co-teaching provided opportunities for teachers to observe one another's practice in the context of their own and each other's classrooms and Casey suggested that was "part of the benefit" [GM\#7]. Teachers valued the opportunity to observe teaching approaches that were different to their own. For instance, Pat had access to a particularly strong aspect of Casey's practice, that of strategically using concrete materials to model and build understanding of mathematical concepts, and later described adopting a more materials-based approach in her own mathematics teaching.

As previously mentioned, at Waterview School it was an established practice for teachers in leadership roles to observe in other teachers' classrooms and provide feedback about strengths and areas for further development. Contrasting co-teaching with appraisal observations, the teachers saw that co-teaching offered them a learning opportunity that involved both a shared classroom experience and co-constructing feedback afterwards:

There's a shared experience and then, regardless of what happens, the learning that takes place from the feedback and that's what's pivotal. [K-GM\#5].

The teachers were "used to being observed" [C-GM\#7] and, at the beginning of the project, they often requested feedback from me on their practice. The routine nature of classroom observations by other teachers seemed to be reinforced by the teachers who often referred to their co-teaching partner as "coming in to see me teach" and then correcting themselves. Despite observations being a routine element of teachers' work at the school, however, teachers generally did not often get opportunities to see each other teach for the purpose of their own professional learning; when observations did occur, the observer tended to take an expert role and the teacher being observed was presumed to be the learner. Furthermore, an additional affordance of co-teaching appeared to be the opportunity to observe novel teaching practices in one's own classroom. For instance, being able to see Casey's teaching in action had provided Pat with opportunities to observe both Casey's use of materials as a pedagogical approach that was different to her own, and the impacts of 
this teaching approach within Pat's own usual teaching context and with Pat's own students.

Co-teaching as active participation in the co-construction of practice

The active participation of both teachers in the co-teaching activity appeared to deepen and expand the teachers' access to one another's practice. Co-teaching supported teachers to remember, and subsequently access, what was learned in the context of their future practice. For instance, Casey's focus on developing success criteria with the students was a planned response to a self-identified problem of practice and she suggested that actively participating in the teaching supported her to recall what was learned without the need to refer to an external record of the event. The notion of not "hav[ing] to refer to my notes" suggested that new learning that is not easily remembered is made inaccessible and therefore not readily available for subsequent activity. Casey's active engagement in developing the success criteria with Pat and her students supported Casey to integrate this approach into her future practice because she had participated in creating an artefact that had immediate relevance to her students and their current mathematics programme. Being there and co-constructing practice afforded an important opportunity for teachers to engage deeply in one another's teaching, in contrast to the more passive involvement of viewing classroom video. Furthermore, co-teaching pressed teachers to justify aspects of their practice thus opening space to consider new possibilities for their own action. Being adaptive: Thinking time "in the midst of the hurly burly"

Teachers saw their shared practice as adaptive whereby co-teaching opened space for them to notice and respond. They described the need to be responsive to the students, each other and the unpredictable nature of lesson as it unfolded. The coteaching arrangement opened space for teachers to think and respond to students in the moment' because they were sharing responsibility for the multiple moment-bymoment classroom events they had to attend to. Teachers explicitly agreed to adjust their teaching in response to what emerged in co-taught lessons. Pat and Casey explained how during one of their co-taught lessons they took the lesson "off on a little tangent" [C-GM\#7]. This was an agreed action that was jointly taken although apparently not explicitly discussed. Casey reflected after the lesson that they may not 
have achieved what Pat had anticipated however this was countered by Pat who assured Casey that she was satisfied with the lesson outcome. The group meeting then provided a further opportunity to deepen both teachers' reflections on their shared teaching experience and affirm one another's roles in achieving the lesson's outcomes. The co-teaching activity appeared to open space for them to reflect on their teaching practice 'in the moment' during the co-taught lesson, enhancing opportunities to notice and respond to their students' mathematical thinking.

The teachers saw co-teaching as providing additional resources for their teaching | learning including giving them more time to think about their responses to students, and another pair of eyes to offer additional perspectives to expand their understanding of what was going on in the classroom. They reported attending less to the management of students' behaviour and described enhanced opportunities to notice and respond to student learning as it was taking place:

When we co-teach together, some of the things that I didn't pick up from my own lessons, others were able to pick up. You notice different things and that's where the improvement comes from. [P-Int\#2]

Attention, or noticing, appeared to be heightened because teachers needed to follow what was happening in order to actively participate in co-teaching the lesson. As discussed previously, the teachers felt that the conversations they had prior to teaching together were important preparation. Co-planning appeared to set teachers up to be responsive during the lesson by supporting them to anticipate how students might respond to a task. Furthermore, explicitly positioning themselves as learners in the co-teaching activity prompted teachers to be more thorough in their preparation to both make the most of the learning opportunity available and to honour the contribution that colleagues were making. Taking a stance as a learner appeared to promote deeper thinking about students and their learning to maximise teachers' learning alongside their co-teaching partners.

\section{Students and teachers learning together}

Co-teaching experiences were explicitly aimed at both student and teacher learning goals however balancing student and teacher learning goals was experienced as a contradiction for Casey who appeared to see these goals as in conflict 
(contradiction 19 [object $\leftrightarrow \rightarrow$ division of labour]). For instance, she had expressed the view that a co-teacher was in the first instance a co-teacher and not a co-learner (her emphasis), and therefore not knowing the content of what she was teaching would be a barrier to her co-teaching at higher class levels. Casey saw the teachers' collective activity as being primarily directed at improving student learning and as such actions aimed at teacher learning could be seen as at the expense of, and contrary to, this object. In other words, for Casey, when engaging with students in the classroom her role was primarily that of a teacher and so it was problematic for her to engage in teaching where she did not feel adequately prepared. As such she did not see teaching episodes as an appropriate context for her own learning. Casey wondered what the role of co-teacher entailed in an unfamiliar setting in light of what she understood to be the teacher's role. At the same time, Kris was interrogating why Casey appeared to be reluctant to take up co-teaching which she saw as highly synchronous with the role of co-learner and not at all in conflict with her own perspective on the role of teacher. Casey had previously expressed concerns that coteaching for the purposes of teacher learning might be at the expense of the students' learning. For her, it was not sufficient that there were impacts on teachers; students needed to benefit directly from the co-teaching activity. Pat had challenged Casey's position that her primary role as a teacher could be compromised when she was coteaching however, from Casey's perspective, the learning goals for both lessons she cotaught with Pat were predominantly focused on addressing identified learning goals for the students and Pat and Casey had made these goals explicit in their co-planning prior to the lesson. Casey's position echoes Grossman, Wineburg and Woolworth's (2001) observation that it is challenging to negotiate an essential tension whereby teacher learning is seen to detract from teachers' "real" work of classroom instruction thus teachers experience conflicting identities as teacher and learner. In activity theory terms this illustrates a contradiction between the multiple roles of the teacher as both teacher and learner, and the object towards which their collaborative activity was directed.

Nevertheless, because Pat had been explicit about what the students in her classroom were expected to learn, Casey had been given an opportunity to plan how 
she might contribute and brought with her pedagogical tools that would not otherwise have been part of the lesson thus creating learning opportunities for both Pat and her students. Furthermore, in the lesson co-taught with Pat in Casey's classroom, Casey had explicitly positioned herself as a learner. She had identified making success criteria explicit with her students as her own learning goal. For the same lesson, Pat reported that the co-teaching experience had afforded her an additional opportunity to learn to use materials better in her teaching. In both cases, co-teaching appeared to allow Pat and Casey to flexibly and simultaneously attend to their own learning and the learning of their students both in relation to pre-planned learning goals and in response to learning needs and opportunities that emerged within the lessons themselves.

Similarly, in the case of Pat and Kris's co-taught lesson, the presence of Pat required a student to extend his explanations to include details that would otherwise have been assumed as understood by Kris. This appeared to press the student to make explicit connections with his prior understandings which he otherwise may not have made. Furthermore, Pat had responded to Kris's students in ways that were different to Kris's approach and this had opened opportunities for Kris to see how Pat's different pedagogical moves had impacted on the students' learning. Kris saw this as offering her new pedagogical tools to extend her existing repertoire of classroom practices. Kris's learning in this case appeared to be unanticipated and, like Pat's learning in her co-taught lesson with Casey, emerged from the teachers' and students' responses to classroom events as they unfolded during the lesson. Kris observed that their different approaches expanded the resources available to the students while simultaneously expanding her perspectives of the mathematics involved. Working with Pat had "reminded" Kris about promoting flexible approaches to problems, thus expanding Kris's repertoire of ready practices which could be drawn on in the teaching moment. This did not represent a new pedagogical approach for Kris perhaps, rather her access to the practice was expanded.

\subsubsection{Connecting the familiar with the new}

The co-teaching inquiry was situated within the context of the teachers' practice and this shaped the knowledge, expertise and beliefs teachers brought to the 
co-teaching experience. Their learning was connected with the contexts within which their co-teaching inquiry activity was occurring including whether their shared work was in relatively familiar or new contexts (contradiction 13 [rules $\leftrightarrow \rightarrow$ division of labour]).

\section{Changing places: Bringing your teaching to my space}

The co-teaching arrangement involved two teachers jointly teaching a mathematics lesson in the usual classroom of one of the teachers, and so the teaching context was more familiar, and the students were more well-known, for one teacher than the other. The teacher 'coming in' to co-teach was introducing teaching practices that were new in this context and seeing practice ideas enacted in different classrooms supported the teachers to see the purpose of new pedagogical moves and connect them with student impacts. New practice ideas were able to be introduced by one teacher into another teacher's classroom thereby providing evidence of what is possible and expanding teachers' possibilities for action. For instance, within the context of her otherwise 'business as usual' teaching in her own classroom, Casey had an opportunity to see aspects of Pat's practice enacted, including approaches that differed from her own. As discussed previously, Casey had previously talked and thought about the possibility of making success criteria explicit with her students however she had not made this part of her own practice because she had anticipated that it would constrain other aspects of her teaching. Pat introducing what was a new practice into Casey's classroom afforded Casey the opportunity to observe and reflect on the impacts of that practice within her own, familiar practice context and for her students. The experience of having Pat's practice enacted within Casey's day-to-day practice context contradicted what Casey had anticipated and thus served as an interruption to her beliefs about the value and potential impact of this practice. What Casey knew about making success criteria explicit with children was both challenged and expanded by the opportunity to see this new, yet fundamentally familiar, practice enacted in her own usual teaching context. She had previously seen making success criteria explicit as being at odds with her usual practice, whereas seeing Pat enact the practice she was able to see it as strongly aligned with, and building on, her current teaching. Pat had provided Casey with a model of the pedagogical move, and evidence 
that it had potential benefits for the learning of Casey's students. Specifically, Casey could see that the lesson review discussions she already had with her children could be recorded to create an additional tool they could draw on in their future learning and thereby improved a current practice rather than introducing something new and unfamiliar. Co-teaching served to introduce 'new' practices into what was a familiar setting for each teacher thus expanding teachers' experiences of what was possible in that setting.

Teacher expertise is tied to class level: "She knows how to teach those ones a lot better"

The teachers saw classroom expertise as related to familiarity with a given context and linked to teachers' experience teaching at specific class levels. Their perceptions about the knowledge they had, or lacked, was connected to their experience at their current teaching level. This appeared to influence their emotions about the prospect of co-teaching at different levels and thus their willingness to engage in co-teaching experiences (contradiction 19 [object $\leftrightarrow \rightarrow$ division of labour]). Familiarity with the teaching | learning context influenced how confident teachers felt about co-teaching and a teacher's experience at lower year levels was thought to equip them for working with the lower achieving students at a higher year level. Accordingly, where the co-teacher who had 'come in' brought some identified expertise, the host teacher was happy for them to take the lead in that aspect of the instruction.

Casey's reflection on a co-taught lesson with Pat that "I think I pretty soon got a sense of where the children were at and what I could come in with" [C-GM\#7] highlights the connection between teachers' knowledge of the students and their approaches to instruction. Casey felt constrained from actively participating in the teaching of the lesson until she had a "sense of where [they] were at" thus perhaps promoting greater attention to what the students knew and could do. Similarly, Pat commented about the importance of knowing how "to actually teach those ones", related to familiarity with the mathematics content and associated pedagogy at different levels. The importance of the teachers' knowledge of the students that they were teaching, and familiarity with what was involved in teaching mathematics at different levels, appeared to supersede the need to be confident about the content that 
was to be taught. In other words, they saw that knowing "those students" and how to teach "at that level" was a more pressing factor in teacher efficacy than understanding the mathematics to be taught. An apparent contradiction was that experience teaching students at a given year level also appeared to constrain teachers whereby they saw their expertise as limited to their current teaching level and so felt that they lacked important knowledge for teaching at other levels.

\section{Out of my comfort zone: "I don't want to feel like a dumbo"}

Teachers' beliefs about their ability to successfully co-teach in another teacher's classroom appeared to be connected to their own judgements about whether they possessed the required knowledge and expertise prior to the co-teaching experience. A classroom context where the children and the mathematics teaching were at least somewhat unknown posed a risk to the teacher who was 'coming in' to co-teach, but less so to the teacher of the host class. When it was perceived by teachers that they lacked knowledge or experience in relation to teaching mathematics in the class they were 'going into' to co-teach, they experienced negative emotions including discomfort, nervousness and a lack of confidence. Negative emotions appeared to be a constraining factor for teachers who were considering the prospect of co-teaching in another teacher's classroom. This was particularly so for Casey who primarily taught younger students and had been reluctant to co-teach with Kris in her classroom of Year 7 and 8 students. Casey's experience suggests that co-teaching at an unfamiliar level can involve taking teachers out of their comfort zones and it appears that the collaboration supported, and even pressed, Casey to engage in what was a challenging experience for her. Taking a viewpoint that engaging in productive struggle and experiencing that which is unknown are productive for learning, it would follow that co-teaching was a potentially productive context for Casey's learning.

Where teachers perceived that their knowledge of what was to be taught was insufficient, this might prompt reluctance to engage in co-teaching and thus limit the learning opportunities available to both potential co-teaching partners. For instance, having previously expressed her reluctance to co-teach at higher year levels, when Casey agreed at the final group meeting that she would be prepared to co-teach with Kris in the future, Kris's response surfaced her feelings of isolation as a teacher of older 
students. Furthermore, it seemed that a perceived lack of prior content knowledge might prompt better preparation for co-teaching thereby extending the resources available to teachers within the co-taught lesson and extending the possibilities for teacher learning that could be afforded by an increased attention to planning. Planning and preparation for teaching appeared to provide an opportunity to develop important teacher knowledge thus the co-teaching inquiry model was adaptive in that teachers identified and responded to what they perceived as gaps in the knowledge they required to teach well.

\subsection{Chapter summary}

This chapter has outlined the emergence and refinement of a design for teachers' collaborative inquiry. The emerging design featured co-teaching mathematics lessons in pairs as a key component of the inquiry activity. This and the previous chapter have aimed to outline two phases of a design cycle whereby the group first video-recorded their own teaching and shared and reflected on excerpts of the video with the group. Later, participants co-taught mathematics lessons which were then shared and reflected on with the group, sometimes also involving the sharing of video excerpts. Chapters 5 and 6 have followed a chronology that separates these two design phases, however the design process was messy and non-linear and the two phases overlap and are dynamically interrelated. As co-teaching was emerging as a key component of the second design phase, the use of classroom video as a primary tool continued to be refined, tested and evaluated. Furthermore, co-teaching was a refinement to the original design that was developed to address limitations to the access video excerpts gave teachers to one another's classroom practice.

Chapter 7 that follows discusses the findings with the aim of understanding how the teachers' co-teaching inquiry activity expanded teachers' opportunities to generate knowledge for mathematics teaching | learning. The chapter provides a discussion of the findings in relation to the five themes outlined here and the interactions amongst them. The discussion will examine how the restructuring of teachers' work afforded enhanced opportunities to engage with one another's practice and thinking as a collective resource for their professional learning; actively negotiate 
the purpose towards which their shared activity was directed; and participate in expanded roles including both as equal co-learners and leaders with diverse expertise. 


\section{Chapter 7 Restructuring teachers' work: Teacher learning as adaptive, transformative and expansive}

This chapter aims to support a richer understanding of how the teachers viewed the co-teaching inquiry activity including their co-teaching experiences and ongoing reflections. CHAT has provided an analytical framework to address the research question: how does participation in collaborative inquiry expand teachers' knowledge for mathematics teaching | learning? The previous chapter has outlined findings relating to the affordances of the co-teaching inquiry model for promoting teacher learning. The current chapter discusses the ways in which the teachers' joint work, through a co-teaching structure, appeared to support the collective generation of knowledge for mathematics teaching | learning.

\subsection{Co-teaching inquiry: Activity in a state of flux}

Preceding chapters have examined how the design for the teachers' collaborative inquiry developed over the course of the project, providing an analysis of the decisions made and actions taken during the design process. Discussion has focused on the contradictions that arose within the co-teaching inquiry activity, and the actions that were taken to resolve these, to explain how the co-teaching inquiry opened space for an expanded set of understandings and practices for the participants. Attention was on examining the affordances of teacher learning within the teachers' collaborative inquiry activity including how opportunities to learn are both opened and constrained within the activity (Little, 2003). The design of the teachers' collaborative inquiry activity occurred across three distinct phases: sharing teaching ideas in staff meetings prior to the study as a starting point; the initial designed approach involving reflecting together on classroom video (design phase 1); and the final designed approach involving co-teaching (design phase 2). Each of the three design phases has been illustrated as an activity system and these were depicted in sections 4.3, 5.6 and 6.7. Each of the activity system diagrams define the group's collaborative inquiry activity at a point in time and with specific aspects in focus, however the teachers' activity constituted a complex system of dynamically interrelated elements and so was constantly in flux and not assumed to be fixed or 
stable. An analysis of the activity systems illustrated in the preceding chapters has examined how the design process generated shifts in the nature of the teachers' collective activity and in doing so opened space for teacher learning. CHAT provided an analytical framework to identify and examine contradictions within the teachers' inquiry activity at each of three design phases, and how these influenced the ongoing design process. The aim was to show how the teachers' collaborative inquiry activity developed by examining shifts that occurred over the course of the design process in relation to changes in the three activity systems, and by making connections among these shifts and aspects of the design process itself. An analysis of the co-teaching inquiry model that emerged at the end of the study has explored the question: what are the affordances of teachers' co-teaching inquiry activity for teacher learning? Coteaching and reflecting together on co-taught lessons represented new ways of working for teachers in the study, and the analysis has aimed to capture the participants' perspectives and understand the complex nature of their experiences. Five themes that emerged from the data have been identified and examined in relation to how the teachers' co-teaching inquiry activity afforded and constrained teacher learning. These are related to teachers' roles and relationships; how values such as trust and respect influenced those relationships and shaped the activity; the nature and role of dialogue in the teachers' shared work; the reciprocal nature of teaching and learning; and the role of context for learning in practice. Through participating in the co-construction of a design for their collaborative inquiry, teachers were able to restructure their work and expand the possibilities for both their individual and collective practice.

The discussion that follows aims to present a nuanced view of the expansion of the activity and begins by outlining a sociocultural perspective on teacher learning. Notions of teacher learning as cultural transformation and expansion of activity are outlined. Contradictions in the activity of co-teaching inquiry are then discussed in relation to how these opened, and constrained, opportunities for the teachers' learning by expanding or limiting access to resources within their jointly constructed teaching practice, their conversations about practice, and their noticing of students' responses to their teaching. Interrelationships amongst these three fields of the teachers' shared 
practice, and actions taken to resolve the contradictions that emerged, are examined. These include the interplay of risk and trust, the role of explicitly negotiated norms, the emergence of a shared sense of responsibility for student learning and the constant renegotiation of the activity's goals. In summary, this chapter discusses the central theme of engagement with differences as reflexive objects and catalysts for the ongoing transformation of the teachers' work. The discussion centres on the cogeneration of knowledge for mathematics teaching | learning within multiple parallel layers of collaborative inquiry.

\subsection{Teacher learning as cultural transformation}

Mathematics teaching | learning is viewed in this thesis as enacted culture, and teacher learning as cultural transformation. Sewell (2005) conceptualises culture as a category of social life that "possess[es] a real but thin coherence that is continually put at risk in practice and therefore subject to transformation" (p. 52). Viewed through a socio-cultural lens aimed at capturing the complexity of mathematics teaching | learning, teacher learning can be seen as a shared contribution to purposefully transformative practices in which the role of past, present and future actions are considered (Gutiérrez \& Rogoff, 2003). Examining the co-teaching inquiry activity from this perspective, teacher learning was revealed to be a generative process that was emergent and contingent (Powietrzynska, 2015); that is, as new understandings of mathematics teaching | learning unfolded and were generated across co-teaching experiences and group conversations, these were contingent on what had gone before and therefore were constantly fluid. Such a perspective accounts for the contested nature of what counts as knowledge in the teaching | learning mathematics and aligns with a conception of knowledge-of-practice whereby creating new knowledge is conceived as a pedagogical undertaking (Cochran-Smith \& Lytle, 1999). It captures the complexity of teacher knowledge (Ball et al., 2008) and the interrelatedness of mathematics and approaches to teaching it. As Sinnema, Meyer and Aitken (2017) suggest "to separate the strands of classroom management skills, subject matter knowledge and pedagogical techniques, for example, would fail to recognize the interrelated nature of those strands, and the complex, dynamic nature of teaching" (p. 15). 
Taking the co-teaching inquiry activity as the unit of analysis, the primary sources of transformation within activity were the internal contradictions that emerged from "the clash between individual actions and the total activity system" and the mediated actions that are taken to address these (Engeström, 2015, p. 66, emphasis in original). Contradictions emerged in the design and enactment of the coteaching inquiry activity, and the actions that the teachers took to reconcile and remove the contradictions expanded the activity, affording new possibilities for their future action. As examined in the previous chapter, co-teaching mathematics lessons in pairs and reflecting together on the experience represented a key innovation in the second iteration of the design for the teachers' collaborative inquiry. Drawing on the contradictions identified in the previous chapter and illustrated in Figure 6.4, this chapter will discuss how participation in a co-teaching inquiry community expanded teachers' access to resources for their ongoing learning within three interconnected fields, specifically co-constructing and enacting shared practice, talking together about practice, and noticing student thinking within practice. Tobin and Ritchie (2012) posit that

as individuals conduct social life, they enact culture in fields, comprised of structures including actors and what they do. Fields do not have boundaries and, as a result, they interpenetrate. In this way structures emanating from particular fields become resources for action in other fields (p. 118).

Engeström's (2015) notion of expansion is used to examine how structures within the co-teaching inquiry activity afforded teachers' individual and collective agency, specifically how teachers' joint work expanded their access to resources for their learning. Engeström describes learning activity as a process that begins with subjects questioning accepted practice and taking specific epistemic actions that spark and sustain cycles of expansion. Within such a process, difference is regarded as a resource alongside sameness and each is interpreted in relation to the other (Tobin \& Ritchie, 2012).

Possibilities for action are produced in a dialectic relationship between structure and agency and thus mediated by the circumstances in which the activity occurs (Sewell, 1992). In other words, changes in structure effect agency and any change in agency brings about an associated change in structure. Sewell describes 
structures as "sets of mutually sustaining schemas and resources that empower and constrain social action" (p.19) and agency is understood as the power to act in a particular situation. Thus, expansion of agency can be conceptualised as expansion in the range of possibilities available for action. Describing praxis as "the outcome of the dialectic between agency and structure”, Roth and Tobin (2004) suggest that the range of possibilities for action is mediated by structural conditions and "constitutes the room to manoeuvre a practitioner has at a particular point in his/her praxis" (p. 170). Engeström posits that expansion promotes collective and transformative agency which he defines as "breaking away from the given frame of action and taking the initiative to transform it" (2015, p. xxiii).

The section that follows examines how co-teaching expanded teachers' access to resources, and thus their individual and collective agency, in the contexts of their jointly enacted practice; enriched conversations about practice; and enhanced opportunities to reflect 'in the moment' on the impacts of their practice.

\subsection{Expanding teachers' access to resources within three fields of practice}

This thesis examines teacher learning in the context of a group of teachers designing and enacting an approach to collaborative teacher inquiry that was aimed at strengthening mathematics teaching | learning. A feature of the co-teaching inquiry approach that emerged from the design process was the teachers' active participation in shared classroom practice. The teachers' joint work expanded their access to resources for their learning within three fields of their shared practice: their enacted practice, their conversations about practice and their noticing of student thinking within practice. The following sections explore how teachers' access to resources for their learning, and thus their opportunities to act, were expanded within each of the three fields of practice, and how structures deriving from one field became resources in others.

\subsubsection{Enacting shared practice: The familiar meets the new}

Two teachers' active participation in the joint work of co-teaching a mathematics lesson afforded increased opportunities for them to bump up against practice ideas that were different to, and challenged, their existing beliefs and 
practices. Sharing the teaching role opened space for teachers to access aspects of the other's practice as resources for their own teaching and, at the same time, gain feedback on their practice. The visibility of one another's classroom practice was enhanced for both participants including each teacher's actions and decisions, and students' responses. This is consistent with Roth and Tobin's (2004) findings in their study of two teachers co-teaching science that, "as teaching was enacted, each teacher experienced the actions of the other, and those actions became resources for teaching, and for learning how to teach" (p. 162). Co-teaching extended the field of teachers' classroom practice and provided co-teaching pairs with enhanced access to one another's teaching that went beyond seeing or hearing about representations and observations of teaching. The co-teaching arrangement made each teacher's practice visible to the other and created opportunities to co-construct new practices which were then available to be integrated into each teacher's repertoires of possible future actions in their own practice. For instance, co-teaching with Pat supported Casey to develop and enact an approach to using success criteria with her students where this had previously been an explicit but elusive goal for her.

The teachers' knowledge of students and curriculum was largely situated in their classroom experience and for the co-teaching pairs ideas about practice, classroom actions and decisions, and students' responses were made available in situ. Thus, the co-teaching arrangement afforded teacher learning that was grounded in immediate problems of practice (Timperley et al., 2007); teachers were at the coalface so to speak, and enacting responses to problems of practice as they emerged in an authentic practice context in real time. Moreover, the co-teaching arrangement meant that one teacher had access to the practice of another within their own teaching context, in their own class, with their own students. Thus, for one teacher, co-teaching created opportunities to notice the impacts of a novel set of actions, those of their coteaching partner, in the familiar setting of their own classroom. For the other teacher, there were opportunities to notice the impacts of taken-for-granted practices in a novel setting. What teachers knew about their students appeared to mediate the actions that they directed towards their shared mathematics teaching | learning practice. The ambiguity they experienced within their shared practice in unfamiliar 
contexts opened new learning possibilities for students and teachers by expanding the resources available to develop new understandings of the mathematics and pedagogy simultaneously. On one hand, the conceptual resources on which the students and teachers could draw were expanded thus extending their understandings of the mathematical concept being explored. At the same time, co-teaching pairs were afforded access to an expanded range of approaches to mathematical tasks that had the potential to promote their better understanding of mathematical content and student thinking thus expanding the possibilities for their future practice (Horn et al., 2017). This was evident, for instance, in Pat's naïve questioning of students who were using decimats to make sense of decimal fractions, affording new understandings of decimal fractions for Pat, and of students' thinking for Kris. As Ma (1999) suggests, teacher learning does not necessarily precede student learning but rather the development of each supports the other in a reciprocal and simultaneous manner. Furthermore, Ma contends that teachers' learning of mathematics content occurs largely as they are engaged in its teaching. To this end, she concludes that what is needed "is a teaching context in which it is possible for teachers to improve their knowledge of school mathematics as they work to improve their teaching of mathematics" (p. 146). The co-teaching inquiry activity appeared to provide such a context.

Reflexivity involves becoming "aware of the unaware" (Alexakos, 2015, p. 42) and the teachers were collaboratively designing and enacting new classroom practices. These acted as reflexive objects to promote awareness of specific characteristics of mathematics teaching | learning and increase the likelihood of expansion of each teacher's individual repertoire of possible pedagogical actions. Making differences in practice visible opened opportunities to learn about and from those differences (Tobin, 2014). As Katz and Dack (2014) argue, paying attention to data that interrupt the status quo "holds the potential to yield new professional learning" (p. 36).

\subsubsection{Conversations about practice: Cogenerative dialogue}

Talking together about mathematics teaching | learning was a key aspect of the group's shared activity and the findings illustrate a dynamic and mutually constitutive relationship between the teachers' joint participation in designing and enacting 
classroom practice, and their reflective conversations about that practice. Data shows that the teachers in this study were increasingly willing to open their practice to the scrutiny of others through the sharing of classroom video and reflecting together on episodes of classroom practice.

During their initial meetings, the focus of discussion was on individual teachers' lessons, and conversations tended to be characterised by affirmations of practice; challenging one another's practice was avoided. Sharing individual teacher's video excerpts created opportunities for teachers to examine their own practice and thus appeared to support the professional learning of the teacher whose practice was being examined. Teachers were pressed to describe and justify aspects of the practice examples they were sharing. For the other teachers, there were limitations to the extent to which they could access the practice of others, and thus the conceptual resources available for teacher learning (Horn et al., 2017) as observers of rather than participants in the practice.

In contrast, the co-teaching inquiry activity promoted conversations about practice that gave teachers access to expanded resources for their learning in two ways. Firstly, the inquiry activity opened new and extended spaces for talking about teaching | learning mathematics with colleagues, and secondly it enhanced the range and value of potential learning resources available within teachers' conversations. Participants' conversations about their inquiry activity continued outside of the group's scheduled work and started to involve additional teachers from outside of the project group, thus providing new forums in formal and informal settings for the discussion of mathematics teaching | learning. The field of teachers' conversations about their shared practice was thus extended and opened new opportunities for the professional learning of teachers, including those not directly involved in the group's activity.

Alongside increasing the occurrence of talk about mathematics teaching | learning, changes in the nature and focus of teachers' conversations promoted expanded access to the learning resources available within them. Traditional group structures tend to position teachers as sole operators and recipients of professional learning, and norms of politeness and privacy constrain their active participation in 
rigorous discussions about teaching and learning (Little, 2003). The cultural norms of a group are made up of assumptions, beliefs, values, expectations and habits, and dictate "the way we do things around here" (Eaker \& Keating, 2012, p. 4). Group norms associated with conflict in teachers' shared activity can be both inhibitors and promoters of professional learning. For instance, norms of politeness and collegiality where validation rather than critical reflection is the focus can constrain teachers from questioning or challenging one another's ideas and thus constrain teacher learning (Allen, 2013; Little, 2003).

Within the co-teaching inquiry there were shifts in the norms that influenced the way the teachers participated in conversations about practice and thus what learning opportunities were opened up or constrained within the conversations. Explicit group norms such as those negotiated through the kawa, and implicit norms such as the obligation to protect one another's mana, served to increase the group's engagement in dialogue that examined difference and surfaced previously unexamined practice. Furthermore, a purposefully designed structure aimed at highlighting differences between the teachers' beliefs about practice and what was articulated in research literature appeared to support teachers to challenge divergent practice ideas. This lends weight to Levine and Marcus's (2010) tentative conclusion that providing intentional structures might help to counteract conflict-avoidance norms in teachers' conversations about practice. Through the duration of the project there were notable shifts in the cultural norms operating in the group which saw teachers begin to routinely challenge one another's thinking whereby explicitly negotiated roles and norms in relation to the group's shared work promoted increasingly learning-oriented conversations about practice.

Within the teachers' conversations about their shared practice, expanded opportunities for robust, learning-focused dialogue were made available as the teachers confronted differences in their practice and challenged one another's ideas. Like other studies of teachers' community (e.g. Andrews \& Lewis, 2002; Little, 2003), the group's conversations surfaced otherwise tacit ideas about practice and created openings for teachers to engage with and challenge one another's thinking as they engaged with and worked to reconcile differences. Such challenges opened 
conversations and surfaced otherwise tacit knowledge as actions were taken to reconcile differences. As teachers raised and responded to challenges, they were pressed to provide justification for the claims they were making. The usually tacit assumptions that underpinned their understandings and beliefs about aspects of their practice were surfaced and could be examined. These findings align with those of Achinstein (2002) who, in a study of the micropolitics of conflict within teacher community, observed that conflict extends the boundaries of teachers' talk opening the space for important conversations and catalysing learning. Conflicting views opened conversations and expanded the resources available within them.

Engaging in conversations about their joint work where conflicting views were examined afforded the teachers multiple opportunities to access their colleagues' thinking as a resource to expand their own. Challenging another teacher's position extended conversations and allowed ideas to be more fully examined whereby statements were examined rather than simply accepted as agreed. Conversational threads extended to include multiple turns in which the teachers provided increasingly nuanced justifications for their thinking. In doing so they surfaced tacitly held beliefs about the nature of knowledge and the role of the teacher. As their different views were surfaced and the contradictions among their different perspective were negotiated, an examination of the possibilities of teacher learning as a valid and valued outcome of the co-teaching activity was explored at length.

Extending the degree and depth of teachers' engagement in talking about practice served to expand the repertoire of practice ideas available to them as conceptual resources and reflexive objects that could mediate their individual actions and collective activity. As Horn and Little (2010) concluded, a group's orientation towards problems of practice influences the resources they are positioned to draw on when engaging with it. What they talked about, and how they talked about it, opened opportunities for the teachers to engage productively with new perspectives and ideas about practice.

The way teachers talked together about their classroom practice exhibited many of the characteristics of cogenerative dialoguing as conceptualised by Tobin and Roth (2005). That is, the teachers' talk was directed at a specific classroom episode as 
a common concrete object which was often made available through video excerpts. Importantly, the purpose of the conversations was increasingly to "articulate salient elements of what worked and what did not work for the purposes of designing strategies for improvements" (Tobin \& Roth, 2005, p. 315) and the perspectives and understandings of all group members were valued.

The group's dialogue was also increasingly focused on mathematics teaching | learning thus broadening access to pedagogical constructs as resources for expanding future practice. Co-teaching between intern (student) and cooperating (associate) teachers has been found to surface different perspectives on practice as teachers negotiate which pedagogical approaches to use and talk about practice informally (Gallo-Fox, 2010). Gallo-Fox's study revealed that disagreement about aspects of practice encouraged rich debate about the nature of practice, pedagogy and knowledge and helped to illuminate the complexity and uncertainty of teaching. These findings align with the teachers' experiences of co-teaching in our study, and it appears that such debate opens space for teachers to seek flexible solutions to practice problems. Such debate can challenge conservative teacher practice and open space for innovation and risk-taking, and further expand practice. In other words, debating practice in the context of co-teaching appeared to support iterative and sustained cycles of expansion and opened new possibilities for future action.

Within the group of teachers there was a dynamic interplay between what was talked about and how it was talked about. For instance, challenge opened space for conversations to occur in the first place as people engaged with conflicting viewpoints, at the same time as increasingly trusting relationships and the participants' past experiences of raising challenges without negative consequences afforded the occurrence of such conversations. The dynamic interplay between risk and trust in the group's work together is discussed in section 7.4.3.

\subsubsection{The complexity of co-teaching sharpens teacher noticing}

Teaching mathematics is complex and teachers' knowledge, orientations and actions interact in complex ways; "it all has to come together" (Sullivan, 2008, p. 433) to promote mathematics learning. As the teachers engaged in shared classroom 
practice their attention was increasingly directed to the impacts of their teaching. The teachers' sharpened noticing of students' mathematical thinking served to further expand the possibilities for their future activity. The complexity of the co-teaching activity and the need to be responsive to unpredictable events meant that teachers needed to carefully observe one another's actions, and the impacts of those actions, in order to respond to events as they unfolded.

The co-teaching experiences involved two teachers simultaneously engaging in the activity of teaching whereby elements of the activity were shared including the object of the activity and the role of teacher. At the same time, each teacher could be seen to act individually; that is, individual teachers took their own actions during the co-taught lessons, some of which were explicitly discussed in advance while at other times the teachers "bounced ideas off" one another as the lesson proceeded. As described in section 6.5.2, Casey evoked the image of co-teaching as a dance in which partners, in unison, step up to occupy and step back to create space. Like unrehearsed dancers, teachers were engaging in a familiar activity with heightened awareness, ready to respond to the unanticipated moves of their co-teaching partner and the unexpected responses of their students. They created space for one another, and at the same time, they needed to occupy their shared space (the dancefloor) with care to avoid 'stepping on the toes' of their partner or tripping them up altogether. In other words, the teachers' co-constructed practice was emergent and contingent on one another's actions and the students' responses as they each made carefully considered moves to keep the lesson on track.

Teachers' interactions within practice are central to co-teaching and it is through such interactions that meanings are shared, and change is created (Gallo-Fox, 2010). Teachers' sharpened noticing promoted enhanced opportunities for their reflection-in-action (Schön, 1983) and thus afforded co-teachers access to enhanced resources for generating understandings of mathematics teaching | learning and expanding the possibilities for their future classroom practice. This is in keeping with the notion of transfer as preparation for future learning whereby what is known or learned in one situation informs what is noticed and understood in another (Bransford \& Schwartz, 1999), in contrast to a view of transfer as the direct application of 
something that has been learned in a new setting. An example is Pat's increasingly sophisticated attention to Casey's use of concrete materials in her teaching whereby Pat had not, at the end of the project, shown evidence of any change in her use of materials in mathematics lessons. Nevertheless, her increased noticing and expanded understanding of Casey's practice was evident and set the scene for future noticing in her own classroom, and potentially for associated shifts in her practice.

Co-teaching pressed teachers to engage with their existing practice theories and reconcile new and sometimes dissonant understandings with those they currently held, a process that Timperley and colleagues (2007) identified as necessary for substantive teacher change. Engaging with teachers' prior beliefs and understandings provides contrasting cases that can help provide a basis for appreciating the critical features of the new learning (Bransford \& Schwartz, 1999). Co-teaching also pressed teachers to make sense of the intentions and impacts of their co-teaching partner's moves. Each teacher needed to understand why their partner did or said what they did in order that their own next move could advance the lesson towards agreed goals. Their co-teaching partner's moves were experienced as non-routine and thus served as mini interruptions to practice, provoking unanticipated responses which teachers then needed to make sense of. Thus, the unfamiliar moves of co-teaching partners and unanticipated responses of students introduced novel practices (teacher moves) and tools (students' responses) into the activity system constituting new possibilities for others and leading to expanded action possibilities; that is learning (Roth \& Lee, 2007). Teacher learning was afforded within the co-teaching activity whereby possibilities for teachers' moment-by-moment actions in the context of the co-taught lesson were expanded. Furthermore, what teachers noticed within co-taught lessons was available as a resource for teachers' actions within other interrelated fields of the teachers' shared practice.

The shared teaching activity was emergent, and teachers' individual actions were contingent on students' responses during the lesson. Sharing the teaching task expanded teachers' opportunities to attend to important details in the complex classroom environment as the teaching was enacted. Furthermore, there appeared to be dynamic and mutually generative relationship between the teachers' reflections-in- 
action and their later reflections-on-action in that their sharpened noticing during a co-taught lesson expanded the breadth and depth of their reflective thinking after the lesson. Carambo and Stickney (2009) argue, in the context of pre-service teachers coteaching science during practicum placements, reflection after the fact, or reflection on action, "cannot replicate the depth of understanding that emerges when two teachers cohabit the classroom and cooperate on the variety of actions needed to successfully teach [a lesson together]" (p. 438). Nevertheless, co-teaching experiences where teachers took different approaches, including those that were not necessarily agreed upon prior to the lesson, catalysed conversations that allowed the teachers to surface their different understandings and goals. Such conversations prompted teachers to make otherwise tacit ideas about practice explicit. Furthermore, the shared plan developed prior to teaching appeared to provide a reflexive object for the two coteachers that promoted their noticing of their adaptive practice. In other words, it was because they had an intended direction that they were able to notice that their lesson had diverted from it. This represented both a sharpening of the teachers' noticing of what happened during their co-taught lesson and a comparative case, in the form of a set of anticipated events, in light of which to make sense of what did occur in the lesson. Teacher learning was afforded by the teachers' heightened attention to important aspects of practice as they acted to make sense of and reconcile the contradiction between what was anticipated and what actually occurred in the lesson.

\subsubsection{Teacher learning within shared practice: Talking / Enacting / Noticing}

The teachers' jointly enacted classroom practice, their reflective conversations and their sharpened noticing of student thinking were inextricably connected in ways that appeared to support self-sustaining cycles of expansion. Figure 7.1 illustrates a trialectical relationship among these fields of the co-teaching inquiry activity. The expansion of resources within each of the three fields was dynamically interrelated and mutually constitutive; each impacted on, and was impacted by, the others. 


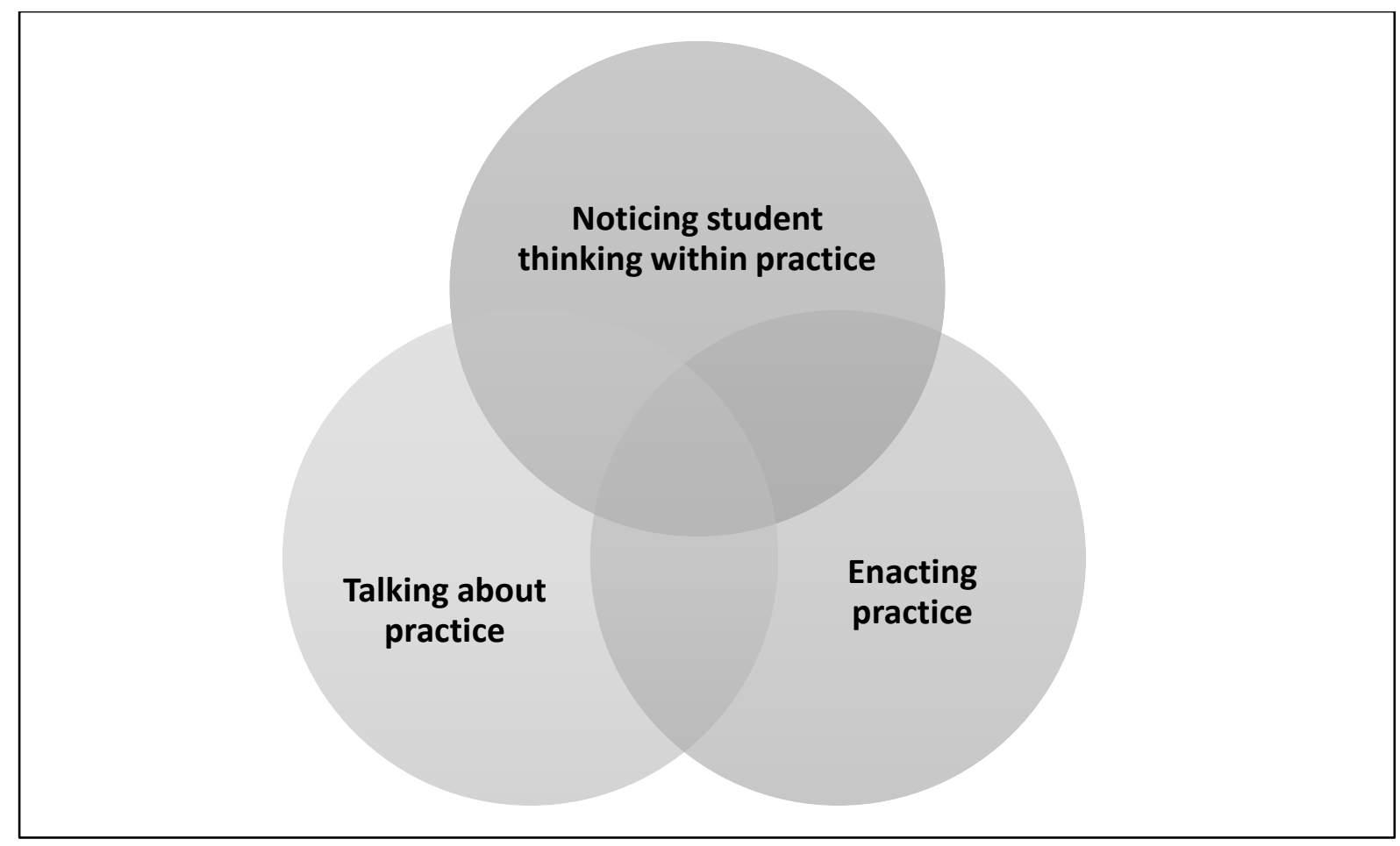

Figure 7.1. Interconnected fields of teachers' co-teaching inquiry practice.

The trialectic, which is illustrated using three overlapping circles, provides a useful conceptual tool to understand the multidimensional nature of the co-teaching inquiry activity and the dynamically interrelated catalysts for expansion within the system of activity. The notion of a trialectic allows us to explore the reciprocal relationships amongst each element by examining them together without confounding them, and distinguishing among the composite parts without fully separating them (Corsi \& Morin, 2015). In the case of the co-teaching inquiry activity, a shift in any of the three aspects of the teachers' shared work created new possibilities in relation to one, or both, of the other aspects. For instance, as the teachers' conversations more robustly interrogated their assumptions and beliefs about mathematics teaching | learning and they were pressed to justify aspects of their classroom practice, those conversation surfaced ideas about practice that opened new possibilities for action within their co-taught lessons and their own classrooms.

Conversely, new practices that were experienced within co-taught lessons opened possibilities for practice ideas that could be introduced and made sense of in subsequent conversations. Similarly, conversations about aspects of pedagogy prior to 
co-teaching oriented teachers to notice those pedagogical moves and students' responses to them, which then had the potential to inform future practice and conversations about practice. An example that illustrates the reciprocal and iterative relationship amongst these three fields of the teachers' collective activity is Casey's experience in relation to the pedagogical practice of making success criteria explicit with students. Prior to co-teaching, Casey had engaged in conversations with both Kris, as her appraiser, and Pat in the context of co-planning a lesson, about this as a practice that diverged from normal classroom routines for her. During the co-taught lesson, she was able to experience the pedagogical practice as part of a lesson she was actively involved in teaching and had space to observe the students' responses. Furthermore, she could do so in the context of the lesson itself as well as after the completion of the lesson as she and the students continued to engage with the classroom artefact that had been produced. The group's reflective conversation about the co-taught lesson subsequently provided an additional space for Casey to deepen her understanding of the practice, informed by her lived experience and what she had noticed of the students' responses.

The iterative, reciprocal and multidimensional nature of Casey's experience of developing a new pedagogical practice is consistent with Bransford and Schwartz's (1999) notion of transfer of learning as involving preparation for future learning (PFL) whereby learning experiences may be subsequently forgotten nevertheless they set the stage for future noticing. Casey encountered the practice on multiple occasions and each encounter built on previous encounters and opened possibilities for future actions.

The sections that follow discuss how the teachers' active engagement in shared practice through the co-teaching inquiry promoted a broader range of possible actions within their own practice. The aim, as Timperley and colleagues (2007) put it, is to get inside the "black box" of teacher learning and understand the mechanisms and processes that promote the transformation of conceptual understandings and enacted practice. As teachers participated in the co-teaching inquiry activity, they were afforded expanded access to resources that were available within each of the three fields of their shared practice through enhanced opportunities to engage with 
challenge and negotiate difference. Expansion occurred within the broader field of shared mathematics teaching | learning through co-teaching, an activity that was characterised by the ongoing negotiation, and renegotiation, of activity goals; the emergence of collective responsibility for student learning; re-imagined roles and relationships among participants; and the interplay of trust and risk in relation to how teachers participated in the activity.

\subsection{Opening space for new ways of working: The mechanisms of change}

This section examines the ways in which the teachers' engagement with an expanded set of learning resources within their shared practice catalysed ongoing cycles of expansive learning. Aspects of the teachers' co-teaching inquiry activity were restructured to afford teachers' learning through expanded access to resources within their shared practice, including how the interplay of trust and risk supported increased participation in the collaborative inquiry activity; how shared responsibility shifted the teachers' attention from their practice towards student learning; how explicitly negotiating group norms opened space for re-imagined roles and relationships for participants; and how the co-teaching inquiry was sustained by the ongoing re-negotiation of the object of the activity. The teachers were afforded expanded access to learning resources within three interrelated fields of their work together, as described in the preceding section. This section addresses the question of how participation in the co-teaching inquiry restructured teachers' work and afforded them expanded access to learning resources within their shared practice.

\subsubsection{Re-imagined roles and relationships}

Respectful relationships are central to teachers' collaborative activity. Respect among participants and a commitment to shared decisions are key factors promoting teachers' open engagement in conversations about their practice (Robinson et al., 2009). In the activity system, the division of labour encapsulates the historically evolving relationship between individual action and collective activity (Engeström, 2015). Contradictions emerged in the group's co-teaching inquiry activity in relation to norms of practice and norms of social interaction that influenced how teachers worked together, the various roles teachers identified with, and the hierarches of 
power associated with those roles. The process of negotiating the group's kawa explicitly surfaced the idea that participants held multiple roles, including schoolbased roles involving hierarchical power relationships and functions such as performance appraisal and the evaluation of teachers' practice. In negotiating their kawa, group members agreed that in the work of this project they were all assumed to hold equal status and power and their role was primarily that of a learner. As Sam had said "I do have different roles with different people but ... I'm just here as a teacher. I'm not here as a [leader]". This explicit relinquishing of identified roles, particularly school leadership roles, and positioning all participants as learners and co-researchers represented both a narrowing and levelling of the division of labour (in activity theory terms) and was experienced as a contradiction which appeared to create space for a restructuring of the social norms at play in the group conversations, and practice norms in relation to the privacy of teachers' work. Moreover, explicitly negotiating the kawa as a protocol for how teachers would work together sparked an ongoing conversation that served to both flatten power hierarchies and expand the boundaries of participants' roles; it allowed participants to talk about how they viewed their own and others' roles in relation to mathematics teaching | learning generally, and their coteaching inquiry more specifically.

Explicitly identifying as learners in the context of their work together mediated how the teachers negotiated the conflicts that emerged for them in relation to the multiple roles they each held including as learners, teachers and school leaders, and between their own and others' roles. At the beginning of the project, the group had negotiated the kawa with the aim of making explicit some of the norms governing the group's interactions. The kawa appeared to act as a heuristic, mediating how the teachers engaged with and acted towards resolving the contradictions that emerged in relation to their various roles. According to Powietrzynska, Tobin and Alexkos (2014), heuristics are "meant to reveal the meanings associated with a particular social construct [and] assist in bringing difference into light" (p. 69) and afford change through "reflexivity, or becoming aware of the unaware" (p.70). During the initial discussion about the group kawa, when Sam specified her primary role as a learner and not a leader for the purposes of this group's work, she opened the possibility for 
teachers to reimagine their roles. At the same time, she surfaced a potential conflict between her leadership role and the group's learning goals. The kawa, specifically the agreement that the primary role of participants was of equal co-learners, catalysed ongoing conversations about teachers' roles and provided a reflexive object against which contrasting ideas about role could be interrogated and understood. As a heuristic, the kawa served to heighten awareness of the different roles that teachers identified with and thus raised for them the question "to what extent is this role reflected in my actions?” (Powietrzynska et al., 2014).

Through co-teaching, teachers were able to reposition themselves as simultaneously taking the role of expert/teacher and learner which contrasts with the expert-novice relationship commonly assumed to underpin teachers' professional learning. Teachers' experiences of conflicting roles were surfaced and debated in the public forum of group meetings, thus teachers had opportunities to make explicit and interrogate not only their own multiple roles, but also those of their colleagues. As discussed previously, the dual role of teacher/expert and learner is a challenging contradiction for teachers to negotiate (Grossman et al., 2001) and voicing this tension served to open space for alternative views to be brought to the teachers' reasoning. Surfacing teachers' experiences of role conflict acted as a reflexive object for the group to consider wide-ranging ideas about what it meant to be in the role of a co-teacher. This conversational thread was ongoing and was picked up and expanded on in successive meetings. As teachers were pressed to elaborate on and justify their different perspectives, the ongoing conversation opened multiple opportunities to test, refine and deepen their understandings. As described by Powietrzynska and colleagues (2014), the teachers' ongoing conversations about their multiple and sometimes conflicting roles fuelled "a reflexive process that serve[d] as an intervention, driven by hermeneutical-phenomenological processes" (p. 72). In other words, through their interactions, teachers were exploring the questions "what is happening here?" in relation to how they saw their different roles enacted in the context of their work, and "why is it (or is it not) happening?" Engaging with and working to reconcile their contrasting perspectives of what it meant to be a teacher 
and a learner afforded opportunities for reflexive thinking that supported new understandings for all participants.

Alongside the teachers' shifting roles was the constant repositioning of my role in the inquiry activity. As anticipated, the researcher role shifted from active participant and project leader, to participant observer. As Parr and Timperley (2015) observed in the context of a collaborative study aimed at raising literacy achievement, researchers' previous involvements with schools mediated how they viewed their role and thus what tensions and affordances were surfaced. In this study, like for Parr and Timperley, the aim was for interdependent relationships amongst different roles and sources of expertise and, as expected, contradictions emerged in terms of the various roles the teachers in the study ascribed to me, including those of teaching colleague, curriculum expert and researcher. From the outset, I sought to explicitly position myself as co-researcher and co-learner however there was evidence that the teachers initially positioned me as expert and leader, for instance seeking feedback on teaching practice and assuming I would take responsibility for the agenda for meetings. Nevertheless, like Hunter (2010) in her work developing a mathematical inquiry community alongside a teacher, as our conversations shifted towards those that were increasingly multi-voiced and equal, my role was transformed to one more of listener and learner. Of particular interest in this study was how my role as critical friend and provider of external knowledge to stimulate dialogue (Stoll, 2011) was somewhat subsumed by the teachers' increasing willingness to raise challenges to existing assumptions and practices. It appeared that the challenge was important for stimulating critical dialogue, and not necessarily where from where that challenge arose.

\subsubsection{Shared responsibility for student learning: The emergence of the collective}

Pedagogical change is difficult because it disrupts taken-for-granted practice and challenges conservative norms of classroom activity (Gallo-Fox, 2010). The conservatism of classroom practice is not only reinforced by teachers; students, can also actively resist changes in teaching approaches (Higgins, Moeed, \& Eden, 2018; Roth \& Tobin, 2004). The teachers' individual characteristics, the nature of their relationships and their explicit and assumed roles were dynamically interrelated. The 
teachers' co-teaching inquiry activity promoted the emergence of family-like group structures and productive working relationships amongst group members.

Importantly, the teachers experienced a sense of responsibility for one another's wellbeing and success, and a sense of shared accountability for the learning of their students. This aligns with previous research findings that within a co-teaching community comprising teaching interns and their more experienced cooperating teachers, taking pedagogical risks was directed towards efforts to improve student learning and "supported by the collective resources, energy and support" (Gallo-Fox, 2010, p.120) that were offered by the group.

Explicitly identifying as learners and equals appeared to support the teachers to engage with one another in ways that interrupted previous patterns of participation. The teachers had previously seen difficult working relationships as an unavoidable product of incompatible personalities. In contrast, co-teaching appeared to create opportunities to reimagine and build increasingly productive relationships centred on the teachers' shared accountability for teacher and student learning. Productive relationships were important for the success of the teachers' collaboration however it appeared that such relationships were not necessarily a prerequisite of effective collaboration but also developed from the teachers' shared work. As the teachers' sense of responsibility for student learning extended beyond their own classrooms, their actions were increasingly directed towards a common object which supported their sense of collective. For instance, the teachers' accountability towards one another meant that co-taught lessons were carefully prepared and thus more likely to be successful, and their success served to further enhance their enthusiasm and sense of achievement as a group.

Shifting attention from their feelings about one another and their focus on an individual teacher's practice, to a shared and perhaps more neutral focus on the children's learning, redefined what constituted success. Achievements and challenges in the teachers' work were collectively realised outcomes thereby the teachers experienced working together as both promoting success and providing support which in turn promoted increasingly positive feelings about working together. Successful coteaching is not contingent upon friendship (Gallo-Fox, 2010) and these findings 
suggest that co-teaching can provide fertile ground for nurturing positive

relationships. Co-teaching - the act of jointly engaging in the teaching task - served to focus teachers' attention on the shared goal of student learning and thus away from their individual practice, perhaps removing a potentially competitive structure which might compromise relationships between teachers.

\subsubsection{Interplay of trust and risk: Inviting participation}

Teachers' emotions mediated how they participated in the co-teaching inquiry activity and thus how their classroom practice was shared with others. Increased opportunities to talk about and engage together in mathematics teaching | learning appeared to expand teachers' access to new ideas about practice and to promote positive emotions that supported their increased motivation to engage with new practices. Nevertheless, making teachers' usually private classroom practice public, and thus available to others as a resource for learning, involved risk and required trust. Previous sections have discussed how professional conversations need to surface and challenge problematic aspects of teachers' practice, as well as affirming effective practice, if they are to be productive for teachers' ongoing learning. However, teachers' perceptions about the expertise they had, or lacked, influenced how they felt about coteaching where perceived gaps in their expertise might be exposed and make them vulnerable. Trust was seen as a prerequisite to teachers being willing to share their teaching with others and previous research has shown that where trust is compromised this can act as a barrier to teachers working together productively and teacher learning can be constrained (Le Fevre, 2014).

For Casey, Kris and Pat, the usual teaching arrangement was largely traditional whereby they were each individually responsible for the learning of one class of students. An historical contradiction was apparent whereby exposing classroom challenges had been seen to direct unwanted attention to the quality of the individual teacher's practice thus making the teacher vulnerable to negative critique. The teachers recalled negative past experiences of having their teaching observed by others, and sharing aspects of their practice that were problematic required them to trust their colleagues. As part of the school's performance appraisal process, for instance, judgements about the quality of a teacher's practice had carried the risk of 
punitive action and so they usually avoided exposing problems of practice. In a recent study exploring trust in teachers' reflective practice, Benade (2018) identifies a contradiction for teachers between reflecting publicly on practice and having one's practice judged.

Within the co-teaching inquiry activity, the role of trust in both affording and constraining teacher learning represented an important contradiction in relation to the teachers sharing aspects of their work with the aim of interrogating and improving their practice. Kazemi and Franke (2004) observed that past experiences mediate what ideas teachers make public within their collaborative activity. Trust was emergent within the co-teaching inquiry activity and contingent on teachers' actions involving risk and their responses to the risk-taking actions of others. For instance, contrary to the perceived risks associated with sharing their practice, the teachers believed that reflecting on classroom video with colleagues had the potential to be instructive. Furthermore, the teachers' initial experiences of sharing videos of practice focused on celebration rather than critique and this appeared to mitigate the anticipation of negative responses and promote future sharing. Sharing video was always voluntary and excerpts were usually chosen with an explicit learning purpose whereby statements like, "I'm showing you this because ..." became routine. This appeared to support teachers to take the risk of exposing weaknesses in their practice and positive experiences of sharing video in this context appeared to promote relationships increasingly characterised by trust.

The influence of trust appeared to be iterative whereby increasingly trustful relationships promoted increased levels sharing of teachers' practice, and this in turn supported the kinds of robust, learning-oriented conversations that could both promote shifts in practice and strengthen trust. As discussed previously, it was evident that working together promoted enhanced well-being for the teachers and strengthened their sense of collective whereby the group took on a family-like structure in which teachers experienced a sense of responsibility for one another's well-being and success. The notion of whānau (family) was similarly used by a teacher in a study by Hunter (2007) to promote the emergence of collective responsibility for learning amongst students in the mathematics classroom, and illustrates some 
synergies amongst productive learning conditions for students and teachers in the context of inquiry communities. The teachers' engagement in and reflection on jointly constructed practice, that of a co-taught lesson, appeared to represent highly productive conditions for promoting the risk-taking and challenge necessary for teachers to transform mathematics teaching | learning.

The shared responsibility characterising co-teaching supported the development of productive working relationships amongst teachers and productive conditions for teacher learning. In the teachers' reflective conversations, the focus shifted from teachers' actions towards impacts on learners thereby mitigating some of the risks involved in opening practice to critique and supporting the development of trust amongst participants. Critical conversations about practice were contingent on risk-taking and openness to vulnerability, as well as respectful communication, and these were dynamically related. Furthermore, teaching together appeared to provide support for teachers to take risks and try new pedagogical practices where the responsibility for 'getting it wrong' didn't lie with any one teacher individually. Sharing responsibility for student learning characterised their co-teaching experience and achievements and challenges in the teachers' shared work were collectively realised outcomes. The teachers experienced working together as both promoting success and providing support, which supported the development of increasingly productive working relationships amongst them. Furthermore, in their reflective conversations, the shifting focus from teachers' actions towards impacts on learners served to mitigate some of the risks involved in opening practice to critique thus supporting the development of trust amongst participants. Co-teaching diffused the risk of teaching challenges being exposed as weaknesses because the focus was on the students' learning rather than on an individual teachers' practice. This in turn promoted increasingly positive feelings about working together.

The teachers had initially suggested that some co-teaching arrangements might be problematic if they had previously experienced challenges in their relationship with a co-teaching partner. Contrary to the teachers' expectations, co-teaching provided a context for strengthening the trust within collegial relationships, particularly for coteaching pairs where there had been some initial reluctance to work together. This is 
an important finding as it highlights how avoiding working with particular colleagues due to a perceived incompatibility and associated lack of trust can be self-fulfilling and constrain opportunities for developing productive professional relationships. This finding supports Benade's (2018) assertion that without vulnerability there is unlikely to be trust.

Within the co-teaching inquiry activity, the shifting of attention from the teachers' feelings about one another and their focus on an individual teacher's practice, to a shared and perhaps more neutral focus on the children's learning, redefined what constituted successful collaboration. The teachers increasingly saw that challenging problematic practice served to promote thinking and support learning. Their actions towards attending to and upholding one another's mana, or esteem, supported the building of trust that then opened space for teachers to engage in increasingly robust, learning-focused conversations. Thus, earning or building trust was contingent on risk taking just as risk-taking was contingent on trust. That is, the willingness of teachers to expose vulnerabilities was required for teachers to experience the positive impacts of doing so. Casey, for instance, needed other teachers to risk sharing problematic aspects of their practice, as Pat and Sam had done, to counteract her expectation of possible negative responses to teachers who were sharing, and for her to experience the benefits to the group of them doing so. Observing the support others received when they shared their practices opened for Casey the previously unanticipated, or at least not fully trusted, possibility that if she shared her video there might be a similarly supportive response.

Distrust towards management was a barrier to exposing what might be perceived as weaknesses in teachers' practice, and this was mediated by the teachers' past experiences of performance appraisal observations. This surfaced a contradiction whereby the teachers saw that being trusted by management supported them to expose and publicly engage with problems of practice whereas not having trust in management appeared to constrain them from doing so. The teachers' distrust towards management appeared to be connected with the assumed motives of school leaders in examining classroom practice and this is discussed in more detail in the following section. 
Vulnerability diminishes agency (Benade, 2018) and thus trust promotes expansion. Green, Preston and Sabates (2003) draw on Robert Putnam's notion of social capital as "features of social life - networks, norms and trust - that enable participants to act together more effectively to pursue shared objectives" (p. 456) and assert that education, specifically teacher learning in this case, has a powerful influence on trust and thus on the resources available to teachers and their collective power to act. This helps to explain the apparently expansive cycle of contingence and emergence whereby the development of trust is emergent and contingent on past successes. 'Successfully' taking a risk in a safe social context builds trust and promotes further risk-taking. This can be seen as one of many smaller cycles of potential expansion that Engeström (2015) explains make up the larger cycle of expansive learning which in this case refers to the co-teaching inquiry activity. As Green and colleagues suggest, "trust is understood as a relational, dynamic and institutionally dependent phenomena. Trust breeds trust; distrust, distrust" (2003, p. 20). Illustrating the complexity of the teachers' activity and the interconnectedness of its various elements, the teachers' actions towards attending to and upholding one another's mana (or prestige) supported the building of trust that then opened space for teachers to engage in increasingly robust, learning-focused conversations.

\subsubsection{Flexible goals: (Re-)negotiating the object}

Trust, as discussed in the previous section, was promoted by the teachers' activity increasingly being directed at shared goals. The teachers recognised that having a shared understanding of learning goals, and of teaching approaches that might support those goals, promoted trust in one another as they engaged in coinstruction. Having shared goals allowed teachers to practice together trusting that their partner's classroom actions would be productively directed at agreed goals; that they would be 'on the same page' in their teaching. Nevertheless, findings point to the constantly shifting landscape of teacher learning, in a day-by-day and moment-bymoment sense. The teachers were constantly learning, and their practice was continuously being restructured thus the object of their shared activity was always shifting, and the activity system itself was in a constant state of flux. It was necessary for the teachers' inquiry activity to be flexible and responsive to such shifts in order 
that they could direct their activity at an unstable object. Conversations prior to, during and after co-taught lessons created opportunities to both surface and agree on learning goals, and to reconcile contradictions that emerged in relation to competing goals, including those that might be unstated.

Grossman and colleagues (2001) note a tension between the dual and sometimes conflicting roles of teacher and learner. Similarly, in our study, teachers initially saw that co-teaching directed at teachers' learning goals might be at the expense of students' opportunities to learn. It was anticipated that feeling unprepared for teaching at an unfamiliar level, for instance, would limit the contribution a teacher could make to a co-taught lesson and would thus compromise the quality of the learning experience for students. In activity theory terms, this represents a contradiction between the multiple roles of the teachers as both teachers and learners, and the object towards which their collaborative activity was directed. Voicing concerns about not having the requisite content knowledge to teach at a higher level surfaced this contradiction and thus opened space for the group to negotiate and reconcile conflicting goals in conversations that spanned several group meetings. Such conversations illuminated a reciprocal relationship between student learning and teacher learning whereby introducing new pedagogical approaches expanded the possibilities for both teachers and their students beyond the co-taught lesson.

The co-teaching arrangement allowed a simultaneous focus on teacher and student learning goals whereby teachers reported evidence of their own learning and that of their students being simultaneously supported by the co-teaching arrangement. Learning outcomes for teachers and students were both intentionally planned for and serendipitously occasioned, often mutually within the context of the same co-teaching event. For instance, when Kris invited Pat to co-teach in her classroom, her motives were directed at supporting Pat to strengthen her practice, potentially at the expense of the students' learning and her own whereby Kris anticipated that her attention would be primarily on supporting Pat's learning rather than her own or her students. Unexpectedly, Kris found that she gained new and productive perspectives on her students' thinking as they responded to Pat's different approach to questioning. The expected novice/learner (Pat) and expert/teacher (Kris) 
relationship was disrupted as the activity was directed at the learning of both teachers. The students' possibilities for learning were simultaneously expanded as they had access to new entry points for thinking about the problem they were solving as a result of Pat's questioning.

Contradictions emerged in relation to the multiple goals of the inquiry activity whereby teachers' actions directed towards one goal were experienced as incompatible or in direct competition with another goal. For instance, fore-fronting actions directed at social goals, such as celebrating teachers' successes, was sometimes at the expense of other goals such as pressing for improved understanding of a mathematical misconception or challenging problematic pedagogical practices. Actions towards goals that were of importance to the collective were sometimes experienced as competing with teachers' individual goals, and vice versa. An example of this is described in the previous section whereby individual teachers acted to keep their practice private in order to avoid the expected negative consequences of having problems exposed, however in doing so they made a potential learning resource unavailable to the group. Conversely, actions towards an individual's preferred goal could be in tension with an alternative and apparently competing collective goal.

Conflicts emerged also between the goals and motives of individual teachers in the context of sharing their classroom practice. For instance, a teacher that used the collaborative space to demonstrate her expertise, to 'show off her practice, was at odds with others who might be participating with more of a learning purpose. When participants made a choice to direct their actions towards a specific goal at the apparent expense of another, this was sometimes experienced as making a sacrifice for the greater good. In one such example, Kris agreed to a request for help from Sam that she did not expect to be reciprocated or fully appreciated. Nevertheless, Kris found that teaching together in Sam's classroom created an opportunity for her to better understand Sam's teaching context as they worked together towards shared student learning goals. The co-teaching experience, where teaching was a shared practice in contrast to teaching that is more individually enacted, perhaps removed a potentially competitive structure which would be likely to compromise the relationship between the two teachers. The removal of conflicting goals appeared to support teachers to 
work together towards a shared goal and thus redirect their attention towards the object of student learning. In this case, the co-teaching experience opened space for the learning of the two teachers involved, something Kris had not anticipated. Furthermore, the co-teaching experience served to challenge some of the assumptions that underpinned relationships that were experienced as difficult and opened the possibility for future productive collaboration.

In negotiating activity goals, the teachers agreed that their collaborative activity might be directed at wide ranging needs, and teacher learning was both an explicit and a tacit object of their co-teaching. Their experience of the co-teaching inquiry throughout the project had made them different teachers and they recognised the shifting practice norms associated with the teaching and learning of mathematics, from individual to shared, and private to public. They highlighted this at their penultimate group meeting when they wondered what might happen if they extended their co-teaching inquiry to include colleagues who had not been involved from the beginning. The co-teaching inquiry activity supported expansion in relational agency within the group. Relational agency is described as “a capacity to align one's thought and actions with those of others in order to interpret problems of practice and to respond to those interpretations" (Edwards, 2005, p. 169). The notion of relational agency helps to explain how the co-teaching inquiry supported the strengthening of collective agency within the teachers' shared practice as they acted towards constantly shifting objects.

Conflicting goals served to constrain the co-teaching inquiry activity where the teachers had restricted access to resources and thus limited agency. In the teachers' discussion about possibilities for extending their co-teaching inquiry work beyond the timeframe of the study, an important contradiction arose. The teachers saw Dale's primary goal as improving literacy teaching and learning through school-wide professional development whereas for them it was the improvement of mathematics teaching and learning. It appeared that Dale and the teachers had different objects to which they were wanting to direct activity, and thus resources, and these were in competition. Dale and the group of teachers had unequal agency to act towards these competing goals; Dale's role afforded her the power to schedule staffing and meeting 
times, for instance, and to approve or decline the teachers' request for additional resources to continue this work. In response to this contradiction, the teachers hoped to provide evidence of the potential benefits of the co-teaching inquiry for the wider teaching staff, and in so doing encourage the principal to direct activity towards a shared object. That the teachers were unable to gain Dale's support to apply for project funding to extend the co-teaching inquiry is perhaps evidence of the importance of school leaders' active participation in teachers' professional learning activity, a practice that Robinson and colleagues (2009) found to have a significant impact on student learning. These authors found that active participation in teacher learning afforded a deeper appreciation of what is required to strengthen students' learning opportunities and leaders provided organisational and material resources accordingly. Once our study was underway and Dale ceased to actively participate in the teachers' shared work, the teachers' agency was constrained, illuminating the contradiction between the object of the teachers' activity, their professional learning directed at strengthening their mathematics teaching | learning, and their limited agency in terms of directing resources towards this goal. Sewell (1992) argues that "to be an agent means to be capable of exerting some degree of control over the social relations in which one is enmeshed, which in turn implies the ability to transform those social relations to some degree" (p. 20). Role hierarchy and the power that went with Dale's position as school principal were structures that constrained the collective agency of the teachers.

\subsection{Engaging with difference: Co-generating knowledge}

Engagement with difference was central to the teachers' ongoing co-generation of knowledge for teaching | learning mathematics though co-teaching inquiry. It was observed by Skattebol and Arthur (2014) that the need for participants to explain their thinking across different fields of practice and areas of expertise "spark[s] provocative lines of intellectual engagement" (p. 362) and during the penultimate group meeting I had noted the interrelated challenges and affordances connected with collaborating across difference:

The conversation that sits around [co-teaching] is a tool but also the fact that people might have different approaches, so it might be "Oh, I was deliberately 
leaving space then and you kept talking" then gives a reason to have a conversation about that, that you wouldn't otherwise have. [R-GM\#6]

Differences that emerged within the teachers' co-constructed and enacted practice, the conflicting ideas about practice that emerged in their conversations about practice, and what teachers noticed about students' sometimes unexpected responses to practice, served to expand the teachers' conceptual and material resources for practice. The co-teaching inquiry activity constituted authentic inquiry and "as multiple and diverse voices are empowered, reflexivity, learning from the other and from difference, become central" (Alexakos, 2015, p. 6).

Participation in the co-teaching inquiry transformed mathematics teaching | learning practice. Figure 7.2 below illustrates aspects of the teachers' shared practice that were restructured to afford teacher learning through their expanded access to resources within three interconnected fields. Three interconnected fields of coteaching practice are depicted in the overlapping circles, within which teachers were afforded expanded access to resources for their learning. The intersections between circles depict aspects of the co-teaching practice that were restructured and thus catalysed ongoing cycles of expansive learning. As described in the preceding sections, the interplay of trust and risk supported increased participation in the collaborative inquiry activity, shared responsibility shifted the teachers' attention from their practice towards student learning, and explicitly negotiating group norms opened space for re-imagined roles and relationships for participants. The co-teaching inquiry and ongoing cycles of expansion of the inquiry activity were sustained by the ongoing re-negotiation of the object of the activity. As these aspects of the teachers' work were restructured, teacher learning was promoted; that is there were interconnected shifts in practice that expanded the possibilities for teachers to act within and beyond their co-teaching inquiry activity. For instance, developing a sense of shared responsibility and making group norms explicit together promoted expanded participation in learning conversation that were robust and afforded opportunities to interrogate, make sense of, and co-construct new possibilities for classroom practice. As Roth and Tobin (2004) have pointed out, co-teaching is about "developing as teachers while 
teaching" (p. 165, emphasis added) and is fundamentally underpinned by processes of inquiry as knowledge-creation.

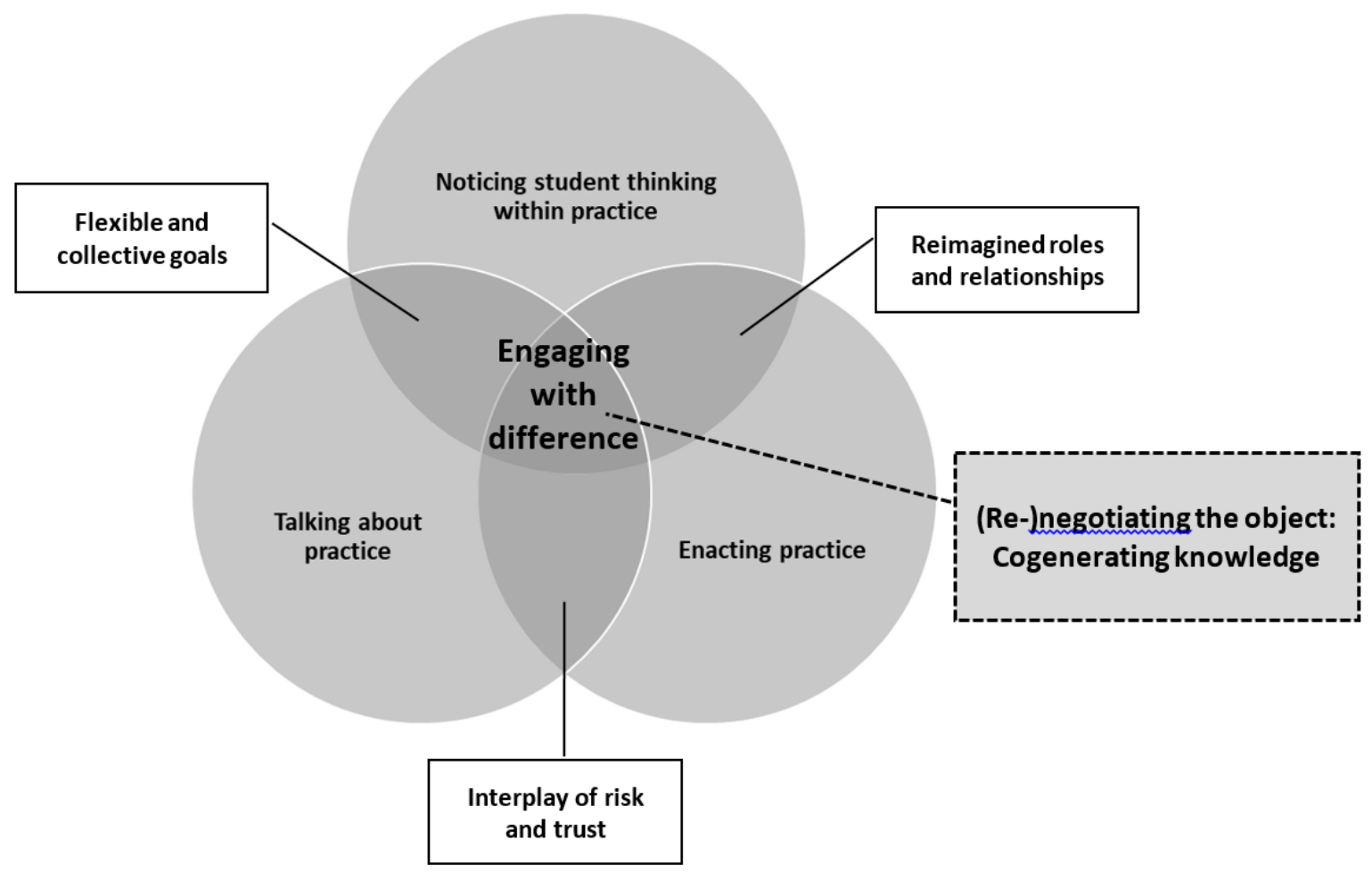

Figure 7.2. Restructuring mathematics teaching | learning within interconnected fields of co-teaching practice.

Central to teacher learning within the co-teaching inquiry activity, and thus central to the diagram, was the teachers' ongoing engagement with difference. The coteaching inquiry included reflective conversations that were integral to the activity and could be characterised as co-generative. Roth and Tobin (2004) describe cogenerative dialogue as aimed at collectively generating local theory. Co-teaching and co-generative dialogue together assume that teachers act agentically to design future classroom actions with a shared sense of purpose and responsibility for enacting those actions. A sense of collective responsibility for classroom events is at the heart of coteaching (Roth \& Tobin, 2004) and the emergence of collective responsibility in this study appeared to be both promote and be promoted by the teachers' increasing engagement with difference in the context of their shared work. Engaging with 
difference supported ongoing cycles of expansion whereby difference was experienced as a disruption and thus a source of contradiction within the activity. Action towards reconciling differences and thus removing contradictions, created new possibilities for future action. The reconciliation of difference played out in multiple spaces including as teachers debated their different understandings of pedagogy informed by experience and research literature, drew on wide-ranging past experiences and contextual knowledge to understand classroom events, surfaced and discussed conflicting ideas about role, negotiated learning goals and made explicit different perspectives on what was important to focus attention on and why.

The project involved multiple levels of inquiry through which participants cogenerated theory-in-action, and each inquiry informed the others. New understandings about practice that were co-generated through the group's ongoing reflective conversations influenced their co-teaching experiences and mitigated some of the uncertainty that may otherwise have been experienced. That is, participation in an inquiry community generated shared understandings of co-teaching practice and so, as Casey suggested, the teachers had "a lot of pre-knowledge we're bringing already" [C-GM\#6] to each subsequent co-teaching experience. Part of what the teachers were learning was how to participate in the co-teaching inquiry. This was evident, for instance, in the ongoing development of productive working relationships which promoted increasingly rich conversations about practice. These changes represented a restructuring of the teachers' work; the way teachers worked together was fundamentally transformed as they co-generated new understandings of the activity of co-teaching inquiry. The co-teaching inquiry supported teachers to notice and respond flexibly to what emerged during mathematics lessons, and to their students' mathematical thinking. They increasingly took the role of inquirers (learners) as teachers, co-generating local theory about mathematics teaching | learning in the act of participating in the co-teaching inquiry activity. Carambo and Stickney (2009) discuss how co-teaching as a structure for the pre-service practicum occurs as an intersection of diverse cultural fields and promotes reflection that is "scholarly and informed by multiple perspectives" (p. 400), conditions that they have argued are difficult to replicate for practising teachers. This study appears to answer 
their call for research into "ways that the co-teaching collaboration can reintegrate reflective practice into the lives of practising teachers" (p. 440). As the teachers engaged in the shared practice of co-teaching, their conversations about practice, and the restructured classroom practice itself, opened multiple spaces where difference was encountered and engaged with, including culturally and historically informed differences in expertise, experience, and context-specific knowledge. As Roth and Tobin (2004) have previously observed, co-teaching afforded expanded opportunities to act within the lesson whereby the presence and the actions of each co-teacher was a resource for the other. Furthermore, access to expanded resources within co-taught lessons also expanded possibilities for future learning. Having two teachers in the room provided an opportunity for teachers to carefully observe and respond to students during a lesson despite the "hurly-burly" of a busy classroom. Later conversations about what had been noticed then prompted teachers to both provide additional information which extended teachers' understandings of students, and pressed them to justify, and therefore make explicit, an otherwise tacit rationale for interacting with students in a certain way.

An important finding of the co-teaching inquiry was that participation simultaneously promoted expanded opportunities for the teachers to act towards the dual objects of their own and their students' learning goals and this is consistent with previous research findings (e.g. Roth \& Tobin, 2004). Expanding teachers' opportunities to learn within their mathematics teaching | learning practice was the primary focus of this study and a participatory research approach involving authentic collaboration between myself and a group of teachers appeared to create a productive site for the generation of local theory with broader implications for the policy and practice environment. As Alexakos (2015) points out "teaching, learning, and research are interrelated and dialectically entangled processes" (p. 1). The teachers' co-teaching inquiry activity constituted conditions within which local theory could be cogenerated and at the same time the overarching research project created a space in which teachers' theories of practice could be made public and available for peer review and critique. The co-teaching inquiry promoted ontological authenticity whereby all participants became increasingly open to changing not only what they knew and could 
do, but also their perspectives, or ontologies (Alexakos, 2015). Gade (2015) has argued that attending to stakeholder ontology is as critical to school reform as methodological concerns in relation to the educative, catalytic and tactical potential of research activity. In other words, the teachers' ownership of, and intentionally forefronted voices within, this project supported the design of an approach to teachers' professional learning that is fit-for-purpose. A design-based, participatory approach to researching teacher learning, and the broader collaboration inherent in the teacher learning activity, together constituted authentic inquiry through which participants could "transform knowledge as it transforms us" (Alexakos, 2015, p. 104).

In the context of their work in early childhood education settings, Skattebol and Arthur (2013) suggest that where the policy landscape is experiencing significant expansion, as is the case for New Zealand's education system in general, and specifically for mathematics education, there is a need to create new spaces for the production of contextually relevant knowledge. They posit that practitioner research is one space for generating necessary knowledge and building capacity for the shifting context. These authors argue for the explicit positioning of practitioners as knowledge producers, and researchers as "resource gatherers and co-learners" (p. 1). Accordingly, in this study, project participants were explicitly positioned as having shared ownership of the research, by statements such as "this is your research project as much as [mine]" [R-GM\#7]. An example of this principle being enacted relates to the negotiated focus for the teachers' inquiry. From the outset, I had intended the study to focus on the mathematics teaching | learning of Pasifika students however with little or no explicit discussion the teachers focused their conversations on those students they had identified as target students, routinely referring to their "target groups", for instance. This was both appropriate and welcomed in the context of research that was genuinely co-owned by participants and directed at solving locally-defined problems. As Alexakos (2015) describes:

While we may start with a focus of inquiry, researcher and participant feedback, interests, and interpretations of what is learned constantly are used to re-evaluate and rethink our inquiry and interventions, examine underlying assumptions, and create new understandings and knowledge (p. 5). 
In such a research context everything is contested, including the premise itself. The notion of co-researcher was not entirely synchronous with how teachers might view their roles, for instance. During the final meeting, Casey asked "are there school models where co-teaching is happening?" suggesting that valid structures for teachers' work are pre-existing and imposed from the outside. The invitation to participate in restructuring their work in collaboration with others represented an apparent contradiction whereby the teachers perhaps initially expected to take a less agentic role. Space was opened for an alternative perspective on the group's role in cogenerating new knowledge:

We're actually creating knowledge. It's not about here's a well documented idea let's go and test it out in this context. It's actually let's innovate and design something and we'll see where it goes. [R-GM\#7]

Consistent with Tobin (2012), difference amongst teachers became a resource for their practice. Where there were differences in the teachers' practice, these were experienced as contradictions that afforded an expanded set of possible actions for each of the teachers as they collectively generated new knowledge through the process of reconciling those differences. The notion of expansive learning contradicts traditional views of professional learning whereby new knowledge is presumed to be mandated by management and unproblematically passed on to learners from more knowledgeable others within conflict-free social spaces (Engeström, 2001). Such a scenario positions the challenger and questioner within a community as problematic and conflict as counteractive to learning. In contrast, the dissonant and discrepant concepts and lived experiences that teachers encountered within their shared work became seeds of thought that created new openings into learning (Sivia, 2017) and afforded new possibilities for action within the activity of co-teaching inquiry. Through co-teaching inquiry, mathematics teaching | learning was an epistemological undertaking whereby teaching is learning. A key to expanding the possibilities of practice through a co-teaching inquiry appears to be that teachers were learning together through teaching together; collaborative teaching is collaborative learning. 


\subsection{Chapter summary}

The co-teaching inquiry approach fostered conditions that afforded teachers' expanded access to and depth of engagement with new, and often dissonant, practice ideas. Through co-teaching, mathematics teaching | learning was restructured within three interconnected fields of practice: the teachers' enacted practice, their talk about practice, and their noticing of student thinking within practice. The co-teaching inquiry activity was increasingly directed at shared goals for which the teachers were collectively responsible, including in relation to both student and teacher learning goals; involved an interplay of risk and trust; prompted the re-imagination of teachers' roles and responsibilities; and allowed teachers to constantly renegotiate the goals of their shared activity. The co-teaching arrangement disrupted practice whereby the contributions of each teacher to the shared practice served as minor interruptions to the teaching of the other and thus each teacher's actions became a resource for the other's learning. Engaging with difference prompted the constant renegotiation of the object towards which the co-teaching inquiry was directed and served to promote increasingly cogenerative dialogue. Opportunities to engage deeply with one another's practice opened space for an expanded set of actions for each of the teachers in their own practice. Co-teaching allowed teachers to reconstruct their identities from the lone operator whose professional reputation needs protection from exposure of any weaknesses in their mathematics knowledge or practice, to a learner whose naïve questions and gaps in practice serve as a resource for all in their learning of teaching. 


\section{Chapter 8 Conclusions and Implications}

The overarching purpose of the study was to co-design and enact an approach to collaborative teacher inquiry aimed at strengthening mathematics teaching | learning. The literature review outlined the complexity of teachers' knowledge necessary for mathematics teaching | learning, and explored the nature, conditions and processes of teacher learning within the context of their work. Drawing together the threads of teacher collaboration in community, and teacher inquiry, the review of the literature provided a rationale for the study's focus on teacher learning as the cogeneration of knowledge through teachers' collaborative inquiry. The study addressed one main question:

How does participation in collaborative inquiry generate teachers' knowledge for mathematics teaching | learning?

The research sought to account for the affordances of collaborative inquiry for teacher learning and to explain how opportunities to learn were opened up and constrained within the activity. A design-based research approach was taken, chosen for its focus on connecting processes of enacting learning designs with outcomes of interest (Design-based Research Collective, 2003).

The findings have traced the design process incorporating two distinct phases of design from the starting point of examining the teachers' collaborative activity prior to the project start, to an end-point culminating in the emergence of the co-teaching inquiry approach. At each stage of the design process, the teachers' collaborative activity has been analysed with a focus on the contradictions that arose, and actions that were taken, and culminating in an analysis of the affordances of the co-teaching inquiry model for promoting teacher learning. Study findings trace a design process that was messy and non-linear and culminated in the emergence of an approach to collaborative inquiry that featured co-teaching mathematics lessons in pairs. The lessons were co-planned and later the teachers reflected on co-taught lessons in pairs and then in the larger group, sometimes also sharing video excerpts from the lesson.

CHAT provided an analytical and theoretical framework to address the research question whereby contradictions in the co-teaching inquiry activity could be seen to 
expand (or constrain) teachers' access to resources and thus opened space for an expanded set of understandings and classroom practices. The affordances of the coteaching inquiry for promoting teacher learning, and the ways in which the teachers' joint work, through a co-teaching structure, appeared to support the collective generation of knowledge for mathematics teaching | learning, are outlined in the following section.

\subsection{Summary of findings}

The co-teaching inquiry approach to teachers' professional learning fostered conditions that afforded teachers expanded access to, and depth of engagement with, new and often dissonant, practice ideas. Co-teaching represented a restructuring of teachers' work that afforded them enhanced opportunities to engage with one another's practice and thinking as a collective resource for their professional learning; actively negotiate the purpose towards which their shared activity was directed; and participate in expanded roles including both as equal co-learners and leaders with diverse expertise.

Within the collaborative inquiry activity, there were shifts in relationships and participation patterns whereby positive emotions and a sense of belonging were generated, and the teachers' sense of shared responsibility for everybody's learning and collective agency to act in the interests of their students were strengthened. There was a notable shift in the teachers' attention towards the learning of their students and this supported the development of increasingly productive relationships amongst the teachers as attention was diverted away from teacher performance. Trust, respect and issues of power, especially in relation to risks associated with exposing weaknesses in practice, emerged within and impacted on relationships within the group. Trust both supported and was generated within the co-teaching activity and influenced the extent to which teachers were prepared to open their practice to scrutiny as a resource for learning. The expansion of trust within the group promoted the emergence of increasingly robust conversations whereby teachers were increasingly willing to interrogate and challenge aspects of classroom practice. The teachers had extended opportunities to articulate practice ideas including through co-planning and co- 
reflecting. In addition, their increasing willingness to engage with dissonance and challenge one another's thinking served to expand the breadth and depth of their conversations, and the conceptual resources available within them. Furthermore, the contingent nature of co-instruction promoted sharpened noticing of students' mathematical thinking and thus provided a rich resource for teachers to consider the impacts of their pedagogical practices.

A key finding of the study is that through co-teaching, engaging with difference is central to the teachers' ongoing co-generation of knowledge for teaching | learning mathematics. The co-teaching arrangement disrupted practice whereby teachers' actions served as minor interruptions to each other's practice and became a resource for teacher learning. Differences that emerged within the teachers' co-constructed and enacted practice, the conflicting ideas about practice that emerged in their conversations about practice, and what teachers noticed about students' sometimes unexpected responses to practice, served to expand the teachers' conceptual and material resources for practice. Opportunities to engage deeply with one another's practice opened space for an expanded set of actions for each of the teachers in their own practice. The co-teaching inquiry approach appeared to be a rich site for the generation of local theory. Working across difference, including differences among the perspectives and expertise that the participating teachers brought to their shared practice, and across the multiple roles and contexts of peoples' day-to-day work, acted as both catalyst and context for transformation.

\subsection{Contributions of the study}

Following Engeström (2015), the study took the axiological position that "research needs to be actively involved in making the world better" (p. xiii). This thesis adds nuanced understandings of the interrelated roles of collaboration and inquiry in improving teaching. The emergence of a promising design for teachers' collaborative inquiry featuring co-teaching answers Koellner and Jacobs' (2015) call for more research into adaptive models of teachers' professional learning. To that end, the coteaching inquiry design that emerged from this study builds on other models of teachers' professional learning with some similar characteristics, such as video clubs 
(van Es \& Sherin, 2008) and lesson study (Lewis et al., 2009) for instance. The findings of this study add to the growing body of literature exploring co-teaching arrangements for teacher learning, in this case in the previously under-examined context of teachers' professional learning through collaborative inquiry situated in practice. The study appears to be unique in that there is little or no previous literature exploring co-teaching arrangements between teaching colleagues in the course of their day-to-day work where the focus is on promoting their professional learning.

A key characteristic of the co-teaching inquiry approach was that the teaching itself was a jointly enacted and shared experience whereby the co-teaching inquiry experience involved active participation in joint classroom practice. This contrasts with other similar models that primarily involve teachers' engaging with observations or representations of one another's practice. Co-teaching simultaneously afforded teachers opportunities for 'in the moment' reflection on, and response to, events as they unfolded in the lesson, and a range of perspectives against which to test their interpretations of those events.

This thesis offers an analysis of teachers' interactions in processes of collaboration. As Horn and Kane (2015) argue, such analyses serve to strengthen understandings of the work of teacher groups within schools and can improve professional development efforts. Furthermore, as these authors suggest, enhancing our theoretical understanding of the complex phenomenon of collaborative inquiry contributes to the literature on teachers' professional learning specifically, and to that on workplace learning generally. Although the scope of the study was small, and the co-teaching inquiry design was emergent, the flexible and negotiated nature of the design suggests the potential for the model to be expanded and applied within and across a range of schooling contexts.

There remains the question of how the knowledge produced in such settings can be made more widely available both to practitioners and as a contribution to broader dialogues involving other research forms. As Skattebol and Arthur (2013) point out, such dialogues have the potential to be rich in that small-scale, site-specific research can provide rich accounts of the complexities that shape the lived reality of day-to-day life. At a local and pragmatic level, the teachers in our study were 
enthusiastic about sharing the study's findings and noted a range of positive outcomes for themselves and their learners. They were interested in creating opportunities to continue the activity, including possibly applying to the Ministry of Education's (2018) recently established Teacher-led Innovation Fund for resources to extend the work they had been doing. As Kris mentioned:

We're now talking about these benefits and it's exciting to think that there's a way that something could be funded for us to keep exploring it.

Nonetheless, spaces for practitioner-researchers to have a voice beyond their own institutions remain limited and difficult to access.

\subsection{Limitations}

This study contributes new knowledge at several levels, however, any research has limitations. The study's findings are the result of research conducted in a single setting with a small number of participating teachers. As such, generalisability of the findings to groups of teachers in different teaching contexts may be limited. Nevertheless, it is expected the research will contribute in broader contexts by providing detailed descriptions of the design processes and rich accounts of the enactment of the design outputs in order for others to make judgements of the value of the innovation and connections to their own settings.

Time constraints, the complexity of the data set and limitations associated with a single-researcher design created challenges that needed to be managed within the resources available. Schools and classrooms are complex research contexts and any interpretation of the findings from this study can only provide an emerging understanding of the nature and affordances of co-teaching inquiry for teacher learning. Consideration was given to the integrity of the process for producing data to promote the trustworthiness of the conclusions drawn from them, as described in section 3.5.6. However, the findings presented here are based on the interpretation of one researcher and alternative interpretations are possible. The analysis and resulting findings are strengthened by the use of multiple data sources, employing thick descriptions of data and processes, explicitly attending to discrepancies in the data, and the prolonged and iterative engagement in the field with participants as co- 
researchers. The iterative and collaborative nature of the design-based approach to the research inherently supports trustworthiness (Cobb et al., 2003; Design-based Research Collective, 2003). The potential bias of a single-researcher design was further mitigated by the use of a research journal as a tool for eliciting and testing researcher assumptions.

Given that the ultimate aim of exploring teacher knowledge is to understand how to improve student learning, (Bobis et al., 2012) it can be argued that for teachers' professional learning to be effective, it must positively impact on student learning. Research should explicitly link teacher and student learning (Timperley et al., 2007). For this study, however, the analysis of student outcomes associated with the professional learning intervention fell outside the scope of the research. As Hodges (1996) suggests, it was necessary to observe changes in teaching practice before looking for changed student outcomes as time is needed for new practices to be refined and embedded in teachers' practice. Nevertheless, student learning was an explicit focus as the ultimate object of the intervention, and as a source of data to evaluate the impacts of classroom practices within the teachers' inquiry.

\subsection{Implications and future research}

There are implications for teachers, schools and school leaders, designers and facilitators of teacher learning, policy makers and researchers arising from this research. In many cases, these roles and their associated implications overlap, for instance for the school leader who plans and leads professional learning, or government policy makers and school leaders who at different levels both make resourcing decisions that influence what is possible in schools. Implications of the research findings, and possibilities for future research, are discussed in this section.

\subsubsection{Implications for policy and practice}

New possibilities for arrangements for mathematics teaching | learning in schools are suggested by this study and raise implications for resource allocation decisions including scheduling and staffing, and the design and use of teaching spaces. There is widespread and rapid change occurring in New Zealand primary classrooms whereby teachers are increasingly working in flexible spaces occupied by more than 
one teacher and it is evident from this study that co-teaching might be a productive way to organise the teaching of mathematics in such spaces. Restructuring teachers' work to allow time and space for co-teaching inquiry suggests implications for teaching teams, school leaders and funding bodies with respect to how staffing is organised and resourced to create new sites for teachers' collaborative work.

The research suggests that there is value in teachers, school leaders and researchers working together to co-design arrangements for teachers' work within such spaces. Participation in the study provided teachers with opportunities to shape aspects of their professional practice including negotiating shared goals for their learning and decisions about when and how to work together. Findings from this study align with those of Barnes (2019) who highlighted the challenges of balancing accountability functions with teachers' learning goals in appraisal systems. Teachers in this study felt constrained in sharing practice challenges where they perceived there was a risk that they would be negatively judged. Consideration needs to be given to expanding the opportunities for teacher autonomy in specifying professional learning goals and ways of working towards these. To this end, school leaders and government policy makers might reconsider the purpose and design of appraisal systems to enable a more learning-focused space for the sharing of practice, particularly those aspects which are problematic. Furthermore, appraisal and other accountability mechanisms might be shifted to take a more collective view whereby groups of teachers share responsibility for the ongoing improvement of teaching | learning.

The study's findings suggest that designers and leaders of professional learning, whether they are school-based or external providers, should be cognisant of the interplay of risk and trust when teachers are sharing aspects of their work to examine and improve on their practice. Teachers are reluctant to expose weaknesses in their practice where there is a fear of negative consequences and where teachers are reluctant to take perceived risks, change can be constrained (Le Fevre, 2014). The coteaching inquiry approach appeared productive for promoting trust and supporting challenging conversations, suggesting that the co-teaching structure might be a useful tool in the design and implementation of planned professional learning experiences. Furthermore, this research suggests there is value in purposefully structuring teachers' 
interactions to promote challenge and engagement with dissonant views. Explicitly planned interactions such as the reading activity where teachers were asked to identify and discuss points they disagreed with, and more implicit conditions whereby teachers were participants in classroom practices that contrasted with their own, supported shifts in norms of interaction towards more challenging conversations. Such conditions might be specifically planned for by leaders of teachers' professional learning.

\subsubsection{Possibilities for future research}

This study was exploratory in nature and further research into the co-teaching inquiry approach is warranted, including studies aimed at further refining the coteaching inquiry design, and those aimed at exploring its implementation in different contexts. The application of co-teaching structures in the context of learning areas other than mathematics was of particular interest to the teachers in this study and is a potential area for further study. Investigating the implications of scaling up the approach to work with larger groups of teachers across multiple school sites is another possibility for future research. Addressing the challenge of connecting teacher learning with improved student learning is worthy of continued attention and to this end research explicitly examining the impacts of teachers' co-teaching inquiry on both teachers and students over an extended period of time might be considered. Such research might include extended time in the classroom and the analysis of classroom events.

\subsection{Concluding thoughts}

This research builds on a long-held interest in students' learning in collaboration with one another, and my role as a teacher to design learning experiences that maximised the possibilities for productive interaction. It is interesting to note that findings related to conditions and processes that are productive for teacher learning parallel what we know to be important for the learning of students in our primary mathematics classrooms. Specifically, the teachers' collaborative inquiry activity shared many of the characteristics of the work of mathematical inquiry communities that are being developed within New Zealand primary classrooms (e.g. 
Hunter \& Anthony, 2010). For instance, the promotion of mathematical argumentation and explicit attention to the establishment of productive group norms might be seen to mirror these teachers' experiences of establishing a group kawa and engaging in increasingly robust conversations involving articulating and justifying aspects of their classroom practice. Inquiry communities presuppose teaching | learning as an epistemological undertaking and so it is perhaps unsurprising to find that approaches to teaching | learning that are based on collaborative inquiry are similarly productive for teachers' and students' learning. Robyn Jorgensen (2014) reminds us of the urgency of addressing the enduring and important problem of inequity in mathematics achievement. Co-teaching inquiry offers a promising contribution towards this complex and challenging goal. 


\section{References}

Achinstein, B. (2002). Conflict amid community: The micropolitics of teacher collaboration. Teachers College Record, 104(3), 421-455. https://doi.org/10.1111/1467-9620.00168

Adler, J., \& Ball, D. (2009). Knowing and using mathematics in teaching: Introduction to and overview of this special issue. For the Learning of Mathematics, 29(3), 23.

Aitken, G., \& Sinnema, C. (2008). Effective pedagogy in social sciences/tikanga à iwi: Best evidence synthesis iteration (BES). Wellington, New Zealand: New Zealand Ministry of Education.

Alexakos, K. (2015). Being a teacher / researcher: A primer on doing authentic inquiry research on teaching and learning. Sense Publishers.

Allen, D. (2013). Reconstructing professional learning community as collective creation. Improving Schools, 16(3), 191-208. https://doi.org/10.1177/1365480213501056

Alton-Lee, A. (2003). Quality teaching for diverse students in schooling: Best evidence synthesis. Wellington, New Zealand: Ministry of Education.

Alton-Lee, A. (2008). Designing and supporting teacher professional development to improve valued student outcomes. Presented at the Education of Teachers Symposium at the General Assembly of the International Academy of Education, Limassol, Cyprus.

Alton-Lee, A. (2012, April). The use of evidence to improve education and serve the public good. Presented at the Annual Meeting of the American Educational Research Association, Vancouver, Canada. 
Anderson, T., \& Shattuck, J. (2012). Design-based research: A decade of progress in education research? Educational Researcher, 41(1), 16-25. https://doi.org/10.3102/o013189X11428813

Andrews, D., \& Lewis, M. (2002). The experience of a professional community: Teachers developing a new image of themselves and their workplace. Educational Research, 44(3), 237-254. https://doi.org/10.1080/o0131880210135340 Anthony, G., Hunter, R., \& Thompson, Z. (2014). Expansive learning: Lessons from one teacher's learning journey. ZDM, 46(2), 279-291. https://doi.org/10.1007/s11858013-0553-Z

Anthony, G., \& Walshaw, M. (2007). Effective pedagogy in mathematics/pāngarau: Best evidence synthesis iteration (BES). Wellington, New Zealand: Ministry of Education.

Averill, R. (2012). Reflecting heritage cultures in mathematics learning: The views of teachers and students. Journal of Urban Mathematics Education, 5(2), 157-181.

Ball, D. L. (2011). Foreword. In Mathematics teacher noticing: Seeing through teachers' eyes (pp. xx-xxiv). New York: Routledge.

Ball, D. L., Thames, M. H., \& Phelps, G. (2008). Content knowledge for teaching: What makes it special? Journal of Teacher Education, 59(5), 389-407. https://doi.org/10.1177/0022487108324554

Baptiste, I. (2001). Qualitative data analysis: Common phases, strategic differences. Forum Qualitative Sozialforschung/Forum: Qualitative Social Research, 2(3). Retrieved from http://www.qualitativeresearch.net/index.php/fqs/article/viewArticle/917 
Barnes, P. D. (2019). Teacher standards and professionalism (Unpublished master's thesis). Victoria University of Wellington, Wellington, New Zealand.

Baumert, J., Kunter, M., Blum, W., Brunner, M., Voss, T., Jordan, A., ... Tsai, Y.-M. (2010). Teachers' mathematical knowledge, cognitive activation in the classroom, and student progress. American Educational Research Journal, 47(1), 133-180. https://doi.org/10.3102/ooo2831209345157

Benade, L. (2015). Teaching as inquiry: Well intentioned, but fundamentally flawed. New Zealand Journal of Educational Studies. https://doi.org/10.1007/s40841-0150005-0

Benade, L. (2018). The role of trust in reflective practice. Educational Philosophy and Theory, 5o(2), 123-132. https://doi.org/10.1080/00131857.2016.1142415

Berings, M. G. M. C., Doornbos, A. J., \& Simons, P. R.-J. (2006). Methodological practices in on-the-job learning research. Human Resource Development International, 9(3), 333-363. https://doi.org/10.1080/136788606oo893557

Beswick, K., Callingham, R., \& Watson, J. (2011). The nature and development of middle school mathematics teachers' knowledge. Journal of Mathematics Teacher Education, 15(2), 131-157. https://doi.org/10.1007/s10857-011-9177-9

Bishop, R. (1999). Kaupapa Maori research: An indigenous approach to creating knowledge. In N. Robertson (Ed.), Maori and psychology: Research and practice-The proceedings of a symposium sponsored by the Maori and Psychology Research Unit. Hamilton: Department of Psychology, University of Waikato.

Boaler, J. (2016). Mathematical mindsets. San Francisco, CA: Jossey-Bass. 
Boaler, J., \& Staples, M. (2008). Creating mathematical futures through an equitable teaching approach: The case of Railside School. The Teachers College Record, $110(3), 608-645$.

Bobis, J., Higgins, J., Cavanagh, M., \& Roche, A. (2012). Professional knowledge of practising teachers of mathematics. In B. Perry, T. Lowrie, T. Logan, A. MacDonald, \& J. Greenlees (Eds.), Research in Mathematics Education in Australasia 2008-2011 (pp. 313-341). Retrieved from http://link.springer.com/chapter/10.1007/978-94-6o91-970-1_15

Bransford, J. D., \& Schwartz, D. L. (1999). Rethinking transfer: A simple proposal with multiple implications. Review of Research in Education, 24, 61-100. https://doi.org/10.2307/1167267

Bransford, J., Darling-Hammond, L., \& LePage, P. (2005). Introduction. In L. DarlingHammond \& J. Bransford (Eds.), Preparing teachers for a changing world: What teachers should learn and be able to do (pp. 1-39). San Francisco, CA: John Wiley \& Sons.

Bransford, J., Derry, S., Berliner, D., \& Hammerness, K. (2005). Theories of learning and their roles in teaching. In L. Darling-Hammond \& J. Bransford (Eds.), Preparing teachers for a changing world: What teachers should learn and be able to do (pp. 40-87). San Francisco, CA: Jossey-Bass.

Braun, V., \& Clarke, V. (2006). Using thematic analysis in psychology. Qualitative Research in Psychology, 3(2), 77-101. https://doi.org/10.1191/1478088706qpo63oa Brophy, J. (1991). Conclusion to teachers' knowledge of subject matter as it relates to their teaching practice. In J. Brophy (Ed.), Advances in research on teaching (Vol. 2, pp. 349-364). Greenwich, Connecticut: JAI Press. 
Broudy, H. S. (1970). On knowing with. Proceedings of the 26th Annual Meeting of the Philosophy of Education Society, 89-104. Southern Illinois University, Edwardsville.

Carambo, C., \& Stickney, C. T. (2009). Coteaching praxis and professional service: Facilitating the transition of beliefs and practices. Cultural Studies of Science Education, 4(2), 433-441. https://doi.org/10.1007/s11422-008-9148-3

Carpenter, T. P., Fennema, E., \& Franke, M. L. (1996). Cognitively guided instruction: A knowledge base for reform in primary mathematics instruction. The Elementary School Journal, 97(1), 3-20.

Chapin, S. H., \& O’Connor, C. (2007). Academically productive talk: Supporting students' learning in mathematics. In W. Martin G. \& M. Strutchens E. (Eds.), The learning of mathematics (pp. 113-128). Reeston, VA: National Council of Teachers of Mathematics.

Charmaz, K. (2006). Constructing Grounded Theory: A Practical Guide Through Qualitative Analysis. Pine Forge Press.

Chick, H., Baker, M., Pham, T., \& Cheng, H. (2006). Aspects of teachers' pedagogical content knowledge for decimals. Proceedings zoth Conference of the International Group for the Psychology of Mathematics Education, 2, 297-304. Prague, Czech Republic: Psychology of Mathematics Education.

Chick, H. L. (2009). Choice and use of examples as a window on mathematical knowledge for teaching. For the Learning of Mathematics, 29(3), 26-30.

Choppin, J. (2011). The role of local theories: Teacher knowledge and its impact on engaging students with challenging tasks. Mathematics Education Research Journal, 23(1), 5-25. https://doi.org/10.1007/s13394-011-0oo1-8 
Christians, C. G. (2005). Ethics and politics in qualitative research. In N. K. Denzin \& Y. S. Lincoln (Eds.), The Sage handbook of qualitative research (3rd ed., pp. 139164). Thousand Oaks, California: Sage Publications.

Cobb, P., Confrey, J., diSessa, A., Lehrer, R., \& Schauble, L. (2003). Design experiments in educational research. Educational Researcher, 32(1), 9-13. https://doi.org/10.3102/o013189X032001009

Cobb, Paul. (2007). International foreword. In Effective pedagogy in mathematics/pāngarau: Best evidence synthesis iteration (BES) (pp. viii-xi). Wellington, New Zealand: Ministry of Education.

Cobb, Paul, \& Bowers, J. (1999). Cognitive and situated learning perspectives in theory and practice. Educational Researcher, 28(2), 4-15. https://doi.org/10.3102/0013189X028002004

Cochran-Smith, M., \& Lytle, S. L. (1999). Relationships of knowledge and practice: Teacher learning in communities. Review of Research in Education, 24(1), 249305.

Cochran-Smith, M., \& Lytle, S. L. (2009). Inquiry as stance: Practitioner research for the next generation. New York, NY: Teachers College Press.

Cook, L., \& Friend, M. (1995). Co-teaching: Guidelines for creating effective practices. Focus on Exceptional Children, 28(3), 1-16.

Cook, L., \& Friend, M. (2010). The state of the art of collaboration on behalf of students with disabilities. Journal of Educational and Psychological Consultation, 20(1), 18. https://doi.org/10.108o/10474410903535398

Corbin, J., \& Strauss, A. (1990). Grounded theory research: Procedures, canons, and evaluative criteria. Qualitative Sociology, 13(1), 3-21. 
Corsi, P., \& Morin, D. (2015). Appendix 5: Tips on deepening understanding by using trialectics. In Sequencing Apple’s DNA (pp. 177-185). https://doi.org/10.1002/9781119261575.app5

Creswell, J. W. (2013). Qualitative inquiry and research design: Choosing among five approaches (3rd ed.). Thousand Oaks, California: Sage Publications.

Creswell, J. W. (2014). Research design: Qualitative, quantitative, and mixed methods approaches (4th ed.). Thousand Oaks, California: Sage Publications.

Darling-Hammond, L., \& Bransford, J. (2005). Preparing teachers for a changing world: What teachers should learn and be able to do. San Francisco, CA: John Wiley \& Sons.

Darling-Hammond, L., \& Richardson, N. (2009). Teacher learning: What matters? Educational Leadership, 66(5), 46-53.

Darling-Hammond, L., Wei, R. C., Andree, A., Richardson, N., \& Orphanos, S. (2009). Professional learning in the learning profession: A status report on teacher development in the United States and abroad. Retrieved from National Staff Development Council website: http://www.learningforward.org/docs/pdf/nsdcstudy2009.pdf

Denzin, N. K. (2005). Emancipatory discourses and the ethics and politics of interpretation. In The Sage handbook of qualitative research (3rd ed., pp. 933958). Thousand Oaks, California: Sage Publications.

Denzin, N. K., \& Lincoln, Y. S. (2011). Introduction: The discipline and practice of qualitative research. In N. K. Denzin \& Y. S. Lincoln (Eds.), The Sage handbook of qualitative research (4th ed., pp. 1-19). Thousand Oaks, California: Sage Publications. 
Design-based Research Collective. (2003). Design-based research: An emerging paradigm for educational inquiry. Educational Researcher, 32(1), 5-8.

Desimone, L. M. (2009). Improving impact studies of teachers' professional development: Toward better conceptualizations and measures. Educational Researcher, 38(3), 181-199. https://doi.org/10.3102/o013189Xo8331140

Dillenbourg, P. (1999). What do you mean by collaborative learning? In P. Dillenbourg (Ed.), Collaborative-learning: Cognitive and computational approaches. (pp. 119). Bingley, UK: Emerald Group Publishing.

Doig, B., \& Groves, S. (2011). Japanese lesson study: Teacher professional development through communities of inquiry. Mathematics Teacher Education and Development, 13(1), 77-93.

DuFour, R. (2004). What is a "professional learning community"? Educational Leadership, 61(8), 6-11.

DuFour, R., DuFour, R., Eaker, R., \& Karhanek, G. (2004). Whatever it takes: How professional learning communities respond when kids don't learn. Bloomington, Indiana: Solution Tree Press.

Eaker, R., \& Keating, J. (2012). Improving mathematics achievement: The power of professional learning communities. In J. M. Bay-Williams \& W. R. Speer (Eds.), Professional collaborations in mathematics teaching and learning: Seeking success for all-Seventy-fourth yearbook. Reston, VA: National Council of Teachers of Mathematics.

Education Council. (2017). Our code our standards: Code of professional responsibility and standards for the teaching profession. Wellington, New Zealand: Education Council. 
Education Review Office. (2012). Teaching as inquiry: Responding to learners [National Evaluation Report]. Wellington, New Zealand.

Education Review Office. (2016). School evaluation indicators. Wellington, NZ: New Zealand Government.

Education Review Office. (n.d.). Review process. Retrieved from http://www.ero.govt.nz/Review-Process

Edwards, A. (2005). Relational agency: Learning to be a resourceful practitioner. International Journal of Educational Research, 43(3), 168-182. https://doi.org/10.1016/j.ijer.2006.06.010

Ellis, V., Edwards, A., \& Smagorinsky, P. (Eds.). (2010). Cultural-historical perspectives on teacher education and development: Learning teaching. London: Routledge.

Engeström, Y. (2001). Expansive learning at work: Toward an activity theoretical reconceptualization. Journal of Education and Work, 14(1), 133-156. https://doi.org/10.1080/13639080020028747

Engeström, Y. (2009). Expansive learning: Toward an activity-theoretical reconceptualization. In Contemporary theories of learning: Learning theorists ... In their own words (pp. 53-73). London: Taylor \& Francis.

Engestrom, Y. (2014). Learning by Expanding: An Activity-Theoretical Approach to Developmental Research (2nd ed.). https://doi.org/10.1017/CBO9781139814744 Engeström, Y. (2015). Learning by expanding: An activity-theoretical approach to developmental research (2nd ed.). https://doi.org/10.1017/CBO9781139814744

Eteläpelto, A., \& Collin, K. (2004). From individual cognition to communities of practice. In H. P. A. Boshuizen, R. Bromme, \& H. Gruber (Eds.), Professional 
learning: Gaps and transitions on the way from novice to expert (pp. 231-249). The Netherlands: Springer.

Fishman, B. J., Marx, R. W., Best, S., \& Tal, R. T. (2003). Linking teacher and student learning to improve professional development in systemic reform. Teaching and Teacher Education, 19(6), 643-658. https://doi.org/10.1016/So742051X(03)00059-3

Fletcher, J., Parkhill, F., Fa'afoi, A., Taleni, L. T., \& O’Regan, B. (2009). Pasifika students: Teachers and parents voice their perceptions of what provides supports and barriers to Pasifika students' achievement in literacy and learning. Teaching and Teacher Education, 25(1), 24-33. https://doi.org/10.1016/j.tate.2008.06.002

Franke, M. L., Carpenter, T. P., Levi, L., \& Fennema, E. (2001). Capturing teachers' generative change: A follow-up study of professional development in mathematics. American Educational Research Journal, 38(3), 653-689. https://doi.org/10.3102/00028312038003653

Friend, M., \& Cook, L. (1992). Interactions: Collaboration skills for school professionals. Whie Plains, NY: Longman.

Friend, M., \& Cook, L. (2014). Interactions: Collaboration skills for school professionals (7th ed.). Harlow, United Kingdom: Pearson.

Fullan, M. (2006). Leading professional learning. School Administrator, 63(10), 10-14. Fullan, M., Rincón-Gallardo, S., \& Hargreaves, A. (2015). Professional capital as accountability. Education Policy Analysis Archives, 23(15), 1-18. https://doi.org/10.14507/epaa.v23.1998 
Gade, S. (2015). Unpacking teacher-researcher collaboration with three theoretical frameworks: A case of expansive learning activity? Cultural Studies of Science Education, 10(3), 603-619. https://doi.org/10.1007/s11422-014-9619-7

Gallo-Fox, J. (2010). Risk-taking as practice in a co-teaching professional learning community. In C. Murphy \& K. Scantlebury (Eds.), Coteaching in international contexts: Research and practice (pp. 109-128). Retrieved from http://link.springer.com/10.1007/978-90-481-3707-7

Garet, M. S., Porter, A. C., Desimone, L., Birman, B. F., \& Yoon, K. S. (2001). What makes professional development effective? Results from a national sample of teachers. American Educational Research Journal, 38(4), 915-945. https://doi.org/10.3102/00028312038004915

Gersten, R., Dimino, J., Jayanthi, M., Kim, J. S., \& Santoro, L. E. (2010). Teacher study group: Impact of the professional development model on reading instruction and student outcomes in first grade classrooms. American Educational Research Journal, 47(3), 694-739. https://doi.org/10.3102/o002831209361208

Gibbs, P., Costley, C., Armsby, P., \& Trakakis, A. (2007). Developing the ethics of worker-researchers through phronesis. Teaching in Higher Education, 12(3), 365-375. https://doi.org/10.108o/13562510701278716

Good, T. L. (1981). Teacher expectations and student perceptions: A decade of research. Educational Leadership, 38(5), 415-422.

Good, T. L. (1987). Two decades of research on teacher expectations: Findings and future directions. Journal of Teacher Education, 38(4), 32-47. https://doi.org/10.1177/002248718703800406 
Graneheim, U. H., \& Lundman, B. (2004). Qualitative content analysis in nursing research: Concepts, procedures and measures to achieve trustworthiness. Nurse Education Today, 24(2), 105-112. https://doi.org/10.1016/j.nedt.2003.10.001

Green, A., Preston, J., \& Sabates, R. (2003). Education, equality and social cohesion: A distributional approach. Compare: A Journal of Comparative and International Education, 33(4), 453-470. https://doi.org/10.108o/0305792032000127757

Green, J., Franquiz, M., \& Dixon, C. (1997). The myth of the objective transcript: Transcribing as a situated act. TESOL Quarterly, 31(1), 172-176. https://doi.org/10.2307/3587984

Grossman, P., Wineburg, S., \& Woolworth, S. (2001). Toward a theory of teacher community. Teachers College Record, 103(6), 942-1012.

Guba, E. G. (1981). Criteria for assessing the trustworthiness of naturalistic inquiries. Educational Communication and Technology, 29(2), 75-91.

Guskey, T. (2002). Professional development and teacher change. Teachers and Teaching, 8(3), 381-391. https://doi.org/10.1080/135406002100000512

Gutiérrez, K. D., \& Rogoff, B. (2003). Cultural ways of learning: Individual traits or repertoires of practice. Educational Researcher, 32(5), 19-25. https://doi.org/10.3102/o013189X032005019

Hatano, G., \& Oura, Y. (2003). Commentary: Reconceptualizing school learning using insight from expertise research. Educational Researcher, 32(8), 26-29. https://doi.org/10.3102/0013189X032008026

Herrington, J., McKenney, S., Reeves, T., \& Oliver, R. (2007). Design-based research and doctoral students: Guidelines for preparing a dissertation proposal. World Conference on Educational Multimedia, Hypermedia and Telecommunications 
(EDMEDIA) 2007, 25-29 June. Presented at the Vancouver, Canada. Retrieved from http://researchrepository.murdoch.edu.au/6762/

Hickley, A. (n.d.). Verbatim, intelligent verbatim or edited transcription? Retrieved from http://penguin-transcription.co.uk/transcription-type-verbatimintelligent-verbatim-or-edited/

Higgins, J., \& Eden, R. (2015). Practice-based inservice teacher education: Generating local theory about the pedagogy of group work. Mathematics Teacher Education and Development, 17(2), 84-97.

Higgins, J., Moeed, A., \& Eden, R. (2018). Video as a mediating artefact of science learning: Cogenerated views of what helps students learn from watching video. Asia-Pacific Science Education, 4(1), 6. https://doi.org/10.1186/s41029-018-0022-7

Higgins, J., \& Parsons, R. (2009). A successful professional development model in mathematics: A system-wide New Zealand case. Journal of Teacher Education, 6o(3), 231-242. https://doi.org/10.1177/0022487109336894

Hill, H. C., Ball, D. L., \& Schilling, S. G. (2008). Unpacking pedagogical content knowledge: Conceptualizing and measuring teachers' topic-specific knowledge of students. Journal for Research in Mathematics Education, 39(4), 372-400.

Hintz, A., Kazemi, E., Granger, J., Lind, T., Lewis, B., Simpson, L., \& Crandall, D. (2013). Innovations in improving mathematics instruction: One school's story of implementing job-embedded school-wide professional development. Washington State Kappan, 6(2). Retrieved from https://journals.lib.washington.edu/index.php/wsk/article/view/14166 
Hipp, K. K., \& Huffman, J. B. (2010). Demystifying professional learning communities: School leadership at its best. Lanham, Maryland: Rowman \& Littlefield Education.

Hodges, H. L. B. (1996). Using research to inform practice in urban schools: 10 key strategies for success. Educational Policy, 10(2), 223-252. https://doi.org/10.1177/0895904896010002006

Hodkinson, P., \& Hodkinson, H. (2004). The significance of individuals' dispositions in workplace learning: A case study of two teachers. Journal of Education and Work, $17(2)$, 167-182. https://doi.org/10.1080/13639080410001677383

Hord, S. M. (2009). Professional learning communities. Journal of Staff Development, $30(1), 40-43,78$.

Horn, I. S., Garner, B., Kane, B. D., \& Brasel, J. (2017). A taxonomy of instructional learning opportunities in teachers' workgroup conversations. Journal of Teacher Education, 68(1), 41-54. https://doi.org/10.1177/oo22487116676315

Horn, I. S., \& Kane, B. D. (2015). Opportunities for professional learning in mathematics teacher workgroup conversations: Relationships to instructional expertise. Journal of the Learning Sciences, 24(3), 373-418. https://doi.org/10.1080/10508406.2015.1034865

Horn, I. S., \& Little, J. W. (2010). Attending to problems of practice: Routines and resources for professional learning in teachers' workplace interactions. American Educational Research Journal, 47(1), 181-217. https://doi.org/10.3102/0002831209345158 
Hudson, M. L., \& Russell, K. (2009). The Treaty of Waitangi and research ethics in Aotearoa. Journal of Bioethical Inquiry, 6(1), 61-68. https://doi.org/10.1007/s11673-0o8-9127-o

Hunter, J., \& Back, J. (2011). Facilitating sustainable professional development through lesson study. Mathematics Teacher Education and Development, 13(1), 94-114.

Hunter, R. (2010). Changing roles and identities in the construction of a community of mathematical inquiry. Journal of Mathematics Teacher Education, 13(5), 397409. https://doi.org/10.1007/s10857-010-9152-X

Hunter, R., \& Anthony, G. (2010). Developing mathematical inquiry and argumentation. In R. Averill \& R. Harvey (Eds.), Teaching primary school mathematics and statistics: Evidence-based practice (pp. 197-206). Wellington, New Zealand: NZCER Press.

Hunter, R., \& Anthony, G. (2011). Forging mathematical relationships in inquiry-based classrooms with Pasifika students. Journal of Urban Mathematics Education, 4(1), 98-119.

Hunter, R., \& Hunter, J. (2017). Maintaining a cultural identity while constructing a mathematical disposition as a Pāsifika learner. In E. A. McKinley \& L. T. Smith (Eds.), Handbook of Indigenous Education (pp. 1-19). https://doi.org/10.1007/978-981-10-1839-8_14-1

Hunter, R. K. (2007). Teachers developing communities of mathematical inquiry (Unpublished doctoral thesis). Massey University, Auckland, New Zealand. Ingvarson, L., Beavis, A., Bishop, A., Peck, R., \& Elsworth, G. (2004). Investigation of effective mathematics teaching and learning in Australian secondary schools. Canberra, Australia: Australian Council for Educational Research. 
Jacob, L. (2011). Remote schools working together in the Kimberley: Initial impact on teachers' mathematics content-pedagogic knowledge and classroom practice. Presented at the AARE Annual Conference, Hobart. Retrieved from http://www.aare.edu.au/data/publications/2011/aarefinaloo235.pdf

Jacobs, V. R., Lamb, L. L., \& Philipp, R. A. (2010). Professional noticing of children's mathematical thinking. Journal for Research in Mathematics Education, 41(2), 169-202.

Jacobs, V. R., Philipp, R. A., \& Sherin, M. G. (Eds.). (2011). Preface. New York: Routledge.

Jaworski, B. (2003). Inquiry as a pervasive pedagogic process in mathematics education development. Proceedings of the Third Conference of the European Society for Research in Mathematics Education, 28. Retrieved from http://fibonacci.dm.unipi.it/ didattica/CERME3/proceedings/Groups/TG11/TG1 1_Jaworski_cerme3.pdf

Jaworski, B. (2008). Building and sustaining inquiry communities in mathematics teaching development. In K. Krainer \& T. Wood (Eds.), Participants in mathematics teacher education: Individuals, teams, communities and networks (Vol. 3, pp. 309-330). Rotterdam: Sense Publishers. Jaworski, B. (2014). Mathematics education development: Research in teaching, learning in practice. In J. Anderson, M. Cavanagh, \& A. Prescott (Eds.), Curriculum in focus: Research guided practice (p. 22). Sydney: MERGA. Jorgensen, R. (2014). Social theories of learning: A need for a new paradigm in mathematics education. In J. Anderson, M. Cavanagh, \& A. Prescott (Eds.), Curriculum in focus: Research guided practice. (pp. 311-318). Sydney: MERGA. 
Juck, M., Scantlebury, K., \& Gallo-Fox, J. (2010). Now it's time to go solo. In C. Murphy \& K. Scantlebury (Eds.), Coteaching in international contexts: Research and practice (pp. 245-265). Retrieved from http://link.springer.com/10.1007/978-90481-3707-7

Katz, S., \& Dack, L. A. (2014). Towards a culture of inquiry for data use in schools: Breaking down professional learning barriers through intentional interruption. Studies in Educational Evaluation, 42, 35-40. https://doi.org/10.1016/j.stueduc.2013.10.006

Kazemi, E., \& Franke, M. L. (2004). Teacher learning in mathematics: Using student work to promote collective inquiry. Journal of Mathematics Teacher Education, $7(3), 203-235$

Keane, B. (2013, May 9). Marae protocol - te kawa o te marae-Kawa of the marae. Retrieved from Te Ara-The encyclopedia of New Zealand website: https://teara.govt.nz/en

Kelchtermans, G. (2006). Teacher collaboration and collegiality as workplace conditions. A review. Zeitschrift Für Pädagogik, 52(2), 220-237.

Kennedy, M. M. (2016). How does professional development improve teaching? Review of Educational Research, 86(4), 945-980. https://doi.org/10.3102/o03465431562680o

Kincheloe, J. L. (2007a). Introduction: Educational psychology_Limitations and possibilities. In J. L. Kincheloe \& R. A. Horn (Eds.), The Praeger handbook of education and psychology (Vol. 1, pp. 3-40). Westport, Connecticut: Praeger Publishers. 
Kincheloe, J. L. (2007b). Postformalism and critical ontology-part 1: Difference, indigenous knowledge, and cognition. In J. L. Kincheloe \& R. A. Horn (Eds.), The Praeger handbook of education and psychology (Vol. 4, pp. 884-891). Westport, Connecticut: Praeger Publishers.

Kincheloe, J. L. (2009). Critical complexity and participatory action research: Decolonizing “democratic" knowledge production. In D. Kapoor \& S. Jordan (Eds.), Education, participatory action research, and social change (pp. 107-121). New York, New York: Palgrave Macmillan.

Kincheloe, J. L. (2011). The knowledges of teacher education: Developing a critical complex epistemology. In K. Hayes, S. R. Steinberg, \& K. G. Tobin (Eds.), Key works in critical pedagogy. Rotterdam; Boston; Taipei: Sense Publishers.

Koellner, K., \& Jacobs, J. (2015). Distinguishing models of professional development: The case of an adaptive model's impact on teachers' knowledge, instruction, and student achievement. Journal of Teacher Education, 66(1), 51-67. https://doi.org/10.1177/0022487114549599

Koellner, K., Jacobs, J., Borko, H., Schneider, C., Pittman, M. E., Eiteljorg, E., ... Frykholm, J. (2007). The problem-solving cycle: A model to support the development of teachers' professional knowledge. Mathematical Thinking and Learning, 9(3), 273-303. https://doi.org/10.1080/10986060701360944

Larrivee, B. (2000). Transforming teaching practice: Becoming the critically reflective teacher. Reflective Practice, 1(3), 293-307. https://doi.org/10.108o/713693162

Lave, J., \& Wenger, E. (1991). Situated learning: Legitimate peripheral participation. Cambridge, UK: Cambridge University Press. 
Le Fevre, D. M. (2014). Barriers to implementing pedagogical change: The role of teachers' perceptions of risk. Teaching and Teacher Education, 38, 56-64. https://doi.org/10.1016/j.tate.2013.11.007

Le Fevre, D. M., Robinson, V. M. J., \& Sinnema, C. E. L. (2015). Genuine inquiry: Widely espoused yet rarely enacted. Educational Management Administration $\mathcal{E}$ Leadership, 43(6), 883-899. https://doi.org/10.1177/1741143214543204

Levine, T. H. (2010). Tools for the study and design of collaborative teacher learning: The affordances of different conceptions of teacher community and activity theory. Teacher Education Quarterly, 37(1), 109-130.

Levine, T. H., \& Marcus, A. S. (2010). How the structure and focus of teachers' collaborative activities facilitate and constrain teacher learning. Teaching and Teacher Education, 26(3), 389-398. https://doi.org/10.1016/j.tate.2009.03.001

Lewis, C. C., Perry, R. R., \& Hurd, J. (2009). Improving mathematics instruction through lesson study: A theoretical model and North American case. Journal of Mathematics Teacher Education, 12(4), 285-304. https://doi.org/10.1007/s10857009-9102-7

Lincoln, Y. S., Lynham, S. A., \& Guba, E. G. (2011). Paradigmatic controversies, contradictions, and emerging confluences, revisited. In N. K. Denzin \& Y. S. Lincoln (Eds.), The Sage handbook of qualitative research (4th ed.). Thousand Oaks, California: Sage Publications.

Little, J. W. (1990). The persistence of privacy: Autonomy and initiative in teachers' professional relations. Teachers College Record, 91(4), 509-536.

Little, J. W. (2003). Inside teacher community: Representations of classroom practice. Teachers College Record, 105(6), 913-945. 
Lortie, D. C. (1975). Schoolteacher: A sociological study. Chicago: University of Chicago Press.

Loucks-Horsley, S., Stiles, K. E., Mundry, S., Love, N., \& Hewson, P. W. (2010). Designing professional development for teachers of science and mathematics. Thousand Oaks, California: Corwin Press.

Lovett, S., \& Verstappen, P. (2004). Improving teachers' professional learning: The quality circle approach. New Zealand Journal of Education Leadership, 10(2), 3142.

Ma, L. (1999). Knowing and teaching elementary mathematics: Teachers' understanding of fundamental mathematics in China and the United States. Mahwah, N.J: Lawrence Erlbaum Associates.

Mason, J. (2009). Teaching as disciplined enquiry. Teachers and Teaching, 15(2), 205223. https://doi.org/10.108o/13540600902875308

May, S., Cowles, S., \& Lamy, M. (2013). PISA 2012: New Zealand summary report. Wellington, NZ: Ministry of Education.

McCutcheon, G. (1981). On the interpretation of classroom observations. Educational Researcher, 6.

McDonald, L. (2009). Teacher change: A dynamic interactive approach. International Journal of Learning, 16(10), 623-636.

McKenney, S., \& Reeves, T. C. (2013). Systematic review of design-based research progress: Is a little knowledge a dangerous thing? Educational Researcher, 42(2), 97-10o. https://doi.org/10.3102/oo13189X12463781

McPhan, G., Pegg, J., \& Horarik, S. (2008). Feedback about professional growth for teachers of mathematics: A developmental perspective. In M. Goos, R. Brown, \& 
K. Makar (Eds.), Proceedings of the 31st Annual Conference of the Mathematics Education Research Group of Australasia (p. 345). Retrieved from http://http://www.merga.net.au/documents/RP402008.pdf

Meaney, T., McMurchy-Pilkington, C., \& Trinick, T. (2012). Indigenous students and the learning of mathematics. In B. Perry, T. Lowrie, T. Logan, A. MacDonald, \& J. Greenlees (Eds.), Research in Mathematics Education in Australasia 2008-2011 (pp. 67-87). Retrieved from http://link.springer.com/chapter/10.1007/978-946o91-970-1_5

Ministry of Education. (2007). The New Zealand curriculum. Wellington, New Zealand: Learning Media.

Ministry of Education. (2008a). Book 1: The number framework. Wellington, New Zealand: Ministry of Education.

Ministry of Education. (20o8b). Book 3: Getting started. Wellington, New Zealand: Ministry of Education.

Ministry of Education. (2008c). Book 7: Teaching fractions, decimals, and percentages. Wellington, New Zealand: Ministry of Education.

Ministry of Education. (2013). Junior assessment of mathematics (JAM) teachers' guide. Retrieved from https://nzmaths.co.nz/sites/default/files/jam/JAM-TeacherGuide.pdf

Ministry of Education. (2017, September 11). Programmes for students (PfS)_ALL, ALiM, MST. Retrieved from https://nzcurriculum.tki.org.nz/System-ofsupport-incl.-PLD/School-initiated-supports/Programmes-for-Students-PfS 
Ministry of Education. (2018). Teacher-led Innovation Fund (TLIF). Retrieved from https://www.education.govt.nz/school/working-in-a-school/scholarships-forpeople-working-in-schools/teacher-led-innovation-fund/

Ministry of Education. (2019a). Mathematics/Pāngarau: Primary schooling. Retrieved from Education Counts website:

https://www.educationcounts.govt.nz/statistics/indicators/main/educationand-learning-outcomes/Mathematics-Pangarau-Primary-Schooling

Ministry of Education. (2019b). Statement of intent. Retrieved from Education.govt.nz website: https://www.education.govt.nz/our-work/publications/statement-ofintent/

Ministry of Education. (n.d.-a). Accelerating learning. Retrieved from https://nzmaths.co.nz/accelerating-learning

Ministry of Education. (n.d.-b). GloSS forms. Retrieved from Nzmaths website: https://nzmaths.co.nz/gloss-forms

Ministry of Education. (n.d.-c). New Zealand schools directory. Retrieved from https://www.educationcounts.govt.nz/data-services/directories/list-of-nzschools

Mitchell, C., \& Sackney, L. (2009). Sustainable improvement: Building learning communities that endure. Rotterdam: Sense Publishers.

Mitchell, C., \& Sackney, L. (2011). Building and leading within learning ecologies. In T. Townsend \& J. MacBeath (Eds.), International handbook of leadership for learning. The Netherlands: Springer. 
Murphy, C., \& Scantlebury, K. (2010). Introduction to coteaching. In C. Murphy \& K. Scantlebury (Eds.), Coteaching in international contexts: Research and practice (pp. 1-7). Dordrecht: Springer.

Nusche, D., Laveault, D., MacBeath, J., \& Santiago, P. (2012). OECD reviews of evaluation and assessment in education: New Zealand 2011. OECD Publishing.

OECD. (2012). Equity and Quality in Education. Retrieved from http://www.oecdilibrary.org/content/book/9789264130852-en

Opfer, V. D., \& Pedder, D. (2011). Conceptualizing teacher professional learning. Review of Educational Research, 81(3), 376-407. https://doi.org/10.3102/0034654311413609

Owen, S. M. (2015). Teacher professional learning communities in innovative contexts: 'Ah hah moments', 'passion' and 'making a difference' for student learning. Professional Development in Education, 41(1), 57-74. https://doi.org/10.108o/19415257.2013.869504

Owens, K., Paraides, P., Jannok Nutti, Y., Johansson, G., Bennet, M., Doolan, P., ... Taylor, P. (2011). Cultural horizons for mathematics. Mathematics Education Research Journal, 23(2), 253-274. https://doi.org/10.1007/s13394-011-0014-3

Parr, J. M., \& Timperley, H. S. (2015). Exemplifying a continuum of collaborative engagement: Raising literacy achievement of at-risk students in New Zealand. Journal of Education for Students Placed at Risk (JESPAR), 2o(1-2), 29-41. https://doi.org/10.108o/10824669.2014.983512

Perry, R. R., \& Lewis, C. C. (2009). What is successful adaptation of lesson study in the US? Journal of Educational Change, 10(4), 365-391. https://doi.org/10.1007/s10833-0o8-9069-7 
Ponterotto, J. G. (2005). Qualitative Research in Counseling Psychology: A Primer on Research Paradigms and Philosophy of Science. Journal of Counseling Psychology, 52(2), 126-136. https://doi.org/10.1037/oo22-0167.52.2.126

Powietrzynska, M. (2015). Heuristics for mindfulness in education and beyond. In C. Milne, K. Tobin, \& D. DeGennaro (Eds.), Sociocultural studies and implications for science education (pp. 59-8o). https://doi.org/10.1007/978-94-007-4240-6

Powietrzynska, M., Tobin, K., \& Alexakos, K. (2014). Facing the grand challenges through heuristics and mindfulness. Cultural Studies of Science Education, 1-17. https://doi.org/10.1007/s11422-014-9588-X

Putnam, R. T., \& Borko, H. (200o). What do new views of knowledge and thinking have to say about research on teacher learning? Educational Researcher, 29(1), $4^{-15}$

Reeves, T. (2006). Design research from a technology perspective. In J. van den Akker, K. Gravemeijer, S. McKenney, \& N. Nieveen (Eds.), Educational design research (pp. 52-66). London: Routeledge.

Robinson, V. M., Hohepa, M. K., \& Lloyd, C. (2009). School leadership and student outcomes: Identifying what works and why : best evidence synthesis iteration [BES]. Wellington, N.Z.: Ministry of Education.

Roth, W.-M. (2007). Situating situated cognition. In The Praeger handbook of education and psychology (Vol. 4, pp. 717-728). Westport, Connecticut: Praeger Publishers.

Roth, W.-M., \& Lee, Y.-J. (2007). "Vygotsky’s neglected legacy”: Cultural-historical activity theory. Review of Educational Research, 77(2), 186-232. 
Roth, W.-M., \& Tobin, K. (2002). At the elbow of another: Learning to teach by coteaching. New York, NY: Peter Lang.

Roth, W.-M., \& Tobin, K. (2004). Coteaching: From praxis to theory. Teachers and Teaching: Theory and Practice, 10(2), 161-180.

Saldana, J. (2013). The coding manual for qualitative researchers. London: Sage Publications.

Scanlan, P. (2013). Mangere East students can't get enough of “Bobbie” maths. New Zealand Education Gazette Tukutuku Kōrero, 2-3.

Schoen, L. T. (2011). Conceptual and methodological issues in sociocultural research and theory development in education. In D. M. McInerney, R. A. Walker, \& G. A. D. Liem (Eds.), Sociocultural theories of learning and motivation: Looking back, looking forward (pp. 11-40). Charlotte, NC: Information Age Publishing.

Schön, D. A. (1983). The reflective practitioner: How professionals think in action. London: Temple Smith.

Scrimsher, S., \& Tudge, J. (2003). The teaching/learning relationship in the first years of school: Some revolutionary implications of Vygotskya's theory. Early Education E Development, 14(3), 293-312. https://doi.org/10.1207/s15566935eed1403_3

Sewell, W. H., Jr. (1992). A theory of structure: Duality, agency, and transformation. American Journal of Sociology, 98(1), 1-29.

Sewell, W. H. Jr. (2005). Logics of history: Social theory and social transformation. Chicago: University of Chicago Press.

Sfard, A. (1998). On two metaphors for learning and the dangers of choosing just one. Educational Researcher, 27(2), 4-13. https://doi.org/10.3102/0013189X027002004 
Shenton, A. K. (2004). Strategies for ensuring trustworthiness in qualitative research projects. Education for Information, 22(2), 63-75.

Sherin, M., Jacobs, V., \& Philipp, R. (2011). Mathematics teacher noticing: Seeing through teachers' eyes (1st ed.). Hoboken: Taylor and Francis.

Shulman, L. S. (1986). Those who understand: Knowledge growth in teaching. Educational Researcher, 15(2), 4-14. https://doi.org/10.3102/0013189X015002004

Shulman, L., S. (1987). Knowledge and teaching: Foundations of the new reform. Harvard Educational Review, 57(1), 1-22.

Shulman, L. S., \& Shulman, J. H. (2004). How and what teachers learn: A shifting perspective. Journal of Curriculum Studies, 36(2), 257-271. https://doi.org/10.1080/0022027032000148298

Sinnema, C., \& Aitken, G. (2011). Teaching as inquiry in the New Zealand Curriculum: Origins and implementation. In J. M. Parr, H. Hedges, \& S. May (Eds.), Changing trajectories of teaching and learning. Wellington, New Zealand: NZCER Press.

Sinnema, C., Meyer, F., \& Aitken, G. (2017). Capturing the complex, situated, and active nature of teaching through inquiry-oriented standards for teaching. Journal of Teacher Education, 68(1), 9-27. https://doi.org/10.1177/0022487116668017

Sivia, A. K. (2017). Discord and dissonance: Living through and learning from a teacher educator's memories (PhD). Simon Fraser University, Canada.

Skattebol, J., \& Arthur, L. M. (2014). Collaborative practitioner research: Opening a third space for local knowledge production. Asia Pacific Journal of Education, 34(3), 351-365. https://doi.org/10.108o/o2188791.2013.87169o 
Smith, L. T. (2005). On tricky ground: Researching the native in the age of uncertainty. In N. K. Denzin \& Y. S. Lincoln (Eds.), The Sage handbook of qualitative research (3rd ed.). Thousand Oaks, California: Sage Publications.

Spillane, J. P. (1999). External reform initiatives and teachers' efforts to reconstruct their practice: The mediating role of teachers' zones of enactment. Journal of Curriculum Studies, 31(2), 143-175.

State Education Resource Centre (SERC). (2004). Six approaches to co-teaching. Retrieved from SERC website: http://ctserc.org/component/k2/item/5o-sixapproaches-to-co-teaching

Stetsenko, A. (2008). From relational ontology to transformative activist stance on development and learning: Expanding Vygotsky's (CHAT) project. Cultural Studies of Science Education, 3(2), 471-491. https://doi.org/10.1007/s11422-0o8$9111-3$

Stoll, L. (2011). Leading professional learning communities. In J. Robertson \& H. Timperley (Eds.), Leadership and learning (pp. 103-117). Thousand Oaks, California: Sage Publications.

Stoll, L., \& Louis, K. S. (2007). Professional learning communities: Elaborating new approaches. In L. Stoll \& K. S. Louis (Eds.), Professional learning communities: Divergence, depth and dilemmas (pp. 1-13). New York, NY: McGraw-Hill International.

Sullivan, P. (2008). Education for the knowledge to teach mathematics: It all has to come together. Journal of Mathematics Teacher Education, ${ }_{11}(6)$, 431-433. https://doi.org/10.1007/s10857-008-9090-z 
Sullivan, P., Clarke, D., \& Clarke, B. (2009). Converting mathematics tasks to learning opportunities: An important aspect of knowledge for mathematics teaching. Mathematics Education Research Journal, 21(1), 85-105. https://doi.org/10.1007/BFo3217539

Thomson, A. M., \& Perry, J. L. (2006). Collaboration processes: Inside the black box. Public Administration Review, 66(s1), 20-32. https://doi.org/10.1111/j.15406210.2006.00663.x

Timperley, H., \& Alton-Lee, A. (2008). Reframing teacher professional learning: An alternative policy approach to strengthening valued outcomes for diverse learners. Review of Research in Education, 32(1), 328-369. https://doi.org/10.3102/o091732Xo7308968

Timperley, H., Kaser, L., \& Halbert, J. (2014). A framework for transforming learning in schools: Innovation and the spiral of inquiry. Victoria, Australia: Centre for Strategic Education.

Timperley, H. S., Parr, J. M., \& Bertanees, C. (2009). Promoting professional inquiry for improved outcomes for students in New Zealand. Professional Development in Education, 35(2), 227-245. https://doi.org/10.1080/13674580802550094

Timperley, H., Wilson, A., Barrar, H., \& Fung, I. (2007). Teacher professional learning and development: Best evidence synthesis iteration (BES). Wellington, New Zealand: Ministry of Education.

Tobin, K. (2012). Interpretive approaches to multi-level, multi-method, multi-theoretic research. In S. R. Steinberg \& G. S. Cannella (Eds.), Critical qualitative research reader (First printing edition, pp. 116-128). New York: Peter Lang Publishing Inc. 
Tobin, K. (2014). Transforming Science Education by Expanding Teacher and Student Collaboration. In A.-L. Tan, C.-L. Poon, \& S. S. L. Lim (Eds.), Inquiry into the Singapore Science Classroom (pp. 47-66). Retrieved from http://link.springer.com/chapter/10.1007/978-981-4585-78-1_3

Tobin, K., \& Ritchie, S. M. (2012). Multi-method, multi-theoretical, multi-level research in the learning sciences. Asia-Pacific Education Researcher (De La Salle University Manila), 21(1), 117-129.

Tobin, K., \& Roth, W.-M. (2005). Implementing coteaching and cogenerative dialoguing in urban science education. School Science and Mathematics, 105(6), 313-322. https://doi.org/10.1111/j.1949-8594.2005.tb18132.x

Tomlins-Jahnke, H., \& Warren, K. T. R. (2011). Full, Exclusive and Undisturbed Possession: Māori Education and the Treaty. In V. Tawhai \& K. Gray-Sharp (Eds.), Always speaking: The Treaty of Waitangi and public policy (pp. 43-62). Wellington, New Zealand: Huia.

Turner, H., Rubie-Davies, C. M., \& Webber, M. (2015). Teacher expectations, ethnicity and the achievement gap. New Zealand Journal of Educational Studies, 50(1), 5569.

van Es, E. A., \& Sherin, M. G. (2008). Mathematics teachers' "learning to notice" in the context of a video club. Teaching and Teacher Education, 24(2), 244-276. https://doi.org/10.1016/j.tate.2006.11.005

Vygotsky, L. S. (1978). Mind in society: The development of higher psychological processes (M. Cole, V. John-Steiner, S. Scribner, \& E. Souberman, Eds.). Cambridge: Harvard University Press. 
Wenger, E. (1998). Communities of practice: Learning, meaning and identity. Cambridge, UK: Cambridge University Press.

Wilson, S. M., \& Berne, J. (1999). Learning and the acquisition of professional knowledge: An examination of research on contemporary professional development. Review of Research in Education, 24, 173-209.

Young-Loveridge, J. (2010). A decade of reform in mathematics education: Results for 2009 and earlier years. In Ministry of Education, Findings from the New Zealand Numeracy Development Projects 2009 (pp. 15-35). 


\section{Appendices}




\subsection{Project information sheets and consent/assent forms}

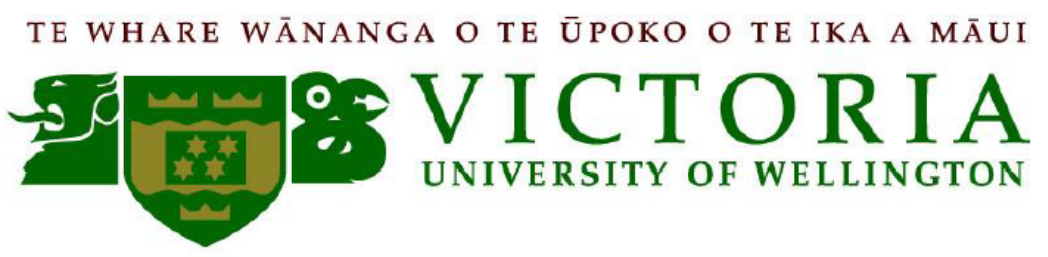

Research project - Information sheet for the Principal and Board of Trustees

"Collaborative inquiry to promote Pasifika achievement in mathematics: Explaining the impact on teachers' knowledge in practice"

\section{Researcher}

I am Raewyn Eden, a PhD student at the Faculty of Education, Victoria University of Wellington. As part of my doctoral study, I am conducting research to examine how teachers' collaborative inquiry to promote Pasifika students' achievement in mathematics impacts on their knowledge in practice.

This sheet gives you information about this study. If you have any questions or would like to receive further information about the project, please contact me at raewyn.eden@vuw.ac.nz. You can also contact my supervisors, Associate Professor Joanna Higgins at joanna.higgins@vuw.ac.nz, Phone: 044639576 and/or Dr Lex McDonald at lex.mcdonald@vuw.ac.nz, Phone: 044635173.

The research has been approved by the Victoria University of Wellington Human Ethics Committee. If you have any concerns about this research please contact Dr Allison Kirkman, Chair of the Human Ethics Committee, Victoria University of Wellington at allison.kirkman@vuw.ac.nz, Phone: 044635676.

\section{The purpose of my PhD research}

The overarching purpose of the study is for the researcher, Raewyn Eden, and a group of teachers to co-design and participate in a collaborative teaching inquiry and to investigate participants' perceptions of the experience and actions taken. 


\section{Research questions}

The broad overall question to be addressed is:

How does collaborative inquiry support teachers to promote educational outcomes that they perceive as valued for Pasifika students in mathematics?

Specific questions to be investigated in relation to promoting Pasifika students' educational outcomes are:

How do teachers describe valued educational outcomes in mathematics?

What contradictions arise within collaborative inquiry activity and what actions are taken?

How do participants describe their experiences of collaborative inquiry?

How do participants explain the impacts of collaborative inquiry on their teaching?

What changes in mathematical knowledge-in-use are evident in participants' teaching practices?

\section{Research participants}

I am asking for teachers from your school to volunteer to take part in this research within your school context and all teachers of mathematics in your school will be given the opportunity to participate should they wish to.

\section{Research process and data to be gathered}

This study will be conducted in a primary or intermediate school (or two neighbouring schools) in the Wellington region. Your school meets the criteria for participating in research aiming to develop an understanding of the impacts of teachers' collaborative inquiry to promote Pasifika success in mathematics. To achieve an in-depth understanding, I plan to employ a variety of data gathering methods in the research process. The schedule of proposed research activities below gives you an idea of what this might look like over the course of the remainder of the school year. 


\begin{tabular}{|c|c|}
\hline Activities & Expected timeframe \\
\hline $\begin{array}{l}\text { Entry, exploration and design phase and initial data gathering } \\
\text { - Information sharing and gaining informed consent } \\
\text { - Classroom observations and interviews with each } \\
\text { participating teacher } \\
\text { - Initial meetings with teacher participants as a group: } \\
\quad \text { focusing inquiry/problem analysis } \\
0 \text { design of collaborative activity }\end{array}$ & $\begin{array}{l}\text { Term 2, } 2014 \\
\text { (May - June) }\end{array}$ \\
\hline $\begin{array}{l}\text { Cycles of inquiry and design and in-field data analysis } \\
\text { - At least three cycles of inquiry/design } \\
\text { - Data gathering, including: } \\
\text { teachers' weekly reflections } \\
\text { records of collaborative activity - including video } \\
\text { and audio recording and field notes } \\
\text { additional supplementary sources - including } \\
\text { examples of teachers' and students' work, planning } \\
\text { documents, notes from discussions, or material } \\
\text { resources used } \\
\text { - Analysis of data for initial themes which will then be fed } \\
\text { back into the design cycle through the teachers' planned } \\
\text { collaborative activity }\end{array}$ & $\begin{array}{l}\text { Terms } 2 \text { - 4, } 2014 \\
\text { (June - November) }\end{array}$ \\
\hline $\begin{array}{l}\text { Future planning and exit phase and final data gathering } \\
\text { - Classroom observations and interviews with each } \\
\text { participating teacher } \\
\text { - Final meetings with teacher participants as a group to } \\
\text { finalise agreed design principles and plan for } 2015\end{array}$ & $\begin{array}{l}\text { Term 4, } 2014 \\
\text { (November - December) }\end{array}$ \\
\hline
\end{tabular}

\section{Confidentiality and access to information}

The information provided is strictly confidential. You, your teachers, your students and your school will not be identifiable. Digital files of audio and video recordings will be password protected and copies of transcripts, written reflections and other documents will be stored securely in a locked cabinet in the office of Raewyn Eden at Victoria University of Wellington.

\section{Participation and right to withdraw}

Participants may withdraw from the research project for any reason at any stage up to four weeks after the initial interviews and observations and any data collected during these activities would then be destroyed. After this, participants may withdraw from further 
involvement in the research project for any reason, however data gathered during activities prior to their withdrawal may still be used.

Participation for the Principal and Board of Trustees would involve:

- Agreeing that the researcher, Raewyn Eden, will be given access to the school over the remainder of the 2014 school year for the purpose of conducting research activities as described.

- $\quad$ Agreeing that the researcher, Raewyn Eden, may return to the school during Term 1 of 2015 for any necessary follow up.

\section{Publication of results}

The information gained in this research will be used for publication purposes including academic or professional journals, conference presentations and papers and for the deposit of the thesis at the Victoria University of Wellington library.

Your consent to participate in this study is highly valued and deeply appreciated.

Thank you

Raewyn Eden 


\section{Research project - Consent form for the principal and Board of Trustees}

"Collaborative inquiry to promote Pasifika achievement in mathematics: Explaining the impact on teachers' knowledge in practice"

We agree that teachers who volunteer may participate in the following research activities (tick all that apply):
Being available for interviews, classroom observations and follow up discussions.
Keeping a reflective journal at least weekly and making this available for the use of the researcher, Raewyn Eden.
$\square \quad$ Participating in planned inquiry activities such as meetings, shared planning, peer observations, discussing video recordings of teaching episodes, as agreed by the group.
$\square \quad$ Being available to read summary reports and interview transcripts and offer feedback as required.
$\square \quad$ Making available any pertinent documents such as records of planning, assessment data, and teaching materials for the use of the researcher, Raewyn Eden.

We agree that students who volunteer may participate in the following ways (tick all that apply):

The collection of video and audio recordings and observation notes of classroom activities they are involved in.

$\square$ The collection of other relevant documents such as examples of children's work or assessment information.

$\square$ The use the information collected for the purposes of this study. 


\section{We understand that}

- Participation is entirely voluntary and participants can withdraw for any reason at any stage. If participants withdraw within four weeks of the initial classroom observation and interview, any data provided would be destroyed; otherwise data provided prior to withdrawal may be used in the research project.

- Data collected will only be used for the research project and may be used in a thesis and for conference papers and other publication by the researcher, Raewyn Eden.

- The research is confidential and that data will be kept securely and destroyed five years after the conclusion of the project.

- Participants will have the opportunity to check the accuracy of the data collected from them.

Please indicate your preference for involvement in the research (tick one as appropriate):

We have had the project explained to us and have had the chance to ask any questions.

We do not give consent to take part in the research.

We would like further questions to be answered about this project.

We have had the project explained to us and have had the chance to ask any questions.

We agree to take part in the above research.

Name

Signature Date 


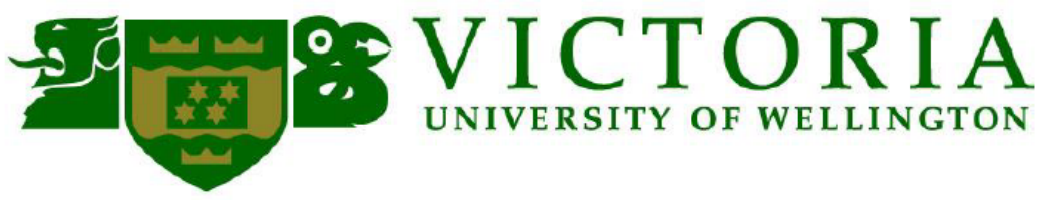

\section{Research project - Information sheet for teachers}

\section{"Collaborative inquiry to promote Pasifika achievement in mathematics: Explaining the impact on teachers' knowledge in practice"}

\section{Researcher}

I am Raewyn Eden, a PhD student at the Faculty of Education, Victoria University of Wellington. As part of my doctoral study, I am conducting research to examine how teachers' collaborative inquiry to promote Pasifika students' achievement in mathematics impacts on their knowledge in practice.

This sheet gives you information about this study. If you have any questions or would like to receive further information about the project, please contact me at raewyn.eden@vuw.ac.nz. You can also contact my supervisors, Associate Professor Joanna Higgins at joanna.higgins@vuw.ac.nz, Phone: 044639576 and/or Dr Lex McDonald at lex.mcdonald@vuw.ac.nz, Phone: 044635173.

The research has been approved by the Victoria University of Wellington Human Ethics Committee. If you have any concerns about this research please contact Dr Allison Kirkman, Chair of the Human Ethics Committee, Victoria University of Wellington at allison.kirkman@vuw.ac.nz, Phone: 044635676.

\section{The purpose of my PhD research}

The overarching purpose of the study is for the researcher, Raewyn Eden, and a group of teachers to co-design and participate in a collaborative teaching inquiry and to investigate participants' perceptions of the experience and actions taken. 


\section{Research questions}

The broad overall question to be addressed is:

How does collaborative inquiry support teachers to promote educational outcomes that they perceive as valued for Pasifika students in mathematics?

Specific questions to be investigated in relation to promoting Pasifika students' educational outcomes are:

How do teachers describe valued educational outcomes in mathematics?

What contradictions arise within collaborative inquiry activity and what actions are taken?

How do participants describe their experiences of collaborative inquiry?

How do participants explain the impacts of collaborative inquiry on their teaching?

What changes in mathematical knowledge-in-use are evident in participants' teaching practices?

\section{Research process and data to be gathered}

This study will be conducted in a primary or intermediate school (or two neighbouring schools) in the Wellington region. Your school meets the criteria for participating in research aiming to develop an understanding of the impacts of teachers' collaborative inquiry to promote Pasifika success in mathematics. To achieve an in-depth understanding, I plan to employ a variety of data gathering methods in the research process. The schedule of proposed research activities on the following page gives you an idea of what this might look like over the course of the remainder of the school year. 


\begin{tabular}{|c|c|}
\hline Activities & Expected timeframe \\
\hline $\begin{array}{l}\text { Entry, exploration and design phase and initial data gathering } \\
\text { - Information sharing and gaining informed consent } \\
\text { - Classroom observations and interviews with each } \\
\text { participating teacher } \\
\text { - Initial meetings with teacher participants as a group: } \\
0 \text { focusing inquiry/problem analysis } \\
0 \text { design of collaborative activity }\end{array}$ & $\begin{array}{l}\text { Term 2, } 2014 \\
\text { (May - June) }\end{array}$ \\
\hline $\begin{array}{l}\text { Cycles of inquiry and design and in-field data analysis } \\
\text { - At least three cycles of inquiry/design } \\
\text { - Data gathering, including: } \\
0 \text { teachers' weekly reflections } \\
0 \text { records of collaborative activity } \\
0 \text { additional supplementary sources } \\
\text { - Analysis of data for initial themes which will then be fed } \\
\text { back into the design cycle through the teachers' planned } \\
\text { collaborative activity }\end{array}$ & $\begin{array}{l}\text { Terms } 2 \text { - 4, } 2014 \\
\text { (June - November) }\end{array}$ \\
\hline $\begin{array}{l}\text { Future planning and exit phase and final data gathering } \\
\text { - Classroom observations and interviews with each } \\
\text { participating teacher } \\
\text { - Final meetings with teacher participants as a group to } \\
\text { finalise agreed design principles and plan for } 2015\end{array}$ & $\begin{array}{l}\text { Term 4, } 2014 \\
\text { (November - December) }\end{array}$ \\
\hline
\end{tabular}

Initially, I would like to observe you in your classroom for at least 30 minutes during a mathematics lesson and then have a follow-up face-to-face interview with you lasting up to one hour. Classroom release will be provided for the interview if you require it. I would also like to collect copies of any appropriate documents that might support the observation and/or interview such as (but not limited to) planning documents, examples of student work, assessment data or resources used. The classroom observation will be video and audio recorded and the interview will be audio recorded and both will later be transcribed. Data generated from the classroom observation will form the basis of further discussions with you. At the end of the research project, a further classroom observation and follow-up interview will be conducted as outlined for our initial meeting.

Following initial interviews and observations with each participating teacher, it is intended that participating teachers will work as a group to plan and participate in at least three cycles of collaborative teaching inquiry focused on the mathematics achievements of Pasifika 
students. The exact nature of the inquiry focus and collaborative inquiry activities will be negotiated with the group of participating teachers to reflect your specific context. The knowledge building and inquiry cycle illustrated below will be used as an initial framework for the inquiry activities.

\section{Inquiry and knowledge-building cycle}

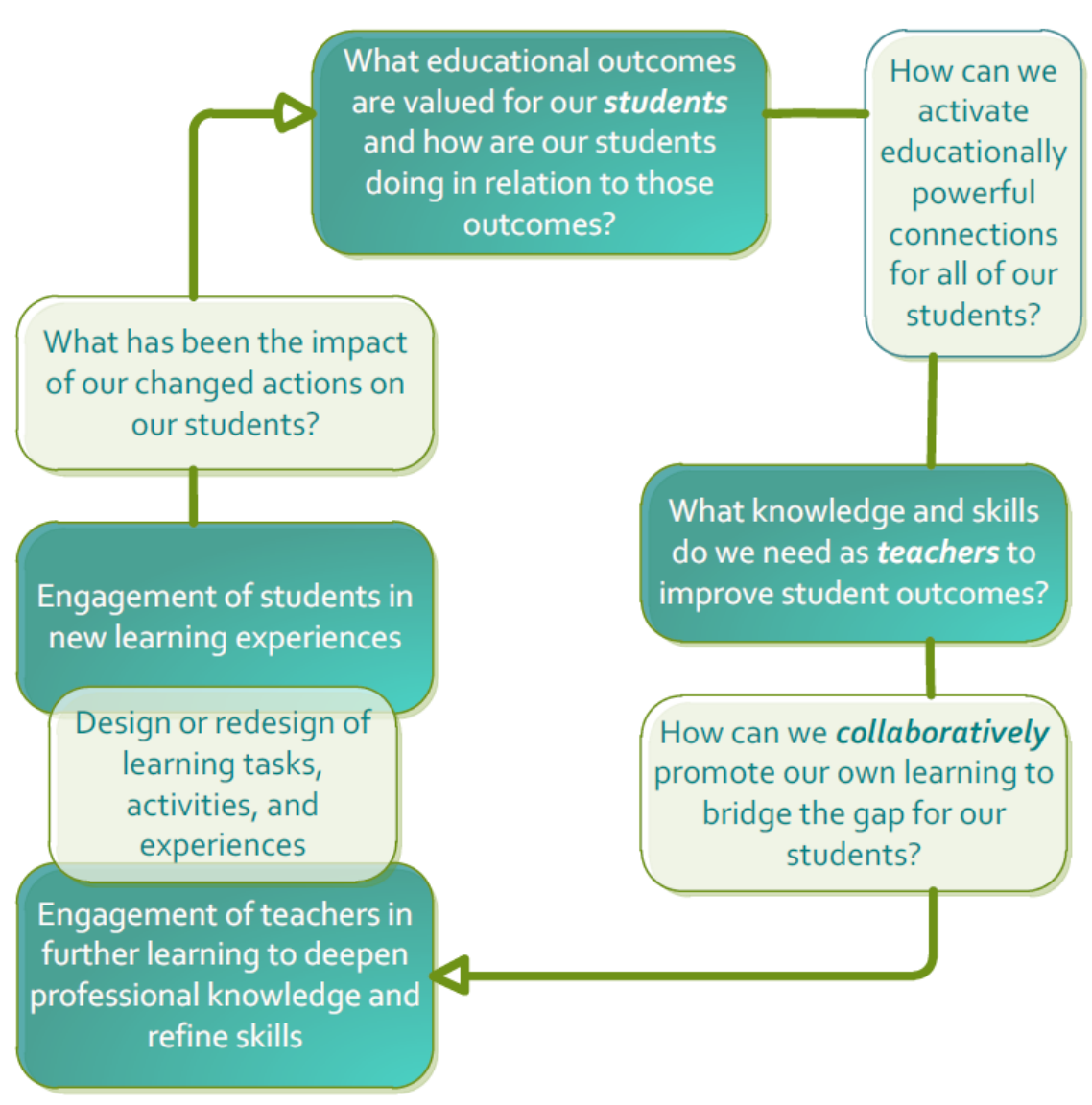

(adapted from Alton-Lee, 2012)

Selected activities of the group of teachers as you design and participate in processes of collaborative inquiry will be audio and/or video recorded, and field notes taken. Transcripts of recordings will be made as soon as possible after each observed activity and made available to you for checking. Copies of appropriate documents to support the understanding of 
observed activities will be collected, such as examples of teachers' and students' work, planning documents, notes from discussions, or material resources used.

You will be asked to keep a journal to reflect on your experiences as a participant in the research project. You may choose how you record your reflections: in writing, by audiorecording or by video-recording. You will be asked to make reflective comments at least weekly and I will collect copies of these periodically from you at school. Audio and videorecorded reflective comments will be transcribed by the researcher and all reflections will be kept confidential. You may choose to share your reflections with others at your discretion.

In addition, I will be reflecting on my experiences at your school via my research journal. Here I will be making notes of my perceptions of the research context including the climate of the school, how my interactions have gone and what I could be doing more effectively as a researcher. I am happy to have these field notes available for you to see.

\section{Research participants}

I am asking for teachers from your school to volunteer to take part in this research within your school context and all teachers of mathematics in your school will be given the opportunity to participate should they wish to.

\section{Confidentiality and access to information}

The information provided is strictly confidential. You, your students and your school will not be identifiable. Digital files of audio and video recordings will be password protected and copies of transcripts, written reflections and other documents will be stored securely in a locked cabinet in the office of Raewyn Eden at Victoria University of Wellington. Data provided by individuals which is made available to other participants for the purposes of infield data analysis to inform later iterations of the design cycle will be aggregated and summarised and contributions will not be attributed to the individuals providing them. You will have the opportunity to review transcripts and amend or delete any comments if you wish. 


\section{Participation and right to withdraw}

You may withdraw from the research project for any reason at any stage up to four weeks after the initial interview and observation and any data collected during these activities would then be destroyed. After this, you may withdraw from further involvement in the research project for any reason, however data gathered during activities prior to your withdrawal may still be used.

Participation for teachers would involve:

- Being available for a classroom observation of at least 30 minutes and an interview of up to one hour at the start and end of the project.

- $\quad$ Being available for up to three additional classroom observations of between 30 and 45 minutes and informal follow-up discussions of up to 20 minutes as negotiated between the researcher and yourself.

- Spend 10-15 minutes recording reflective comments at least once per week and making these available for the use of the researcher, Raewyn Eden.

- $\quad$ Participating in planned inquiry activities such as meetings, shared planning, peer observations, discussing video recordings of teaching episodes, as agreed by the group.

- $\quad$ Being available to read transcripts of initial and final interviews and summary reports up to two pages of planned observations and follow-up discussions, and offer feedback.

- Making available any pertinent documentation such as records of planning, assessment data, and teaching materials for the use of the researcher, Raewyn Eden.

- $\quad$ Agreeing that the information given can be used by the researcher, Raewyn Eden for this study. 


\section{Publication of results}

The information gained in this research will be used for publication purposes including academic or professional journals, conference presentations and papers and for the deposit of the thesis at the Victoria University of Wellington library.

Your consent to participate in this study is highly valued and deeply appreciated.

Thank you

Raewyn Eden 


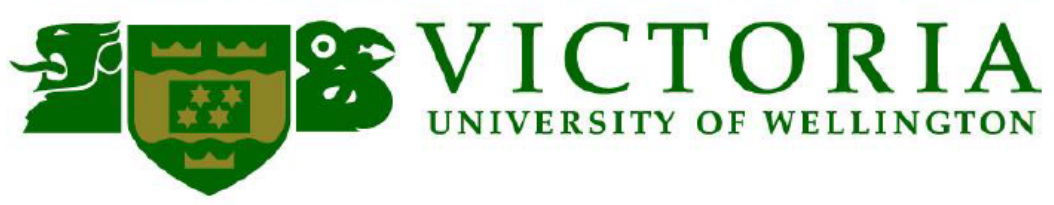

\section{Research project - Consent form for teachers}

"Collaborative inquiry to promote Pasifika achievement in mathematics: Explaining the impact on teachers' knowledge in practice"

I agree to participate in the following research activities (tick all that apply):

Being available for interviews, classroom observations and follow up discussions.

Keeping a reflective journal at least weekly and making this available for the use of the researcher, Raewyn Eden.

Participating in planned inquiry activities such as meetings, shared planning, peer observations, discussing video recordings of teaching episodes, as agreed by the group.

Being available to read summary reports and interview transcripts and offer feedback as required.

Making available any pertinent documents such as records of planning, assessment data, and teaching materials for the use of the researcher, Raewyn Eden.

I understand that:

- My participation is entirely voluntary and I can withdraw for any reason at any stage. If I withdraw within four weeks of the initial classroom observation and interview, any data provided would be destroyed; otherwise data provided prior to my withdrawal may be used in the research project.

- Data collected will only be used for the research project and may be used in a thesis and for conference papers and other publication by the researcher, Raewyn Eden.

- I understand that the research is confidential and that data will be kept securely and destroyed five years after the conclusion of the project.

- I will have the opportunity to check the accuracy of the data collected from me.

Please indicate your preference for involvement in the research (tick one as appropriate):

I have had the project explained and have had the chance to ask any questions.

I do not give consent to take part in the research.

I would like further questions to be answered about this project.

I have had the project explained to me and have had the chance to ask any questions.

I agree to take part in the above research.

Name

Signature

Date 


\section{Research project - Information sheet for parents}

"Collaborative inquiry to promote Pasifika achievement in mathematics: Explaining the impact on teachers' knowledge in practice"

\section{Researcher}

I am Raewyn Eden, a PhD student at the Faculty of Education, Victoria University of Wellington. As part of my doctoral study, I am conducting research to examine how teachers' collaborative inquiry to promote Pasifika students' achievement in mathematics impacts on their knowledge in practice.

This sheet gives you information about this study. If you have any questions or would like to receive further information about the project, please contact me at raewyn.eden@vuw.ac.nz. You can also contact my supervisors, Associate Professor Joanna Higgins at joanna.higgins@vuw.ac.nz, Phone: 044639576 and/or Dr Lex McDonald at lex.mcdonald@vuw.ac.nz, Phone: 044635173.

The research has been approved by the Victoria University of Wellington Human Ethics Committee. If you have any concerns about this research please contact Dr Allison Kirkman, Chair of the Human Ethics Committee, Victoria University of Wellington at allison.kirkman@vuw.ac.nz, Phone: 044635676.

\section{The purpose of my PhD research}

The purpose of the study is to design and investigate the experience of participating in a collaborative teaching inquiry.

The broad overall research question to be addressed is:

How does collaborative inquiry support teachers to promote educational outcomes that they perceive as valued for Pasifika students in mathematics? 


\section{How will the research involve your child?}

The study will take place over the remainder of the school year. Teachers from your child's school have volunteered to take part in this research and it is likely research activities will be taking place during mathematics lessons involving your child. I will be observing teachers in their classrooms during mathematics lessons and taking observation notes. These observations will also be video and audio recorded. The focus for research activities in your child's classroom will be on what the teacher says and does and will include interactions between the teacher and students in the class.

I would also like to collect copies of any appropriate documents that might support the observations and teacher interviews such as examples of students' work and teachers' records of student assessment information.

If you do not wish for your child to take part in the research, they will still participate in all mathematics lessons as normal. I will make sure the video and audio recording is directed away from them, and I will not collect examples of their work or assessment information to use in the research.

Participation is completely voluntary and you can choose for your child to participate or withdraw at any time by telling their teacher or myself that you wish for them to do so. If students withdraw, information from research activities that they were previously involved in may still be used in the research.

\section{Confidentiality and access to information}

The information provided is strictly confidential. The teachers, the students and the school will not be identifiable in any reporting of this research. Information collected will be kept in a locked filing cabinet at the office of Raewyn Eden, Victoria University of Wellington. You and your child will be able to review and to amend or delete any data collected from or about your child if you wish. 


\section{Participation for students would involve:}

- Agreeing to the researcher collecting video and audio recordings and observation notes of classroom activities they are involved in.

- Agreeing that data collected from classroom activities they are involved in including their interactions with the teacher and other students, can be used by the researcher, Raewyn Eden, for this study.

- Agreeing that other data such as examples of their work or assessment information can be used by the researcher, Raewyn Eden, for the study.

\section{Publication of results}

The information gained in this research will be used for publication purposes including academic or professional journals, conference presentations and papers and for the deposit of the thesis at the Victoria University of Wellington library.

Your consent to participate in this study is highly valued and deeply appreciated.

Thank you

Raewyn Eden 


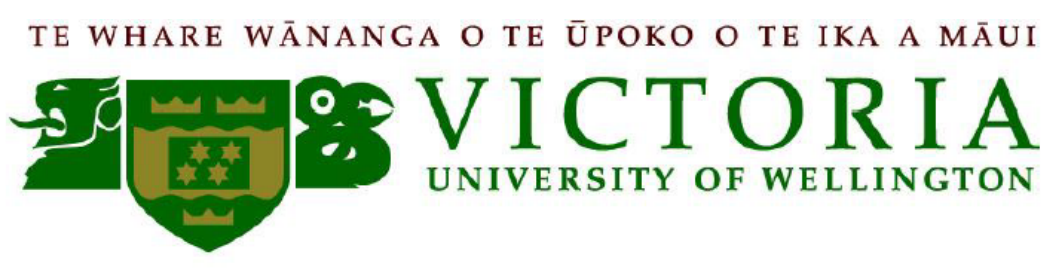

Research project - Consent form for parents

"Collaborative inquiry to promote Pasifika achievement in mathematics: Explaining the impact on teachers' knowledge in practice"

Please read the following and tick all that apply:

I agree to my child participating in this study and give my consent for the researcher, Raewyn Eden, to:

Collect video and audio recordings and make observation notes of classroom activities my child is involved in.

Collect copies of other relevant documents such as examples of my child's work or assessment information.

Use the information collected for the purposes of this study.

I understand that:

- my child's participation is entirely voluntary and he/she can withdraw at any time;

- the research is confidential - my child's name will not be used in research reports and the information that is collected will be kept secure and destroyed after five years; and

- the information collected will only be used for this research project and will be included in a thesis and other research reports such as conference papers and journal articles.

Please indicate your preference for your child's involvement in the research (tick one as appropriate):

I have had the project explained and have had the chance to ask questions.

I do not give consent for my child to take part in the research.

I would like further questions to be answered about this project.

I have had the project explained to me and have had the chance to ask any questions.

I agree for my child to take part in the above research.

Child's name

Room

Parent's name

Signature

Date 


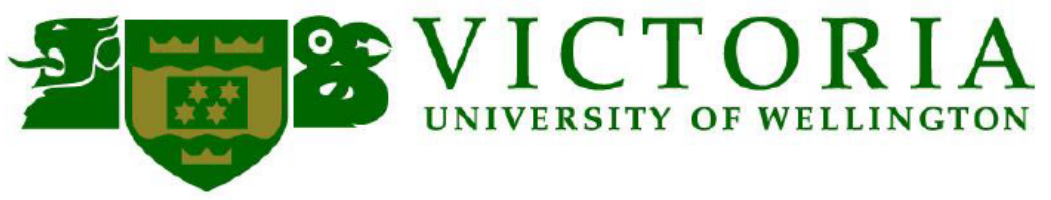

\section{Research project - Information sheet for students}

"Collaborative inquiry to promote Pasifika achievement in mathematics: Explaining the impact on teachers' knowledge in practice"

\section{Researcher}

My name is Raewyn Eden and I am a student at Victoria University of Wellington. I am going to be doing a research project in your school over the rest of this year.

This sheet gives you information about my project. If you have any questions about the research, you can ask me or your teachers. Your parents and teachers can also contact me about the research if they wish.

\section{What is this research about and what is involved?}

My study will be looking at what teachers say and do when they are planning for and teaching mathematics. Teachers from your school have volunteered to take part in this research and some of the research activities will probably happen during your mathematics lessons. I will be visiting classrooms to observe teachers during mathematics lessons and to take notes about what I see and hear. These observations will also be video and audio recorded. I will be focusing on what the teacher says and does, including when he or she is working with students during the lessons.

I would also like to collect copies of other documents that might help me to understand what is happening in the class, such as examples of some students' work and assessment information that teachers have about students' learning.

If you do not want to be videoed or recorded you will still be able to participate in all mathematics lessons as normal. I will make sure the video and audio recording is directed away from you, and I will not collect examples of your work or your assessment information to use in the research. 
You do not have to participate and you can choose to join in or withdraw at any time by telling your teacher or myself that you would like to do so. If you decide to withdraw, information that I have collected already may still be used in the research.

\section{Confidentiality and access to information}

The information I collect will be strictly confidential. The teachers, the students and the school will not be able to be identified when I write about the research for others to read - your name will not be used. The information I collect will be kept safe and you will be able to check that any information I have collected about you is correct.

\section{Participation for you would involve:}

- Agreeing that I can video and audio record you and make notes about what you say and do during mathematics lessons I am observing.

- Agreeing that the recordings and notes I make can be used for this study.

- Agreeing that I can use examples of your work and information from your assessment records in my study.

Thank you for considering taking part in my research project - I really appreciate it.

Raewyn Eden 


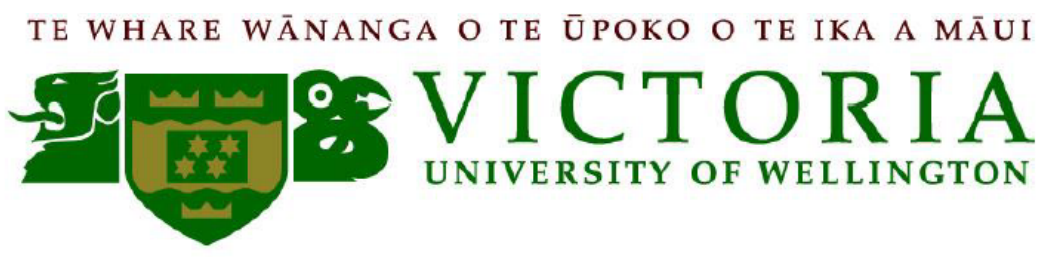

\section{Research project - Assent form for students}

"Collaborative inquiry to promote Pasifika achievement in mathematics: Explaining the impact on teachers' knowledge in practice"

\section{I agree that the researcher, Raewyn Eden, can:}

- video and audio record me and make notes about what I say and do during mathematics lessons, and use this information for this study; and

- use examples of my work and information from my assessment records in this study.

\section{I understand that:}

- I can choose whether I participate or not - I don't have to

- I can stop participating at any time - I just need to tell the researcher or my teacher that I want to

- the research is confidential - my name won't be used when this research is written about

- the information collected by the researcher will be kept safe and will only be used for this research project

Please tick one to show your choice:

I have had the project explained and have had the chance to ask questions.

I do not want to take part in this research.

I would like further questions to be answered about this project.

I have had the project explained to me and have had the chance to ask any questions.

I do want to take part in this research.

Child's name

Room

Signature

Date 


\subsection{Teacher interview protocols}

Initial teacher interview protocol

Teacher:

Brief summary of the lesson:
Date/time:

Thank you so much for letting me spend time in your classroom - it is such a privilege to see teochers at work. Before we start, I want to emphasise thot l'm not an "expert" and I'm not here to critique your teoching. I'm really interested in understanding your experiences as a teocher and the thinking behind the decisions you make and actions you take.

\section{Reflecting on the lesson...}

How did you go about planning for this lesson? What informed/contributed to the lesson planning?

What were some of the important decisions you made in your planning and teaching and why did you make them?

What outcomes were you aiming for? Why?

In what ways were these achieved/not achieved? Why/why not?

Mathematics teaching and teacher knowledge...

What knowledge do you bring to your mathematics teaching? 
What aspects of your knowledge are strongest/least strong?

How does this impact on your teaching/on student learning?

What do you see as important next steps in your learning as a teacher of mathematics?

\section{Teacher collaboration...}

In what ways do you collaborate with other teachers in planning and teaching mathematics?

Can you describe any experiences of collaborating with other teachers that stand out for you?

What have been some of the impacts of these experiences for you? For your students?

\section{Valued mathematical outcomes for Pasifika students...}

What does it mean for Pasifika students to be successful at mathematics?

- What does success in mathematics look like? What counts as success?

- How do you know a student has/hasn't been successful? 
How is success at mathematics important for these students? Why?

What are important factors that influence the mathematics achievements of Pasifika students?

What does this look like in your class/this school?

Is there anything else you would like to add?

Ask to take copies of ...

- The lesson plan (including ony reflection notes)

- Any resources used

- Modelling book (or equivolent)

- Student work examples

- Sources of doto to inform planning ( $\mathrm{g}$ teachers' guide for resources used; assessment records)

Thank you again for welcoming me into your classroom - I really appreciate it.

Contextual factors (eq durotion, location of interview, any interruptions/distroctions, potential influence of significant school/other events):

Researcher's reflective comments (brief and as soon as possible immediately following the interview) 
Teacher:

Date/time:

Brief summary of the lesson:

Thank you so much for letting me spend time in your classroom ogain, and for making this time available to talk today - it is such a gift that you are willing to share your practice. I again want to emphasise that l'm not an "expert" and I'm not here to critique your teaching. I'm really interested in understonding your experience of the collaboration and ony impacts it has had.

Reflecting on your participation in the group's collaborative activity (including meetings, shared reading, discussions about practice, sharing videos, coteaching etc)...

What were your goals and expectations for the collaborative inquiry? How were these met/not met? Were there any surprises/unexpected outcomes for you?

What have been the most successful/positive aspects of participating in the collaboration? What promoted this success?

What challenges/tensions were experienced? Which of these were overcome/resolved and how? What challenges/tensions have not been resolved?

How would you describe your role (or roles) in the collaboration?

How did relationships impact on the collaboration?

Is there anything else that stands out for you as important in relation to the group's collaborative activity?

Thinking about any impacts of the collaboration...

What has changed for you in relation to..

- the knowledge you bring to teaching/learning maths?

- your beliefs about teaching/learning in maths?

- your teaching practice?

- how you feel about teaching/learning in maths?

(Can you think of any specific examples related to the lesson I observed?)

What promoted/facilitated these changes for you? In what ways are these changes important for you and your teaching?

What has changed for your students - particularly your target students? In what ways are these changes important for your students?

Is there anything else you would like to add?

Could l pleose also toke copies of ony documents (e.g. lesson plan, resources you used in planning etc) that might help me better understond the lesson? 
Thank you again for welcoming me into your classroom and for the time and energy you have contributed to this project - I really appreciate it.

Contextual factors (eg durotion, locotion of interview, any interruptions/distroctions, potential influence of significant school/other events):

Researcher's reflective comments (brief and as soon as possible immediately following the interview) 


\subsection{Abbreviations for data sources}

Quotes from interviews are identified by the speaker's initial and the interview number, for example:

C-Int\#1 = Casey, Interview 1 (Initial interview)

P-Int\#2 = Pat, Interview 2 (Final interview)

Quotes from group meetings are identified by the speaker's initial and the number of the group meeting, for example:

K-GM\#2 = Kris, Group Meeting 2 


\subsection{Transcription protocols}

\begin{tabular}{|l|l|}
\hline Transcription convention & Description \\
\hline italics & spoken emphasis \\
\hline$\ldots$ & pause \\
\hline unfinished wor- & an utterance that was incomplete or was interrupted \\
\hline underline & simultaneous/overlapping speech \\
\hline [comment in italics] & $\begin{array}{l}\text { comments related to context, tone, non-speech utterances } \\
\text { (e.g. laughing) }\end{array}$ \\
\hline (inaudible) & indistinguishable speech \\
\hline (?word?) & speech that may have been misheard \\
\hline
\end{tabular}




\subsection{Selection of literature made available to teachers}

Anthony, G., \& Walshaw, M. (2007). Effective pedagogy in mathematics/pāngarau: Best evidence synthesis iteration (BES). Wellington, New Zealand: Ministry of Education.

Chapin, S. H., O'Connor, C., \& Anderson, N. C. (2009). Preface: Talk in action - Project challenge research. In Classroom discussions: Using math talk to help students learn (2nd ed., pp. xv-xix). Sausalito, California: Scholastic. Retrieved from http://www.barnesandnoble.com/w/classroom-discussions-suzanne-h-chapin/1101578758

Hunter, R., \& Anthony, G. (2010). Developing mathematical inquiry and argumentation. In R. Averill \& R. Harvey (Eds.), Teaching primary school mathematics and statistics: Evidence-based practice (pp. 197-206). Wellington, New Zealand: NZCER Press.

Scanlan, P. (2013). Mangare East students can't get enough of "Bobbie" maths. New Zealand Education Gazette Tukutuku Kōrero, 2-3.

Schoenfeld, A. (2007). A practical and theoretical agenda for progress in mathematics education (Unpublished). Berkeley, CA, USA: University of California.

Stein, M. K., Engle, R. A., Smith, M. S., \& Hughes, E. K. (2008). Orchestrating productive mathematical discussions: Five practices for helping teachers move beyond show and tell. Mathematical Thinking and Learning, 10(4), 313-340. https://doi.org/10.1080/10986060802229675

Storeygard, J. (Ed.). (2009). Chapters 13-17: Building understanding through talk. In My kids can: Making math accessible to all learners, K-5 (pp. 99-144). Portsmouth, NH: Heinemann.

University of Cambridge. (n.d.). Developing a classroom culture that supports a problem-solving approach to mathematics. Retrieved from https://nrich.maths.org/public/titlesearch.php?search=Developing\%20a\%20Classroom\%20C ulture\%20That\%20Supports\%20a\%20Problem-solving\%20Approach\%20to\%20Mathematics

Van de Walle, J. A., Karp, Karen S, \& Bay-Williams, Jennifer M. (2013). Chapter 2: Exploring what it means to know and do mathematics. In Elementary and middle school mathematics: Teaching developmentally (8th ed., pp. 13-29). Harlow, United Kingdom: Pearson Education. 